\title{
OFF-GRID PUBLIC LIGHTING SYSTEM - DESIGN AND CHARACTERIZATION OF AN LED LUMINAIRE
}

\author{
A Thesis \\ presented to \\ the Faculty of California Polytechnic State University, \\ San Luis Obispo
}

\author{
In Partial Fulfillment \\ of the Requirements for the Degree \\ Master of Science in Electrical Engineering
}

By

Quanghuy Le

June 2011 
(C)2011

Quanghuy Le ALL RIGHTS RESEVED 


\title{
COMMITTEE MEMBERSHIP
}

Title: $\quad$ Off-Grid Public Lighting System -Design and Characterization of an

\author{
LED Luminaire
}
Author:
Quanghuy Le
Date Submitted:
June 2011
Committee Chair:
Dr. Vladimir Prodanov
Committee Member:
Dr. Taufik
Committee Member:
Dr. Ahmad Nafisi 


\section{ABSTRACT}

Title: $\quad$ Off-Grid Public Lighting System—Design and Characterization of an LED Luminaire

Author: Quanghuy Le

The technological advances made in the photovoltaic industry have led to a vast exploration of self-sustaining systems. As the consumer demand for electricity rises from increasing population and development of existing technologies, new practices in system designs are required to relieve the impact on the electrical grid.

This thesis delves into a developing concept of using photovoltaic modules for roadway lighting, with emphasis on establishing the fundamental design for a "spot-lighting" luminaire. By effectively extinguishing various sections of the luminaire in the absence of pedestrian trafficking, the proposed design and implementation will minimize the prolonged costs, as well as the overall power consumption. Furthermore, as the first stage in development, this thesis includes justifications for design and part selection, while complying with numerous requirements set forth by the City of Los Angeles and in accordance with regulations established by the Illuminating Engineering Society of North America (IESNA). To accomplish these goals, copious amounts of performance tests and simulations, both before and after system implementation, will characterize the overall feasibility of the stand-alone lighting application. 


\section{ACKNOWLEDGEMENTS}

I would like to take this time to express my gratitude to Dr. Vladimir Prodanov, without whom my thesis would not have been made possible. The time, knowledge, and continual support he provided made this thesis both an exceptional and memorable learning experience. His helpful insight on a weekly basis allowed me to convey my ideas and obtain the necessary feedback in improving numerous areas of my study. Also, I would like to thank my committee members, Dr. Taufik and Dr. Nafisi, for taking an interest in my thesis and providing insight whenever needed.

In addition, I would like to thank my friends for providing the necessary sanity that I needed outside the classroom. Without their input and assistance, I would not have managed the hectic lifestyle of being a college engineering student.

Furthermore, I would like to thank my parents for their endless support throughout my life. Their nurturing ability and interest to partake in various occasions in my life have shaped my character and personality to ultimately develop the individual I am today. 


\section{Table of Contents}

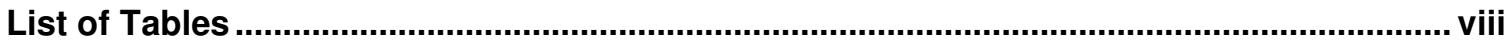

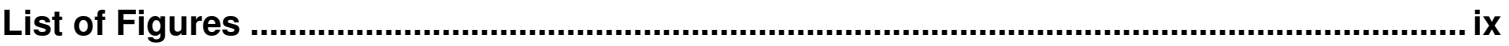

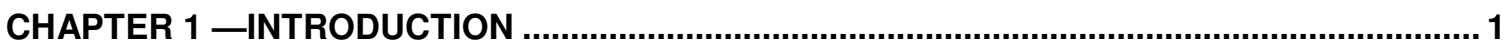

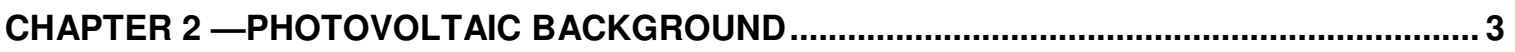

2.1 Introduction to Photovoltaic Cells ........................................................................... 3

2.2-Solar Cell Orientation ...................................................................................... 4

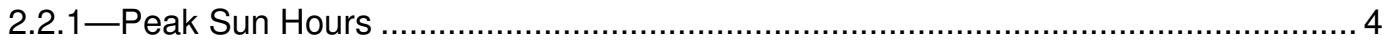

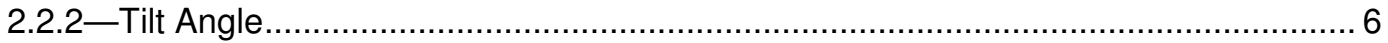

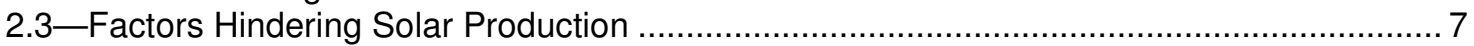

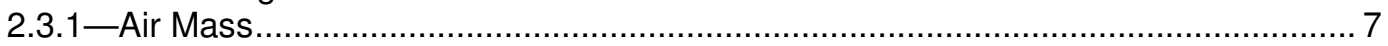

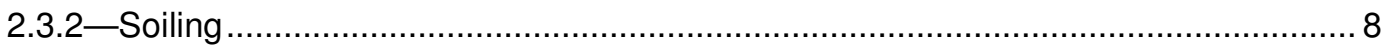

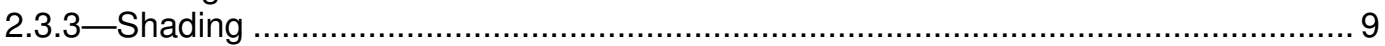

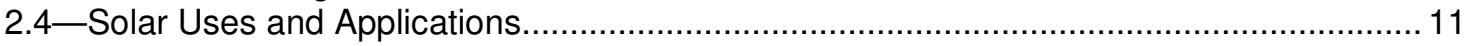

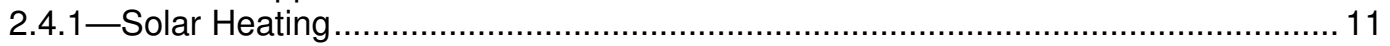

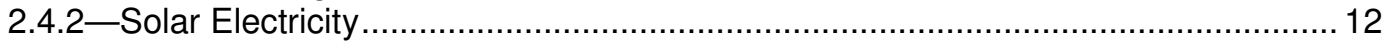

CHAPTER 3 -OPTICAL LIGHTING BACKGROUND ……............................................... 13

3.1-Introduction to Light Emitting Diodes........................................................................ 13

3.2-LED Comparison with Other Lighting Means .......................................................... 13

3.2.1-Advantages of Using LEDs for Lighting …………........................................ 13

3.2.2-Disadvantages of Using LEDs for Lighting.................................................. 15

3.3-Justification for Using LEDs for Roadway Lighting .................................................... 16

CHAPTER 4 _LED FIXTURE DESIGN....................................................................... 18

4.1-Design Concept and Goals ………………………………………………. 18

4.2-Choosing the LED Type (High-Power versus Low-Power) ……………..................... 19

4.3-Basic Guidelines for City of Los Angeles LED Luminaires.............................................2 21

4.4-Justification for LED Selection.......................................................................... 24

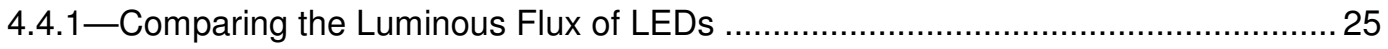

4.4.2-Comparing Theoretical Power Dissipation between LEDs .................................2 27

4.4.3-Comparing Cost of LEDs.......................................................................... 33

4.5-Illumination Distribution of LEDs ..........................................................................34

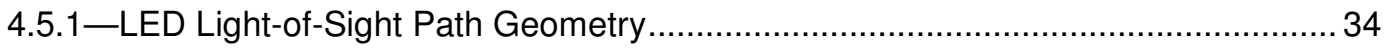

4.5.2-Gaussian Representation for Illumination Distribution ......................................... 35

4.5.3-Comparison of the Two Distribution Models .......................................................3

4.5.4-Developing a Gaussian Representation for Selected LED .................................. 39

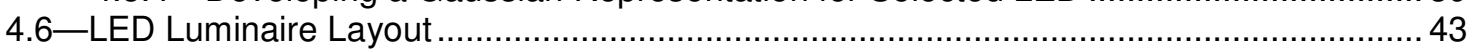

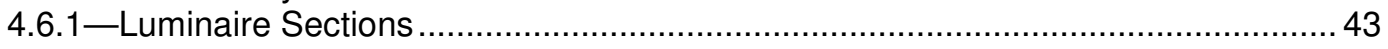

4.6.2-Luminaire Distribution of LEDs by Section .................................................... 46

4.7-Determining the Surface Curvature for Mounting LEDs ............................................... 47

4.8-Optimizing the Power Efficiency for Luminaire .......................................................... 51

4.8.1-Establishing the Allowable Input Voltage Range for Luminaire ...........................51

4.8.2-Comparing Power Efficiency for Varying Input Voltage Selection ........................ 52

4.8.3-Configuration of LED Strings for One Section of the Luminaire.............................56

4.9-Voltage Distribution for a Section of Luminaire ……………………….......................56

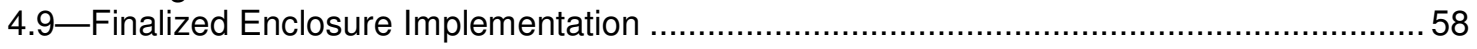

CHAPTER 5 -SYSTEM SIZING ............................................................................59

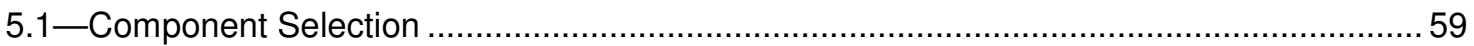

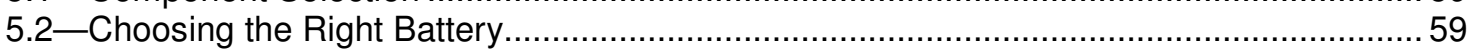

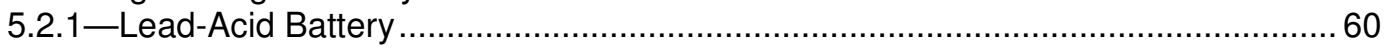

5.2.2-Battery Capacitance and Terminal Voltage .........................................................6 62

5.2.3-Battery Physical Sizing ....................................................................................6 63

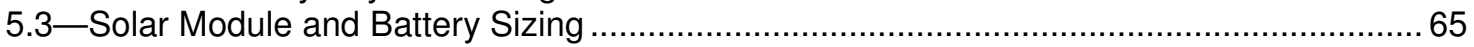


5.3.1_-Operating Time and Power Consumption for Lighting .......................................66

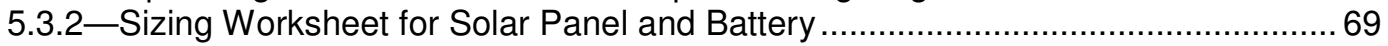

5.4-Examples of Solar Panel and Battery Selection......................................................... 72

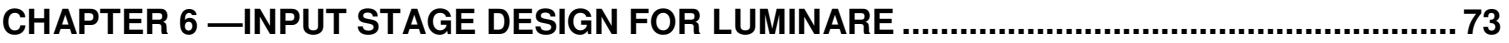

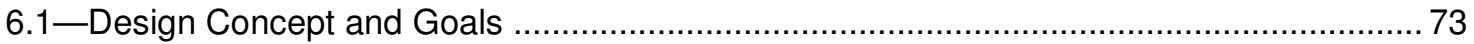

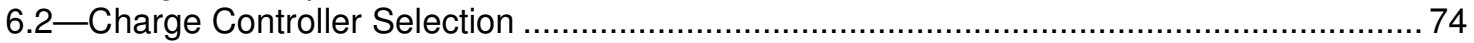

6.3-LT3652 Controller Operation and Component Selections ........................................ 75

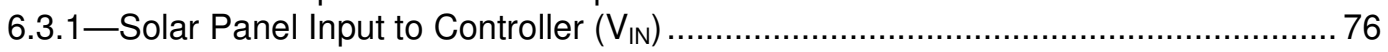

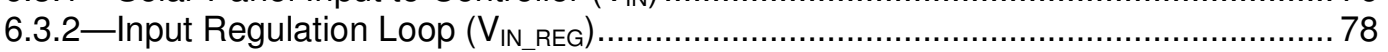

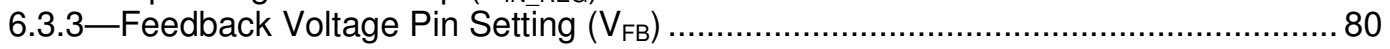

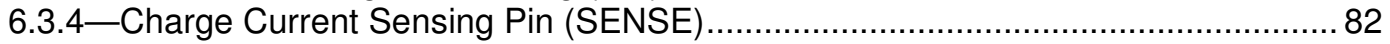

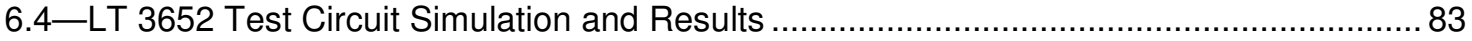

6.5-LT3652 Controller for a 12 V Lead-Acid Battery Simulation and Results .......................... 85

6.5.1-Modifications for Simulation Purposes ............................................................. 86

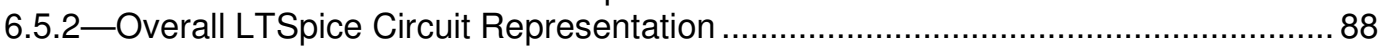

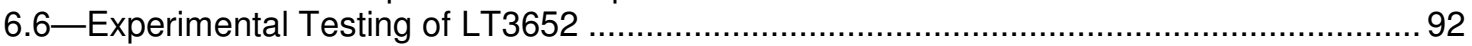

6.6.1-Testing Different Modes of Operation for the Charge Controller ........................... 94

6.6.2-Problems Encountered with Charge Controller .................................................... 94

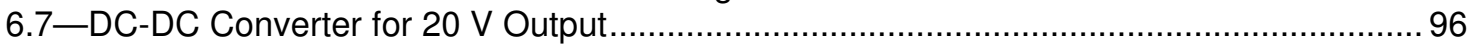

6.8-LT3757 Boost Controller Description and General Schematic........................................ 98

6.9-LT3757 Converter Design and Simulation Results .................................................. 100

6.9.1-Boost Converter LTSpice Schematic ......................................................... 102

6.9.2—Boost Converter LTSpice Simulation Results ............................................... 103

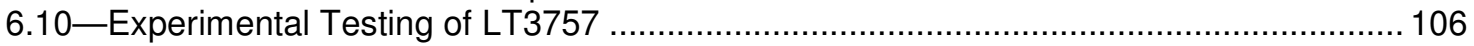

6.10.1—Problems Encountered with Boost Converter Design ...................................... 107

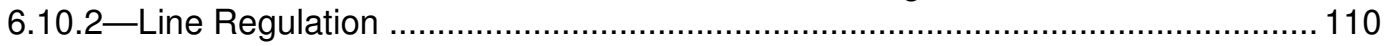

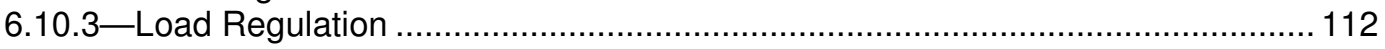

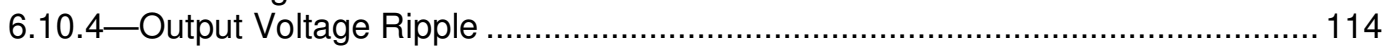

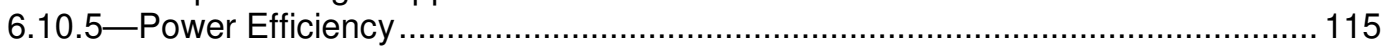

CHAPTER 7 -CHARACTERIZING AND TESTING LUMINAIRE ........................................116

7.1-Testing Techniques for Characterizing Luminaire .................................................... 116

7.2—Light Measurements (LM-79) Specifications for Luminaire Design................................116

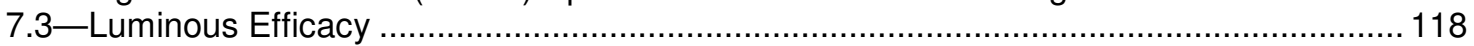

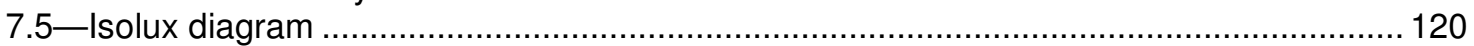

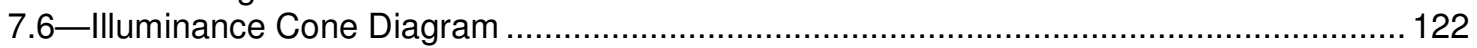

7.7-Comparing Lighting Capabilities to Common IESNA Roadway Practices ....................... 124

7.7.1—Lighting Requirements for Roadways Based on IESNA .................................... 126

7.7.2-Illumination Comparison for Designed Luminaire ........................................... 128

7.7.3_Luminance Comparison for Designed Luminaire ............................................ 130

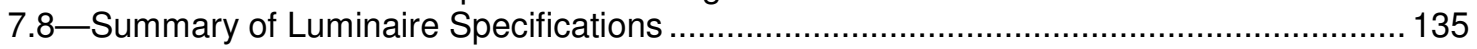

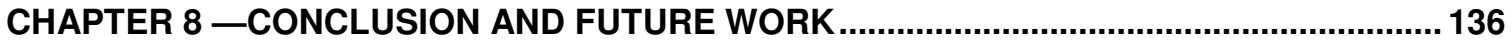

8.1-Cost Reduction in Stand-Alone System Implementation ........................................ 136

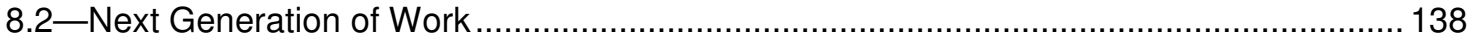

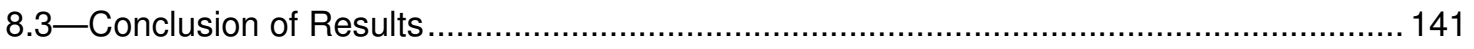

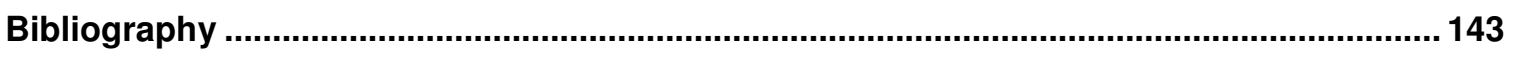

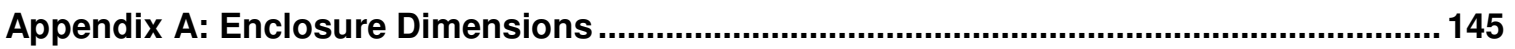




\section{List of Tables}

Table 2-1: Energy production and analysis of photovoltaic sites in California [3] ............................................... 5

Table 3-1: Performance results of LED versus conventional street lamps [13] ..................................................... 17

Table 4-1: Bureau of Street Lighting luminaire requirement for solid state roadway lighting [15].................................22

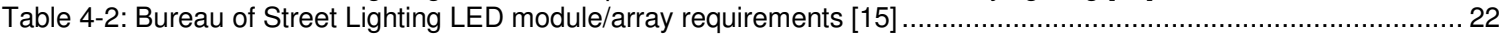

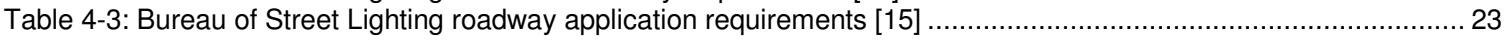

Table 4-4: Maximum LED power consumption to achieve the desired energy savings [16] .......................................2 24

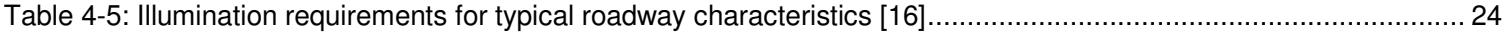

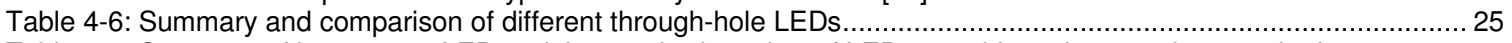

Table 4-7: Summary of lumens per LED and the required number of LEDs to achieve the 3700 lumen criteria $\ldots \ldots \ldots \ldots \ldots . . . .27$

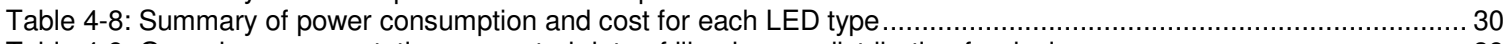

Table 4-9: Gaussian representation generated data of illuminance distribution for design.......................................... 39

Table 4-10: Measured parameters (as described in Figure 21) for different level of bends ............................................49

Table 4-11: Summary of luminaire light span based on farthest reach for point $A$.................................................5 50

Table 4-12: Summary of power efficiencies based on various input voltages .........................................................5 53

Table 4-13: Summary of voltage drops across elements and current through each string .........................................5 57

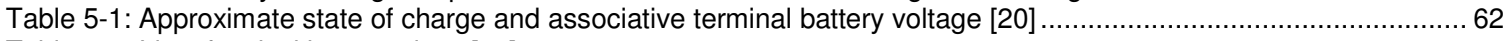

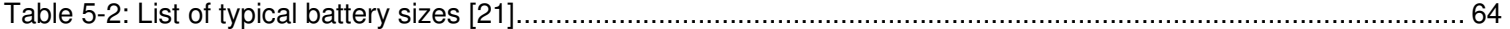

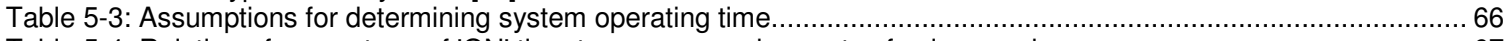

Table 5-4: Relation of percentage of 'ON' time to energy requirements of solar panel .............................................. 67

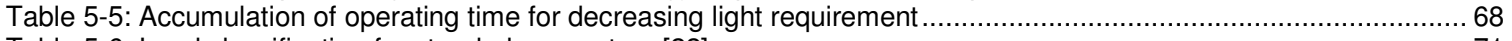

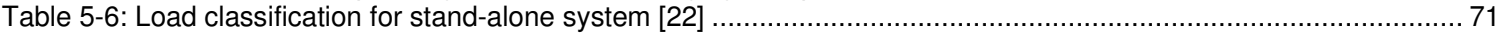

Table 5-7: Sample of available solar panels and associated characteristics ........................................................... 72

Table 5-8: Sample of available batteries and associated characteristics ................................................................ 72

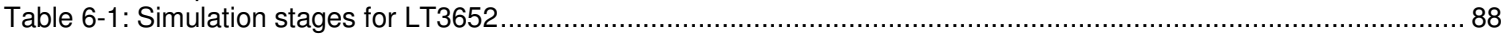

Table 6-2: Measured line regulation data for boost converters ......................................................................... 111

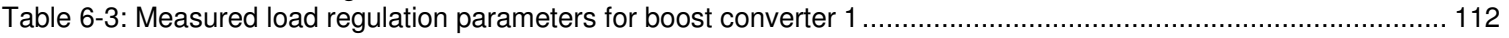

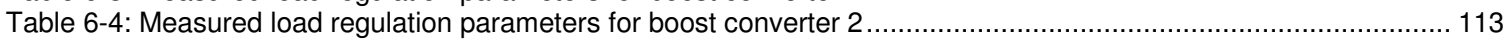

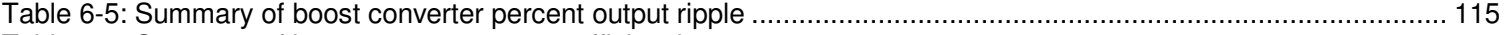

Table 6-6: Summary of boost converter power efficiencies .......................................................................... 115

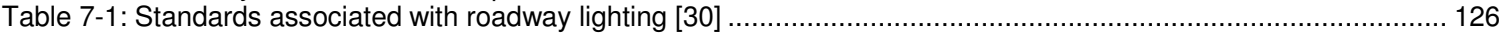

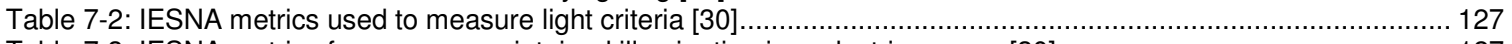

Table 7-3: IESNA metrics for average maintained illumination in pedestrian areas [30]....................................... 127

Table 7-4: Measured illuminance and normalized ratios to compare with IESNA roadway practices .............................128

Table 7-5: Pavement color and conversion values for luminance and illuminance [33] ........................................... 131

Table 7-6: Pavement luminance $\left(\mathrm{cd} / \mathrm{m}^{2}\right)$ for varying distances away from mounted fixture ...................................... 132

Table 7-7: Summary of average luminance and uniformity ratios for luminaire for $12^{\prime}$ x 36 ' area ................................ 132

Table 7-8: Summary of average luminance and uniformity ratios for luminaire for $10^{\prime} \times 30$ ' area..............................133

Table 7-9: Luminaire classification ......

Table 8-1: Estimated cost of implementing designed stand-alone street light (excludes pole installation)..................... 136 


\section{List of Figures}

Figure 2-1: National Renewable Energy Laboratory solar radiation analysis of Santa Maria, CA between 1961 and $1990[4]$

Figure 2-3: Examples of shading impacts on power production [6]

Figure 4-1: Lumen maintenance data at room temperature for two types of white LEDs: curve (a) describes a 5-mm

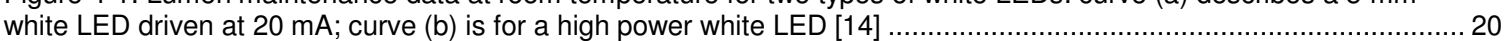

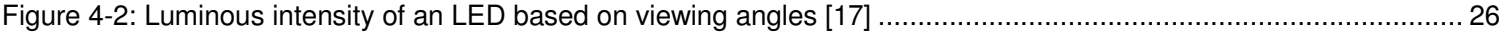

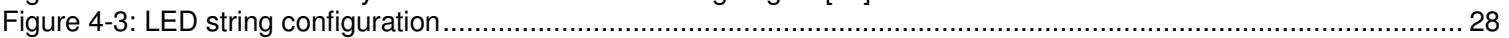

Figure 4-4: LED configurations for $12 \mathrm{~V}$ (top) and $24 \mathrm{~V}$ (bottom) connected sources.................................................. 31

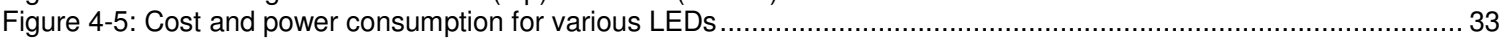

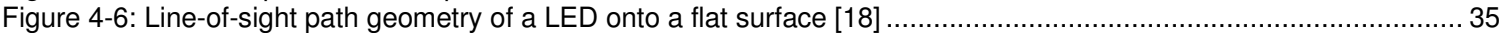

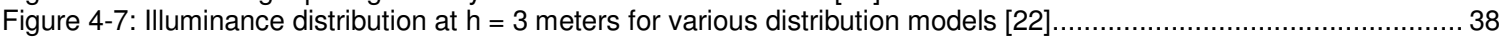

Figure 4-8: Modeled relative illuminance distribution for based on design parameters ..............................................40

Figure 4-9: Gaussian distribution of illuminance--red line indicates the cut-off based on line-of-sight ............................. 41

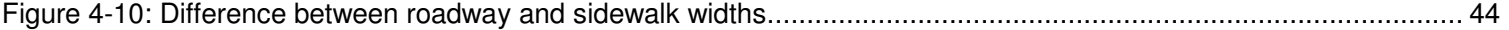

Figure 4-11: Luminaire mounting surface subdivided into ten equal parts for LEDs ............................................... 45

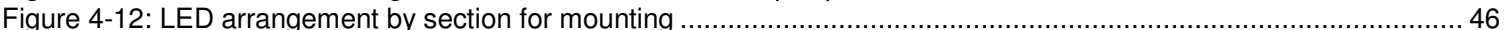

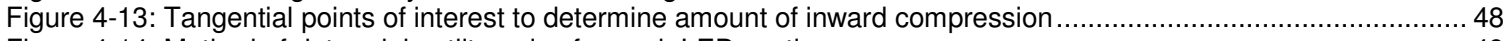

Figure 4-14: Method of determining tilt angles for each LED section ................................................................. 49

Figure 4-15: Illustration of maximum range point A can achieve.......................................................................5 50

Figure 4-16: Plot showing relationship between input voltage and power efficiency ...............................................5 54

Figure 4-17: Circuit configuration for one section of the luminaire ....................................................................5 56

Figure 4-18: LED arrangement with labels for measured values shown in Table 4-13 ............................................5 57

Figure 4-19: Finished LED enclosure with connected LED strings..................................................................5

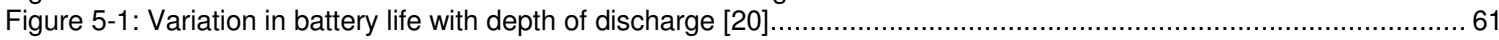

Figure 6-1: Flowchart of different stages to be integrated from the solar panel to the luminaire ...................................74

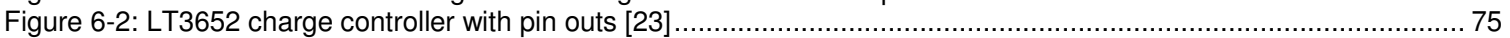

Figure 6-3: 1A solar panel powered 3-stage 12V Lead-Acid Fast/Float Charger [23] .............................................. 76

Figure 6-4: Charger current control voltage vs. proportional input voltage (measured through voltage divider at

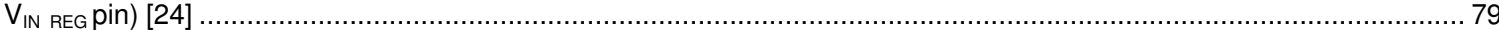

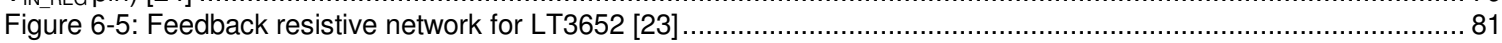

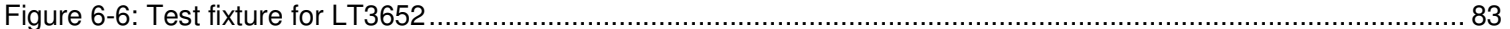

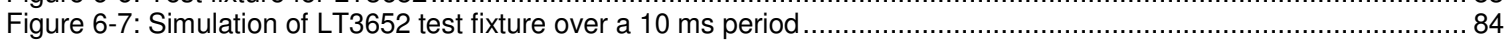

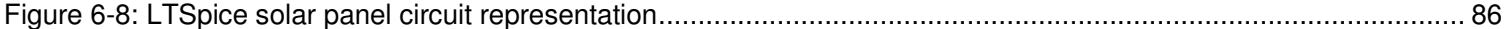

Figure 6-9: I-V and power curves for a simulated $40 \mathrm{~W}$ solar panel model; blue line denotes the I-V curve, red line

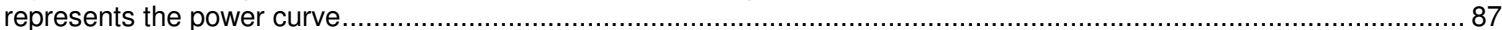

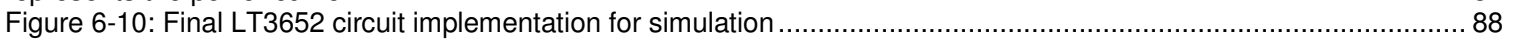

Figure 6-11: Simulation result for LT3652 connected to a $12 \mathrm{~V}$ battery source ......................................................... 89

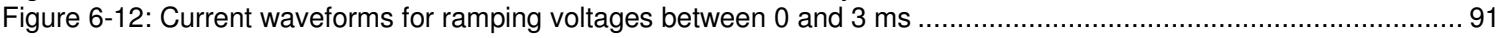

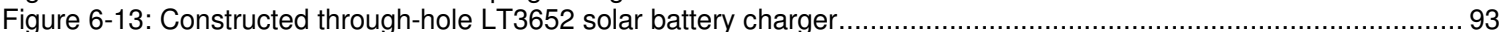

Figure 6-14: Battery voltage variation of time using designed charger................................................................. 95

Figure 6-15: Battery charge current over time using designed charger.................................................................95

Figure 6-16: Basic boost converter circuit layout and general operation ..............................................................97

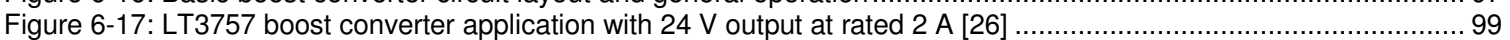

Figure 6-18: LTSpice circuit schematic for simulating the LT3757 controller ...................................................... 103

Figure 6-19: Initialization of LT3757 boost converter modeled by LTSpice ........................................................ 103

Figure 6-20: Steady state voltage of LT3757 boost converter modeled through LTSpice ....................................... 104

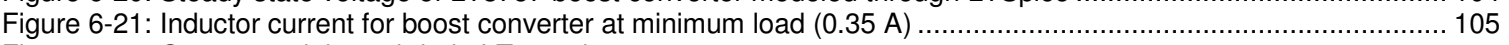

Figure 6-22: Constructed through-hole LT3757 boost converter................................................................... 106

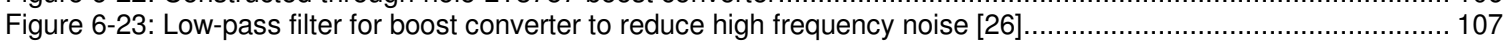

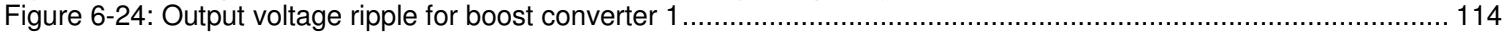

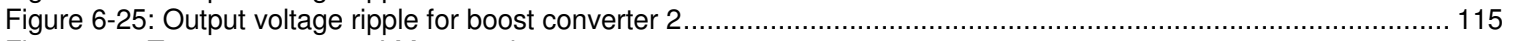

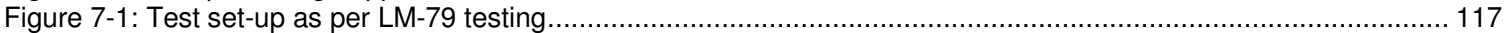

Figure 7-2: Measuring input power with consideration of boost converter efficiency losses ........................................ 119

Figure 7-3: Isolux diagram for developed LED luminaire at a mounting distance of 3 meters ................................... 121

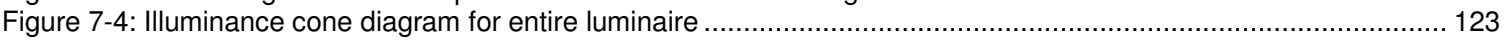

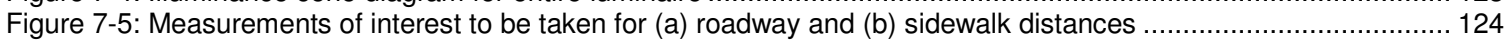

Figure 7-6: Area of illumination constructed based on typical range requirements................................................... 125

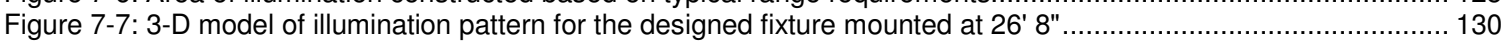

Figure 7-8: 3-D model of luminance pattern for the designed fixture mounted at 26' 8" on a light-colored pavement ...... 134

Figure 8-1: Allocation of sections to corresponding boost converter ....................................................................... 138

Figure 8-2: Connection configuration for powering the luminaire ................................................................... 139

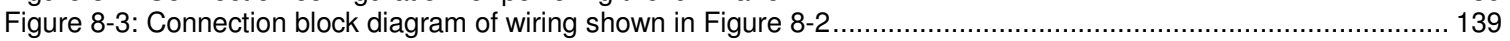




\section{CHAPTER 1-INTRODUCTION}

Utilizing a sectionalized controlled luminaire provides a solution to the energy and pollution problems associated with current roadway lighting technology. In order to advocate the necessary development in off-grid lighting, the overall luminaire system will address the excessive costs, robustness, and energy efficiencies of existing street lights. By effectively limiting operational time and creating a self-sustaining system, the design will reduce the amount of excess lighting during the night and eliminate the need for grid-connected roadway lighting.

This thesis introduces the first stage in a new lighting system design. Chapters 2 and 3 establish the foundation for the integration of a photovoltaic module for the stand-alone system and address concerns associated with LED lighting. These chapters will also introduce preliminary determining factors in the placement of the system, as well as, several specifications for roadway illumination set forth by the IESNA.

The justification for the part selection and overall luminaire layout are thoroughly described in Chapter 4 . With the precedents for new LED fixtures in Los Angeles, the criteria form a basis for determining the quantity of LEDs and layout configurations in order to achieve adequate lighting over desired ranges. Additionally, introduction to the mathematical factors associated with determining illumination distribution of lighting and calculations involved with power consumption for various inputs serve as further evidence as to why particular parameters were chosen to optimize the system design. 
Using a renewable source of energy, solar power, the generated energy will be integrated with a rechargeable battery. Thus, Chapter 5 evinces photovoltaic module and battery selection through energy sizing calculations that include degradation of nominal system operations to allow for extended performance. Sample calculations will provide substantial proof for determining operational duration of the system during the night.

From the information determined in Chapters 4 and 5, Chapter 6 indicates associated intermediate stages for powering the luminaire and monitoring the state of charge for the battery. Simulations and experimental tests provide sufficient characterization of a designed charge controller and two isolated DC/DC converters.

Lastly, Chapters 7 and 8 explain the implementation of experimental photometric tests to characterize the designed luminaire. These tests will serve as a comparable measure to the illumination specifications set by the IESNA and allow a viable mean of contrasting differences between the designed and existing luminaires. With the fundamental design criteria in place, a cost analysis will show the overall savings associated with the designed system. This information will provide the first steps for the next individual to create a feedback detection system. 


\section{CHAPTER 2-PHOTOVOLTAIC BACKGROUND}

\section{1-Introduction to Photovoltaic Cells}

Solar energy has been around since the planet was created. However, not until the recent decades has solar energy and its inexhaustible resource been accepted as a form of usable energy. Originating from the Greeks as a method of heating their homes, solar energy has dramatically evolved into a source for powering towns and cities.

As the economic growth within the photovoltaic industry has grown, solar energy and the associative technology have allowed harvesting energy directly from sunlight to be recognized as a necessary component in future global energy production [1]. Due to the finite supply of fossil fuel sources and the environmental effects of long-term carbon-dioxide emissions, the technological development of harvesting renewable energy has greatly increased over the past decade. Within the following sections, an introduction to solar module placement and photovoltaic uses will provide a solid background for the later chapters, where module selection and sizing selections are made. 


\section{2-Solar Cell Orientation}

One of the most important factors to consider when designing a photovoltaic system is the location of placement. By understanding the parameters associated with the module's tilt, one could optimize the effectiveness of the system to alleviate sizing and costs.

More specifically, the location of placement describes the amount of irradiance the solar panel will be exposed to. Irradiance is defined as the power per unit area of electromagnetic ration at a surface. As an instantaneous quantity, irradiance is normally used to describe the intensity of sunlight, which typically dictates the amount of light energy being converted at any point of the day [2].

\subsection{1-Peak Sun Hours}

In regards to irradiance, irradiation is normally expressed in terms of peak sun hours-the amount of solar radiation energy expressed in hours of full sunlight per square meter. Peak sun hours represent the average amount of sun light available per day throughout the year and correspond to the length of time in hours at an irradiance level of $1 \mathrm{~kW} / \mathrm{m}^{2}$ needed to produce the daily irradiation [2].

In order to illustrate the variation between the daily amounts of peak-sun hours between different areas within California, Table 2-1 summarizes a study conducted by the Regional Economic Research and California Energy Commission. This table describes the amount of observed daily average energy and irradiance for the main area of interest, Los Angeles, CA [3]. Los Angeles is 
selected for the designed luminaire due to the plentiful amount of sunlight and the higher concentration of streetlights that currently reside within the area.

Table 2-1: Energy production and analysis of photovoltaic sites in California [3]

\begin{tabular}{|c|c|c|c|c|c|}
\hline Site & $\begin{array}{c}\text { (A) } \\
\text { Observed } \\
\text { Daily } \\
\text { Average } \\
\text { Energy } \\
\text { (kWh/day) } \\
\end{array}$ & $\begin{array}{c}\text { (B) } \\
\text { Observed } \\
\text { Daily Average } \\
\text { Irradiance } \\
\left(\mathrm{kWh} / \mathrm{m}^{2} / \text { day }\right) \\
\end{array}$ & $\begin{array}{c}(\mathrm{C}) \\
\text { Normalized } \\
\text { Observed } \\
\text { Energy } \\
(\mathrm{Wh} / \mathrm{W} / \\
\left.\mathrm{kWh} / \mathrm{m}^{2}\right) \\
\end{array}$ & $\begin{array}{c}\text { (D) } \\
\text { Assumed } \\
\text { Daily Average } \\
\text { Irradiance } \\
\left(\mathrm{kWh} / \mathrm{m}^{2} / \mathrm{day}\right) \\
\end{array}$ & $\begin{array}{c}(\mathrm{E}) \\
\\
\text { Annualized } \\
\text { Energy } \\
\text { Production } \\
(\mathrm{kWh} / \mathrm{Yr} / \mathrm{kW}) \\
\end{array}$ \\
\hline 1. Orinda & 45.4 & 5.7 & 0.67 & 5.3 & 1,293 \\
\hline 2. Saugus & 26.1 & 6.8 & 0.66 & 5.8 & 1,388 \\
\hline 3. Monrovia & 9.3 & 5.6 & 0.58 & 5.5 & 1,158 \\
\hline 4. Los Altos Hills & 6.8 & 5.0 & 0.63 & 5.4 & 1,242 \\
\hline 5. Hermosa Beach & 7.4 & 5.2 & 0.65 & 5.5 & 1,306 \\
\hline 6. San Francisco & 5.7 & 5.2 & 0.54 & 5.3 & 1,047 \\
\hline 7. Hollister & 6.0 & 5.6 & 0.52 & 5.3 & 1,004 \\
\hline 8. Cupertino & 5.8 & 6.2 & 0.52 & 5.3 & 1,008 \\
\hline 9. Orinda & 2.8 & 5.5 & 0.56 & 5.4 & 1,099 \\
\hline 10. Willits & 12.7 & 5.0 & 0.53 & 4.6 & 889 \\
\hline 11. Ben Lomond & 13.1 & 5.4 & 0.56 & 5.3 & 1,091 \\
\hline 12. Winters & 18.2 & 7.5 & 0.56 & 7.6 & 1,555 \\
\hline 13. Paso Robles & 18.4 & 7.3 & 0.63 & 7.6 & 1,740 \\
\hline 14. Cupertino & 11.0 & 6.0 & 0.59 & 5.3 & 1,132 \\
\hline 15. San Luis Obispo & 7.8 & 5.6 & 0.52 & 5.8 & 1,110 \\
\hline 16. Sunnyvale & 6.2 & 5.6 & 0.46 & 5.3 & 892 \\
\hline 17. Ramona & 5.8 & 5.4 & 0.52 & 5.6 & 1,065 \\
\hline 18. Grass Valley & 6.7 & 6.0 & 0.58 & 5.8 & 1,228 \\
\hline 19. Mariposa & 1.2 & 5.5 & 0.23 & 7.4 & 622 \\
\hline Mean & 11.4 & 5.8 & 0.55 & 5.7 & 1,151 \\
\hline Median & 7.4 & 5.6 & 0.56 & 5.4 & 1,110 \\
\hline
\end{tabular}

Measuring the daily average irradiance produces a good measure in determining ideal locations to place solar panels. However, when sizing a system to determine how much power is generated based on a specific solar panel, peak-sun hours are a more effective measure in describing the theoretical power output from a panel. In order to calculate the amount of peak-sun hours, the average observed daily irradiance in Monrovia (within the greater Los Angeles area) from Table 2-1 will be distributed over the irradiance level of 1 $\mathrm{kW} / \mathrm{m}^{2}$ as shown in equation (2.1).

$$
\text { Peak }- \text { sun hours }=\frac{\text { Average Irradiance per day }}{\text { Irradiance Level }}=\frac{5.6 \frac{\mathrm{kWh}}{\mathrm{m}^{2}}}{1 \frac{\mathrm{kW}}{\mathrm{m}^{2}}}=5.6 \mathrm{hrs}
$$


The peak-sun hours calculated over a six-month span are determined as $5.6 \mathrm{hrs}$. This value will serve as a method of calculating the theoretical amount of power generated by any sort of solar panel in Chapter 5 and will help in deciding which solar panel to select based on the necessary power required by the luminaire.

\subsection{2-Tilt Angle}

The tilt angle, typically denoted by the Greek letter $\varphi$, represents the solar panel's angular displacement, from the horizontal axis, to achieve the most irradiance throughout the day. Solar panels are generally directed at the solar south in the northern hemisphere and solar north in the southern hemisphere with respect to the tilt angle [4]. As the seasons change, the angle of the solar panel can be readjusted between $+15^{\circ}$ or $-15^{\circ}$ of the location's latitude; however, to not discriminate from a location's ability to obtain a higher level of irradiance during one season than another, most solar panels are tilted at an angle equal to the location's latitude.

Figure 2-1 provides an idea how the variation between tilt angle and solar radiation are related through the twelve months. As shown by the data collected over a thirty year span in Los Angeles, CA, the solar panels received the most irradiance when tilted with an angle equal to the latitude (33.93ํ) [4]. 


\section{Los Angeles, CA}

WBAN NO. 23174

LATITUDE: $33.93^{\circ} \mathrm{N}$

LONGITUDE: $118.40^{\circ} \mathrm{W}$

ELEVATION: 32 meters

MEAN PRESSURE: 1012 millibars

STATION TYPE: Primary

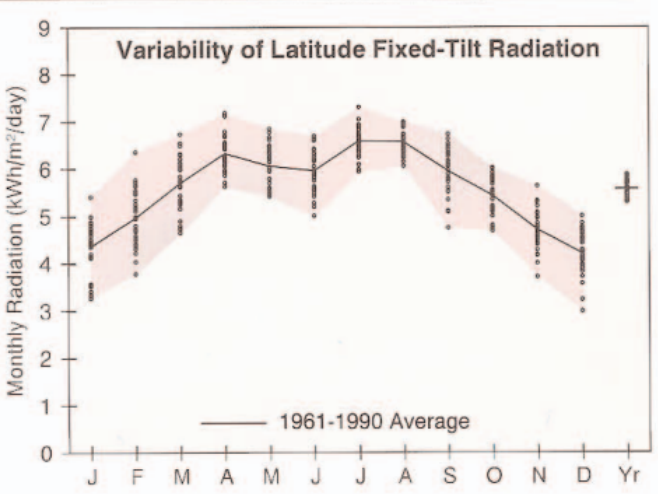

Solar Radiation for Flat-Plate Collectors Facing South at a Fixed Tilt $\left(\mathrm{kWh} / \mathrm{m}^{2} /\right.$ day), Uncertainty $\pm 9 \%$

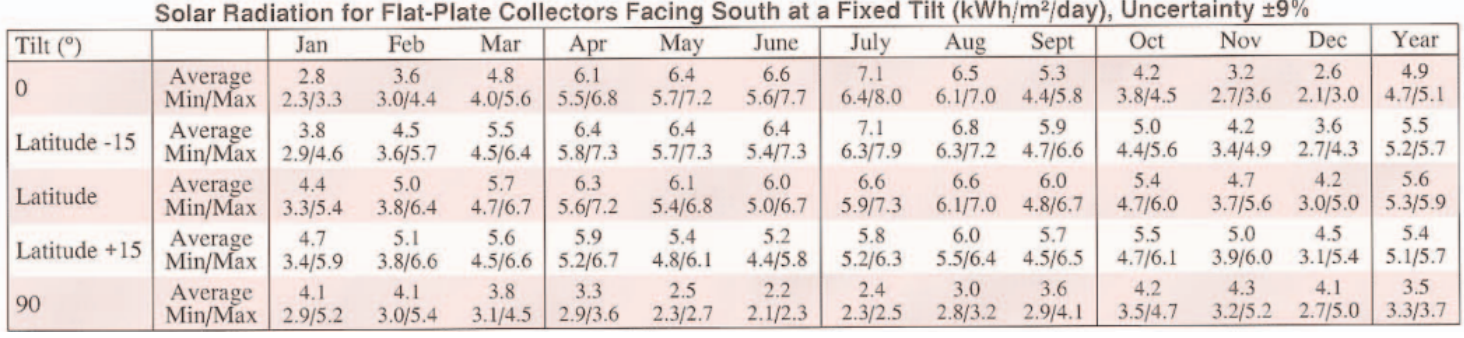

Figure 2-1: National Renewable Energy Laboratory solar radiation analysis of Santa Maria, CA between 1961 and 1990 [4]

\section{3-Factors Hindering Solar Production}

Many environmental problems exist that could significantly lower the solar production of a photovoltaic system. These obstructions can cause the total solar irradiation to decrease and thus, lower the amount of sunlight being converted into electrical energy. Identifying these problems can help design potentially a larger system to accommodate for the surrounding environment or allow for the relocation of where the system should be placed.

\subsection{1-Air Mass}

In regards to the weather affecting the photovoltaic system's operation, air mass is characterized by water vapor and temperature in a large volume of air. A marine layer is an air mass that develops over the surface of a large body of water as the ocean encounters a temperature inversion [2]. 
The amount of sunlight either absorbed or scattered depends on the length of the path through the atmosphere. Since this path length is generally compared with a vertical path directly to sea level, determined by the air mass $=$ 1, the amount of irradiance will ultimately be affected by changes in the air mass. To put values into perspective, refer to the equation (2.2) below:

$$
\text { Irradiance }=1367(0.7)^{(A M)^{0.678}}
$$

Thus as the air mass increases, the solar irradiance will decrease and thus, lowering the actual amount of power being outputted.

\subsection{2-Soiling}

Soiling in photovoltaic systems is one of the largest contributors to losses under the control of the system operator. The accumulation of dirt on solar panels can significantly impact the performance of photovoltaic systems in arid regions where rainfall is limited for several months. Specifically speaking, this problem mainly affects the Southwest regions of the United States.

According to a study of over fifty large, grid-connected photovoltaic systems, soiling rates (the rate at which the system's output power at standard testing conditions declines each day due to the accumulation of dirt on the panels) were approximately linear over time for periods without rainfall. The results of this study indicate that the average performance loss due to soiling in dry climates occurs at a rate of $0.0011 \mathrm{kWh} / \mathrm{kWp} /$ day without rainfall. This soiling rate, over a linear period of time, equates to between $2-6 \%$ of annual energy loss as charted in Figure 2-2 [5]. 


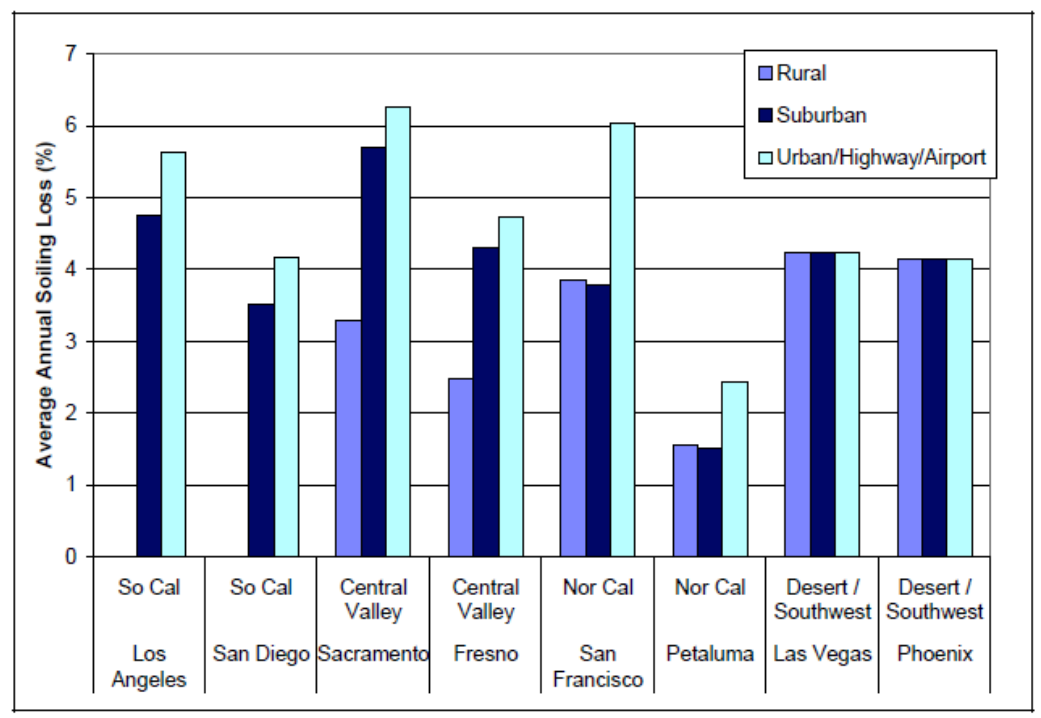

Figure 2-2: Average annual soiling loss rates by region [5]

\subsection{3-Shading}

Another important aspect to consider when positioning a photovoltaic system is the impact of shading on the module. In more populated areas, shading can be derived from tall buildings, trees, roof vents, or any item that creates a diffused or dispersed shadow based on the positioning of the sun throughout the day. Described in further detail within this section, any form of shading can significantly decrease the productivity received from a photovoltaic module.

Shading obstructions are typically classified as either soft or hard sources. Soft sources significantly reduce the amount of light reaching the cell(s) of a module (dispersed shadowing); whereas hard sources completely stop light from reaching the cell(s) (i.e. tree branch, bird dropping, or objects directly sitting on top of the module). If even one full cell is hard shaded, the voltage of that module will drop to half of its unobstructed value. The reason for this drop is due to the finite resistance inherent in the forward direction of the solar cell. When 
exposed to sunlight, the diode's internal resistance within in a solar cell increases. From general electrical engineering practices, current is known to flow through the path of least resistance. Since solar cells are orientated in series string connections, when a cell in the series string is shaded the resistance in that cell increases tremendously, making the bypass diode the path of least resistance. Therefore the current will follow the path of least resistance, shunting the power through the bypass diode and through an alternate path around the photovoltaic cell to another cell in the string [6].

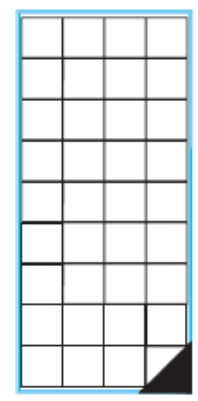

Examples of partial-cell shading that reduce $\mathrm{PV}$ module power by $1 / 2$

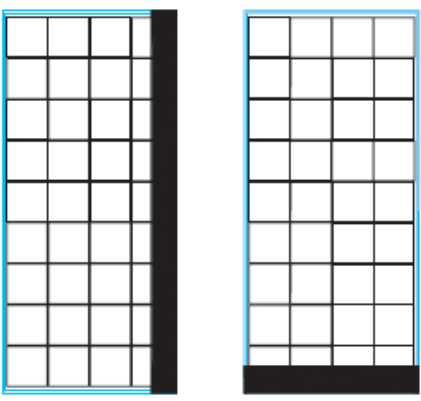

Example of full-cell shading that can reduce $P V$ module power to zero
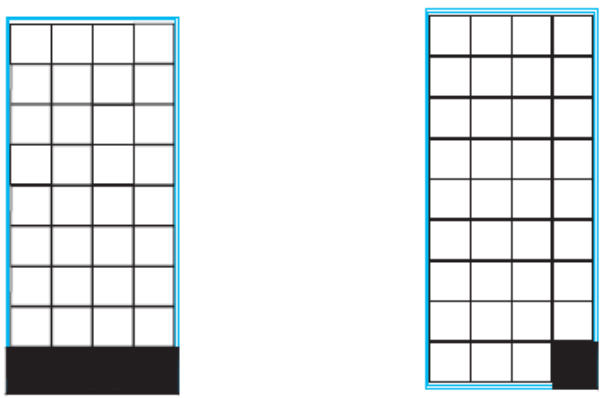

Example of full-cell shading that can reduce PV module power by $1 / 2$

Figure 2-3: Examples of shading impacts on power production [6]

If enough cells are hard shaded, the module will not convert any energy and will, instead, drain energy from the entire system. From Figure 2-3, whether half of a cell or half a row of cells is shaded, the power decrease will be approximately the same and proportional to the percentage of area shaded. When a full cell is shaded, it can act as a consumer of energy produced by the remainder of the cells in the string and trigger the module to protect itself by routing the power around that series' string. Further results of shading show that if even one full cell in a series is shaded, it will likely cause the module to reduce 
its power level to half of its unobstructed value and if a row of cells at the bottom of a module is fully shaded, the power output may drop completely to zero. Although not seemingly obvious, photovoltaic modules are very sensitive to shading - even the branch of a leafless tree can cause the module to have a significant decrease in productivity. Thus from a design perspective, shading should always be avoided whenever possible to allow the best photovoltaic system operation [6].

\section{4-Solar Uses and Applications}

Solar energy can be used in many different ways such as heating, lighting, or generating electricity. Of these uses, solar energy is categorized as either passive or active based on how the energy is used. Passive energy refers to the use of the sun's heating ability to provide warmth in certain areas or to reduce the amount of energy used for daytime lighting by exposing sunlight in various locations. Active energy is more widely recognized by the vast public and refers to the storing and energy conversion for electrical or thermal uses [7]. Within this section, a few solar energy uses will be discussed.

\subsection{1-Solar Heating}

Solar heating, as mentioned above, is a form of passive energy. Although solar heating does not generate electricity per se, it shares the same effect on the electrical grid as active energy in terms of conservation or reducing the need for other forms of energy, such as natural gas and oil. From 1998 to 2005, the solar water heating market produced about the thermal equivalent of 124,000 megawatt-hours of energy annually [8]. 


\subsection{2-Solar Electricity}

Solar electricity can be thought of in small or large scale systems. Within larger photovoltaic networks, solar energy is thought of as a method of reducing the load used by consumers during peak-hours of the day. Without an additional form of energy generation present during periods of high demand, the electric grid can sometimes become overloaded and endure potential blackouts. On the other hand, smaller systems that utilize storage devices, such as batteries, are used in conjunction with photovoltaic modules, eliminating the need for the system to be tied into the electrical grid.

The reduction in cost and need for installation of grid interconnects has allowed numerous forms of solar applications to develop. In rural and underdeveloped countries, the need for stand-alone photovoltaic systems persists due to the absence of electricity. For instance, applications such as small photovoltaic arrays are now being implemented in third-world countries, where electrical grids are located hundreds of miles away. Even within the United States, lighting and roadway signs have incorporated solar energy and the associated storage devices as a method of isolation from the electrical grid. The low energy demand allows exploration into future self-sustaining devices and serves as a basis for the transition into the primary focus of this thesis-a solarpowered luminaire. 


\section{CHAPTER 3-OPTICAL LIGHTING BACKGROUND}

\section{1-Introduction to Light Emitting Diodes}

Over the past thirty years, the criteria for evaluating public lighting systems have become much more extensive in order to improve public approval. Energy consumption, maintenance costs, minimization of light pollution, the feeling of added security, and aesthetically pleasing designs have become just as important as light output and the lifespan of the lamp [9]. As advancements in optical engineering have improved, the development of Light Emitting Diodes (LEDs) serves to address the economic and problematic issues with existing lights.

\section{2-LED Comparison with Other Lighting Means}

When evaluating LEDs with other forms of conventional lighting, cost, efficiency, durability, and longevity, this comparison can help clarify the advantages and disadvantages of LEDs in numerous applications. As a new and upcoming technology, LEDs continue to face challenges that make it inferior to incandescent or other types of lighting. However, when LEDs become more widely recognized and used, other forms of lighting will soon become obsolete.

\subsection{1-Advantages of Using LEDs for Lighting}

Primarily speaking, the main determinants for the cost of traditional incandescent lighting come from the cost of replacing the bulbs and the labor involved. Although labor may not seem like a significant issue from a homeowner's point-of-view, large businesses, schools, and hospitals require continual maintenance of the fluorescent lights. The amount of time and effort 
required to replace each individual light becomes inefficient due to the continual maintenance.

In relation to cost, the efficiency of a lighting solution plays an important factor in how much money would be paid each month for operating a particular light source. The core attribute of LEDs is the reduced power consumption over conventional lighting solutions. Typically an LED circuit can approach an average of $80 \%$ efficiency-meaning $80 \%$ of the electrical energy is converted into light and the remaining $80 \%$ is lost as heat dissipation in current drivers [10]. Comparing the efficiency of LEDs with incandescent bulbs, incandescent lights dissipate $80 \%$ of the electrical energy as heat. Due to the high efficiency of LEDs, one example of the growing application of LEDs is in traffic lights. A red traffic light draws about 10 watts of power versus its incandescent counterpart that consumes 150 watts. From this analysis, it has been estimated that replacing incandescent lamps in all of America's 260,000 traffic signals could reduce energy consumption by nearly 2.5 billion $\mathrm{kWh}$. The initiative has already been put in place and as of 1997, more than 150,000 signal lights were retrofitted to include LEDs [11].

From a design standpoint, LEDs are very flexible in their packaging. Due to their miniature sizes, LEDs can be rearranged to provide directional lighting based on specific applications. In addition to their solid state design, LEDs are very rugged and contain no components that can be altered or damaged due to sudden shocks and movements. To place these design features into perspective, LED lamps are able to withstand a 100,000 hours of use or 
equivalent to 11 years of continuous operation [11].

Knowledge of LED design and optical capabilities provide substantial reason to believe that LEDs would be suitable for this thesis. Since LEDs have a much higher efficiency, the electrical energy generated from the solar panels will be optimized since a vast majority of the energy will be used for lighting purposes, rather than dissipated as heat. In addition, since LEDs provide great directional lighting due to their optical design, they would be great for spotlighting due to the directional focused light molecules with minimal losses and diffusion.

\subsection{2-Disadvantages of Using LEDs for Lighting}

LEDs contain numerous advantages when it comes to cost and efficiency; however these advantages also contain flaws when considering their functionality and immediate costs. For instance, although LEDs will save more money in the long run, the initial price is much higher than its incandescent counterpart. In addition, LEDs are very directional as explained in the previous section; thus to provide the necessary amount of lighting, more LEDs are required to provide lighting in all directions. Since more LEDs are involved, the resulting light can be grainy (mini beams of light on the wall, floor, or ceiling) due to their narrow angle of transmittance.

From a manufacturing point-of-view, LEDs have no true standardizationmeaning there is no specific guideline on how to design a LED. This problem raises the concern about maintaining the specialized form of technology for future use. Furthermore, LEDs are very sensitive to voltage fluctuations; therefore using LEDs for applications where the voltage tends to differentiate can 
cause heat fluctuations that could reduce the lifespan and light output from the LED [12].

The listed disadvantages discriminate against LED lighting based on the amount of years the technology has existed. LEDs have only been recently recognized as a viable form to providing light for a vast amount of applications; thus the ability to classify all the new developments within LED lighting as appropriate or not is nearly impossible. However as the technology further progresses at its current rate, industry standards and regulatory requirements by the Department of Energy and IESNA for new luminaire fixtures will surely arrive. In addition, as the complex structures of LEDs will further be analyzed and explored, material and manufacturing developments will also improve and thus, drive down the cost of purchasing LED luminaires.

\section{3-Justification for Using LEDs for Roadway Lighting}

LED street light installations have already been tested all around the world as a method to soon replace the less efficient high pressurized sodium and mercury vapor fixtures. As described through the previous section, the advantages associated with solid-state lighting have allowed its growing adoption as a viable lighting source in today's society. As a method of comparing a LED fixture with two dominant forms of existing street lights, Table 3-2 summarizes the performance of each fixture. 
Table 3-1: Performance results of LED versus conventional street lamps [13]

\begin{tabular}{|l|c|c|c|}
\hline & LUXEON Rebel & High Pressure Sodium & Mercury Vapor \\
\hline Flux $(\mathrm{Im})$ & 3325 & 5510 & 4340 \\
\hline Power consumption & $67 \mathrm{~W}$ & $90 \mathrm{~W}$ & $138 \mathrm{~W}$ \\
\hline System Efficacy $(\mathrm{Im} / \mathrm{W})$ & 50 & $61^{*}$ & 31 \\
\hline Average lux & 14 & 19 & 14 \\
\hline Utilization & 0.0042 & 0.0034 & 0.0032 \\
\hline Lux/W & 0.21 & $0.21^{* *}$ & 0.10 \\
\hline Min/avg lux ratio & 0.40 & 0.32 & 0.23 \\
\hline Lifetime (hours) & 60,000 & $20,000-30,000$ & $6,000-10,000$ \\
\hline
\end{tabular}

Just from the data alone, major discrepancies can be seen from the listed performance parameters. As far as the power consumption is concerned, the LUXEON Rebel (LED fixture) consumes the least amount of power during operation. In addition, the efficacy (or essential lumens outputted per watt of power) for the LUXEON Rebel is much greater than the Mercury Vapor. The higher efficacy from the High Pressure Sodium fixture is misleading due to the inclusion of wasted light dispersed in various directions. The next important parameter to discuss is the light distribution ratio between the minimum and average illuminance over the intended area of lamination. The higher ratio for the LED fixture indicates that the luminaire is more controllable and directional than the other counterparts. Lastly, in terms of the advantages in maintenance and replacement costs, the LED fixture far surpasses the high pressure sodium and mercury vapor lamps $(60,000$ hours versus the overall range of $6,000-$ 30,000 hours).

With the supporting performance comparison between a LED street light and the two existing conventional forms of lighting available, the transition to LED lamps is imminent. These evaluated parameters further justify the need to improve on LED luminaire designs. 


\section{CHAPTER 4-LED FIXTURE DESIGN}

\section{1-Design Concept and Goals}

Roadway lighting is essential for public safety; thus, the designed LED fixture must supply the proper illumination specified in the Chapter 3 . For the initial criteria, several guidelines for the designed fixture follow specifications set forth by the City of Los Angeles. The following sections describe the approach and justification for the selection of LEDs used for the design.

The goal of the fixture will be to achieve the proper illumination over the listed range specified by the Bureau of Street Lighting in Los Angeles City. Distinctive from the conventional method of having a light source remain on through the duration of the night, the design will incorporate numerous sections that will discretely turn on based on which area requires lighting. Each section of the designed luminaire will emit a narrow beam of light that will provide directional lighting or spot-lighting as pedestrians walk within the designated vicinity. The future design of the detection system will use pre-established thresholds that will trigger various regions of the luminaire based on the individual's location from the fixture. Therefore, different from existing roadway light fixtures, the designed system will effectively extinguish all sections of the luminaire when no pedestrians are present. 


\section{2-Choosing the LED Type (High-Power versus Low-Power)}

As mentioned above, the LEDs chosen for this design are strictly throughhole (low-power). This selection is not typically used in modern lighting techniques due to their lower individual light outputs and light depreciation over long periods of time. However, for the proposed application, low-power LEDs provide the necessary characteristics needed to accommodate the basis of the design. With the low power consumption by individual LEDs, additional factors, such as heat sinks, can be eliminated from the design.

High-power LEDs are characterized by the amount of driving current required to turn on the solid state device. Typically used in lighting applications, high-power LEDs generally draw more than $350 \mathrm{~mA}$ per device as opposed to 30 mA for low-power LEDs. The ten-fold difference in current requires a method of managing the heat dissipated by the high-power LED. Heat sinks will be necessary for each high-power LED and contribute to the overall cost, weight, and size of the system. In addition to the amount of current required to turn on the LED, high-power LEDs tend to have a larger half-beam angle that can range anywhere between 30 to 60 degrees; whereas low power LEDs can have much narrower half-beam angles that range between 10 and 60 degrees. For the luminaire to incorporate sectional lighting, the chosen LEDs must have as narrow of a beam width as possible in order to provide directional lighting.

Lumen depreciation of LEDs is an important aspect when dealing with devices that are constantly biased and remain in the on-state position. LEDs do not fail abruptly; however they dim over time so an LED rated with a specified 
lumen rating will output less lumen after being used for hundreds of hours. The lumen depreciation for LED ranges based on the color of light outputted due to the differences in band-gap and wavelength of light. Figure 4-1 shows the lumen depreciation of LEDs as a percentage of the rated value over various lifetimes for bright white LEDs.

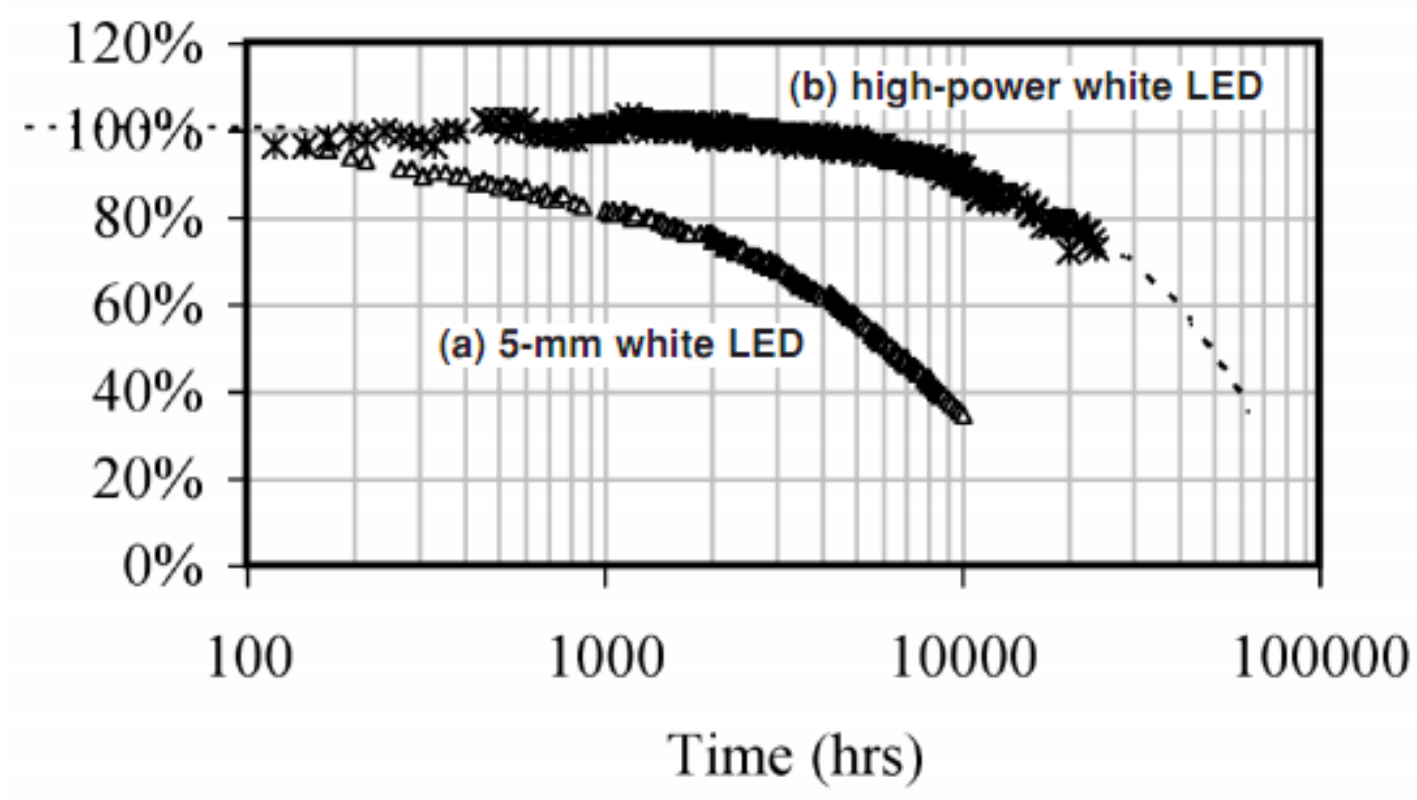

Figure 4-1: Lumen maintenance data at room temperature for two types of white LEDs: curve (a) describes a 5-mm white LED driven at $20 \mathrm{~mA}$; curve (b) is for a high power white LED [14]

As mentioned for the design, the LEDs will not constantly be illuminated; thus, the stress condition for the LED is less than the testing conditions used for determine the lumen depreciation shown in the above figure.

Besides the difference in lumen depreciation between high- and lowpower LEDs, the effect of a LED failing to operate must also be taken into account. For instance, assume twenty LEDs are required to provide the same lumen output of a high power LED. If an individual low power LED was to fail, only one string should turn off-effectively reducing the light outputted. On the 
contrary, if the high power LED was to fail, this would render the section of the light to completely be nonoperational.

\section{3-Basic Guidelines for City of Los Angeles LED Luminaires}

Provided from the Bureau of Street Lighting, the criteria listed in this section summarize the general specifications for solid state lighting LED roadway luminaires to replace equivalent luminaires of $100 \mathrm{~W}$ high-pressurized sodium streetlights. The following tables summarize the criteria used in determining the proper low power LEDs, size of the luminaire enclosure, mounting space, and amount of LEDs necessary to meet the lumen requirement. 
Table 4-1: Bureau of Street Lighting luminaire requirement for solid state roadway lighting [

\begin{tabular}{|c|c|}
\hline $\begin{array}{l}\text { Correlated Color Temperature } \\
(\mathrm{CCT})\end{array}$ & $\frac{\text { Nominal CCT }\left({ }^{\circ} \mathrm{K}\right)}{4300+/-300}$ \\
\hline Color Rendering Index (CRI) & Luminaires shall have a minimum CRI of 65 . \\
\hline Off-state Power Consumption & $\begin{array}{l}\text { The power draw of the luminaire (including PE or remote control } \\
\text { devices) shall not exceed } 2.50 \text { watts when in the off state. }\end{array}$ \\
\hline On-state Power Consumption & $\begin{array}{l}\text { Shall not consume more than (not including optional } \\
\text { monitoring/control device): } \\
-58 \mathrm{~W} \text { for Equivalent Replacement of } 70 \mathrm{~W} \text { HPS } \\
-\quad 85 \mathrm{~W} \text { for Equivalent Replacement of } 100 \mathrm{~W} \text { HPS }\end{array}$ \\
\hline Warranty & $\begin{array}{l}\text { A warranty must be provided for the full replacement of the } \\
\text { luminaire due to any failure for six (6) years. The warranty shall } \\
\text { provide for the repair or replacement of defective electrical parts } \\
\text { (including light source and power supplies/drivers) for a minimum } \\
\text { of eight (8) years from the date of purchase. }\end{array}$ \\
\hline Weight & Luminaire shall not weigh more than 22 pounds. \\
\hline Operating Environment & $\begin{array}{l}\text { Luminaire shall be able to operate normally in temperatures from } \\
-20^{\circ} \mathrm{C} \text { to } 50^{\circ} \mathrm{C} \text {. }\end{array}$ \\
\hline Cooling System & $\begin{array}{l}\text { Shall consist of a heat sink with no fans, pumps, or liquids, and shall } \\
\text { be resistant to debris buildup that does not degrade heat dissipation } \\
\text { performance. }\end{array}$ \\
\hline Dimensions (Approx.) & 30 " long x 16 " wide $\times 7$ " tall \\
\hline Housing & $\begin{array}{l}\text { Shall be primarily constructed of metal. } \\
\text { Finish shall be gray in color, powder coated and rust resistant. } \\
\text { Driver must be mounted internally and be replaceable. } \\
\text { Driver must be accessible without tools. } \\
\text { All screws shall be stainless steel. } \\
\text { Captive screws are needed on any components that require } \\
\text { maintenance after installation. } \\
\text { No parts shall be constructed of polycarbonate unless it is UV } \\
\text { stabilized (lens discoloration shall be considered a failure under } \\
\text { warranty). } \\
\text { Ingress Protection shall be rated a minimum of IP54. }\end{array}$ \\
\hline IESNA Luminaire Classification & Cutoff or using TM-15: B1 U1 G1. \\
\hline Mounting Arm Connection & $\begin{array}{l}\text { Luminaires shall mount on } 2.375 \text { " O.D. horizontal tenon with no } \\
\text { more than four } 9 / 16 \text {-inche hex bolts and two piece clamp with } \\
\text { vertical tilt adjustment range of }+/-5 \% \text {. }\end{array}$ \\
\hline PE Cell Receptacle & $\begin{array}{l}\text { Luminaires shall have a 3-prong twist-lock photo-control receptacle } \\
\text { in accordance with ANSI C136.10. The PE socket needs to be able } \\
\text { to rotate, so that the PE window can always be positioned to face the } \\
\text { North direction. }\end{array}$ \\
\hline House Shield & Shall provide option for house side light control. \\
\hline
\end{tabular}

Table 4-2: Bureau of Street Lighting LED module/array requirements [15]

\begin{tabular}{|l|l|}
\hline $\begin{array}{l}\text { Lumen Depreciation of LED } \\
\text { Light Sources }\end{array}$ & $\begin{array}{l}\text { LED module(s)/array(s) shall deliver at least 70\% of initial lumens, } \\
\text { when installed for a minimum of 50,000 hours. Assembly shall be } \\
\text { rated a minimum of IP66. }\end{array}$ \\
\hline Light Distribution & $\begin{array}{l}\text { Should be in accordance with IESNA Type II Lighting Distribution. } \\
\text { Distribution Type II designated 2X is also acceptable. }\end{array}$ \\
\hline
\end{tabular}


Table 4-3: Bureau of Street Lighting roadway application requirements [15]

\begin{tabular}{|l|l|}
\hline Minimum Light Output & $\begin{array}{l}\text { - For Equivalent Replacement of 70 W HPS, luminaire shall deliver } \\
\text { a minimum of } 3100 \text { lumens (initial) } \\
\text { - For Equivalent Replacement of } 100 \mathrm{~W} \text { HPS, luminaire shall } \\
\text { deliver a minimum of 3700 lumens (initial) }\end{array}$ \\
\hline Luminaire Efficacy & $=\frac{\text { Luminaire Light Output(includes fixture efficiency and thermal effects) }}{\text { Luminaire Input Power }}$ \\
\hline Minimum Luminaire Efficacy & $50 \mathrm{~lm} / \mathrm{W}$ \\
\hline
\end{tabular}

As mentioned earlier, these standards only serve as a general basis for the design. Since several criteria listed only apply to high power solid state devices and luminaires that operate solely in two different modes: 'ON' or 'OFF'. One of the guidelines specifies a minimum of $70 \%$ of initial lumen output after 50,000 hours of use; however for the directional method proposed, the overall time that the LEDs will operate will depend on the amount of traffic (pedestrians) at any given time. In comparison to the conventional LED roadway luminaires that are constantly 'ON', the life-time of the devices will depreciate at a comparable rate to the low power LEDs, which will only turn on based on the detection scheme.

In addition to transitioning to LED luminaires, the Bureau of Street Lighting has several energy requirements (Table 4-4) and existing roadway characteristics that will be useful in determining the curvature for the LED mounting surface (Table 4-5). For the intended replacement, the LED luminaire should consume less than 85 W for replacing the 100 W HPS fixture (described in Table 4-1); however this value is adjustable due to the fact that these systems are interconnected with the grid. 
Table 4-4: Maximum LED power consumption to achieve the desired energy savings [16]

\begin{tabular}{|l|c|}
\cline { 2 - 2 } \multicolumn{1}{c|}{} & Power Consumption \\
\hline LED W HPS lamp and ballast uses: & $138 \mathrm{~W}$ \\
\hline 150 W HPS lamp and ballast uses: & $73 \mathrm{~W}$ \\
\hline LED replacement should use less than: & $190 \mathrm{~W}$ \\
\hline 200 W HPS lamp and ballast uses: & $115 \mathrm{~W}$ \\
\hline LED replacement should use less than: & $240 \mathrm{~W}$ \\
\hline 310 W HPS lamp and ballast uses: & $145 \mathrm{~W}$ \\
LED replacement should use less than: & $365 \mathrm{~W}$ \\
\hline 400 W HPS lamp and ballast uses: & $225 \mathrm{~W}$ \\
LED replacement should use less than: & $465 \mathrm{~W}$ \\
\hline
\end{tabular}

Table 4-5: Illumination requirements for typical roadway characteristics [16]

\begin{tabular}{|c|c|c|c|c|c|}
\hline Lamp Size & $100 \mathrm{~W}$ HPS & 150 W HPS & 200 W HPS & 310 W HPS & 400 W HPS \\
\hline Mounting Height & $26^{\prime} 8^{\prime \prime}$ & 29' 7" to $32^{\prime} 7^{\prime \prime}$ & $30^{\prime}$ to $33^{\prime}$ & $30^{\prime}$ to $40^{\prime}$ & $30^{\prime}$ to $40^{\prime}$ \\
\hline Spacing & $150^{\prime}$ to $170^{\prime}$ & $130^{\prime}$ to $140^{\prime}$ & $125^{\prime}$ to $140^{\prime}$ & $110^{\prime}$ to $160^{\prime}$ & $120^{\prime}$ to $180^{\prime}$ \\
\hline Configuration & One-sided & Staggered & Opposite & Staggered or Opposite & Staggered or Opposite \\
\hline Roadway Classification & Local & Collector & Major & Major & Major \\
\hline Roadway Width & $30^{\prime}-36^{\prime}$ & $40^{\prime}-50^{\prime}$ & $50^{\prime}-70^{\prime}$ & $>70^{\prime}$ & $>80^{\prime}$ \\
\hline Sidewalk Width & $10^{\prime}-12^{\prime}$ & $10^{\prime}-12^{\prime}$ & $10^{\prime}-15^{\prime}$ & $8^{\prime}-20^{\prime}$ & $10^{\prime}-20^{\prime}$ \\
\hline
\end{tabular}

The 100 W HPS system requirements in Table 4-5 show the design constraints for the proposed system. The main criteria of interest is based on the type of roadway (Local) and the roadway/sidewalk widths, 30' - 36' and 10' - 12', respectively. The difference between the widths will be illustrated in section 4.6.

\section{4-Justification for LED Selection}

The initial starting point of the design begins with determining the type of LEDs to use for roadway lighting. The selected LEDs should have a relatively small beam angle, strong light intensity, and cost efficient based on their overall power consumption. From several different online sources, a collection of LEDs and their characteristics are summarized in the Table 4-6: 
Table 4-6: Summary and comparison of different through-hole LEDs

\begin{tabular}{|c|c|c|c|c|c|c|c|c|c|c|c|}
\hline LED Name & Size & Color & $\begin{array}{c}\text { Cost } \\
\text { (per LED) }\end{array}$ & $\begin{array}{c}\text { Luminous } \\
\text { Intensity } \\
\text { (mcd) }\end{array}$ & \begin{tabular}{|c|}
$\begin{array}{c}\text { Viewing } \\
\text { Half- } \odot \\
\left({ }^{\circ}\right)\end{array}$ \\
\end{tabular} & $\begin{array}{c}\text { Reverse } \\
\text { Current } \\
(\mu \mathrm{A})\end{array}$ & $\begin{array}{c}\text { Forward } \\
\text { Voltage } \\
\text { (V) } \\
\end{array}$ & \begin{tabular}{|c|}
$\begin{array}{c}\text { Continuous } \\
\text { Forward } \\
\text { Current (mA) }\end{array}$ \\
\end{tabular} & \begin{tabular}{|c|} 
Max Peak \\
Forward \\
Current $(\mathrm{mA})$ \\
\end{tabular} & $\begin{array}{c}\text { Reverse } \\
\text { Voltage (V) }\end{array}$ & \begin{tabular}{|c}
$\begin{array}{c}\text { Max Power } \\
\text { Dissipation } \\
(\mathrm{mW})\end{array}$ \\
\end{tabular} \\
\hline LE2005 & $10 \mathrm{~mm}$ & White & $\$ 0.25$ & 18000 & 10 & $<=30$ & $3.2-3.8$ & 30 & 75 & $5-6$ & 80 \\
\hline LE1019 & $5 \mathrm{~mm}$ & White & $\$ 0.06$ & 13000 & 10 & $<=30$ & $3.2-3.8$ & 30 & 75 & $5-6$ & 80 \\
\hline LE4002 & $3 \mathrm{~mm}$ & White & $\$ 0.12$ & 8000 & 20 & $<=30$ & $3.2-3.8$ & 30 & 75 & $5-6$ & 80 \\
\hline RL5-W18015 & $5 \mathrm{~mm}$ & White & $\$ 0.89$ & 18000 & 15 & 10 & $3.7-4.2$ & 30 & 100 & 5 & 100 \\
\hline RL5-W10015 & $5 \mathrm{~mm}$ & White & $\$ 0.69$ & 10000 & 15 & 100 & $3.4-4.0$ & 30 & 70 & 5 & 120 \\
\hline C503B-WAN-CABBB231-ND & $5 \mathrm{~mm}$ & Cool White & $\$ 0.42$ & 18000 & 15 & 100 & $3.2-4.0$ & 25 & 100 & 5 & 100 \\
\hline C503C-WAN-CBADA151-ND & $5 \mathrm{~mm}$ & White & $\$ 0.47$ & 24000 & 15 & 100 & $3.2-4.0$ & 30 & 100 & 5 & 120 \\
\hline 160-1728-5-ND & $5 \mathrm{~mm}$ & White & $\$ 0.38$ & 13000 & 15 & 100 & 3.3 to 3.8 & 30 & 100 & 5 & 120 \\
\hline
\end{tabular}

From the table above, various characteristics of manufactured LEDs were documented. The distinguishable characteristics of the LEDs that are more important to the design constraints are the cost, luminous intensity, and halfbeam angle. From these three parameters, the CREE LED, highlighted in Table 4-6 was selected for the lighting application. However, the next few sections describe the basis for why this particular choice was made.

\subsection{1-Comparing the Luminous Flux of LEDs}

As described in Table 4-3, the initial delivered lumens should equate to 3,700 for the entire luminaire. This criterion serves as the first constraint when determining the amount of necessary LEDs required for the design. Luminous flux is described as the quantity of light that that is emitted in unit time per unit solid angle or one lumen per steradian (angular span). To generalize the comparison of the two quantities, the relationship between lumen and candela is determined by the viewing angle of the LED. 


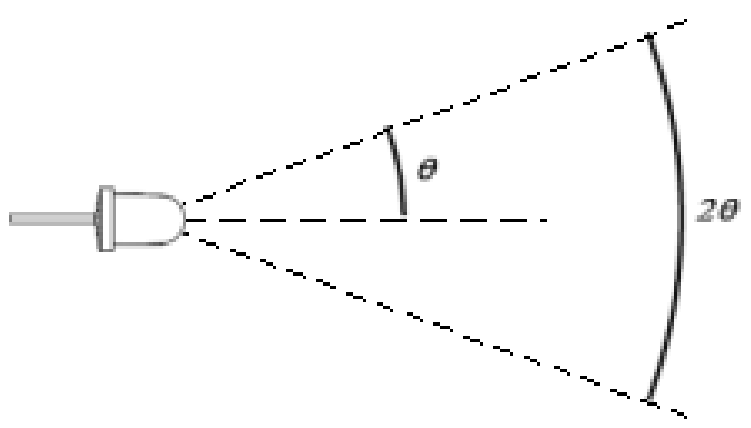

Figure 4-2: Luminous intensity of an LED based on viewing angles [17]

Referring to Figure 4-2, the maximum intensity occurs at the center of the LED (represented by the horizontal dashed line). The half-beam angle (depicted as $\square$ and normally denoted within datasheets of manufactured LEDs), describes the angle at which the light intensity is reduced to $50 \%$ of its rated value. In addition, the apex angle is described as twice the half-beam angle. In order to translate this value into a three-dimensional quantity, the steradian (SI unit for solid angle span) is used. This relationship is described in equation (4.1) below [17]:

Thus relating the angular span to describe the distribution of light, lumen $\left(\Phi_{\mathrm{v}}\right)$ in relation to candela $\left(\mathrm{I}_{\mathrm{v}}\right)$ is described as equation (4.2).

The luminous intensity for each LED was converted from milli-candela to candela and using equation (4.2) the lumen per LED was calculated. The lumen per LED and the amount of LEDs required to achieve a 3,700 lumen fixture are summarized in Table 4-7. 
Table 4-7: Summary of lumens per LED and the required number of LEDs to achieve the 3700 lumen criteria

\begin{tabular}{|c|c|c|c|c|c|}
\hline LED Name & $\begin{array}{c}\text { Luminous } \\
\text { Intensity }(\mathbf{m c d})\end{array}$ & $\begin{array}{c}\text { Luminous } \\
\text { Intensity } \\
(\mathbf{c d})\end{array}$ & $\begin{array}{c}\text { Viewing } \\
\text { Half- } \odot\left(^{\circ}\right)\end{array}$ & $\begin{array}{c}\text { Lumens per } \\
\text { LED (Im) }\end{array}$ & $\begin{array}{c}\text { Number of LEDs Required } \\
\text { for Application } \\
\text { (assuming 3700 Im fixture) }\end{array}$ \\
\hline LE2005 & 18000 & 18 & 10 & 1.7182027 & 2153.413038 \\
LE1019 & 13000 & 13 & 10 & 1.2409241 & 2981.648822 \\
LE4002 & 8000 & 8 & 20 & 3.0313795 & 1220.566407 \\
RL5-W18015 & 18000 & 18 & 15 & 3.8536983 & 960.1166862 \\
RL5-W10015 & 10000 & 10 & 15 & 2.1409435 & 1728.210035 \\
C503B-WAN-CABBB231-ND & 18000 & 18 & 15 & 3.8536983 & 960.1166862 \\
C503C-WAN-CBADA151-ND & $\mathbf{2 4 0 0 0}$ & $\mathbf{2 4}$ & $\mathbf{1 5}$ & $\mathbf{5 . 1 3 8 2 6 4 3}$ & $\mathbf{7 2 0 . 0 8 7 5 1 4 6}$ \\
160-1728-5-ND & 13000 & 13 & 15 & 2.7832265 & 1329.392335 \\
\hline
\end{tabular}

In terms of the amount of lumens produced per LED, the highlighted selection requires the least amount of LEDs to meet the 3,700 lumen requirement.

\subsection{2-Comparing Theoretical Power Dissipation between LEDs}

Another motivator for this design originates from the amount of power consumed by the light fixture. Essentially, the calculated power used by the luminaire is only a theoretical measurement of how the luminaire will operate; nevertheless, this extrapolated value will justify the selection of which LED to use when the overall price of the LEDs is involved.

Since LEDs are current-driven devices, current-limiting devices are required to ensure the necessary current flow through each string of LEDs. Normally a current regulator is used to drive white LEDs because of the voltage variation from the source and discrepancies between LED forward voltage drops; these differences could eventually lead to breakdown or dimming of LEDS due to the lack or excessive current through the LED strings. However, since a large 
array of LEDs is required for the design, implementing low tolerance resistors connected in series with the LEDs and maintaining the voltage through each string with a DC/DC converter are sufficient for this type of application as later described in section 4.9 .

In order to determine the amount of power required by the luminaire, a conceptual idea of how the LEDs will be arranged and the number of resistors required for each type of LED is required. Figure 4-3 shows the generic layout for one string of LEDs with a current-limiting resistor based on a $12 \mathrm{~V}$ DC source.

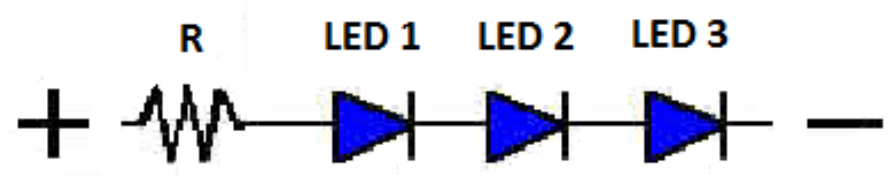

Figure 4-3: LED string configuration

The selection of the number of LEDs per string originates from the selection of a DC source for luminaire input. As shown in Table 4-6, the typical forward voltage is approximately $3.2 \mathrm{~V}$; this voltage describes the voltage across an LED when the device is forward-biased. Thus, with a simple calculation as shown below in equation (4.3), the amount of LEDs per string can be determined for any given input voltage.

$$
\text { Number of LEDs in a string }=\frac{V_{D C-\text { source }}}{V_{\text {forward }}}=\frac{V_{D C-\text { source }}}{3.2 \mathrm{~V}}
$$


In conjunction with the LEDs, a resistor must be selected in order to provide the desired current through the LEDs. For the LEDs to operate, the LEDs require a continuous forward current of $30 \mathrm{~mA}$. Using Ohm's law and the total voltage drop across the three LEDs, the calculated resistance to maintain 30 milliamps across the series elements can be determined using equation (4.4) as shown:

$$
R=\frac{V_{\text {source }}-(\# \text { of LEDS }) * V_{\text {forward }}}{I_{\text {forward }}}=\frac{V_{\text {source }}-(\# \text { of LEDS })(3.2 \mathrm{~V})}{30 \mathrm{~mA}}
$$

With the selected resistor value for each string, the determined amount of strings and corresponding resistors are determined by dividing the number of LEDs (required to achieve the luminaire 3,700 lumen requirement) by amount of LEDs in each string. In addition, the power drawn by each LED and resistor is calculated based on the following parameters: the forward voltage across each LED, the series resistance value, and the current through each string. Equations (4.5) and (4.6) describe the calculation for the power used by the LEDs and the power dissipated through the resistor.

$$
\begin{aligned}
P_{\text {tot }-L E D}=(\# \text { of LEDS }) P_{L E D} & =(\# \text { of LEDS }) V_{\text {forward }} I_{\text {forward }} \\
P_{\text {Resistor }} & =I_{\text {forward }}^{2} R
\end{aligned}
$$

Table 4-8 summarizes the amount of components and total power drawn by each element based on a string of three LEDs using a $12 \mathrm{~V}$ DC input voltage. 
Table 4-8: Summary of power consumption and cost for each LED type

\begin{tabular}{|c|c|c|c|c|c|c|c|}
\hline LED Name & $\begin{array}{c}\text { Number of LEDs Required } \\
\text { for Application } \\
\text { (assuming } \mathbf{3 7 0 0 ~ I m ~ f i x t u r e ) ~}\end{array}$ & $\begin{array}{l}\text { Number of } \\
\text { LED Rows } \\
\text { per Section }\end{array}$ & $\begin{array}{c}\text { Total Cost } \\
\text { for LEDs }\end{array}$ & $\begin{array}{l}\text { Number of } \\
\text { Series } \\
\text { Resistors } \\
\text { Required }\end{array}$ & $\begin{array}{c}\text { Total Power } \\
\text { Dissipation from LEDs } \\
\text { under Continuous } \\
\text { Forward Current (W) }\end{array}$ & $\begin{array}{c}\text { Total Power Dissipation } \\
\text { from Resistors under } \\
\text { Continuous Forward } \\
\text { Current (W) }\end{array}$ & $\begin{array}{l}\text { Total Power } \\
\text { Dissipation } \\
\text { (W) }\end{array}$ \\
\hline LE2005 & 2153 & 120 & $\$ 538.35$ & 718 & 206.728 & 52.9884 & 259.716 \\
\hline LE1019 & 2982 & 166 & $\$ 166.97$ & 994 & 286.238 & 73.3572 & 359.595 \\
\hline LE4002 & 1221 & 68 & $\$ 146.47$ & 407 & 117.174 & 30.0366 & 147.211 \\
\hline RL5-W18015 & 960 & 53 & $\$ 854.50$ & 321 & 92.171 & 23.6529 & 115.824 \\
\hline RL5-W10015 & 1728 & 96 & $\$ 1,192.46$ & 577 & 165.908 & 42.5457 & 208.454 \\
\hline C503B-WAN-CABBB231-ND & 960 & 53 & $\$ 403.25$ & 321 & 76.809 & 16.425625 & 93.235 \\
\hline C503C-WAN-CBADA151-ND & 720 & 40 & $\$ 338.44$ & 240 & 69.128 & 17.712 & 86.840 \\
\hline 160-1728-5-ND & 1329 & 74 & $\$ 505.17$ & 444 & 127.622 & 32.7303 & 160.352 \\
\hline
\end{tabular}

As seen from Table $4-8$, approximately $20 \%$ of the power is being dissipated through the resistors-17.7 out of the 86.84 Watts-regardless of the LED type. Power efficiency goes hand-in-hand with the voltage source used to power the LEDs. For instance, assume a $24 \mathrm{~V}$ DC source was used to power the LEDs. In contrast to the $12 \mathrm{~V}$ source, which is capable of powering three LEDs in series, a $24 \mathrm{~V}$ source could power up to seven LEDs using equation (4.3) with a current-limiting resistance as calculated in equation (4.7).

$$
R=\frac{V_{\text {source }}-3 V_{\text {forward }}}{I_{\text {forward }}}=\frac{24 \mathrm{~V}-7(3.2 \mathrm{~V})}{30 \mathrm{~mA}}=53.333 \Omega
$$

Thus, calculating the total power drawn by the LEDs and resistor as shown in equations (4.8) and (4.9), respectively, the power efficiency has increased to $93.33 \%$ as equation (4.10) shows.

$$
\begin{gathered}
P_{\text {tot }-L E D}=7 P_{L E D}=7 V_{\text {forward }} I_{\text {forward }}=7(3.2 \mathrm{~V})(30 \mathrm{~mA})=0.672 \mathrm{~W} \\
P_{\text {Resistor }}=I_{\text {forward }}^{2} R=0.048 \mathrm{~W} \\
\text { Power Efficiency }=\frac{P_{\text {tot }-L E D}}{P_{\text {tot }-L E D}+P_{\text {Resistor }}} * 100 \%=93.33 \%
\end{gathered}
$$


Ideally, high power efficiency is desirable; however, with higher power efficiency, the trade-off comes from the increase percentage of failure for each string of LEDs. For instance, if a system requires twenty-one LEDs for an application, a $12 \mathrm{~V}$ and $24 \mathrm{~V}$ source could power a maximum of three and seven LEDs, respectively, in series. Thus, by separately combining seven strings for $12 \mathrm{~V}$ source and three strings for the $24 \mathrm{~V}$ source in parallel, the required amounts of LEDs are met. Figure 4-4 shows the two circuit configurations for corresponding voltage sources.
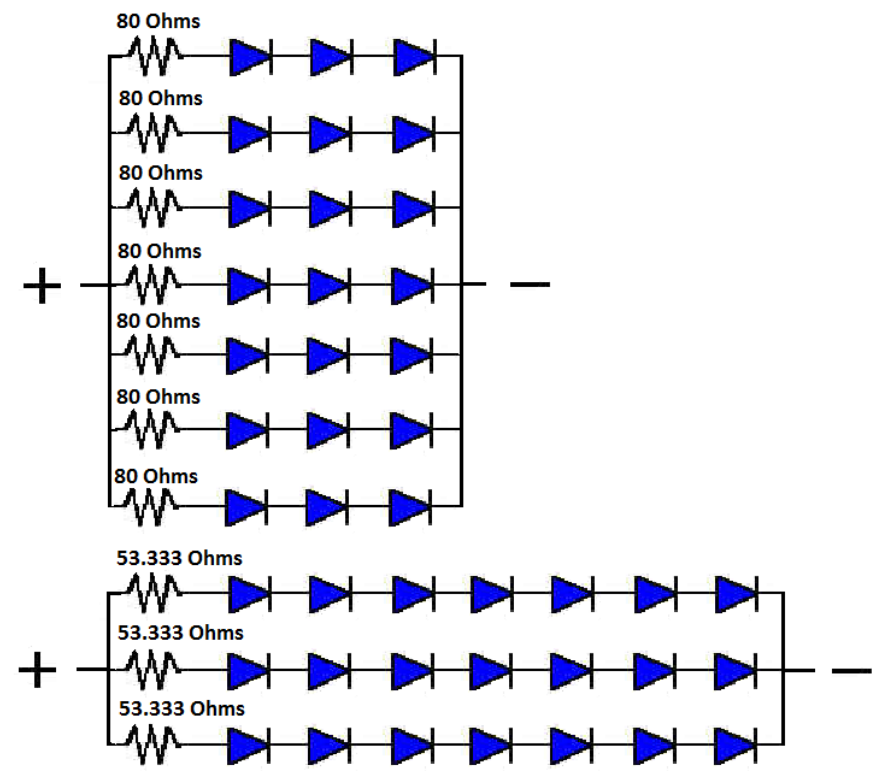

Figure 4-4: LED configurations for $12 \mathrm{~V}$ (top) and $24 \mathrm{~V}$ (bottom) connected sources

Referring to Figure 4-4, if one LED in one of the strings was to somehow fail, the failed LED will appear as an open to the source and the string containing the failed LED would completely turn off. Analyzing the percentage of light being outputted from the LEDs, if one string was open for the $12 \mathrm{~V}$ source, $\frac{6}{7}$ or $85.71 \%$ of the expected light will still be operational, compared to $\frac{2}{3}$ or $66.67 \%$ of the LEDs for the $24 \mathrm{~V}$ source. 
Another concern when dealing with a larger voltage source is the amount of voltage drop across the resistor. Comparing the two voltage sources described above and after excluding the forward voltage drops across the LEDs, the remaining voltages for the current-limiting resistor are, respectively, $2.4 \mathrm{~V}$ and 1.6 $\mathrm{V}$ for the $12 \mathrm{~V}$ and $24 \mathrm{~V}$ sources. This calculation is shown through equations (4.11) and (4.12).

$$
\begin{aligned}
& V_{R 12 \mathrm{~V} \mathrm{supply}}=V_{S}-3 V_{\text {forward }}=12-3(3.2)=2.4 \mathrm{~V} \\
& V_{R 24 \mathrm{~V} \mathrm{supply}}=V_{S}-7 V_{\text {forward }}=24-7(3.2)=1.6 \mathrm{~V}
\end{aligned}
$$

The voltage calculations determined in equations (4.11) and (4.12) denote the theoretical voltages that should appear when measuring the voltage drop across the series resistors. From these values, if the string of LEDs were to be exposed to a different range of voltages, the voltage drop across the resistor will linearly change. The percent difference in the current will change more dramatically for the $24 \mathrm{~V}$ case; i.e. $100 \mathrm{mV}$ will lead to a $4 \%$ variation in current when using a $12 \mathrm{~V}$ supply, whereas, a $6 \%$ discrepancy when using a $24 \mathrm{~V}$ supply.

With the associative loss in power efficiency of the system and the potential risk of LED strings failing, a median voltage value will later be selected in order to optimize both the power efficiency of the luminaire, as well as, minimizing the risk associated when a string of LEDs fails. 


\subsection{3-Comparing Cost of LEDs}

Another important factor to consider is the total cost of the LEDs-more importantly, the cost of LEDs in relation to the power required to operate the entire array. The total amount of LEDs and series resistors displayed in Table 4-8 will illustrate the effective cost and power consumption for the different LEDs.

The power used by the LEDs and cost should both be minimized in order to optimize the cost per power consumption for the overall luminaire. To demonstrate the different thresholds for justifying the highlighted selection, a plot of cost versus power consumption using the values in Table 4-8 is shown in

Figure 4-5.

\section{Demonstrating the Cost Versus the Power Required by the Luminaire}

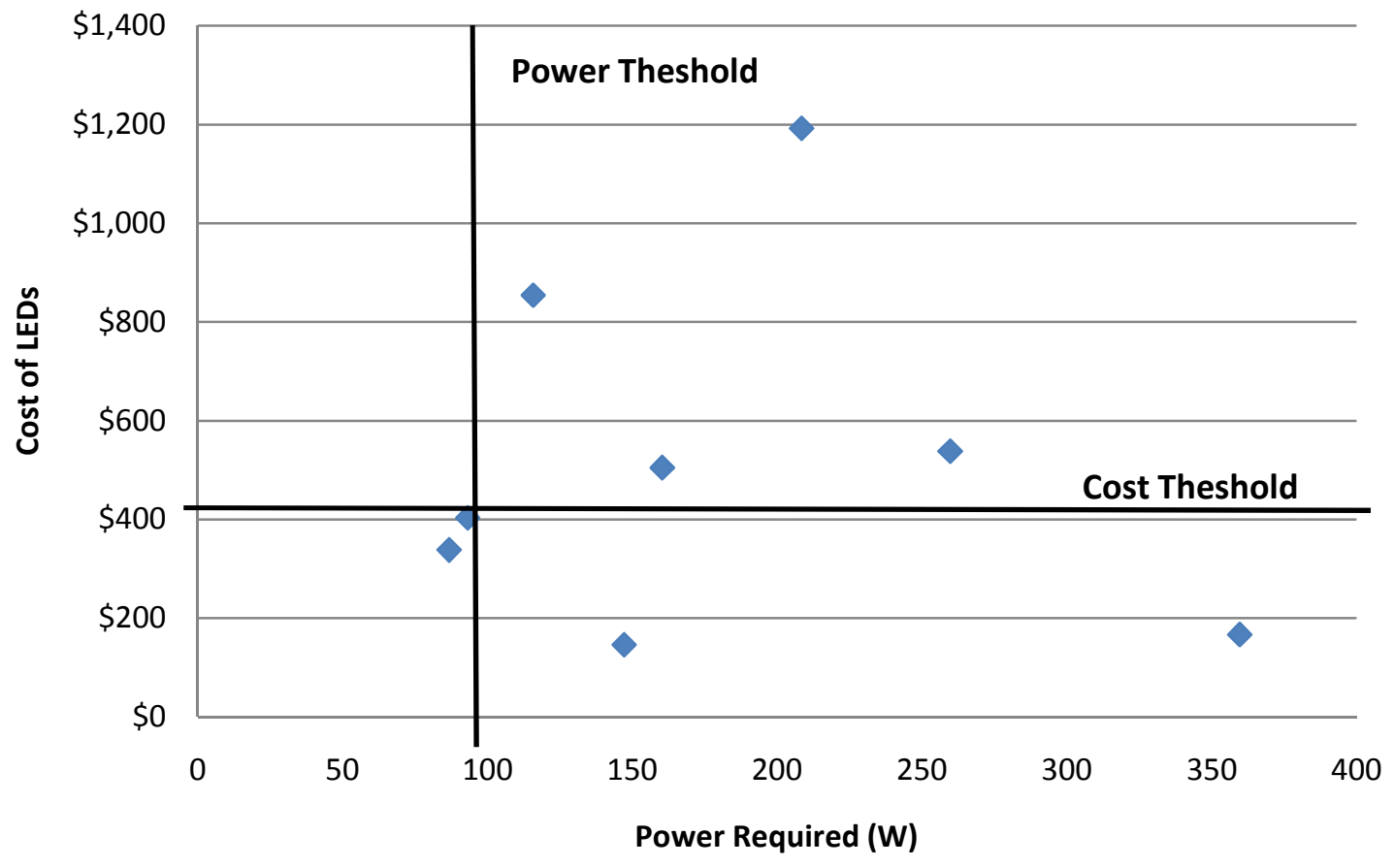

Figure 4-5: Cost and power consumption for various LEDs 
The two asymptotes shown are set thresholds for the cost and power consumption-approximately $\$ 450$ and $100 \mathrm{~W}$, respectively. Ideally, the point (Power Required, Cost of LEDs) should be as close to the origin $(0,0)$ as possible to minimize the cost of the luminaire and the reduce amount of power used. From the figure, only two points fall within the chosen area; thus choosing the highlighted LED (the closest point to the origin from Figure 4-5) labeled in Table 4-8 signifies the best selection for optimizing both cost and power consumption.

\section{5-Illumination Distribution of LEDs}

To begin designing the luminaire, a mathematical approach of the illumination distribution associated with the LEDs. This theoretical analysis will describe how the line-of-light model can be used as an approximation for how light will be distributed over a 2-dimensional area. Since this thesis does not focus on the intricate field of developing and deriving the models discussed, the referenced parameters and equations will be used as the basis of developing a starting model for the designed luminaire.

\subsection{1-LED Light-of-Sight Path Geometry}

The starting point in analyzing the illumination distribution is from the lineof-sight of a LED. Figure 4-6 shows the path geometry of a LED and a flat surface along with the parameters associated with the positioning; these parameters will later be used to create a model to illustrate the distribution. 


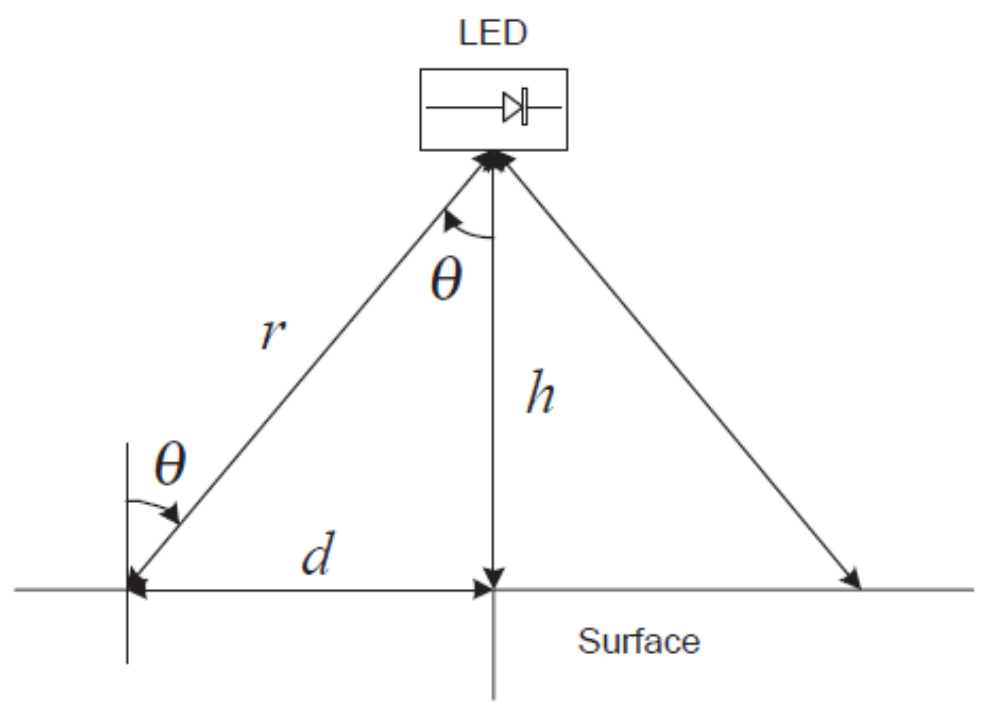

Figure 4-6: Line-of-sight path geometry of a LED onto a flat surface [18]

The angle $\square$ in Figure 4-6 represents the polar angle of the location with respect to the LED as well as the half-beam angle of the LED. To reduce the amount of variables in establishing the Lambertian distribution, the mounting distance of the LED (denoted by $h$ ) will be represented as a function of the distance d.

\subsection{2-Gaussian Representation for Illumination Distribution}

Lighting geometry is not as simplistic as using trigonometric quantities to establish the range. Instead, a generalized Lambertian pattern is widely used as the radiation pattern to illustrate the distribution of a single LED. However to reduce the complexity arising from the Lambertian pattern, an approximated Gaussian function will serve as a viable method of illustrating how the line-ofsight model can be used for determine adequate lighting spans. 
Within the studied paper, the Lambertian model for the LED was decomposed and reconstructed to approximate illuminance as a Gaussian function, $f_{g}(d)$. The final derived Gaussian approximation for the illumination distribution is shown in equation (4.13) [18].

$$
f_{g}(d)=\frac{m+1}{2 \pi h^{2}} f_{o} \exp \left\{-\frac{m+3}{2} * \frac{d^{2}}{h^{2}}\right\}
$$

The parameter $m$ represents the Lambertian mode number where $m>0$. This value also describes the directivity of light in relation to the semi-angle of the light beam at half power-denoted by $\Phi_{1 / 2}$. The representation of the mi'm tode number, $m$, and the half power angle is described by equation (4.14) [18].

$$
m=-\frac{\ln (2)}{\ln \left(\cos \left(\Phi_{\frac{1}{2}}\right)\right)}
$$

From the Lambertian representation for the illumination distribution, the model can also be approximated using a Gaussian distribution. Establishing a Gaussian model would simplify the use of applying probability to describe illuminance values at any distance away from the origin.

For the proposed Gaussian distribution, the variance, $\sigma^{2}$, can be represented as a function of both the height and mode number as represented in equation (4.15) [18].

$$
\sigma^{2}=\frac{2 h^{2}}{m+3}
$$


In order to compensate for the errors made in approximating the Lambertian distribution, a secondary Gaussian model was created to effectively limit the amount of error seen between the discussed Lambertian model and the one shown in Equation (4.13). Equations (4.16) and (4.17), respectively, show the finalized Gaussian approximation model $\left(\widehat{f}_{g}(d)\right)$ and variance [18].

$$
\begin{gathered}
\widehat{f}_{g}(d)=\frac{m+1}{2 \pi h^{2}} f_{o} \exp \left\{-\frac{m}{2} * \frac{d^{2}}{h^{2}}\right\} \\
\sigma^{2}=\frac{2 h^{2}}{m}
\end{gathered}
$$

\subsection{3-Comparison of the Two Distribution Models}

In comparing both distribution models, the value for $d$ will be normalized at $d=0$. For the standard example of representing the effect of the mode number (otherwise described as the half-power angle), a fixed height of 3 meters was selected to illustrate the Lambertian and Gaussian models. In addition, the models are normalized and placed on a logarithmic scale to demonstrate the range of illuminance between 0 and $-20 \mathrm{~dB}$-this range constitutes the limits for which the human eye can perceive visible light when focused on the center part of the light pattern. Equation (4.18) generalizes the proportion used to translate the models into a logarithmic scale [22].

$$
f_{\log }=10 \log _{10} \frac{f(d)}{f(0)}
$$

By representing each distribution model in logarithmic scale, Figure 4-7 shows how each model compares with one another. Within the figure, $f_{L}(d)$ describes the Lambertian model compared with the two Gaussian representations: $\mathrm{f}_{\mathrm{g}}(\mathrm{d})$ and $\widehat{f_{g}}(d)$. 


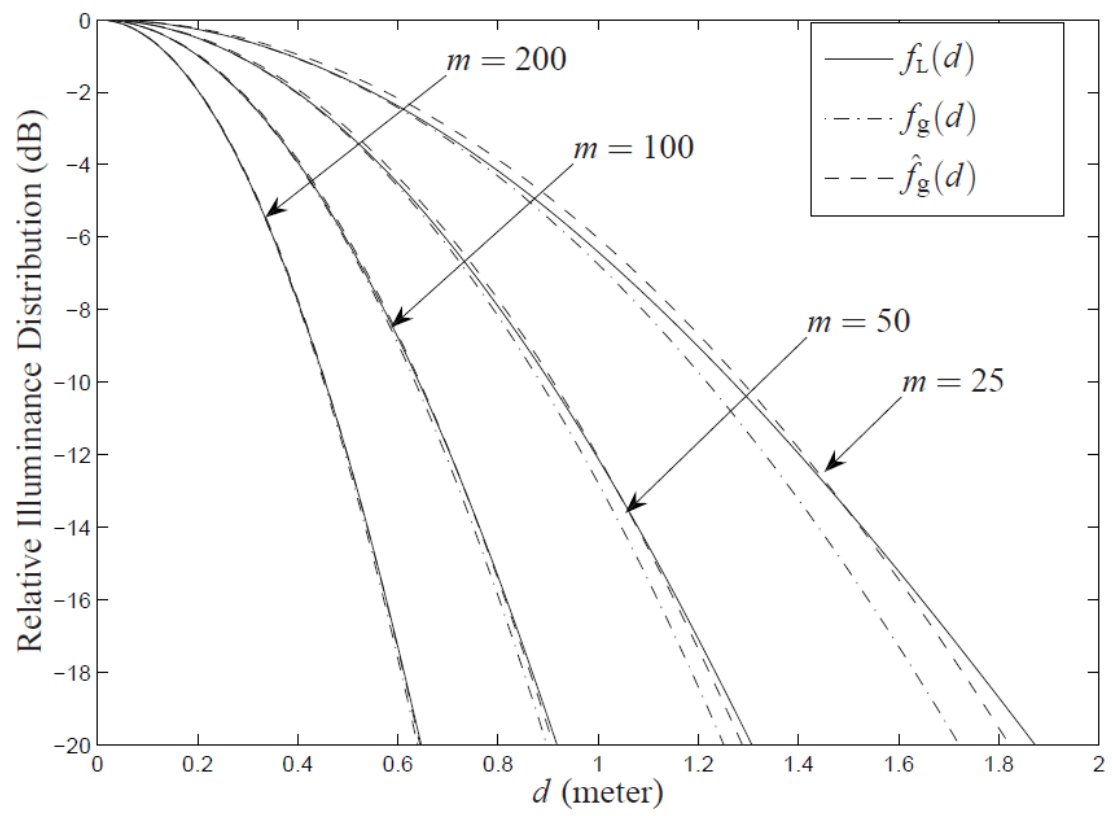

Figure 4-7: Illuminance distribution at $h=3$ meters for various distribution models [22]

Based on the various approximations shown in Figure 4-7, each Gaussian distribution compares favorably with the Lambertian model. For ease of demonstrating the effectiveness of the line-of-sight capability, the error compensated Gaussian model $\left(\left(\widehat{f}_{g}(d)\right)\right.$ will be used for design purposes. 


\subsection{4-Developing a Gaussian Representation for Selected LED}

In order to develop a model for the representing illumination distribution for the design, the parameters shown in the line-of-sight diagram (Figure 4-6) should first be declared. The $\mathrm{h}$ parameter describes the mounting height of the luminaire-26' 8" as denoted in Table 4-5. Since the selected LED for this application was determined to be the 24,000 mcd CREE LED, the $15^{\circ}$ half-power angle will be represented by $\square$ for the model. To be consistent with the previous models, the height will be converted to meters ( $h=8.0808$ meters). Lastly before representing the distribution, the mode number-m-is computed as 19.9937 using equation (4.14) from before.

With the determined parameters, the distribution can now be modeled by using incremental distances (in meters) from the center of LED array. The generated data following the determined parameters is shown in Table 4-9.

Table 4-9: Gaussian representation generated data of illuminance distribution for design

\begin{tabular}{|c|c|c|}
\hline Distance $(\mathrm{m})$ & $\widehat{\boldsymbol{f}_{\boldsymbol{g}}}(\boldsymbol{d})$ & $\widehat{\boldsymbol{f}_{\boldsymbol{g}}}(\boldsymbol{d})[\log ](\mathrm{dB})$ \\
\hline 0 & 0.051 & 0.000 \\
0.5 & 0.049 & -0.166 \\
1 & 0.044 & -0.665 \\
1.5 & 0.036 & -1.496 \\
2 & 0.028 & -2.659 \\
2.5 & 0.020 & -4.155 \\
3 & 0.013 & -5.984 \\
3.5 & 0.008 & -8.145 \\
4 & 0.004 & -10.638 \\
4.5 & 0.002 & -13.464 \\
5 & 0.001 & -16.622 \\
5.5 & 0.000 & -20.112 \\
6 & 0.000 & -23.935 \\
6.5 & 0.000 & -28.091 \\
7 & 0.000 & -32.579 \\
7.5 & 0.000 & -37.399 \\
\hline
\end{tabular}


Based on the values in Table 4-9, Figure 4-8 represents the 0 to $-20 \mathrm{~dB}$ illuminance distribution model from which the human eye can perceive light.

\section{Relative Model of Illumination Distribution}

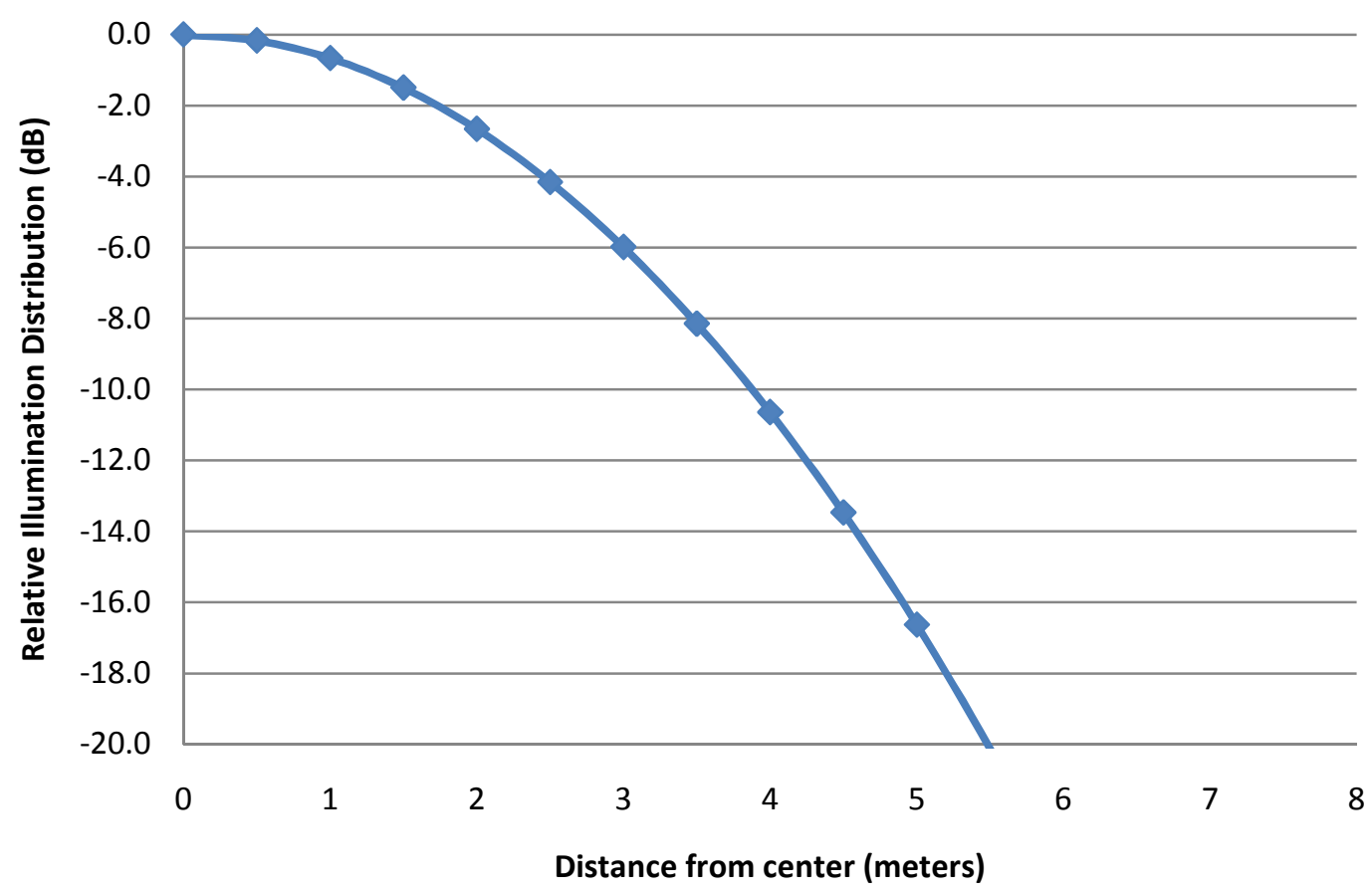

Figure 4-8: Modeled relative illuminance distribution for based on design parameters

From Figure 4-8, the maximum extent at which an individual can

distinguish between areas being lit or not is roughly 5.5 meters or 18.0446 feet.

Thus, since this value describes only half of the light's span, the total effective illuminance distribution can cover 11 meters or 36.089 feet. The calculated value does not truly depict the actual light that an array can output; therefore, the second column in Table 4-8 will be plotted against the distance to effectively show the Gaussian distribution of the illuminance. 


\section{Gaussian Distribution of Illuminance}

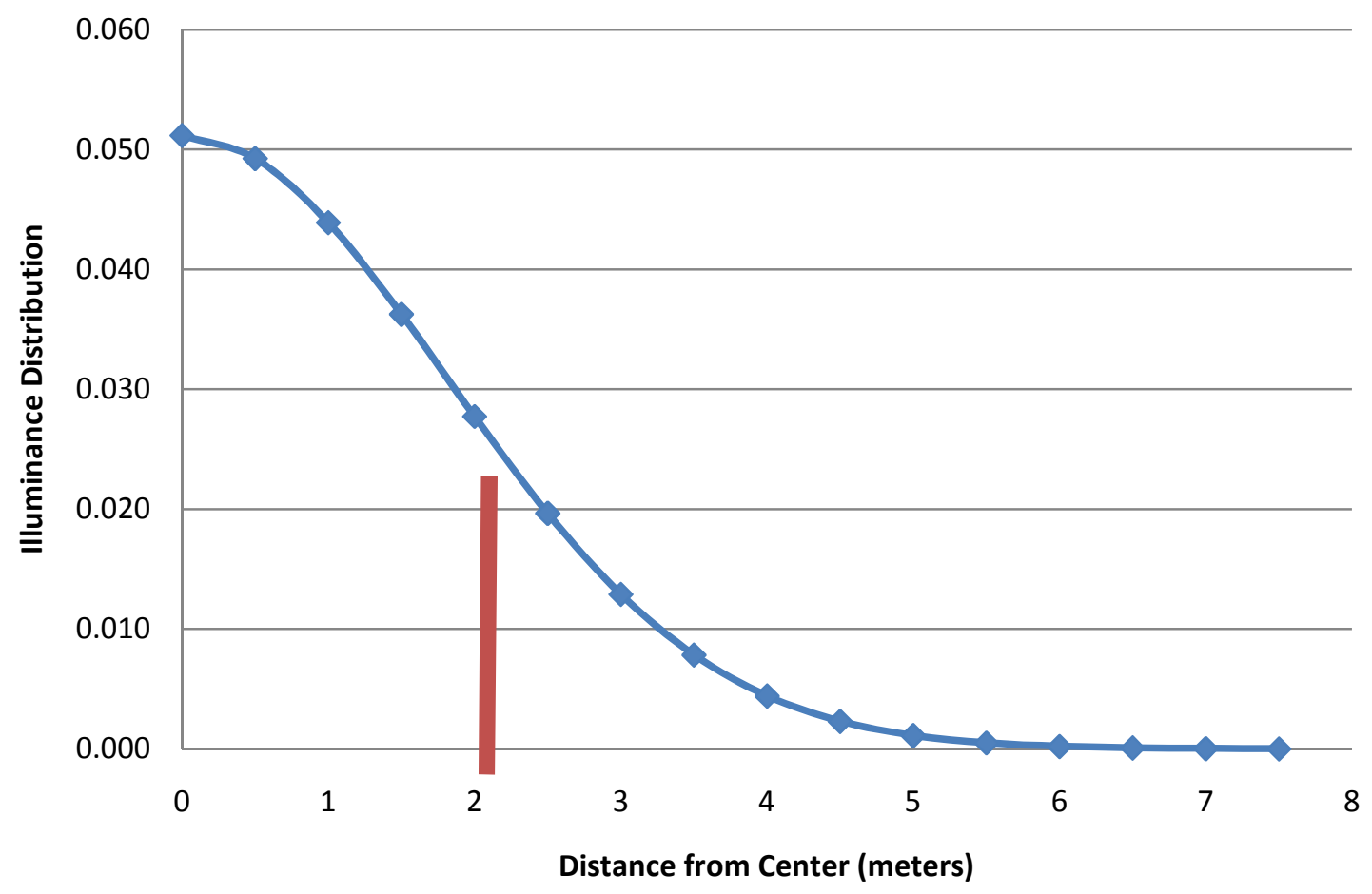

Figure 4-9: Gaussian distribution of illuminance--red line indicates the cut-off based on line-of-sight

The primary objective of Figure 4-9 is to determine whether an LED

section can produce enough lighting over an extended range. As indicated in the Gaussian distribution, the red line illustrates the line of sight cut-off for a mounting height of $26^{\prime} 8^{\prime \prime}$ with a half-power angle of $15^{\circ}$-these values correspond to a theoretical span of 2.178 meters or 7.1453 feet.

The next step proceeds to calculating the probability that the light span exceeds the value indicated by the red line. This process is done by using equation (4.16) which describes the variance relationship between the height and mode number for the modified Gaussian representation. Furthermore, the standard deviation could then be deduced by taking the square-root of the variance; this calculation is shown in equation (4.19). 


$$
\sigma=\sqrt{\frac{2 h^{2}}{m}}=\sqrt{\frac{2\left(8.0808^{2}\right)}{19.9937}}=2.3832 \text { meters }
$$

Also, based on how the models were derived, the Gaussian distribution is centered at a mean distance of 0 meters. From the known mean $(\bar{d})$, standard deviation $(\sigma)$, and desired distance from the mean $(d=2.178$ meters $)$, the z-score can be calculated as shown in equation (4.20).

$$
Z=\frac{d-\bar{d}}{\sigma}=\frac{2.178-0}{2.3832}=0.91
$$

Using the z-score table, a z-score of 0.91 corresponds to a probability of $31.86 \%$ for the half Gaussian; this value symbolizes the percentage of the illumination that will cover the line-of-sight span. Therefore the illumination of $18.14 \%$ (or $36.28 \%$ when describing the full range) represents the percentage of illumination that exceeds the line-of-sight span.

Although the calculated percentages cannot be used as a true measure of how the overall luminaire will truly appear, they provide an adequate justification of whether a specified range will receive enough lighting. For instance, assume a luminaire at the same height as the model describes (26' 8 ") was intended on being used to provide an illumination out to four meters from the center. This criterion would correspond to a z-score of 1.67 and ultimately a $9.5 \%$ illumination from four meters and outwards. Placing this number into perspective for a full Gaussian distribution, $90.5 \%$ of the illumination is encompassed by a span of eight meters (two times four meters), while the remaining seven meters (two times three-and-a-half meters) only obtains $9.5 \%$ of the illuminance. This discrepancy between the two classified regions would provide enough reasoning to reconsider implementing a design that requires lighting only four meters away 
from the center of the distribution.

As tests are conducted in Chapter 7, the experimental representation will show correlations with the theoretical Gaussian model described earlier. However for a starting point in designing the luminaire, utilizing the line-of-sight method should provide suitable illumination even at the tail-end distance from the center of illumination as indicated through the probability calculations. This generalization allows the sectionalizing the luminaire regions and determining the angles associated with each section of the luminaire simpler.

\section{6-LED Luminaire Layout}

The next step, after determining which LED and how many components are required for the design, is to decide how the luminaire should be partitioned-i.e. how many sections should the luminaire have and how many LEDs are required for each section. In decision of how many regions the luminaire should have, many different methods for splitting up the LEDs are possible.

\subsection{1-Luminaire Sections}

For determining the amount of sections, a generalized concept of the span of the LED must first be analyzed. As mentioned in the prior section, the line-ofsight model will represent the area in which luminaire's section will conform to the IESNA average luminance. The span of one section of the luminaire (represented as a single point) in Figure 4-6 will again be used to illustrate the parameters associated with light range. 
From Figure 4-6, the half distance and full span (twice the half distance) are computed using the tangent of the angle and the mounting height of the LED array. The calculations for the half-light span and total light span are denoted by equations (4.21) and (4.22), respectively.

$$
\begin{gathered}
d=g * \tan \left(15^{\circ}\right)=(26.6667 f t .) * \tan \left(15^{\circ}\right)=7.1453 f t . \\
\text { Total span }=2 d=2 * 7.1453=14.2906 f t .
\end{gathered}
$$

Using this knowledge and the required range of illumination described in Table 4-5 from section 4.3, few facts are known for the required area of illumination: the luminaire's section will provide adequate lighting for a width of 14.2906 feet and the minimum desired sidewalk and roadway widths for the illumination required by the City of Los Angeles are 10' - 12' and 30' - 36', respectively. The difference between roadway and sidewalk widths is depicted below in Figure 4-10.

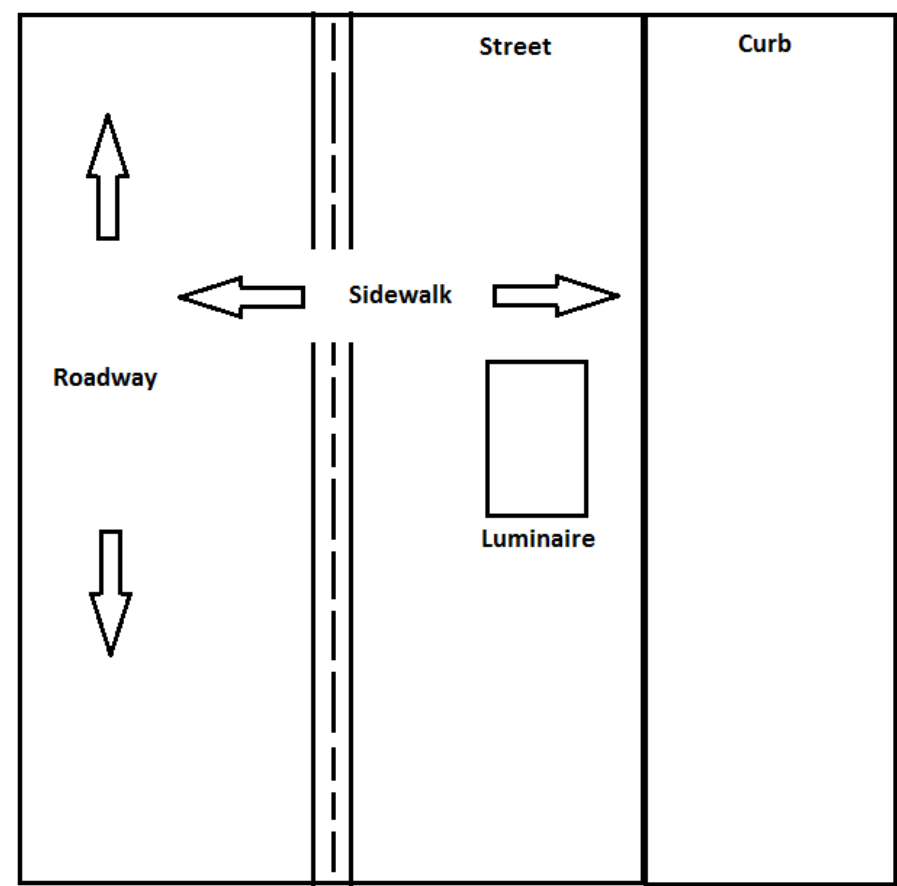

Figure 4-10: Difference between roadway and sidewalk widths 
For broader controllability of the luminaire, the surface should be subdivided at least once vertically and horizontally. Since the luminaire's section will already be able to accommodate the required width range for illumination $\left(10^{\prime}-12\right.$ '), the luminaire will only require an axial bend in one radial direction. In addition, the amount of sections to be subdivided in the axis with the associated tilt is flexible for the design; thus a chosen subdivision of five was selected. As a result, with two divisions made in one direction and five divisions in the other direction, a total of ten sections are created based on the chosen criteria.

Furthermore, the actual dimension of the mounting surface of the luminaire can vary greatly since the physical size is simply derived from typical luminaire designs. For simplicity, a starting point for the layout will be based off the dimensions of Table 4-1-30" $\times 16$ " $\times 6$ ". Since each luminaire design is distinct based on the LED half-power angles, only the length and width are used for sizing the mounting surface for the LEDs. Figure 4-11 illustrates the designed mounting surface for the LEDs.

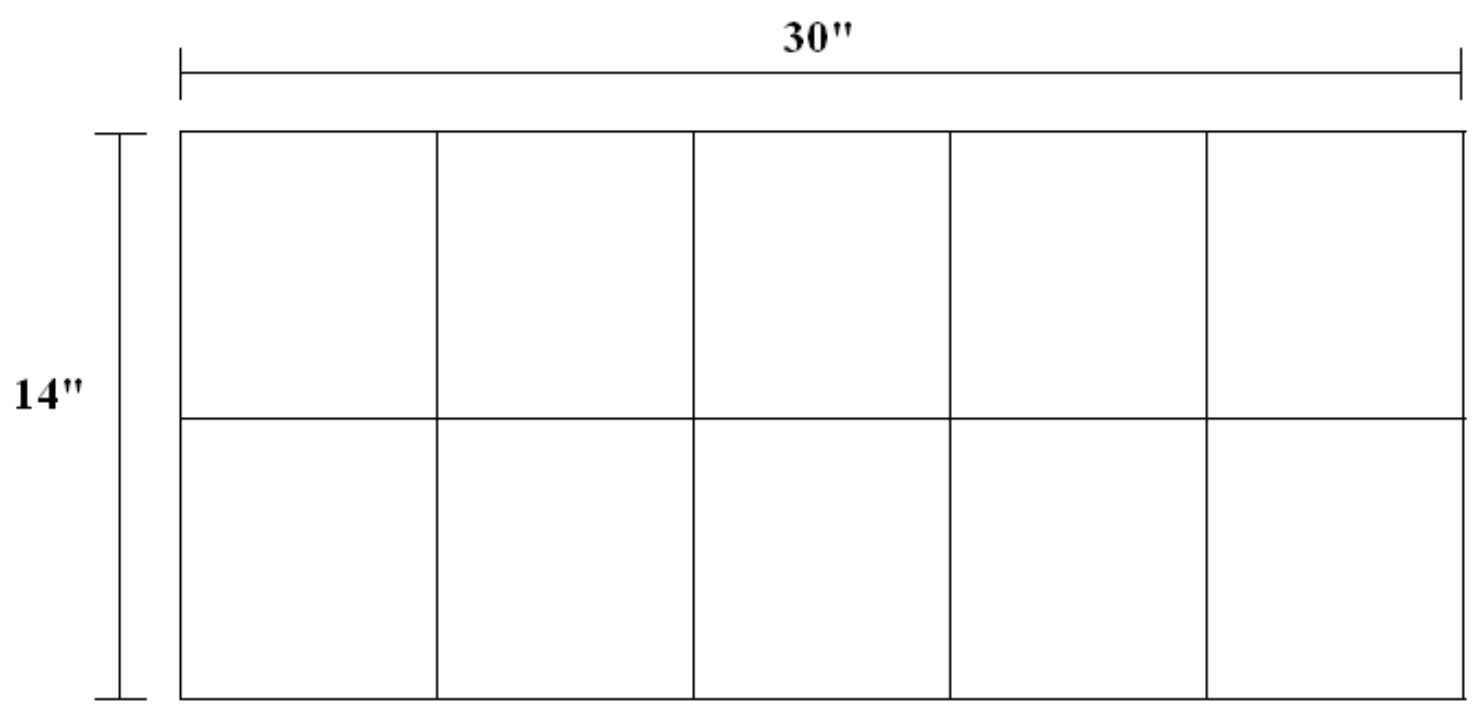

Figure 4-11: Luminaire mounting surface subdivided into ten equal parts for LEDs 


\subsection{2-Luminaire Distribution of LEDs by Section}

After determining the amount of sections for the luminaire, allocating the LEDs for each section is relatively straightforward. From Table 4-8, the calculated 720 LEDs to satisfy the 3,700 lumen requirement are split among the ten sections-equating to seventy-two LEDs per section. Additionally, this value can be further divided into twelve strings per section. Hence, Figure 4-10 can be modified to include the LEDs as shown in Figure 4-12; each section has six columns and twelve rows of LEDs.

\begin{tabular}{|c|c|c|c|c|c|}
\hline \multirow{2}{*}{12 Rows } & \multicolumn{5}{|l|}{6 Columns } \\
\hline & 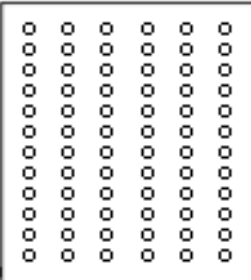 & 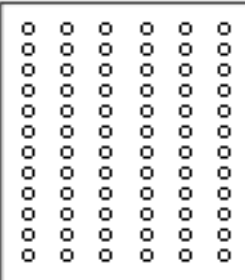 & 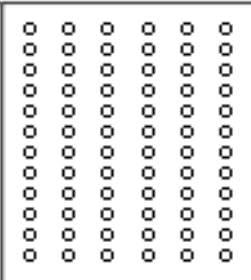 & $\begin{array}{llllll}0 & 0 & 0 & 0 & 0 & 0 \\
0 & 0 & 0 & 0 & 0 & 0 \\
0 & 0 & 0 & 0 & 0 \\
0 & 0 & 0 & 0 & 0 \\
0 & 0 & 0 & 0 & 0 \\
0 & 0 & 0 & 0 \\
0 & 0 & 0 & 0 \\
0 & 0 & 0 & 0 \\
0 & 0 & 0 & 0 & 0 \\
0 & 0 & 0 & 0 & 0 \\
0 & 0 & 0 & 0 & 0 \\
0 & 0 & 0 & 0 \\
0 & 0 & 0 & 0 & 0 \\
0 & 0 & 0 & 0 & 0 & 0 \\
& 0 & 0 & 0 & 0\end{array}$ & 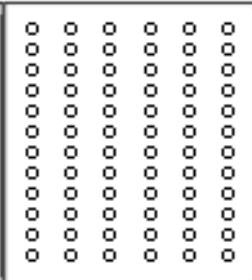 \\
\hline & 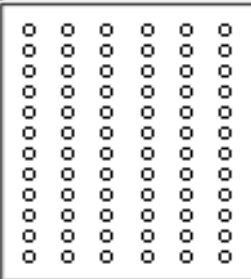 & 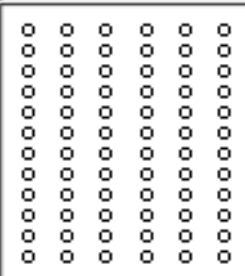 & 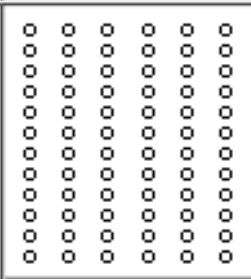 & 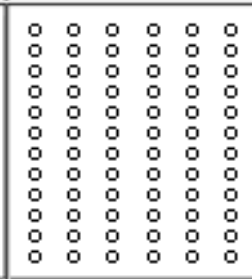 & 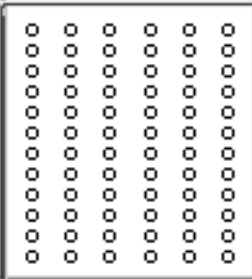 \\
\hline
\end{tabular}

Figure 4-12: LED arrangement by section for mounting

The utilized connection pattern for each section is shown later in the chapter after determining the curvature and the voltage source necessary for the LEDs. 


\section{7-Determining the Surface Curvature for Mounting LEDs}

As mentioned in the earlier section of this chapter, the LED mounting surface of the luminaire only requires shaping in one radial direction. Thus in order to generate the necessary $30^{\prime}-36^{\prime}$ region of illumination, an apt degree of bending is necessary to stretch the light distribution outwards to a desirable range. The associated light distribution cause by the bend will also allow a generic classification for the type of luminaire. Since the spread of the beam is desired to extend between $30^{\prime}-36^{\prime}$ (equivalent of $1.125-1.35$ mounting height distances), the distribution created will be classified as a Type II luminaire, which in turn replicates the desired type specified by the City of Los Angeles [19].

Therefore to test different types of bends based on the specific plastic material, a 30" length long sheet is incrementally bent inward to achieve various tilt angles based on fixed tangential points on the surface of the plastic. Each of these fixed tangential points will represent one section of the LED array. Since

only the length side of the plastic sheet is bent, the sections (labeled A - E) have an associative mounting angle. Figure 4-13 represents the five points of interest and their relative distance from the non-compressed length. 

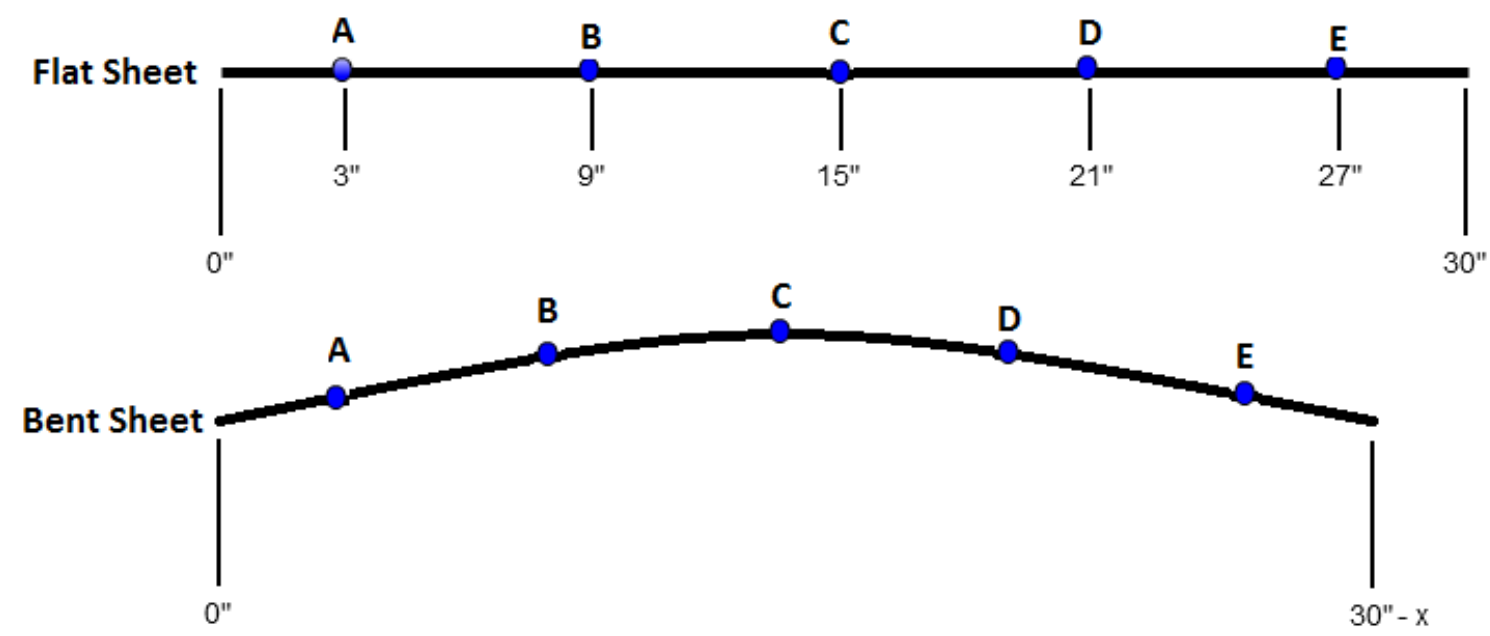

Figure 4-13: Tangential points of interest to determine amount of inward compression

As seen in Figure 4-13, any inward bend will cause the five points to shift from their original position as denoted by the bent sheet. On a flat plane, the points of interest are labeled by their distance away from the left-most side (denoted by 0"). As evident from the points' orientation on a flat sheet, the LED sections are normal to the horizontal plane (i.e. the center of each section is perpendicular to the horizontal plane). However in the case of the bent sheet, the points' orientation is slightly tilted based on the amount of horizontal compression, which is represented with an arbitrary value of " $x$ " in bottom image of Figure 4-13. Therefore using the vertical distance and horizontal distance from the left-most side, the tilt angle can be determined by an inverse tangent function. Figure 4-14 illustrates the horizontal $(\mathrm{X})$ and vertical $(\mathrm{Y})$ values to be measured for modified amounts of compression. 


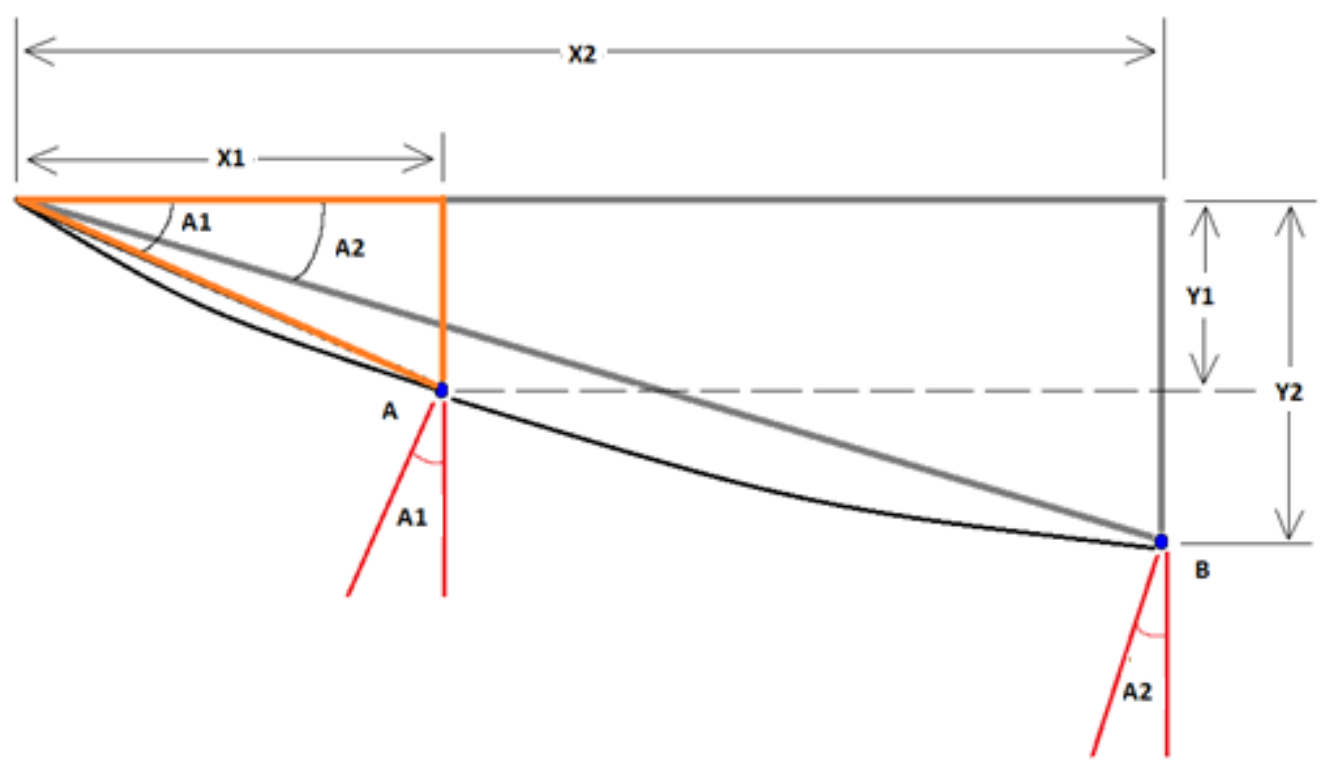

Figure 4-14: Method of determining tilt angles for each LED section

Figure 4-14 describes two out of the five sections that will have an associated tilt angle from the vertical axis. A summary of the parameters to determine the tilt angles A1 and A2 in Figure 4-8 is listed in Table 4-10. These values will allow a theoretical calculation of the farthest extent that the LED section can reach, which will be helpful in determining the optimal amount of bend that will produce the appropriate tilt angles for each section. Furthermore based on symmetry, the magnitude of the tilt angles determined for points $A$ and $B$ described in Figure 4-14 are equal to the angles for points $D$ and $E$, respectively.

Table 4-10: Measured parameters (as described in Figure 21) for different level of bends

\begin{tabular}{|c|c|c|c|c|c|c|c|}
\hline \multirow{2}{*}{$\begin{array}{c}\text { Horizontal } \\
\text { Length } \\
\text { (inches) }\end{array}$} & \multirow{2}{*}{$\begin{array}{c}\text { Maximum } \\
\text { Depth } \\
\text { (inches) }\end{array}$} & \multicolumn{2}{|c|}{$\begin{array}{c}\text { Horizontal Distance } \\
\text { (inches) }\end{array}$} & \multicolumn{2}{|c|}{$\begin{array}{c}\text { Vertical Distance } \\
\text { (inches) }\end{array}$} & \multicolumn{3}{c|}{ Tilt Angles ( ${ }^{\circ}$ ) } \\
\cline { 3 - 9 } & $\mathrm{X} 1$ & $\mathrm{X} 2$ & $\mathrm{Y} 1$ & $\mathrm{Y} 2$ & $\mathrm{~A} 1$ & $\mathrm{~A} 2$ \\
\hline $\mathbf{2 8}$ & 4.75 & 2.6875 & 8.125 & 1.375 & 3.75 & 27.0956 & 24.7751 \\
$\mathbf{2 8 . 5}$ & 4.0625 & 2.75 & 8.375 & 1.25 & 3.125 & 24.4440 & 20.4623 \\
$\mathbf{2 8 . 7 5}$ & 3.625 & 2.875 & 8.4375 & 1.125 & 2.875 & 21.3706 & 18.8161 \\
$\mathbf{2 9}$ & 3.1875 & 2.9375 & 8.5625 & 0.9375 & 2.5625 & 17.7004 & 16.6609 \\
\hline
\end{tabular}


From these four different compressions, the tilt angle $\mathrm{A} 1$ will be used to determine how far the light can reach. Assuming a mounting height of 26' 8" and utilizing the fact that an LED has a half-power angle of $15^{\circ}$, Figure $4-15$ serves as the basis for how the maximum range can be calculated based on the tilt angles determined in Table 4-10.

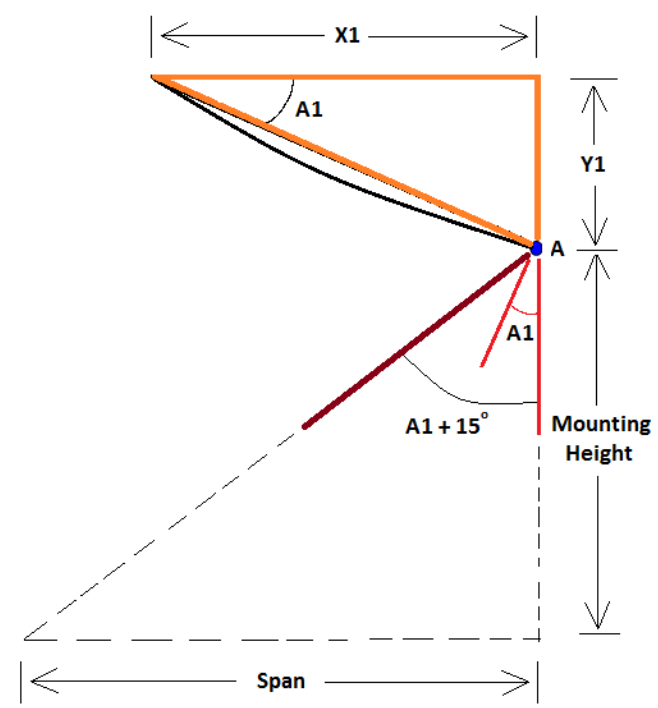

Figure 4-15: Illustration of maximum range point $A$ can achieve

Using geometry, the farthest reach that point A can obtain is determined by the tangent of the angle $\left(A 1+15^{\circ}\right)$ multiplied by the mounting height $\left(26^{\prime} 8^{\prime \prime}\right.$ minus $Y 1$ ). Reflecting that span to point $D$ and including the distance between points $A$ and $D$, the total theoretical span of the luminaire can also be determined as well. Table 4-11 summarizes the calculated span of the luminaire.

Table 4-11: Summary of luminaire light span based on farthest reach for point A

\begin{tabular}{|c|c|c|c|c|c|c|}
\hline \multirow{2}{*}{$\begin{array}{l}\text { Horizontal } \\
\text { Length } \\
\text { (inches) }\end{array}$} & \multirow{2}{*}{$\begin{array}{c}\text { Mounting } \\
\text { Height for } \\
\text { Point A (feet) }\end{array}$} & \multirow{2}{*}{$\begin{array}{l}\text { Maximum } \\
\text { Depth } \\
\text { (inches) }\end{array}$} & \multicolumn{2}{|c|}{ Tilt Angles $\left({ }^{\circ}\right)$} & \multirow{2}{*}{$\begin{array}{c}\text { Farthest } \\
\text { Reach for A } \\
\text { (feet) }\end{array}$} & \multirow{2}{*}{$\begin{array}{c}\text { Total Span of Luminaire } \\
\text { (feet) }\end{array}$} \\
\hline & & & A1 & $\mathrm{A} 1+15$ & & \\
\hline 28 & 26.5521 & 4.75 & 27.0956 & 42.0956 & 23.9879 & 49.8612 \\
\hline 28.5 & 26.5625 & 4.0625 & 24.4440 & 39.4440 & 21.8528 & 45.6223 \\
\hline 28.75 & 26.5729 & 3.625 & 21.3706 & 36.3706 & 19.5702 & 41.0571 \\
\hline 29 & 26.5885 & 3.1875 & 17.7004 & 32.7004 & 17.0698 & 36.0667 \\
\hline
\end{tabular}


With a general idea of the range of lighting provided by the luminaire, a bend can then be selected. Since the compression producing a horizontal length of $29^{\prime \prime}$ barely meets the required $30^{\prime}-36^{\prime}$ range as noted in Table $4-11$, a compression resulting in a horizontal length of 28.75 " will suffice for the design.

\section{8-Optimizing the Power Efficiency for Luminaire}

As mentioned previously in section 4.4.2, an optimal voltage must be selected In order to increase the power efficiency for the luminaire. Initially planned, the luminaire will be connected to a $12 \mathrm{~V} \mathrm{DC}$ battery, which ultimately allows a string of three LEDs to be powered. However as also determined in section 4.4 .2 , the power efficiency of the luminaire is approximately $80 \%$ due to the amount of power dissipated through the current-limiting resistor. Thus in

order to reduce the amount of power being dissipated through the resistor within a string, the string must encompass additional LEDs, which in turn requires a larger input voltage to power the string.

\subsection{1-Establishing the Allowable Input Voltage Range for Luminaire}

With the luminaire layout determined as shown by Figure 4-11 in the previous section, the voltage that can be used to power each string of LEDs has to be less than seven times the forward voltage drop across a single LED. The reasoning behind selecting a string of six LEDs as opposed to seven LEDs is based off the total finite voltage drop across each string. If a string of six LEDs were implemented with a $24 \mathrm{~V}$ source as opposed to a string of seven LEDs, the difference in voltage would all be dropped across the resistor-consequently leading to lower power efficiencies. Furthermore, the minimum voltage required 
to power the LEDs has to be at least six times the forward voltage drop across a single LED. The voltage calculation and range are denoted in equations (4.23) and (4.24), respectively.

$$
\begin{gathered}
V_{\text {in-min }}=6 * V_{\text {forward }}<V_{I n}<7 * V_{\text {forward }}=V_{\text {in-max }} \\
19.2 \mathrm{~V}<V_{I n}<22.4 \mathrm{~V}
\end{gathered}
$$

\subsection{2-Comparing Power Efficiency for Varying Input Voltage Selection}

Based on the constraint shown above in equation (4.24), any input voltage value within this range will effectively work for string of six LEDs; however, the power efficiency increase can range based on how much voltage will be seen by the current-limiting resistor. For a reference as to how the power efficiency would change based on different input voltages within that range, Table 4-12 shows the power efficiency for voltage values from $19.3 \mathrm{~V}$ to $22.3 \mathrm{~V}$ in increments of $100 \mathrm{mV}$. 
Table 4-12: Summary of power efficiencies based on various input voltages

\begin{tabular}{|c|c|c|c|c|c|c|}
\hline$V_{\text {in }}(V)$ & $\begin{array}{c}\text { V }_{\text {drop-Resistor }} \\
\text { (V) }\end{array}$ & $\begin{array}{c}\text { Current Limiting } \\
\text { Resistance }(\Omega)\end{array}$ & $\mathbf{P}_{\text {LEDs }}(\mathrm{W})$ & $P_{R}(W)$ & \begin{tabular}{|c|} 
Total \\
Power (W) \\
\end{tabular} & $\begin{array}{c}\text { Power } \\
\text { Efficiency (\%) }\end{array}$ \\
\hline 19.3 & 0.1 & 3.333 & 0.576 & 0.003 & 0.579 & $99.48 \%$ \\
\hline 19.4 & 0.2 & 6.667 & 0.576 & 0.006 & 0.582 & $98.97 \%$ \\
\hline 19.5 & 0.3 & 10.000 & 0.576 & 0.009 & 0.585 & $98.46 \%$ \\
\hline 19.6 & 0.4 & 13.333 & 0.576 & 0.012 & 0.588 & $97.96 \%$ \\
\hline 19.7 & 0.5 & 16.667 & 0.576 & 0.015 & 0.591 & $97.46 \%$ \\
\hline 19.8 & 0.6 & 20.000 & 0.576 & 0.018 & 0.594 & $96.97 \%$ \\
\hline 19.9 & 0.7 & 23.333 & 0.576 & 0.021 & 0.597 & $96.48 \%$ \\
\hline 20 & 0.8 & 26.667 & 0.576 & 0.024 & 0.6 & $96.00 \%$ \\
\hline 20.1 & 0.9 & 30.000 & 0.576 & 0.027 & 0.603 & $95.52 \%$ \\
\hline 20.2 & 1 & 33.333 & 0.576 & 0.03 & 0.606 & $95.05 \%$ \\
\hline 20.3 & 1.1 & 36.667 & 0.576 & 0.033 & 0.609 & $94.58 \%$ \\
\hline 20.4 & 1.2 & 40.000 & 0.576 & 0.036 & 0.612 & $94.12 \%$ \\
\hline 20.5 & 1.3 & 43.333 & 0.576 & 0.039 & 0.615 & $93.66 \%$ \\
\hline 20.6 & 1.4 & 46.667 & 0.576 & 0.042 & 0.618 & $93.20 \%$ \\
\hline 20.7 & 1.5 & 50.000 & 0.576 & 0.045 & 0.621 & $92.75 \%$ \\
\hline 20.8 & 1.6 & 53.333 & 0.576 & 0.048 & 0.624 & $92.31 \%$ \\
\hline 20.9 & 1.7 & 56.667 & 0.576 & 0.051 & 0.627 & $91.87 \%$ \\
\hline 21 & 1.8 & 60.000 & 0.576 & 0.054 & 0.63 & $91.43 \%$ \\
\hline 21.1 & 1.9 & 63.333 & 0.576 & 0.057 & 0.633 & $91.00 \%$ \\
\hline 21.2 & 2 & 66.667 & 0.576 & 0.06 & 0.636 & $90.57 \%$ \\
\hline 21.3 & 2.1 & 70.000 & 0.576 & 0.063 & 0.639 & $90.14 \%$ \\
\hline 21.4 & 2.2 & 73.333 & 0.576 & 0.066 & 0.642 & $89.72 \%$ \\
\hline 21.5 & 2.3 & 76.667 & 0.576 & 0.069 & 0.645 & $89.30 \%$ \\
\hline 21.6 & 2.4 & 80.000 & 0.576 & 0.072 & 0.648 & $88.89 \%$ \\
\hline 21.7 & 2.5 & 83.333 & 0.576 & 0.075 & 0.651 & $88.48 \%$ \\
\hline 21.8 & 2.6 & 86.667 & 0.576 & 0.078 & 0.654 & $88.07 \%$ \\
\hline 21.9 & 2.7 & 90.000 & 0.576 & 0.081 & 0.657 & $87.67 \%$ \\
\hline 22 & 2.8 & 93.333 & 0.576 & 0.084 & 0.66 & $87.27 \%$ \\
\hline 22.1 & 2.9 & 96.667 & 0.576 & 0.087 & 0.663 & $86.88 \%$ \\
\hline 22.2 & 3 & 100.000 & 0.576 & 0.09 & 0.666 & $86.49 \%$ \\
\hline 22.3 & 3.1 & 103.333 & 0.576 & 0.093 & 0.669 & $86.10 \%$ \\
\hline
\end{tabular}

From Table 4-12, the voltage drop was calculated based on the difference between the input voltage used and the total fixed forward voltage drop across the six LEDs. Then from the voltage drop, the resistance value was calculated based on the required $30 \mathrm{~mA}$ current in each string. Using the known voltage, current, and resistance values, the effective power used to light six LEDs divided by the total power required for each string equates to the power efficiency of the luminaire. Figure 4-15 illustrates the relationship between the power efficiency versus the input voltage. 


\section{Effect of Varying Input Voltage on Luminaire Efficiency}

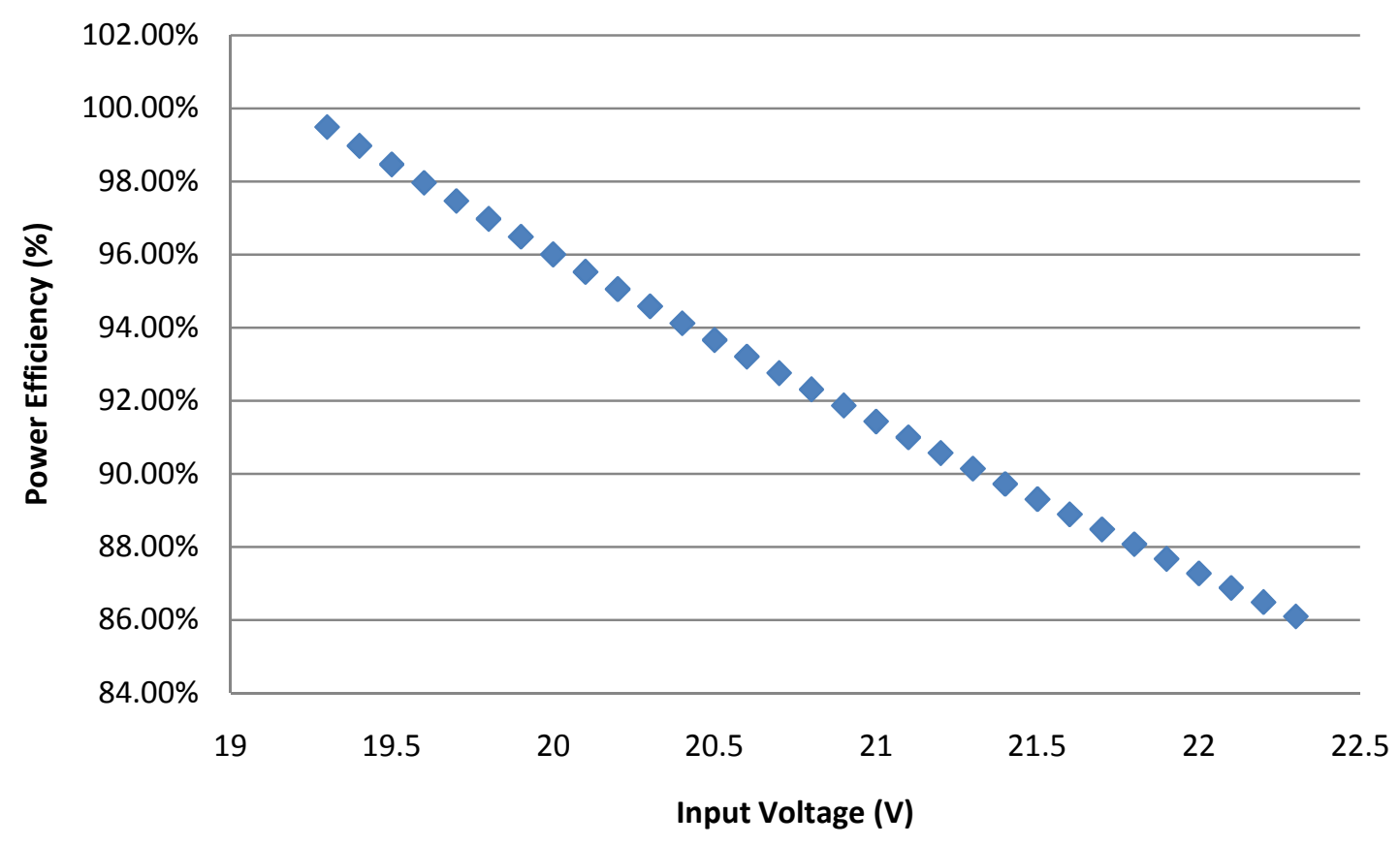

Figure 4-16: Plot showing relationship between input voltage and power efficiency

With the calculations made from Table 4-12, the linear relationship between input voltage and power efficiency makes sense from an analytical standpoint. The current and power through a string of six LEDs is independent of the input voltage (fixed forward voltage); therefore, the power through the resistor is proportional to the voltage drop across the resistor. Thus by interpreting the relationship shown in Figure 4-15, the highest efficiency is obtained when the input voltage used to power the string is at a minimum, which also represents the minimum voltage drop across the resistor. 
Theoretically, the system's $12 \mathrm{~V}$ battery source should be stepped-up to 19.3 V in order to obtain the highest power efficiency (99.48\%). However, in reality, the forward voltage drop across each LED is not always equal to the datasheet value of $3.2 \mathrm{~V}$ due to manufacturing processes. Therefore, the input voltage should be slightly higher than the minimum value of $19.3 \mathrm{~V}$ to ensure an adequate supply voltage is across the LED strings. For this reason, the input voltage for powering the luminaire will be chosen as $20 \mathrm{~V}$-leaving a $0.8 \mathrm{~V}$ margin for error for the forward voltage drop within a LED.

Based on the calculation for the power consumed by one string in the luminaire, the total power consumption using a $20 \mathrm{~V}$ source is calculated as shown in equation (4.25):

$$
P_{\text {luminaire }}=(\# \text { of Strings }) P_{\text {tot-string }}=120(0.6)=72 \mathrm{~W}
$$

The calculated power consumed by the luminaire will later be referred to when determining system sizing values in Chapter 5 and calculating the luminaire efficacy in Chapter 7 . Additionally as referenced from the $20 \mathrm{~V}$ in Table $4-12$, this value corresponds to an efficiency of $96 \%$ with only $4 \%$ of the total power dissipated through the resistor as opposed to the calculated $20 \%$ when using a $12 \mathrm{~V}$ source. 


\subsection{3-Configuration of LED Strings for One Section of the Luminaire}

With the selection of a $20 \mathrm{~V}$ input source, the current-limiting resistor value can be read directly from Table $4-12$ as $26.667 \Omega$; thus, available resistor values of $26.7 \Omega$ will be selected for creating the LED strings. With these parameters established, Figure 4-17 depicts how the LED strings for one section of the luminaire will be connected.

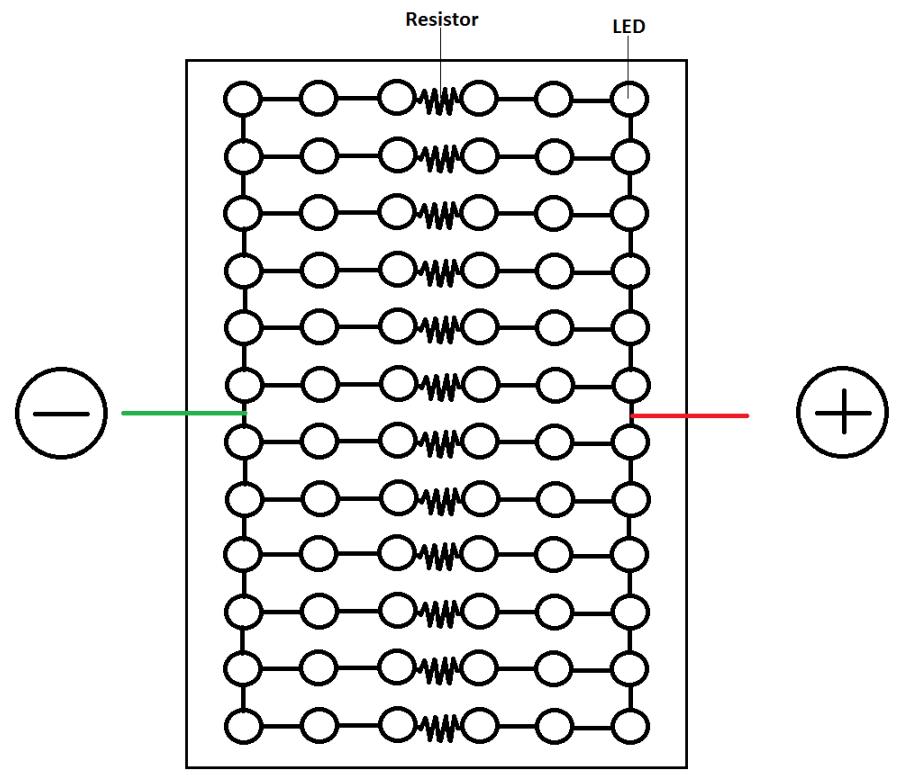

Figure 4-17: Circuit configuration for one section of the luminaire

\section{9-Voltage Distribution for a Section of Luminaire}

The first concern when dealing with the actual operation of the luminaire pertains to the variation in forward voltages through the LEDs by individual strings. If the LED forward voltage drops are relatively consistent with the indicated 3.2 V forward from the datasheet, each string should receive approximately the same current and thus, would not pose current redistribution and over current problems in actual applications. To demonstrate the consistency of current through each string, one section of the luminaire will be analyzed as follows. 
To test the forward voltage across the LED and the effectiveness of the current limiting resistors, a $20 \mathrm{~V}$ source was used to power one section of the luminaire. Obtained sample data will provide a good estimate of the average current expected to be drawn from each section of the luminaire. By tabulating these data, any extreme variations in current can clearly be seen. Table 4-13 summarizes the voltage drops across each element following the layout from Figure 4-18.

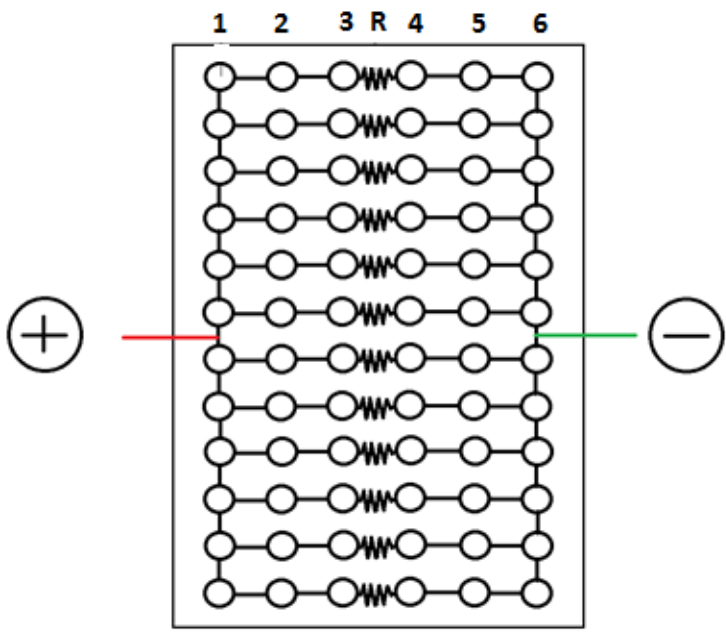

Figure 4-18: LED arrangement with labels for measured values shown in Table 4-13

Table 4-13: Summary of voltage drops across elements and current through each string

\begin{tabular}{|c|c|c|c|c|c|c|c|c|c|c|c|}
\hline & & LED1 (V) & LED2 (V) & LED3 (V) & \begin{tabular}{|c|} 
Average \\
Forward \\
Voltage (V) \\
\end{tabular} & LED4 (V) & LED5 (V) & LED6 (V) & $\begin{array}{c}\text { Average } \\
\text { Forward } \\
\text { Voltage (V) } \\
\end{array}$ & $\begin{array}{c}\text { Voltage } \\
\text { across } \\
\text { Resistor (V) }\end{array}$ & $\begin{array}{c}\text { Current } \\
\text { across each } \\
\text { string (A) }\end{array}$ \\
\hline \multirow{12}{*}{$\begin{array}{l}\text { String } \\
\text { row } \\
\text { Number }\end{array}$} & 1 & 3.176 & 3.2 & 3.186 & 3.1873 & 3.244 & 3.2319 & 3.2546 & 3.2435 & 0.7763 & 0.02911 \\
\hline & 2 & 3.222 & 3.251 & 3.239 & 3.2373 & 3.209 & 3.2077 & 3.1453 & 3.1873 & 0.7976 & 0.02991 \\
\hline & 3 & 3.23 & 3.157 & 3.1982 & 3.1951 & 3.248 & 3.22 & 3.2088 & 3.2256 & 0.8075 & 0.03028 \\
\hline & 4 & 3.211 & 3.185 & 3.189 & 3.1950 & 3.201 & 3.249 & 3.266 & 3.2387 & 0.7659 & 0.02872 \\
\hline & 5 & 3.238 & 3.169 & 3.23 & 3.2123 & 3.217 & 3.189 & 3.1818 & 3.1959 & 0.8453 & 0.03170 \\
\hline & 6 & 3.263 & 3.198 & 3.269 & 3.2433 & 3.1789 & 3.158 & 3.1761 & 3.1710 & 0.8182 & 0.03068 \\
\hline & 7 & 3.163 & 3.35 & 3.203 & 3.2387 & 3.2248 & 3.1396 & 3.1992 & 3.1879 & 0.7779 & 0.02917 \\
\hline & 8 & 3.243 & 3.208 & 3.211 & 3.2207 & 3.141 & 3.214 & 3.2374 & 3.1975 & 0.7411 & 0.02779 \\
\hline & 9 & 3.247 & 3.233 & 3.233 & 3.2377 & 3.24 & 3.1828 & 3.2192 & 3.2140 & 0.8077 & 0.03029 \\
\hline & 10 & 3.244 & 3.136 & 3.227 & 3.2023 & 3.24 & 3.2198 & 3.1623 & 3.2074 & 0.833 & 0.03124 \\
\hline & 11 & 3.291 & 3.213 & 3.218 & 3.2407 & 3.2 & 3.138 & 3.1857 & 3.1746 & 0.8146 & 0.03055 \\
\hline & 12 & 3.15638 & 3.233 & 3.2517 & 3.2137 & 3.2075 & 3.1688 & 3.1833 & 3.1865 & 0.8532 & 0.03199 \\
\hline & & & & & & & & \multicolumn{3}{|c|}{ Average Current Through String } & 0.03012 \\
\hline
\end{tabular}


Table 4-13 shows an average current of $30.12 \mathrm{~mA}$ conducted by each string of LEDs in one section of the luminaire. Since the current is relatively stable for each string, no modifications are necessary to adjust the current drawn by any one string. This result also justifies that the use of current limiting resistors works well with the designed luminaire.

\section{9-Finalized Enclosure Implementation}

The final overall product and display enclosure is shown in Figure 4-18. Additionally, Appendix A contains the enclosure dimensions of the display case for creating the proper shape for the LED mounting surface.

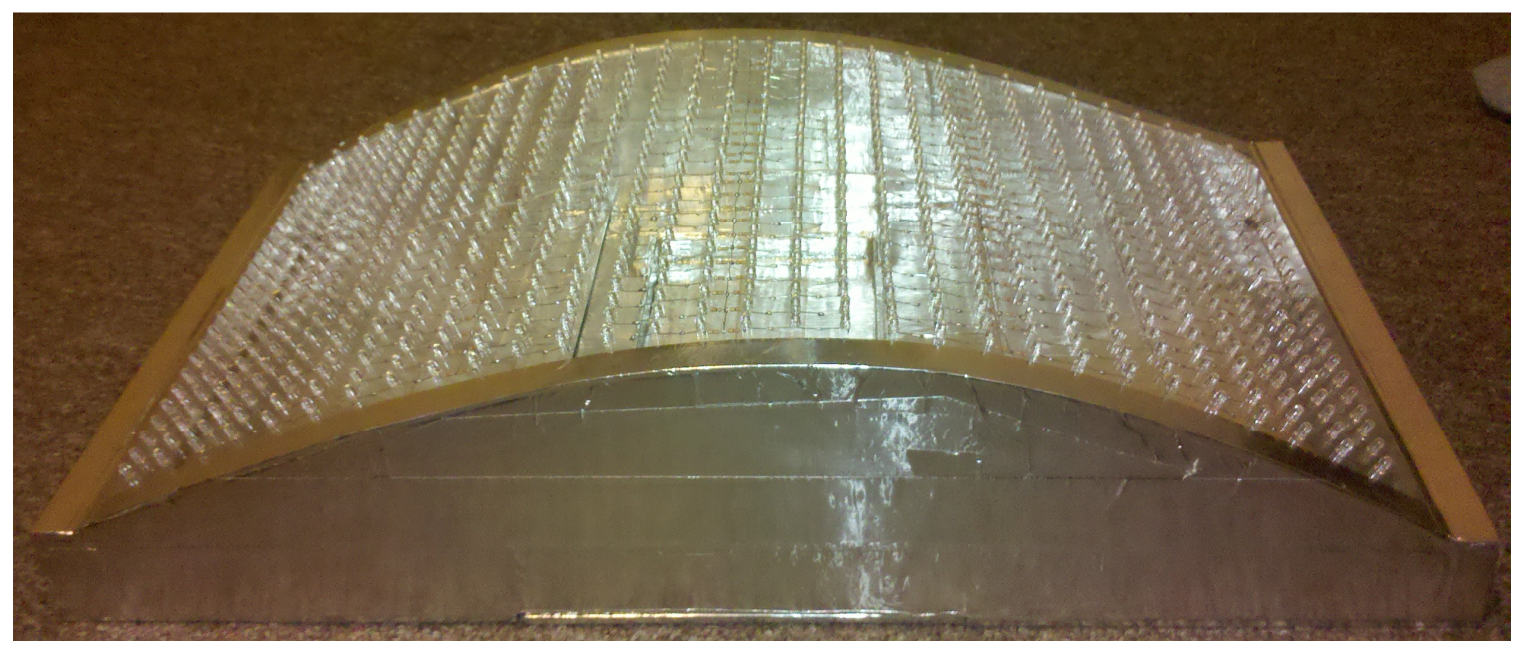

Figure 4-19: Finished LED enclosure with connected LED strings 


\section{CHAPTER 5-SYSTEM SIZING}

\section{1-Component Selection}

When selecting the proper components for lighting applications, many different constraints are taken into account. By predetermining the amount of components required and how the system will operate, cost and redesigning time can be minimized. This chapter will discuss the procedures in determining product sizing and provide justifications as for why each component was selected.

\section{2-Choosing the Right Battery}

One of the major constraints to the possible output of the luminaire system pertains to how the luminaire will be powered. Since the proposed system is powered off-grid or by its own independent source, different battery types and characteristics must be considered in order to choose the best one for illuminating the LEDs. Of the many factors to consider, battery type, capacity (measured in amp-hours), and size are most paramount for optimization of a system. For instance, if a battery capacity (amp-hours) does not meet the necessary requirement for the luminaire operation, the battery can be severely undercharge and risk the possibility of damaging the electrolyte within the battery. In addition, the battery must have the ability to charge and discharge over many cycles of use and tolerate low depth-of-discharges in case the luminaire drains the battery beyond predicted expectations. 


\subsection{1-Lead-Acid Battery}

Selection of batteries can range from their voltage output to their chemical types. Due to voltage requirement, cost limitation, and required battery capacity, lead acid batteries are highly employed for in solar electric system designs. Lead-acid battieries have a high resistance to wear and are capable of recharging over extended periods of time. Due to the commercial availability of lead-acid batteries, selecting a specific lead-acid battery based on its physical size and amp-hour capacity for the designed purpose will be more cost-effective than other battery chemistries that are on the market.

Of the broad category of lead acid batteries, there are three highly regarded batteries used in solar applications: flooded, gelled electrolyte, and absorbed glass mat. These batteries are used due to their ability to store electrical energy and their ability to discharge by as much as $80 \%$ over thousands of charging and discharging cycles. For this reason, deep-cycle batteries can last anywhere between two to twelve years based on the frequent nature of whether the battery is heavily discharged [20]. 


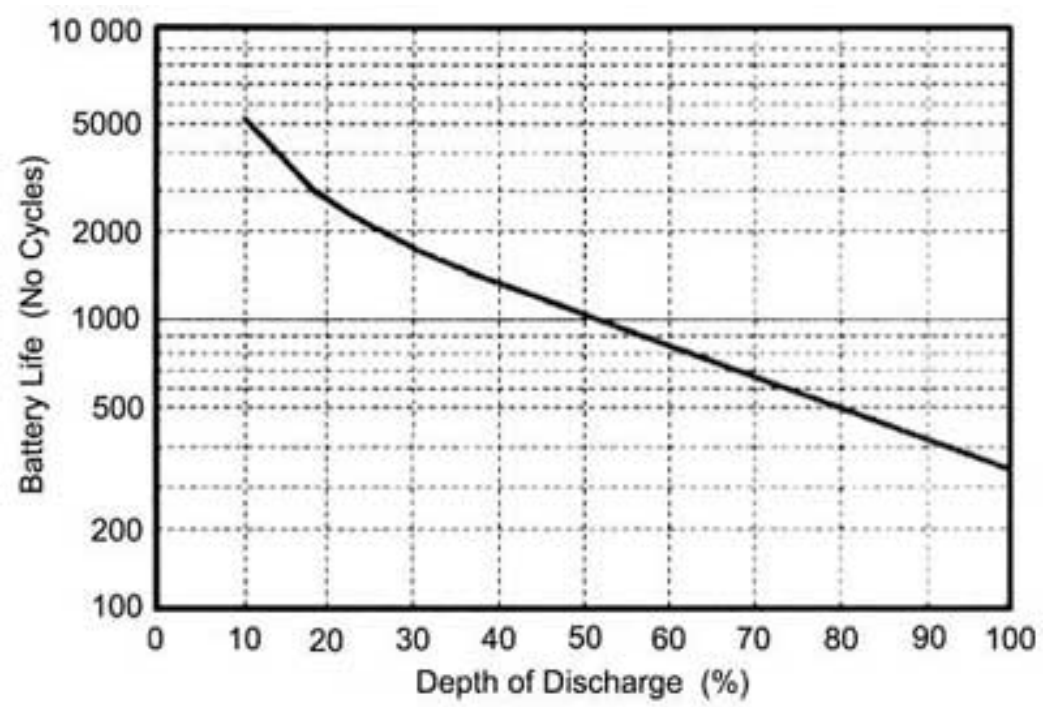

Figure 5-1: Variation in battery life with depth of discharge [20]

Besides the cost associated with gelled cell batteries, their lifetimes are limited to merely two to three years in hotter climates. In addition, when determining how to charge the batteries, the largest available charging current for the gelled battery is only $5 \%$ of its amp-hour capacity—for example, if a 20 amphour battery was required for an application, the rate at which the solar panel could charge the battery is only $1 \mathrm{~A}$; whereas the sealed lead-acid battery can be charged at $10-13 \%$ of the battery capacity. Lastly, the main drawback with the absorbed glass mat batteries is the difference in cost-the typical battery can range anywhere from two to three times as much as the equivalent flooded leadacid battery. Thus, for the stand-alone system, a flooded sealed lead-acid battery will be chosen instead of the gelled electrolyte and absorbed glass mat. [20]. 


\subsection{2-Battery Capacitance and Terminal Voltage}

The major concern when choosing a battery deals with the amount of electrical energy the battery can store. Since the battery is intended on being charged by a solar panel, the selected battery capacity should have an adequate amp-hour capacitance to supply the needed power during the longest determined period of insufficient sunlight (normally due to climate conditions). Therefore, for precautionary reasons, the selected battery capacitance should be sized at least $20 \%$ larger than the amount calculated required for design applications.

Also, a common misconception about a $12 \mathrm{~V}$ lead-acid battery is that the battery will provide a constant $12 \mathrm{~V}$, regardless of the state of charge. In reality, a battery's terminal voltage can range anywhere from an approximate $10.5 \mathrm{~V}$ to $12.7 \mathrm{~V}$; therefore, the system should incorporate a method of regulating the voltage in order to reduce the voltage fluctuation seen by the luminaire. Table 5-1 illustrates the approximate battery voltage based on the state of charge.

Table 5-1: Approximate state of charge and associative terminal battery voltage [20]

\begin{tabular}{|c|c|}
\hline State of Charge (approx.) & 12 Volt Battery \\
\hline $100 \%$ & 12.7 \\
$90 \%$ & 12.5 \\
$80 \%$ & 12.42 \\
$70 \%$ & 13.32 \\
$60 \%$ & 12.2 \\
$50 \%$ & 12.03 \\
$40 \%$ & 11.9 \\
$30 \%$ & 11.75 \\
$20 \%$ & 11.58 \\
$10 \%$ & 11.31 \\
$0 \%$ & 10.5 \\
\hline
\end{tabular}


Another factor to keep in mind is that the battery voltages depicted in Table 5-1 only represent the voltages for a specific case. Depending on the selected battery, the voltage can have a full capacity (100\% state of charge) value of anywhere up to $14.5 \mathrm{~V}$ for batteries with higher specific gravities; thus, when choosing the battery for operation, the datasheet should indicate the appropriate terminal voltage at varying state of charge.

\subsection{3-Battery Physical Sizing}

As a quick reference to the typical types of batteries that are manufactured, Table 5-2 shows different battery specifications based on their voltage and amp-hour ratings. The sizes may slightly vary between manufacturers, but the chart provides a good comparison between the battery dimensions based on their amp-hour rating. In addition, the weight of the battery can be used as a good mechanical indicator of where and how the battery should be placed (i.e. mounted alongside the luminaire, at an elevated height, or at the base of luminaire pole). 
Table 5-2: List of typical battery sizes [21]

\begin{tabular}{|c|c|c|c|c|c|c|c|}
\hline Voltage & $\begin{array}{l}\text { Amp Hours } \\
\text { (20 hour) }\end{array}$ & $\begin{array}{c}\text { Length } \\
\text { (in inches) }\end{array}$ & $\begin{array}{c}\text { Width } \\
\text { (in inches) }\end{array}$ & $\begin{array}{c}\text { Height } \\
\text { (in inches) }\end{array}$ & $\begin{array}{l}\text { Volume } \\
\left(\text { in } \text { in }^{3}\right)\end{array}$ & Weight (Kg) & Weight (lbs) \\
\hline 4 & 10 & 3.98 & 1.97 & 3.7 & 29.010 & 1.33 & 2.93 \\
\hline \multirow{13}{*}{6} & 1 & 1.65 & 2 & 2.01 & 6.633 & 0.26 & 0.57 \\
\hline & 1.2 & 3.82 & 0.98 & 2.01 & 7.525 & 0.3 & 0.66 \\
\hline & 3 & 5.28 & 1.34 & 2.36 & 16.697 & 0.65 & 1.43 \\
\hline & 4 & 2.76 & 1.85 & 3.98 & 20.322 & 0.85 & 1.87 \\
\hline & 4.5 & 2.76 & 1.89 & 4.02 & 20.970 & 0.95 & 2.09 \\
\hline & 5 & 2.76 & 1.89 & 4.02 & 20.970 & 0.98 & 2.16 \\
\hline & 7 & 5.94 & 1.34 & 3.7 & 29.451 & 1.3 & 2.87 \\
\hline & 8 & 5.64 & 1.97 & 3.7 & 41.110 & 1.8 & 3.97 \\
\hline & 8 & 3.86 & 2.2 & 4.65 & 39.488 & 1.5 & 3.31 \\
\hline & 10 & 5.94 & 2.2 & 3.7 & 48.352 & 2 & 4.41 \\
\hline & 12 & 5.94 & 1.97 & 3.7 & 43.297 & 2.05 & 4.52 \\
\hline & 13 & 4.25 & 2.8 & 5.51 & 65.569 & 2.5 & 5.51 \\
\hline & 33 & 7.13 & 2.99 & 6.54 & 139.424 & 6 & 13.23 \\
\hline \multirow{23}{*}{12} & 1.2 & 3.82 & 1.77 & 2.09 & 14.131 & 0.59 & 1.3 \\
\hline & 1.9 & 7.01 & 1.34 & 2.36 & 22.168 & 0.92 & 2.03 \\
\hline & 2.3 & 7.01 & 1.34 & 2.36 & 22.168 & 0.94 & 2.07 \\
\hline & $3,3.6$ & 5.28 & 2.64 & 2.36 & 32.897 & 1.3 & 2.87 \\
\hline & 4 & 3.54 & 2.76 & 4.02 & 39.277 & 1.67 & 3.68 \\
\hline & 4.5 & 3.54 & 2.76 & 4.02 & 39.277 & 1.9 & 4.19 \\
\hline & 5 & 3.54 & 2.76 & 4.02 & 39.277 & 1.92 & 4.23 \\
\hline & 7 & 5.94 & 2.56 & 3.66 & 55.655 & 2.6 & 5.73 \\
\hline & $7.5,8$ & 5.94 & 2.56 & 3.66 & 55.655 & 2.65 & 5.84 \\
\hline & 8 & 4.41 & 3.86 & 4.65 & 79.155 & 3 & 6.62 \\
\hline & 8 & 7.72 & 2.2 & 4.65 & 78.976 & 3 & 6.62 \\
\hline & 12 & 5.94 & 3.86 & 3.7 & 84.835 & 4.03 & 8.89 \\
\hline & 15 & 7.13 & 2.99 & 6.54 & 139.424 & 6 & 13.23 \\
\hline & 17 & 7.13 & 2.99 & 6.54 & 139.424 & 6.15 & 13.56 \\
\hline & 24 & 6.89 & 6.54 & 4.92 & 221.698 & 9.4 & 20.73 \\
\hline & 26 & 6.89 & 6.54 & 4.92 & 221.698 & 9.4 & 20.76 \\
\hline & 28 & 6.89 & 6.54 & 4.92 & 221.698 & 9.6 & 21.17 \\
\hline & 33 & 7.68 & 5.08 & 6.1 & 237.988 & 11.25 & 24.81 \\
\hline & 33 & 8.27 & 5.08 & 6.61 & 277.697 & 11.25 & 24.81 \\
\hline & 40 & 7.72 & 6.5 & 6.73 & 337.711 & 14.3 & 31.53 \\
\hline & 60 & 10.31 & 6.81 & 7.91 & 555.370 & 25 & 55.13 \\
\hline & 80 & 12.05 & 6.81 & 7.95 & 652.381 & 31 & 68.36 \\
\hline & 100 & 13.5 & 6.77 & 8.39 & 766.804 & 33 & 72.77 \\
\hline
\end{tabular}




\section{3-Solar Module and Battery Sizing}

Solar module and battery sizing are important factors to consider when optimizing a system. For instance, overcompensation or underestimation can occur when not properly calculating the energy requirements for powering an apparatus. If the solar panel is incapable of generating enough energy to replenish a battery, the battery will eventually reach a point that exceeds its maximum depth-of-discharge and will be unable to charge back to full capacity. Similarly, if the battery is incapable of delivering sufficient current for the application due to its low state of charge, charging implications will occur and require battery replacement.

From an overcompensation standpoint, the main disadvantages associated with purchasing higher power panels or larger capacity batteries are the cost and physical dimensions of the devices. For the actual lighting application, size is of lesser concern due to the slight variations between physical size and output for both the panel and battery. However, since cost is an issue when trying to associate the designed system with other traditional lighting methods, minimizing the total cost for the system will provide more enticing reasons to implement the proposed lighting scheme.

The following subsections will determine the operating time for the luminaire based on several developed assumptions for a stand-alone photovoltaic system. 


\subsection{1-Operating Time and Power Consumption for Lighting}

The primary determinant of power consumption for a luminaire is derived from the amount of time the system is intended on being used. In contrast to traditional lighting systems that are constantly in the on, the proposed method of lighting will turn off in the absence of pedestrians. For this reason, calculations must be made based on the amount of time the luminaire is expected to be operating at full-load (the average time that all ten sections of the luminaire will turn on). The basis for this analysis begins with the list of assumptions summarized in Table 5-3.

Table 5-3: Assumptions for determining system operating time

\begin{tabular}{|l|c|}
\cline { 2 - 2 } \multicolumn{1}{c|}{} & Unit Value \\
\hline Base Luminaire Wattage [W] & 72 \\
\hline Amount of Hours in a Night [hr] & 12 \\
\hline Peak Sun Hours [hr] & 5.6 \\
\hline $\begin{array}{l}\text { Amount of Storage (number of nights } \\
\text { operational on full charge) [hr] }\end{array}$ & 2 \\
\hline $\begin{array}{l}\text { Derating Factor of PV panel due to } \\
\text { temperature }\end{array}$ & 0.9 \\
\hline
\end{tabular}

Table 5-3 contains a few established assumptions (some specifications are referenced from the previous chapters): the based luminaire wattage when all ten sections are on was calculated based on equation (4.25); a basis of 12 hourlong nights for the duration of time that the luminaire can be operational; the amount of peak sun hours determined from equation (2.1); and the derating factor of $90 \%$ to emblematize the amount of thermal losses from the panel. From these assumptions, Table 5-4 has been created to show the percentage of time that the luminaire will be operating at full-load, the corresponding energy used, and the energy generated by the solar panel per day. 
Table 5-4: Relation of percentage of 'ON' time to energy requirements of solar panel

\begin{tabular}{|c|c|c|c|c|c|c|}
\hline $\begin{array}{c}\text { Percentage } \\
\text { of 'ON' Time }\end{array}$ & $\begin{array}{c}\text { Hours of } \\
\text { 'ON' Time } \\
\text { (hr) }\end{array}$ & $\begin{array}{c}\text { Time on } \\
\text { per Hour } \\
\text { (min) }\end{array}$ & $\begin{array}{c}\text { Energy per } \\
\text { Day Used (W } \\
\text { hr) }\end{array}$ & $\begin{array}{c}\text { Required PV } \\
\text { Output per Day } \\
\text { (W-hr) }\end{array}$ & $\begin{array}{c}\text { PV Panel } \\
\text { Wattage at } \\
\text { STC (W) }\end{array}$ & $\begin{array}{c}\text { Energy Output } \\
\text { from Panel per } \\
\text { Day (W-hr) }\end{array}$ \\
\hline 5 & 0.6 & 3 & 43.2 & 50.82 & 20 & 100.8 \\
10 & 1.2 & 6 & 86.4 & 101.65 & 30 & 151.2 \\
11 & 1.32 & 6.6 & 95.04 & 111.81 & 30 & 151.2 \\
\hline 12 & 1.44 & 7.2 & 103.68 & 121.98 & 30 & 151.2 \\
\hline 13 & 1.56 & 7.8 & 112.32 & 132.14 & 30 & 151.2 \\
15 & 1.68 & 8.4 & 120.96 & 142.31 & 30 & 151.2 \\
16 & 1.8 & 9 & 129.6 & 152.47 & 40 & 201.6 \\
17 & 1.92 & 9.6 & 138.24 & 162.64 & 40 & 201.6 \\
18 & 2.04 & 10.2 & 146.88 & 172.80 & 40 & 201.6 \\
19 & 2.16 & 10.8 & 155.52 & 182.96 & 40 & 201.6 \\
20 & 2.28 & 11.4 & 164.16 & 193.13 & 40 & 201.6 \\
\hline 21 & 2.4 & 12 & 172.8 & 203.29 & 55 & 277.2 \\
\hline 22 & 2.52 & 12.6 & 181.44 & 213.46 & 55 & 277.2 \\
\hline 23 & 2.64 & 13.2 & 190.08 & 223.62 & 55 & 277.2 \\
\hline 24 & 2.76 & 13.8 & 198.72 & 233.79 & 55 & 277.2 \\
\hline 25 & 2.88 & 14.4 & 207.36 & 243.95 & 55 & 277.2 \\
\hline 26 & 3 & 15 & 216 & 254.12 & 55 & 277.2 \\
27 & 3.12 & 15.6 & 224.64 & 264.28 & 55 & 277.2 \\
\hline & 3.24 & 16.2 & 233.28 & 274.45 & 55 & 277.2 \\
\hline
\end{tabular}

For clarity, Table 5-4 is subdivided into four sections based on the panel wattage $(20,30,40$, or 55 Watts $)$-indicated by the color variations. In addition, the divisions also symbolize the type of panel that can be used based on the predetermined percentage of 'ON' time (left-most column). The energy used per day by the luminaire is calculated based on the amount of hours the luminaire is expected to operate and the base power consumption of $72 \mathrm{~W}$ that the luminaire will use. Since this value represents ideal conditions, a 15\% efficiency reduction will be included to allow a more realistic energy requirement. Furthermore, the energy output from the solar panel (right-most column in Table 5-4) is calculated based on the 5.6 peak sun hours and the panel wattage. As an example, if the luminaire is chosen to operate for $10 \%$ of the night, a panel rated at $30 \mathrm{~W}$ is capable of generating enough energy (151.2 W-hr) per day to accommodate for the amount of energy consumed by the luminaire (101.65 W-hr). 
Based on the calculations in the table, a $40 \mathrm{~W}$ panel will be selected for an operating period of 2.28 hours (19\% of the night). This value should sufficiently provide enough lighting throughout the night. As an example of how the operating time can be distributed, Table 5-5 lists one possible scenario for the required lighting based on the time during the night.

Table 5-5: Accumulation of operating time for decreasing light requirement

\begin{tabular}{|c|c|c|c|}
\hline Elapsed Time $(\mathbf{h r})$ & Time of Night & $\begin{array}{c}\text { Percentage of time } \\
\text { on during hour }\end{array}$ & $\begin{array}{c}\text { Accumulating } \\
\text { Operating Time (hr) }\end{array}$ \\
\hline 1 & $7: 00 \mathrm{PM}$ & $50.00 \%$ & 0.50 \\
2 & $8: 00 \mathrm{PM}$ & $40.00 \%$ & 0.90 \\
3 & $9: 00 \mathrm{PM}$ & $40.00 \%$ & 1.30 \\
\hline 4 & $10: 00 \mathrm{PM}$ & $30.00 \%$ & 1.60 \\
\hline 5 & $11: 00 \mathrm{PM}$ & $10.00 \%$ & 1.70 \\
6 & $12: 00 \mathrm{AM}$ & $5.00 \%$ & 1.75 \\
7 & $1: 00 \mathrm{AM}$ & $5.00 \%$ & 1.80 \\
8 & $2: 00 \mathrm{AM}$ & $5.00 \%$ & 1.85 \\
9 & $3: 00 \mathrm{AM}$ & $5.00 \%$ & 1.90 \\
10 & $4: 00 \mathrm{AM}$ & $5.00 \%$ & 1.95 \\
11 & $5: 00 \mathrm{AM}$ & $5.00 \%$ & 2.00 \\
12 & $6: 00 \mathrm{AM}$ & $5.00 \%$ & 2.05 \\
\hline
\end{tabular}

From the generated data, Table 5-5 shows plenty of leeway for the actual amount of lighting required. For instance at 7:00 PM, the amount of 'ON' time has been allocated as $50 \%$ of the first hour (thirty minutes); after 12:00 AM, the amount of allocated time has been reduced to a constant $5 \%$ (three minutes) of each hour. These quantities per hour are quite sufficient since the duration for an individual moving by each section of the luminaire triggers the equivalence of only a few seconds of all sections of the luminaire turning on. 


\subsection{2-Sizing Worksheet for Solar Panel and Battery}

For smaller systems, the use of a sizing worksheet makes calculating the amount of panels or batteries for load requirements much simpler. Table 5-6 represents the full sizing worksheet for a $72 \mathrm{~W}$ stand-alone photovoltaic system. The worksheet is separated into three sections that take certain values such as the panel size and battery capacity to determine whether the proper amount of energy is being generated or if the battery is capable of supply the necessary load.

The first section, labeled as ' $\mathrm{A}$ ', represents the attached system loads. Since the only load requiring current from the battery is the luminaire, the total power needed for operating the device is $72 \mathrm{~W}$. Multiplying the load requirement by the amount of hours per day the device is expected to operate (determined as 2.28 hours within the previous subsection), the total energy required per day is $164.16 \mathrm{~W}$. In addition, the operating time of 2.28 hours that was determined in the previous subsection will be used as the duration of time the device is expected to be operating. 
From section 'B', the determined battery capacitance to operate the system for two days without the presence of sunlight is 31.57 amp-hours; thus, a selected 40 amp-hour battery should provide an adequate safety cushion for the system. Additionally, the daily depth-of-discharge of the battery is approximately $24 \%$ ( $48 \%$ for two days without sunlight), which is within the safe region for operating the battery without affecting the battery's lifespan through numerous charge and discharge cycles.

The last section, denoted as ' $\mathrm{C}$ ' represents the solar panel requirement to achieve the sufficient power to charge the battery. With the predetermined $40 \mathrm{~W}$ panel selection from the earlier subsection, the panel can generate up to 201.6 W per day - this calculation includes a $10 \%$ loss due to temperature and a $15 \%$ battery efficiency loss. Based on these values, a single $40 \mathrm{~W}$ panel is shown to sufficiently provide enough energy to charge the battery as shown by 'C9'. 


\begin{tabular}{|l|l|}
\hline Application & Stand-alone public lighting system \\
\hline Location & Los Angeles, CA \\
\hline Latitude & $33.93^{\circ} \mathrm{N}$ \\
\hline
\end{tabular}

\begin{tabular}{|c|c|}
\hline Design Tilt & $33.93^{\circ} \mathrm{N}$ \\
\hline Design Month & June \\
\hline
\end{tabular}

A. Loads
\begin{tabular}{|c|l|c|c|}
\hline A1 & Inverter Efficiency (decimal) & -- & \\
A2 & Battery Bus Voltage & 13 & volts \\
A3 & Inverter AC Voltage & 110 & volts \\
\hline
\end{tabular}

\begin{tabular}{|c|c|c|c|c|c|}
\hline Component & A4 & A5 & A6 & A7 & A8 \\
\hline Wattage & $\begin{array}{c}\text { Adjustment } \\
\text { Factor (1.0 } \\
\text { for dc A1 for } \\
\text { ac) }\end{array}$ & $\begin{array}{c}\text { Adjusted } \\
\text { Wattage } \\
\text { (A4/A5) }\end{array}$ & $\begin{array}{c}\text { Hours Per Day } \\
\text { Used }\end{array}$ & $\begin{array}{c}\text { Energy Per Day } \\
\text { (A6 x A7) }\end{array}$ \\
\hline LED Fixture & 72 & 1 & 72 & 2.28 & 164.16 \\
\hline
\end{tabular}

\begin{tabular}{|c|l|cc|}
\hline A9 & Total energy demand per day (summation of A8) & $\mathbf{1 6 4 . 1 6}$ & watt-hours \\
A10 & Total amp-hour demand per day (A9/A2) & $\mathbf{1 2 . 6 2 7 6 9 2 3 1}$ & amp-hours \\
A11 & Peak ac-power requirement (summation of A4) & $\mathbf{7 2}$ & watts \\
A12 & Peak dc power requirement (summation of A6) & $\mathbf{7 2}$ & watts \\
\hline
\end{tabular}

B. Battery Sizing

\begin{tabular}{|l|l|c|l|}
\hline B1 & Days of storage desired/required & $\mathbf{2}$ & days \\
\hline B2 & Allowable depht-of discharge limit (decimal) & $\mathbf{0 . 8}$ & amp-hours \\
\hline B3 & Required battery capacity (A10 x B1/B2) & $\mathbf{3 1 . 5 6 9 2 3 0 7 7}$ & amp-hours \\
B4 & Amp-hour capacitor of selected battery & $\mathbf{4 0}$ & amp \\
B5 & Number of batteries in parallel (B3/B4) & $\mathbf{1}$ & \\
B6 & Number of batteries in series (A2/battery voltage) & $\mathbf{1 . 0 8 3 3 3 3 3 3 3 3}$ & \\
B7 & Total number of batteries (B5 x B6) & 40 & amp-hours \\
B8 & Total battery amp-hour capacity (B5 x B4) & $\mathbf{0 . 5 2}$ & kilowatt-hours \\
B9 & Total battery kilowatt-hour capacity (B8 x A2/1000) & $\mathbf{0 . 2 3 6 7 6 9 2 3 1}$ & \\
\hline B10 & Average daily dept of discharge (.75 x A10/B8) & & \\
\hline
\end{tabular}

C. Photovoltaic Array Sizing

\begin{tabular}{|c|c|c|c|}
\hline C1 & Total energy demand per day (A9) & 164.16 & watt-hours \\
\hline C2 & Battery round-trip efficiency $(0.70-0.85)$ & 0.85 & \\
\hline C3 & Required array output per day (C1/C2) & 193.13 & watt-hours \\
\hline C4 & Selected PV module max power voltage at STC $\times 0.85$ & 14.705 & volts \\
\hline C5 & Selected PV module guaranteed power output at STC & 40 & watts \\
\hline c6 & Peak sun hours at design tilt for design month & 5.6 & hours \\
\hline C7 & Energy output per module per day ( $\mathrm{C} 5$ x $\mathrm{C} 6)$ & 224 & watt-hours \\
\hline $\mathrm{C} 8$ & $\begin{array}{l}\text { Module energy output at operating temperature. Use derating factor. DF = } \\
0.80 \text { for hot climates and critical applications; DF }=0.90 \text { for moderate climates } \\
\text { and non-critical applications (DF x C } 7 \text { ) }\end{array}$ & 201.6 & watt-hours \\
\hline C9 & Number of modules required to meet energy requirements $(\mathrm{C} 3 / \mathrm{C} 8)$ & 1 & modules \\
\hline C10 & Number of modules required per string $(\mathrm{A} 2 / \mathrm{C} 4)$ rounded to next higher integer & 1 & modules \\
\hline C11 & Number of strings in parallel $(\mathrm{C} 9 / \mathrm{C} 10)$ rounded to next higher integer & 1 & strings \\
\hline C12 & Number of modules to be purchased $(\mathrm{C} 10 \times \mathrm{C} 11)$ & 1 & modules \\
\hline C13 & Nominal rated PV module output & 40 & watts \\
\hline C14 & Nominal rated array output (C13 x C12) & 40 & watts \\
\hline
\end{tabular}

Table 5-6: Load classification for stand-alone system [22] 
From the sizing worksheet, a 40 amp-hour battery rated at an approximate $13 \mathrm{~V}$ nominal voltage and a $40 \mathrm{~W}$ panel will fulfill the system requirements to power the luminaire.

\section{4-Examples of Solar Panel and Battery Selection}

As a reference for typical solar panel and battery price, datasheet characteristics, and physical size, Table 5-7 and 5-8 will serve as an example of the available online components that can be purchased. Also, the examples shown in the tables will project an estimated initial cost of creating the standalone system as described in the next section.

Table 5-7: Sample of available solar panels and associated characteristics

\begin{tabular}{|c|c|c|c|c|c|c|c|c|c|}
\hline $\begin{array}{c}\text { Solar Panel } \\
\text { Manufacturer }\end{array}$ & Cost & Type of Panel & $\begin{array}{c}\text { Rated } \\
\text { Wattage at } \\
\text { STC (W) }\end{array}$ & $\begin{array}{l}\text { Dimensions } \\
\text { (in } x \text { in } x \text { in) }\end{array}$ & $\begin{array}{c}\text { Weight } \\
\text { (lbs) }\end{array}$ & $\begin{array}{c}\text { Maximum } \\
\text { Power Voltage } \\
\text { (V) }\end{array}$ & $\begin{array}{c}\text { Maximum } \\
\text { Power Current } \\
\text { (A) }\end{array}$ & $\begin{array}{c}\text { Open } \\
\text { Circuit } \\
\text { Voltage (V) }\end{array}$ & $\begin{array}{l}\text { Short Cicuit } \\
\text { Current (A) }\end{array}$ \\
\hline UL Solar & $\$ 159.99$ & Polycryst. silicon & 55 & $25.7 \times 25.2 \times 1.38$ & 13.21 & 18.2 & 3.1 & 22.1 & 3.31 \\
\hline UL Solar & $\$ 109.00$ & Polycryst. silicon & 40 & $26.2 \times 21.8 \times 1.38$ & 11.01 & 17.3 & 2.35 & 21.8 & 2.57 \\
\hline UL Solar & $\$ 99.99$ & Polycryst. silicon & 30 & $26.2 \times 16.2 \times 0.98$ & 7.71 & 17.3 & 1.77 & 21.9 & 1.93 \\
\hline UL Solar & $\$ 69.99$ & Polycryst. silicon & 20 & $21.7 \times 13.8 \times 0.98$ & 6.17 & 17.2 & 1.17 & 21.7 & 1.25 \\
\hline UL Solar & $\$ 34.99$ & Polycryst. silicon & 10 & $13.8 \times 11.8 \times 0.98$ & 3.11 & 17.3 & 0.59 & 21.8 & 0.64 \\
\hline UL Solar & $\$ 15.99$ & Polycryst. silicon & 5 & $13.8 \times 8.8 \times 0.98$ & 2.86 & 17.1 & 0.29 & 21.7 & 0.31 \\
\hline
\end{tabular}

Table 5-8: Sample of available batteries and associated characteristics

\begin{tabular}{|l|c|c|c|c|c|c|c|}
\hline \multicolumn{1}{|c|}{ Battery Name } & Cost & $\begin{array}{c}\text { Battery } \\
\text { Chemistry }\end{array}$ & $\begin{array}{c}\text { Voltage } \\
\text { (V) }\end{array}$ & $\begin{array}{c}\text { Capacity } \\
\text { (Ah) }\end{array}$ & $\begin{array}{c}\text { Rating } \\
\text { (Whr) }\end{array}$ & $\begin{array}{c}\text { Dimensions } \\
\text { (in x in } \mathbf{~ i n )}\end{array}$ & $\begin{array}{c}\text { Weight } \\
\text { (Ib) }\end{array}$ \\
\hline Amstron VLRA RT12220EV EV & $\$ 45.89$ & Lead Acid & 12 & 22 & 264 & $7.13 \times 3.03 \times 6.57$ & 14.1 \\
Amstrong AGM AP-12140EV Deep Cycle Series SLA & $\$ 44.09$ & Lead Acid & 12 & 14 & 168 & $5.97 \times 3.89 \times 3.78$ & 9.7 \\
Amstron VLRA Ap-12180 EV & $\$ 42.29$ & Lead Acid & 12 & 18 & 216 & $7.13 \times 3.03 \times 6.57$ & 13.08 \\
Ritar VLRA RT12240EV & $\$ 53.54$ & Lead Acid & 12 & 24 & 288 & $7.2 \times 3.11 \times 6.57$ & 19 \\
Amstron VLRA & $\$ 97.19$ & Lead Acid & 12 & 40 & 480 & $7.76 \times 6.5 \times 6.69$ & 29.5 \\
\hline
\end{tabular}




\section{CHAPTER 6-INPUT STAGE DESIGN FOR LUMINARE}

\section{1-Design Concept and Goals}

As briefly described in Chapter 4 , the luminaire will be powered by a $12 \mathrm{~V}$ lead-acid battery. Also, the battery, as mentioned in Chapter 5, can have a wide range of voltages—including but not limited to ranges from $10.5 \mathrm{~V}-12.8 \mathrm{~V}$. Thus in order to maintain a constant output voltage of $12 \mathrm{~V}$ for the design, a DC/DC converter is required to step-up the battery's terminal voltage based on various levels of battery charge. In addition, the DC/DC converter should be selected in order to provide enough power (output amperage) for at least one section of the luminaire.

Furthermore, the battery should be able to maintain a high level of charge to avoid falling below $20 \%$ of the battery's capacity. Excessive discharge, as discussed in Chapter 5, could have prolonged harmful effects and wear down the actual capacitance of the battery. As determined in Table 5-6, a $40 \mathrm{~W}$ solar panel will be needed to replenish the battery's state of charge. Although this method of charging the battery may seem simple, a charge controller is required as an intermediate stage between the solar panel and battery to ensure the battery will not be overcharged or undercharged. Figure 6-1 depicts a general flow chart of how each component will be integrated to constitute the input power to the luminaire. 


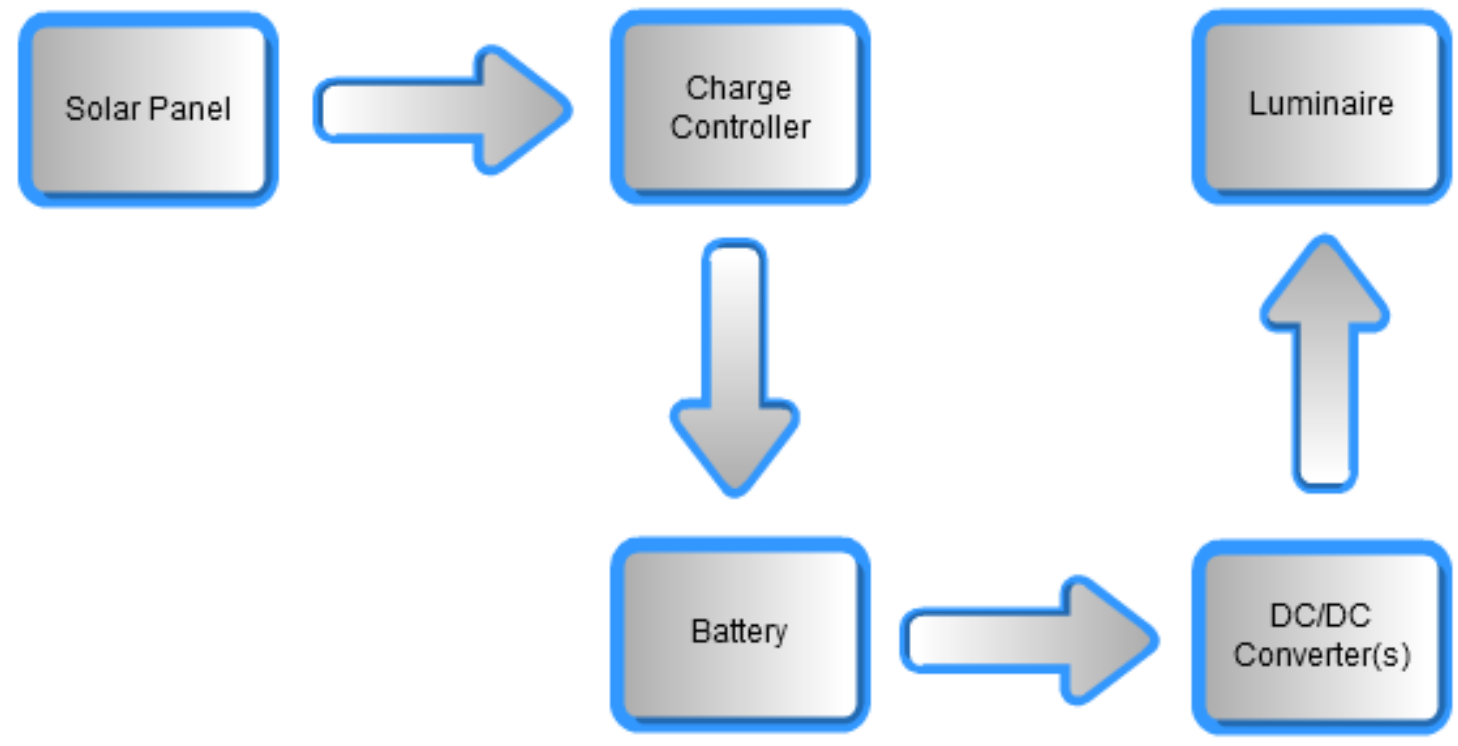

Figure 6-1: Flowchart of different stages to be integrated from the solar panel to the luminaire

The following sections within this chapter will describe the controllers used to implement both the charge controller and DC/DC converter. In addition, several associated simulations tests will be conducted to characterize each design to illustrate the applicability with the constructed luminaire.

\section{2-Charge Controller Selection}

The first task after choosing a solar panel and battery for the overall system is finding a suitable charge controller to monitor the battery's state of charge. A selected charge controller should be chosen based on numerous properties that include a tolerance for a wide range of input voltages-typically values from a $40 \mathrm{~W}-60 \mathrm{~W}$ solar panel-and can easily be incorporated into the system.

Based on these criteria, the Linear Technology's LT3652 integrated circuit is selected as the charge controller for this low power application. The controller is capable of changing different charge rates based on the battery's state of 
charge. In addition, the LT3652 produces peak output power while charging a variety of different battery chemistries and delivers nearly the same efficiency as more complex and expensive Maximum Peak Power Tracking (MPPT) techniques. In summary, the charge controller's ability to operate with different battery chemistries and sustain adequate output power over a wide range of voltages makes this controller suitable for a lighting application.

\section{3-LT3652 Controller Operation and Component Selections}

Depending on the panel characteristics, the LT3652 can generate peak power in excess of $95 \%$ with panel output voltages from $12.5 \mathrm{~V}$ to $18.5 \mathrm{~V}$. In addition, the chip's input voltage regulation loop is capable of adjusting the charge current if the input voltage from the solar panel falls below a programmed level specified by a voltage divider network. Figure 6-2 depicts the controller and associated pins that will be discussed in the following sections.

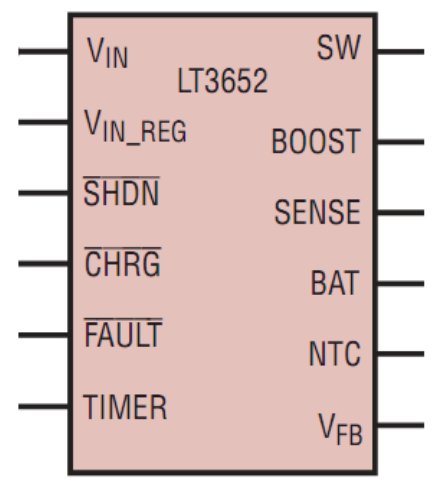

Figure 6-2: LT3652 charge controller with pin outs [23] 


\subsection{1-Solar Panel Input to Controller ( $\left.V_{I N}\right)$}

Figure 6-3 outlines the circuit configuration for the LT3652 integrated with a $12 \mathrm{~V}$ lead-acid battery. Calculations for solar panel sizing and component selection will be further discussed within this section to justify the selection of the $40 \mathrm{~W}$ panel chosen in Chapter 5. In addition, a few modifications for the feedback and input regulation resistors will later be made to accommodate for the peak power voltage for the $40 \mathrm{~W}$ panel.

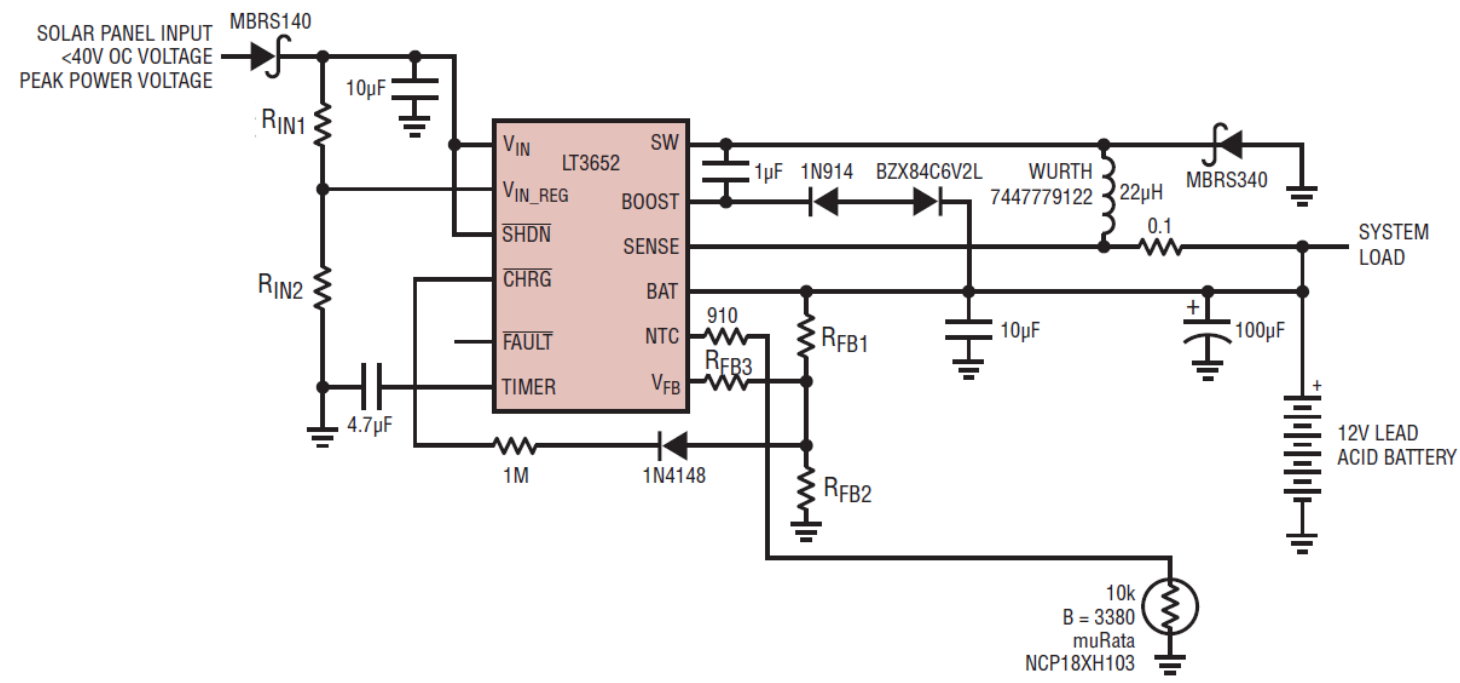

Figure 6-3: 1A solar panel powered 3-stage 12V Lead-Acid Fast/Float Charger [23]

The input voltage pin for the controller has an operating range from $4.95 \mathrm{~V}$ to $32 \mathrm{~V}$ and must be selected to be $3.3 \mathrm{~V}$ larger than the chosen output battery float voltage $\left(\mathrm{V}_{\mathrm{BAT}(\mathrm{FLT})}\right)$.

The first step when choosing a solar panel is to analyze the minimum requirements specified from the controller. Important parameters to consider when selecting a proper panel for applications include open circuit voltage $\left(\mathrm{V}_{\mathrm{OC}}\right)$, peak power voltage $\left(\mathrm{V}_{\mathrm{P}(\mathrm{MAX})}\right)$, and peak power current $\left(\mathrm{I}_{\mathrm{P}(\mathrm{MAX})}\right)$. 
The minimum open circuit voltage must be equal to $3.3 \mathrm{~V}$ plus the forward voltage drop across the Schottky diode plus an additional 15\% for low intensity start-up and operation. Equation (6.1) summarizes how the open circuit voltage will be calculated [24]:

$$
V_{O C}=\left(V_{B A T(F L O A T)}+V_{F O R W A R D}+3.3 \mathrm{~V}\right) * 1.15
$$

Additionally, the peak power voltage must be $0.75 \mathrm{~V}$ plus the forward voltage drop across the diode above the float voltage plus $15 \%$ for low intensity operation. Equation (6.2) describes the maximum peak power voltage in relation to the battery voltage and diode forward voltage [24]:

$$
V_{P(M A X)}=\left(V_{B A T(F L O A T)}+V_{F O R W A R D}+0.75 \mathrm{~V}\right) * 1.15
$$

The charging circuitry for the LT3652 is a current controlled buck regulator; thus, the input current can be directly related to the charge current as a ratio between the input (solar panel) and output (battery) voltages with a nonideality factor $\eta$ resulting based on the efficiency of the controller. Equation (6.3) describes the peak input current [24].

$$
I_{P(M A X)}=I_{C H A R G E} * \frac{V_{B A T(F L O A T)}}{\eta * V_{P(M A X)}}
$$

The battery floating voltage, as indicated by the battery size, will be $13.2 \mathrm{~V}$ and the forward drop across the zener diode will be $0.55 \mathrm{~V}$. Using these two known parameters, the minimum requirements for the solar panel are calculated using equations (6.1) - (6.3):

$$
\begin{gathered}
V_{O C}=19.6075 \mathrm{~V} \\
V_{P(M A X)}=16.675 \mathrm{~V} \\
I_{P(M A X)}=0.8796 \text { A (assuming } 90 \% \text { efficiency of the controller) }
\end{gathered}
$$


These parameters are useful when selecting a solar panel to be integrated with the controller. Comparing the calculated specifications from above for the list of solar panels from Table 5-7, the wattage required for the solar panel has to be at least $30 \mathrm{~W}$ in order to be implemented with the selected charge controller. This proof further solidifies the fact that a $40 \mathrm{~W}$ panel can used for the design.

\subsection{2-Input Regulation LOop (VIN_REG)}

The input voltage for the LT3652 is regulated to maintain the solar panel's power output near the panel's peak value. A resistive voltage divider allows the input voltage into the chip to trigger the amount of charge current that will be supplied to the battery. When the $V_{\text {IN_REG }}$ pin falls below a certain threshold, a sensing resistor will adjust the charge current-representing the battery's need to be charged or limiting the amount of charge as the battery's full capacity is nearing. Thus, when the input voltage drops below the level defined by the voltage divider between the $V_{\mathbb{I N}}$ and $V_{\text {IN_REG }}$ pins, the current control voltage is reduced-also reducing the charging current. Consequently, this action causes the voltage from the solar panel to increase along its characteristic I-V curve until a new peak power operating point is found; this ability allows for MPPT to occur and ensures that the battery will be charged with maximum charging current based on the battery's existent capacity. 


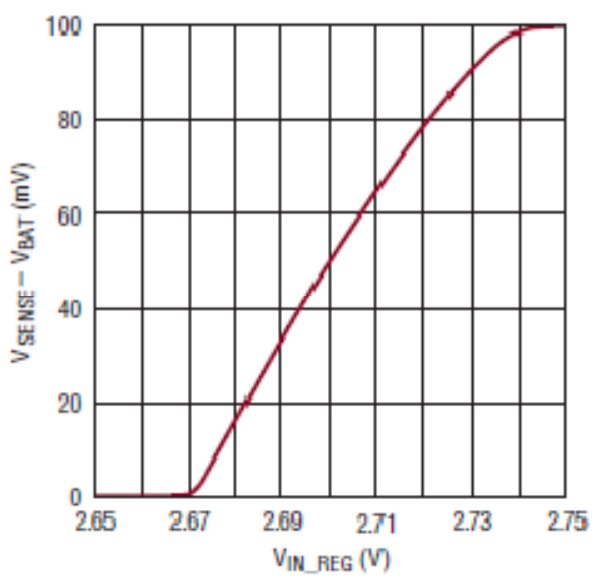

Figure 6-4: Charger current control voltage vs. proportional input voltage (measured through voltage divider at $V_{\text {IN_REG Pin) [24] }}$

Figure 6-4 shows the ideal control characteristics of the $V_{\mathbb{I N}_{-} R E G}$ pin based on the current through the sensing resistor. As seen from the curve, as $V_{I N \_R E G}$ exceeds 2.67V, the voltage $\left(\mathrm{V}_{S E N S E}-\mathrm{V}_{B A T}\right)$ begins to level off at $100 \mathrm{mV}$. This voltage control range can be described with equation (6.4) below, where $R_{I N 1}$ and $R_{I N 2}$ represent the voltage divider to the $\mathrm{V}_{\mathbb{I N} \_ \text {REG }}$ and $\mathrm{V}_{\mathbb{I N}}$ pins [24].

$$
2.67 * \frac{R_{I N 1}+R_{I N 2}}{R_{I N 2}}<V_{I N}(\text { Control Range })<2.74 * \frac{R_{I N 1}+R_{I N 2}}{R_{I N 2}}
$$

Linearizing the curve in Figure 6-4, equation (6.5) describes the current sensing voltage, where $V_{I N_{-} R E G}=V_{I N} \frac{R_{I N 2}}{R_{I N 1}+R_{I N 2}}$.

$$
V_{S E N S E}-V_{B A T}=1.43 *\left(V_{I N \_R E G}-2.67\right)
$$

Equation (6.5) can then be converted into equation (6.6), which describes the charging current for the battery using Ohm's Law $(V=I R)$.

$$
I_{C H A R G E}=\frac{1.43}{R_{S E N S E}} *\left(\frac{V_{I N} * R_{I N 2}}{R_{I N 1}+R_{I N 2}}-2.67\right)
$$


Equations (6.4) to (6.6) will be useful in establishing the control range for the input voltage regulation loop and determining the maximum charge current that can be provided to the battery. Recalling that a $40 \mathrm{~W}$ solar panel was selected for charging the battery, the panel's characteristics shown in Table 5-7 will again be referred to for selecting the input resistances. For the shown $40 \mathrm{~W}$ panel, the corresponding peak power voltage is $17.3 \mathrm{~V}$; this voltage will appear as the input voltage (before the zener blocking diode) in Figure 6-3 and will serve as the minimum regulation voltage to utilize the controller's maximum power point tracking capability. Thus, selecting a $R_{\mathbb{I N} 2}$ as $100 \mathrm{k} \Omega$ and a forward input diode drop of $0.5 \mathrm{~V}, \mathrm{R}_{\mathbb{N} 1}$ can be determined as shown in equation (6.7).

$$
R_{I N 1}=\frac{V_{P(M A X)}-V_{F O R W A R D(D 1)}-2.74}{2.74} * R_{I N 2}=513 k \Omega
$$

Therefore $R_{I N 1}$ and $R_{I N 2}$ can be chosen as $513 \mathrm{k} \Omega$ and $100 \mathrm{k} \Omega$, respectively, to set a threshold voltage for when maximum charge current can be delivered to the battery.

\subsection{3-Feedback Voltage Pin Setting $\left(V_{F B}\right)$}

The feedback loop requires a $3.3 \mathrm{~V}$ reference voltage to determine the floating voltage of the battery. Due to the variability of the battery's floating voltage, the output battery float voltage can be programmed up to values of 14.4 $\mathrm{V}$; however for this application, a $12.7 \mathrm{~V}$ floating voltage will be used to demonstrate how the resistive parameters are calculated. 
In order to achieve the appropriate reference voltage of $3.3 \mathrm{~V}$, a resistor divider network composed of a $250 \mathrm{k}$ equivalent resistance is used at the $V_{F B}$ pin to compensate for any biasing errors on the input side. Since it may be more desirable to use smaller-value feedback resistors with the addition of $\mathrm{R}_{F B 3}$ to generate the $250 \mathrm{k} \Omega$ equivalent resistance, the three resistor network shown in Figure 6.5 will establish the feedback reference voltage.

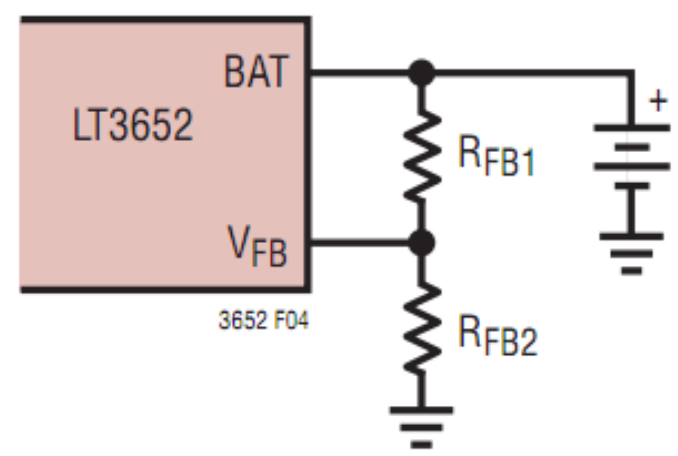

Figure 6-5: Feedback resistive network for LT3652 [23]

The feedback current drawn by the resistor divider is obtained based on the desired feedback reference voltage and $R_{F B 2}$ as shown in equation (6.9).

$$
I_{R F B}=\frac{3.3}{R_{F B 2}}
$$

Also, using $\mathrm{KCL}$ around the resistive network, the ratio between $\mathrm{R}_{\boldsymbol{F B} 1}$ and $\mathrm{R}_{F B 2}$ is shown in equation (6.10) as follows:

$$
\frac{R_{F B 2}}{R_{F B 1}}=\frac{3.3}{V_{B A T(F L T)}-3.3}=0.3511
$$

Selecting $R_{F B 1}$ as $1 M \Omega, R_{F B 2}$ is determined to be $351.1 \mathrm{k} \Omega$ based on the ratio in equation (6.10). 


\subsection{4-Charge Current Sensing Pin (SENSE)}

The SENSE pin is connected to the BAT pin to monitor the voltage at the output terminal of the battery. The voltage across the sensing resistor sets the average charge current of the controller. The maximum charge current of the controller corresponds to a $100 \mathrm{mV}$ drop across the sensing resistor; thus, the resistor can be chosen to allow maximum charging currents up to $2 \mathrm{~A}$. By choosing a maximum charging current, equation (6.11) represents the relationship between a calculated sensing resistance and maximum charging current. A calculation for the sensing resistance based on a maximum charge current of $1 \mathrm{~A}$ is shown.

$$
R_{\text {SENSE }}=\frac{V_{\text {SENSE }}}{I_{\text {CHARGE }(M A X)}}=\frac{100 \mathrm{mV}}{1000 \mathrm{~mA}}=0.1 \Omega
$$

Additionally, using a low tolerance sensing resistor of $0.1 \Omega$, the maximum charging current can be determined using equation (6.6) and through the calculation below:

$$
\begin{gathered}
I_{C H A R G E(M A X)}=\frac{1.43}{R_{S E N S E}} *\left(\frac{V_{I N} * R_{I N 2}}{R_{I N 1}+R_{I N 2}}-2.67\right) \\
=\frac{1.43}{0.1} *(2.74-2.67) \\
=1.0016 \mathrm{~A}
\end{gathered}
$$




\section{4-LT 3652 Test Circuit Simulation and Results}

In order to demonstrate the capabilities and operation of the controller prior to the actual construction of the circuit, LTSpice will be used to show the controller reacting to different output voltage levels and input variations. As a brief introduction, LTSpice is a software provided by Linear Technology that allows the user to simulate and design more advanced circuits using the company's ICs. For this section, the LT3652 will be implemented on LTSpice with a few modifications for simulation purposes. The basis for the simulation circuit will reflect Figure 6-3 with the calculated resistance values.

Prior to implementing the controller for use on LTSpice, a test circuit will be used to demonstrate the circuit's general operation. Figure 6-6 shows the test circuit for the LT3652.

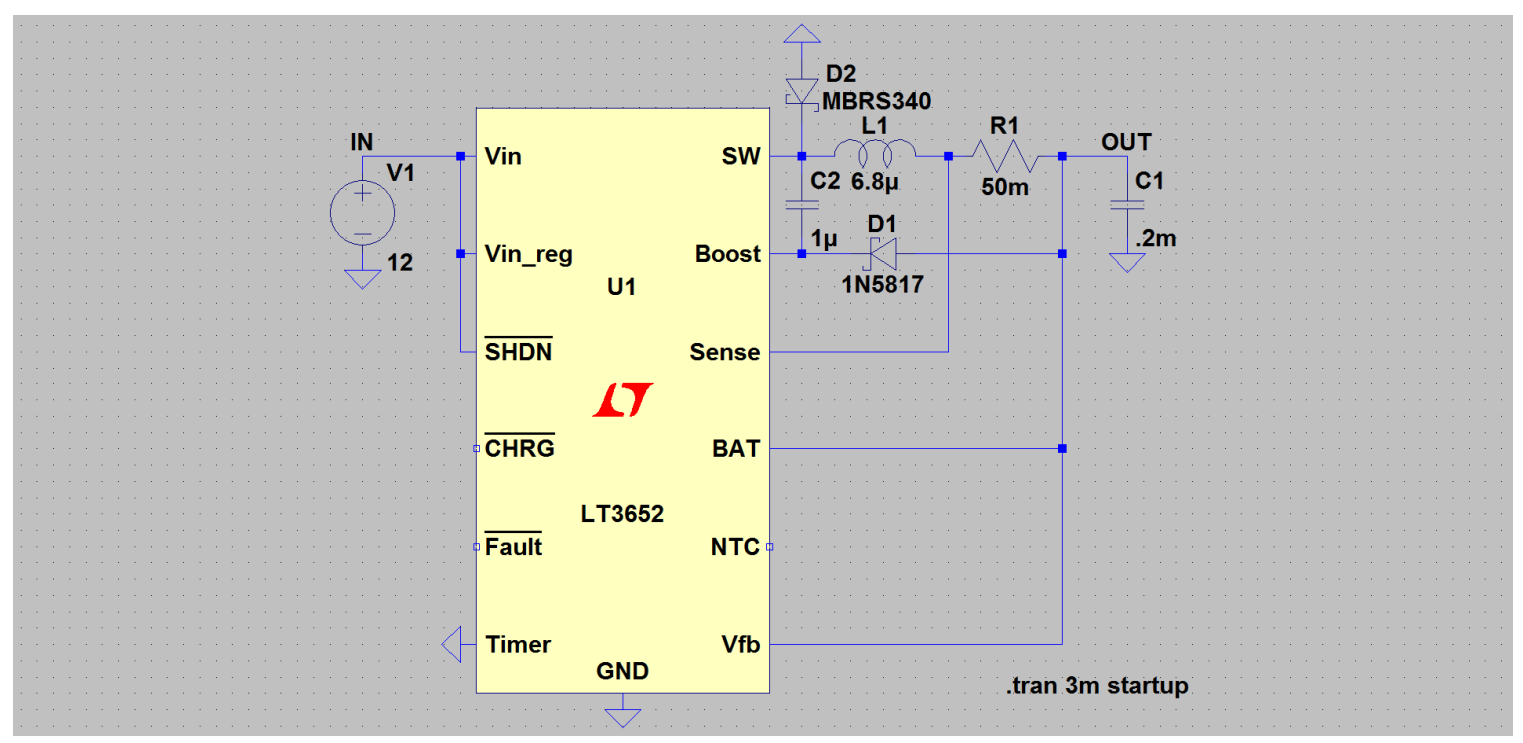

Figure 6-6: Test fixture for LT3652 
A capacitor is used as the battery representation in the test circuit. The purpose of using the capacitor is to show how the charge current (i.e. the current through the battery terminals for the actual design) will fluctuate based on the capacitor's capacity (voltage) at any given time. Next, the circuit will be simulated over $3 \mathrm{~ms}$ to visually show how the controller reacts to various voltage levels as the capacitor builds up charge; the resulting simulation image is shown in Figure 6-7.

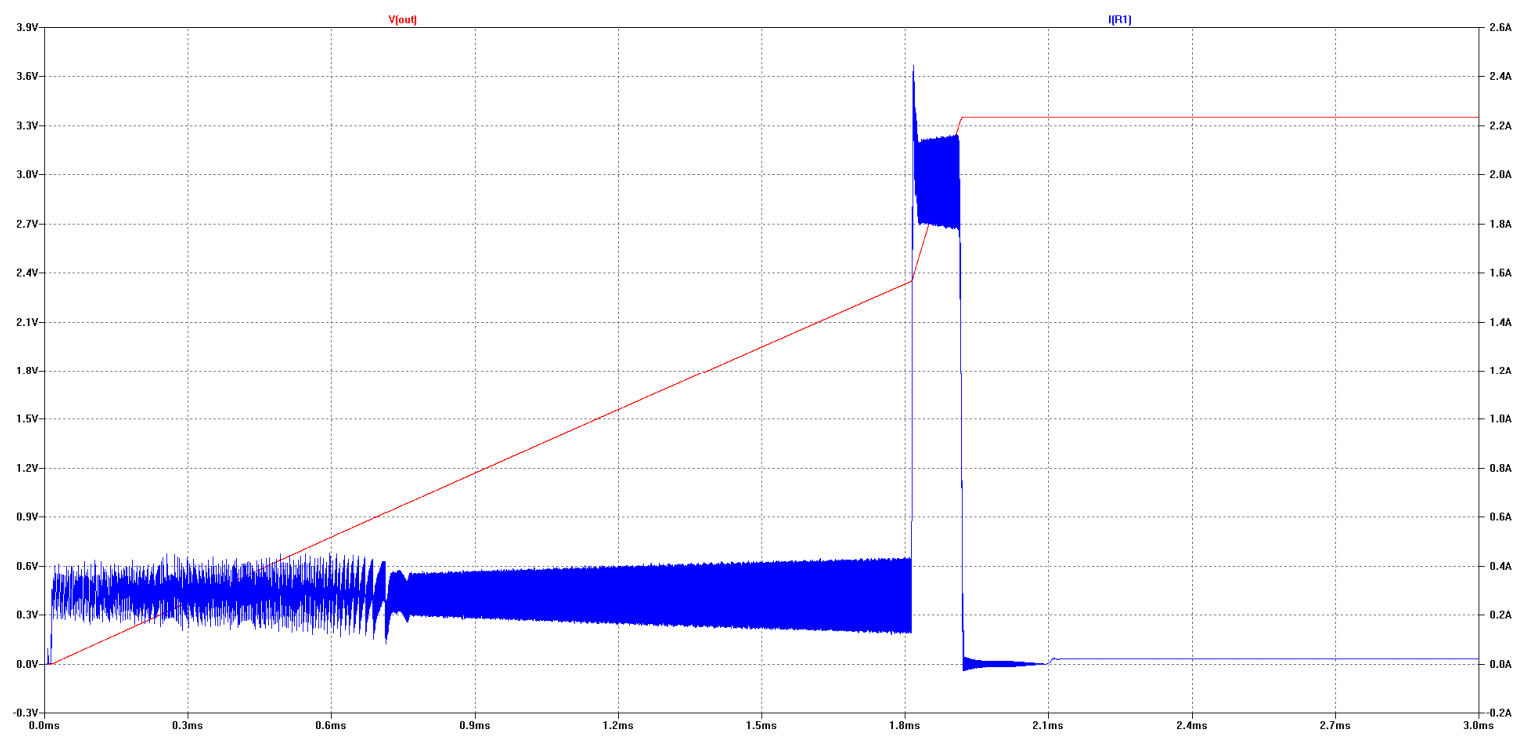

Figure 6-7: Simulation of LT3652 test fixture over a $10 \mathrm{~ms}$ period 
As seen from the waveforms (the red line representing the capacitor voltage and blue line representing the current charging the capacitor), when the reference voltage increases from 0 to approximately $2 \mathrm{~V}$, the current remains

constant-representing the capacitor being charged $\left(i_{c}=C \frac{d V_{c}}{d t}\right)$. Next, as the voltage increases more rapidly over time towards the $3.3 \mathrm{~V}$ reference voltage, the current into the capacitor also increases; thus further describing that the current and first derivative of voltage from the capacitor are directly proportional. Lastly, after the voltage reaches the 3.3 reference voltage, the current is approximately $0 \mathrm{~A}$-illustrating that the capacitor is fully charged or in other words has reached full capacity. From the simulation results, the controller behaves as expected. The following subsections will describe the process for testing the designed charge controller representation that will be used in conjunction with a $12 \mathrm{~V}$ leadacid battery.

\section{5-LT3652 Controller for a 12 V Lead-Acid Battery Simulation and Results}

In order to simulate the circuit from Figure 6-3, a few modifications must be made due to the complexity of the circuit and limitations based on the provided components in the LTSpice library. Within the figure, the three most difficult components to create in LTSpice are the solar panel input, the NTC thermistor, and the output battery. These three components are not readily available for the user to implement in LTSpice; however, by knowing how the various pins on the controller operate, a few assumptions and adjustments to the circuit can be made for simulation purposes. 


\subsection{1-Modifications for Simulation Purposes}

The photovoltaic circuit is the first modification used to represent a $40 \mathrm{~W}$ solar panel. From Table 5-7, the solar panel characteristic shows a maximum power current of $2.35 \mathrm{~A}$ and an open-circuit voltage of $21.8 \mathrm{~V}$. These values are represented by a current source and the amount of diodes strung together in series. Since the diodes each have a forward drop of $0.85 \mathrm{~V}$, approximately 26 diodes will be used to represent the open-circuit voltage of $21.8 \mathrm{~V}$.

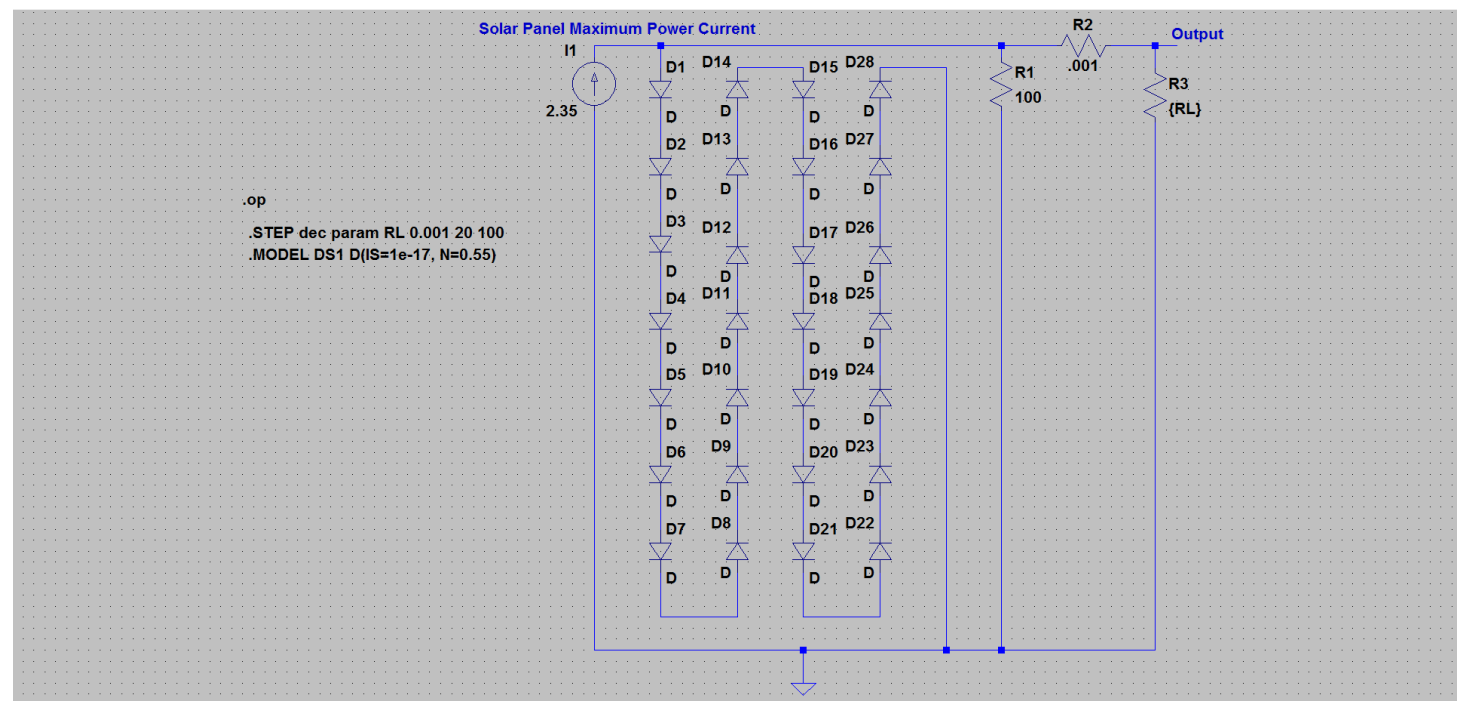

Figure 6-8: LTSpice solar panel circuit representation

Figure 6-8 shows the solar panel model for a $40 \mathrm{~W}$ system. Additionally, to demonstrate the characteristics of the modeled solar panel in Figure 6-8, Figure 6-9 shows the simulation results for the I-V curve. The maximum power point, indicated by the intersection between the output current (blue curve) and the output power (red curve), intersects approximately $40 \mathrm{~W}$, which corresponds to the panel that was chosen to be simulated. Based on these results, this implementation can be used as the input for the LT3652 controller. 


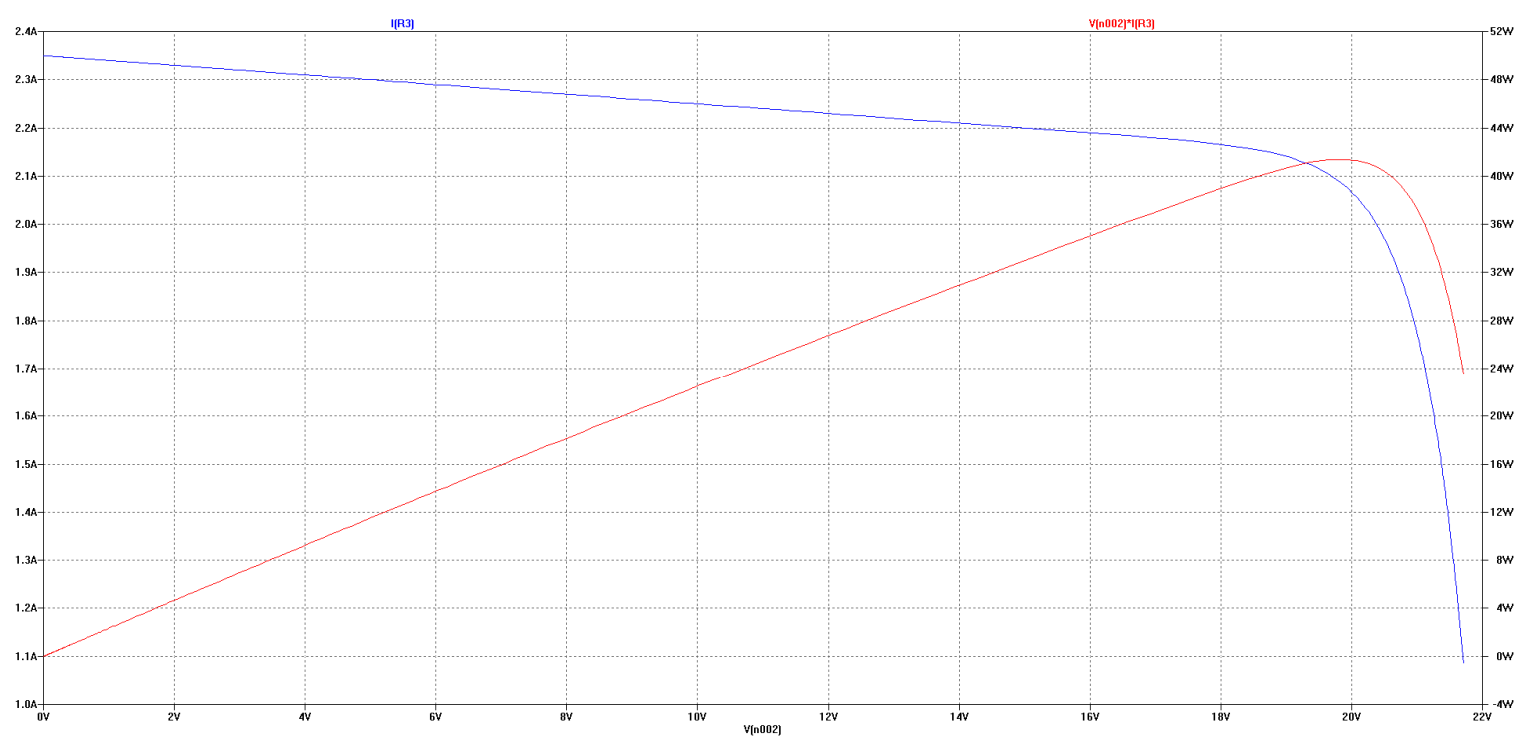

Figure 6-9: I-V and power curves for a simulated $40 \mathrm{~W}$ solar panel model; blue line denotes the I-V curve, red line represents the power curve

The next parameter to be modified is the NTC thermistor. The NTC pin, as described in the previous section, is mainly used as the IC's safe-switch.

When the thermistor exceeds or falls below a certain temperature, the resistance of the thermistor will vary and thus pull the NTC pin high, disabling the charging function of the controller. However, for simulation purposes, temperatures do not pose a problem for the "ideal" situation; thus a simple resistor of $10 \mathrm{k} \Omega$ can be used instead to replace the $10 \mathrm{k} \Omega$ thermistor.

Lastly, the battery source will be modeled as a varying voltage source due to the complexity of implementing a physical model based on an actual battery's chemistry and amp-hour capacity. The voltage source will be linearly swept from numerous DC voltage values that fluctuate between $8 \mathrm{~V}-12 \mathrm{~V}$ to provide a better representation of how the charge controller will operate and hopefully, duplicate similar waveforms as developed in Figure 6-7. 


\subsection{2-Overall LTSpice Circuit Representation}

In order to simulate the circuit model intended for actual use, the three parameters from the previous subsection will be integrated with the circuit schematic shown in Figure 6-10.

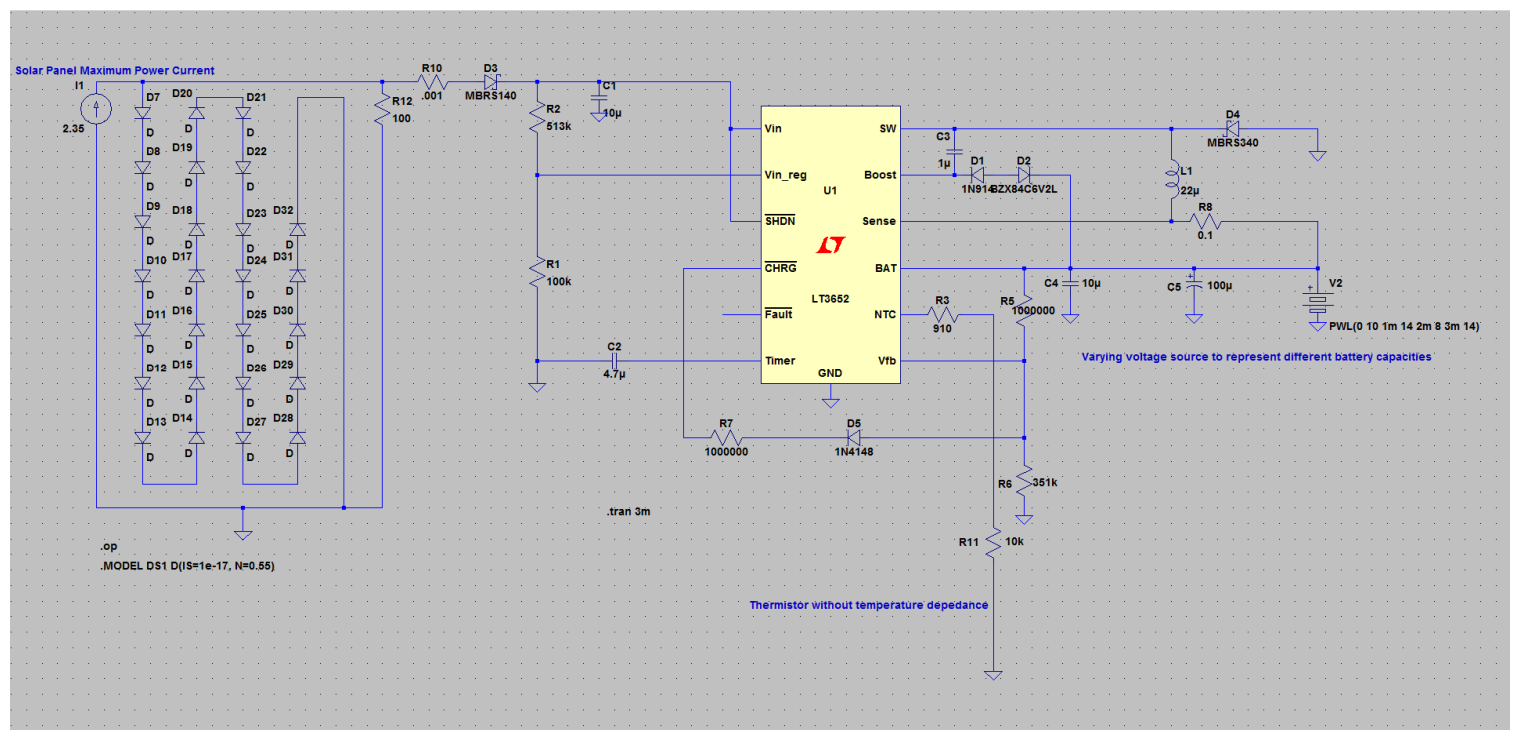

Figure 6-10: Final LT3652 circuit implementation for simulation

For simulation purposes, the battery source will vary linearly through increments of one millisecond. Additionally, each millisecond will represent a stage at which the voltage will fluctuate-Table 6-1 summarizes the stages that the will be monitored and analyzed to show the charge controller's operation.

Table 6-1: Simulation stages for LT3652

\begin{tabular}{|c|c|c|}
\hline Stage & Time Period $(\mathrm{ms})$ & Linear Voltage Ramp (V) \\
\hline 1 & $0-1$ & $10-14$ \\
2 & $1-2$ & $14-8$ \\
3 & $2-3$ & $8-14$ \\
\hline
\end{tabular}




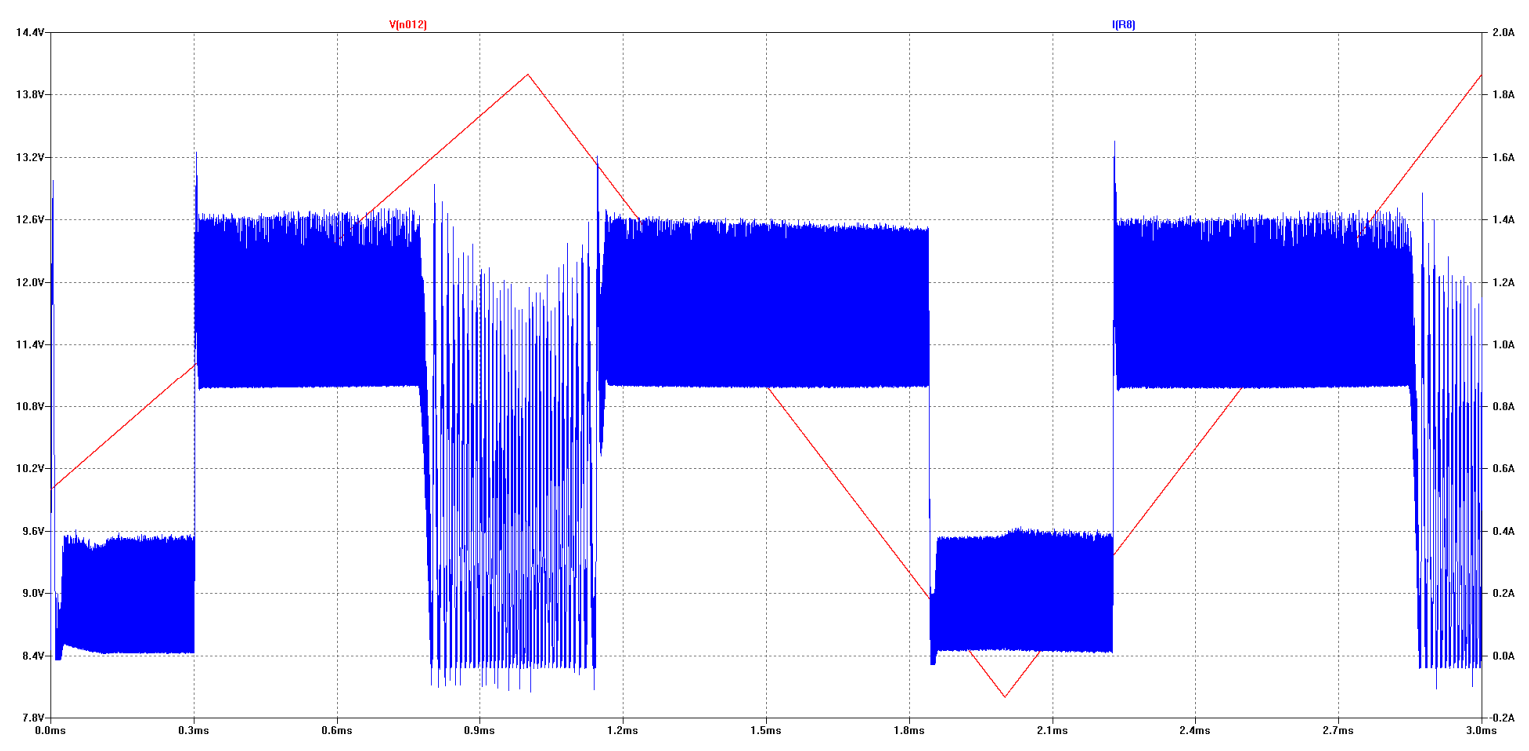

Figure 6-11: Simulation result for LT3652 connected to a $12 \mathrm{~V}$ battery source

Figure 6-10 displays two parameters of interest-the red line represents the varying voltage ramp and the blue line represents the fluctuating current through the sensing resistor. The specifics of the waveform are difficult to see since the current spikes occur instantaneously. However to visually show the current that is flowing through the battery in the absence of instantaneous peak currents, a few finite screenshots are captured to represent the stages in Table 6-1. These stages are captured and shown in Figure 6-11 (a), (b), and (c), where each letter in chronological order represents the sequential stages within the simulation. From these waveforms, the discrete currents for different varying voltages can now be seen and will allow deductions to be made based on how the current will be affected for differing reference voltages as seen by the feedback pin. 


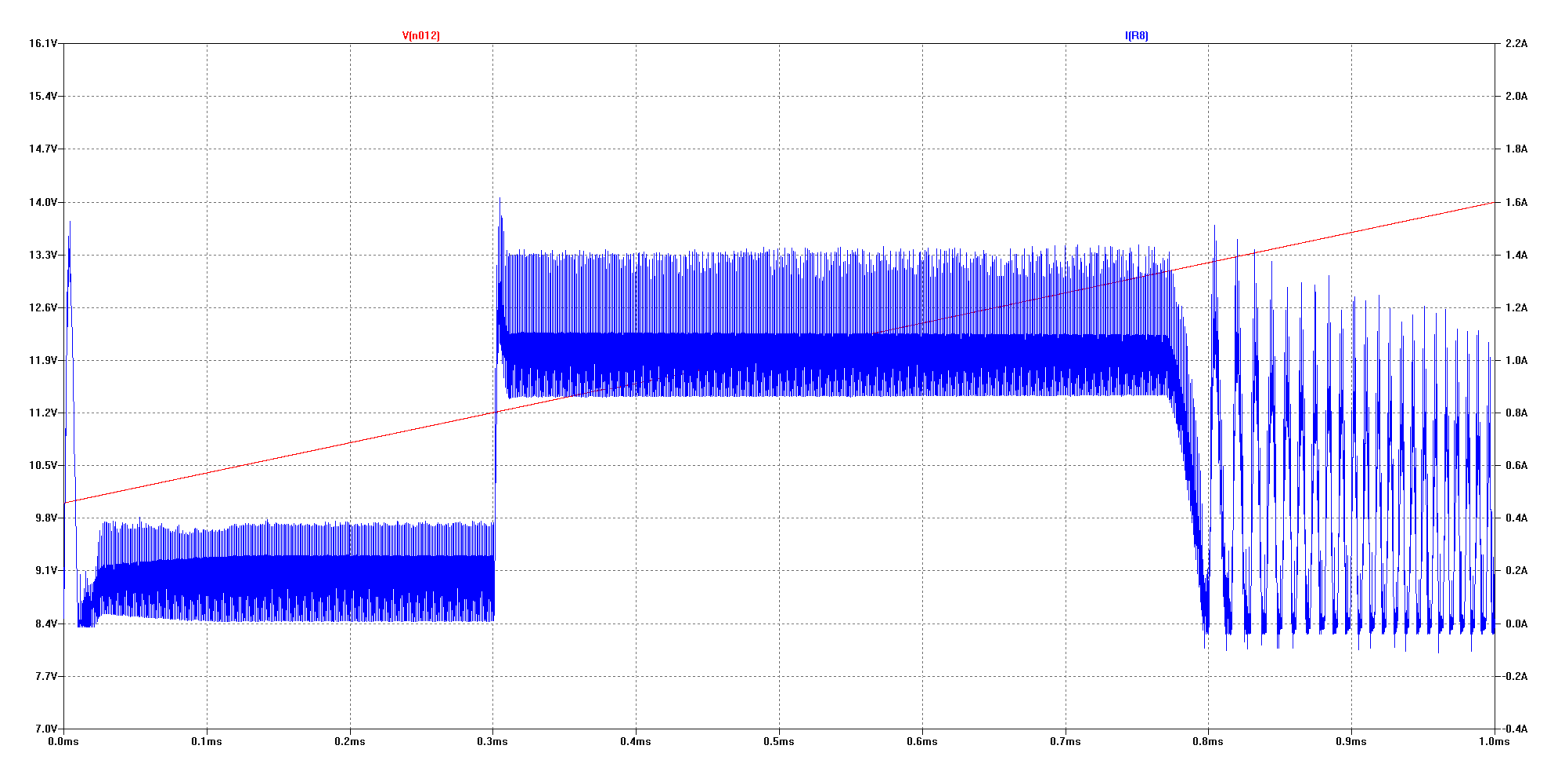

(a) Stage 1: waveforms measured between interval of 0 and $1 \mathrm{~ms}-$ voltage linearly increasing from 10 to $14 \mathrm{~V}$

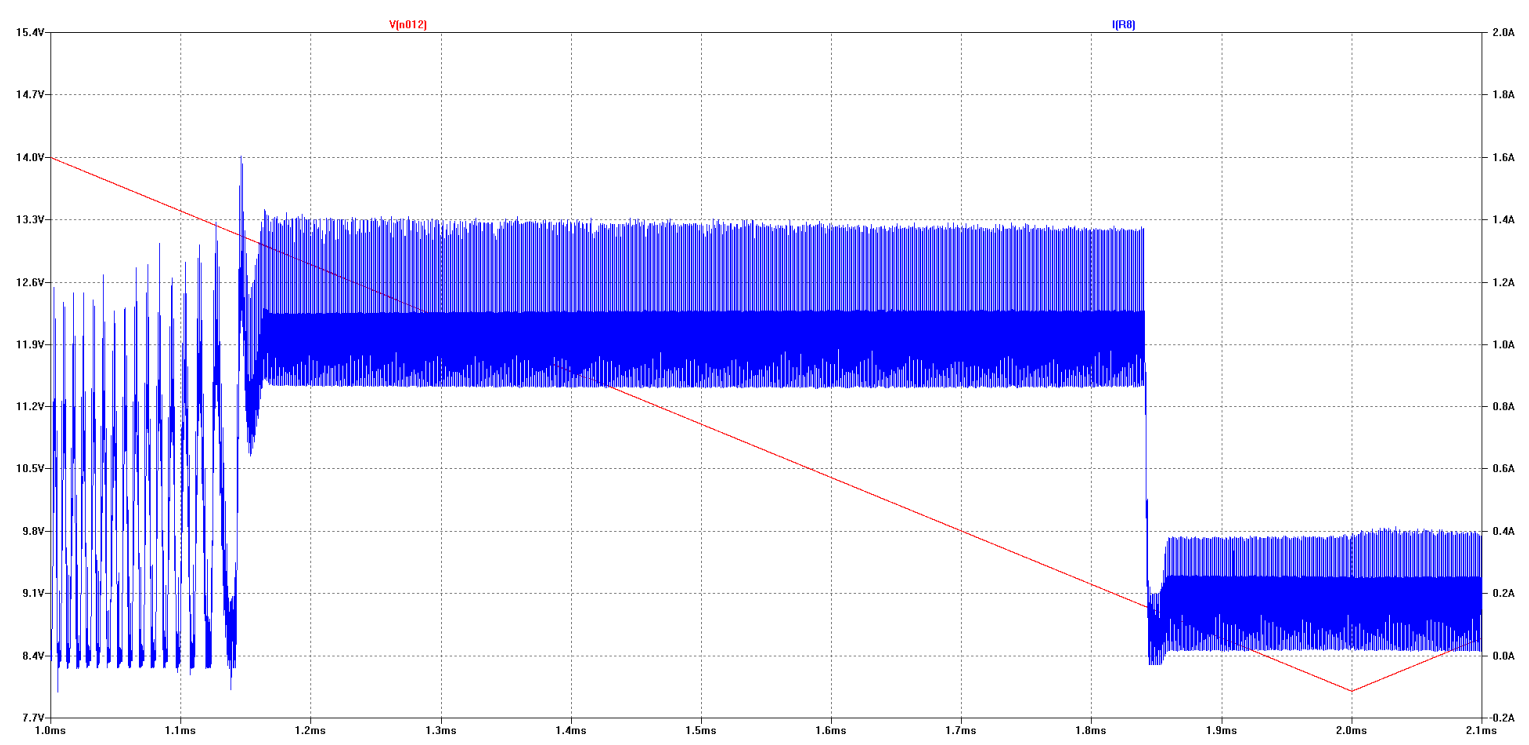

(b) Stage 2: waveforms measured between interval of 1 and $2 \mathrm{~ms}-$ voltage linearly decreasing from 14 to $8 \mathrm{~V}$ 


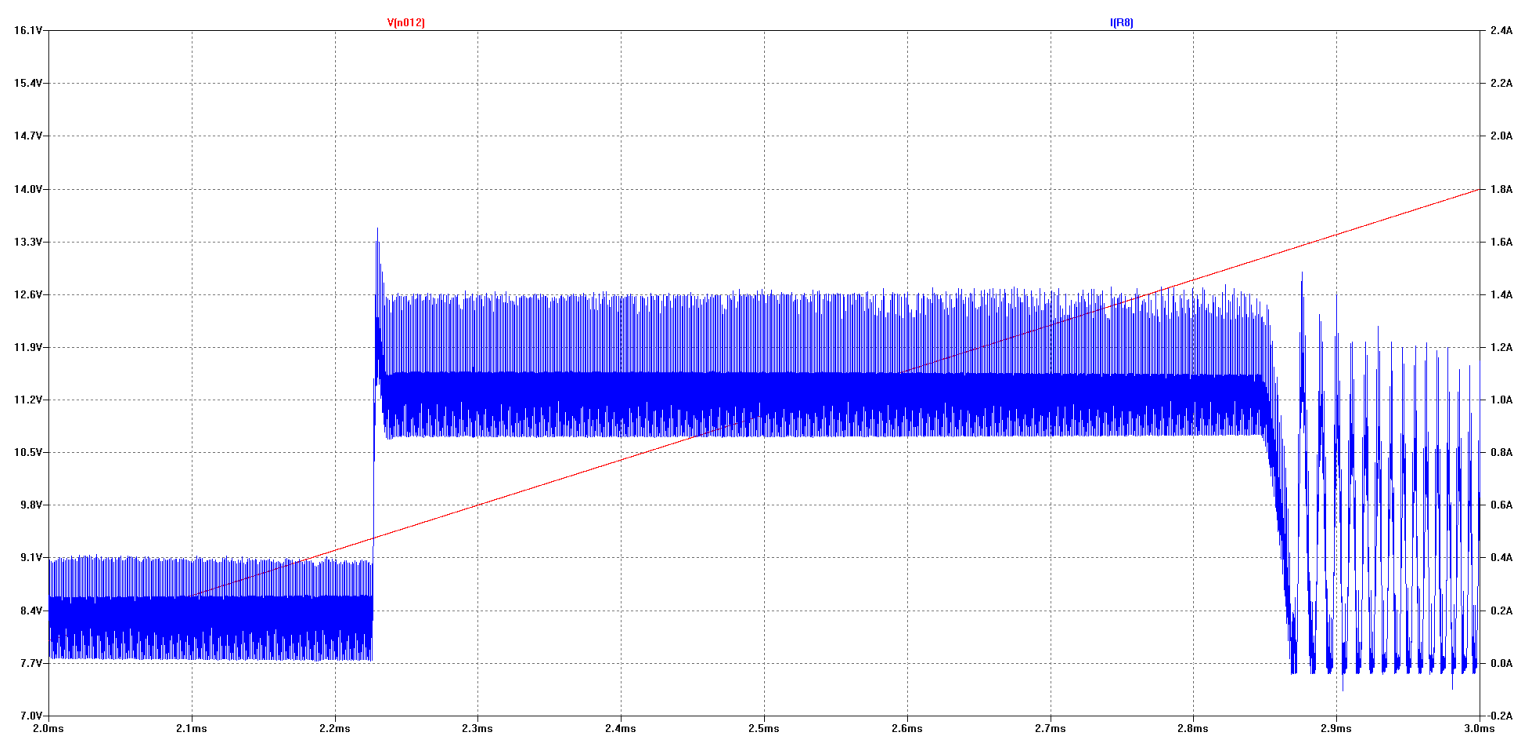

(c) Stage 3: waveforms measured between interval of 2 and $3 \mathrm{~ms}-$ voltage linearly increasing from 8 to $14 \mathrm{~V}$

Figure 6-12: Current waveforms for ramping voltages between 0 and $3 \mathrm{~ms}$

When connected to the varying battery source, the charge controller is designed to switch to a $12.7 \mathrm{~V}$ floating charge mode when the charge current falls below $0.1 \mathrm{~A}$, re-initiates to $13.0 \mathrm{~V}$ fast charge mode if the battery voltage falls below $11.2 \mathrm{~V}$, and trickle charges at $0.15 \mathrm{~A}$ if the battery voltage falls below 9.6 V. These specifications will be often referred to for the description of each image in Figure 6-12.

Part (a) shows the current waveform during the $0-1 \mathrm{~ms}$ period when the voltage is linearly increasing from $10.0 \mathrm{~V}$ to $14 \mathrm{~V}$. As the voltage increases from $10.0 \mathrm{~V}$ to $11.2 \mathrm{~V}$, the current remains approximately constant around $0.15 \mathrm{~A}$. However as the voltage exceeds $11.2 \mathrm{~V}$, the controller switches to a $13.0 \mathrm{~V}$ fast charge mode and increases the current to a maximum $(1.0 \mathrm{~A})$ in order to maintain the battery at full capacity. When the voltage reaches $13.0 \mathrm{~V}$, the controller initiates its floating charge mode, slowly providing a charge current to keep the battery at its state of charge. 
Part (b) illustrates the current waveform during the $1-2$ ms period when the voltage is linearly decreasing from $14 \mathrm{~V}$ to $8 \mathrm{~V}$. As the voltage decreases from $14 \mathrm{~V}$ to approximately $13.0 \mathrm{~V}$, the current increases from its floating charge to $1.0 \mathrm{~A}$ to represent the fast charging mode since the voltage has fallen below the designed threshold. As the voltage drops below about $9.2 \mathrm{~V}$, the current is reduced to $0.15 \mathrm{~A}$ as the controller is trickle charging.

Part (c) depicts the current waveform during the $2-3 \mathrm{~ms}$ interval when the voltage is again linearly increasing from $8 \mathrm{~V}$ back to $14 \mathrm{~V}$. As the voltage increases past $9.2 \mathrm{~V}$, the controller exits its trickling mode and the charger current is then increased to its fast charging rate-supplying the maximum charge current of $1.0 \mathrm{~A}$ to the battery. Lastly, as the voltage again reaches 13.0 $\mathrm{V}$, the current is essentially returned back to a floating charge rate.

\section{6-Experimental Testing of LT3652}

After the simulations were run for the charge controller, parts were ordered for the battery charger and constructed based on the schematic shown in Figure 6-3 with the calculated input and feedback resistances determined in the previous section. In order to minimize costs, all parts were ordered as through-hole and will be mounted onto a protoboard. In addition, since a through-hole technique will be used for construction of the battery charger, a separate adapter must be included in order to match the LT3652 IC package selection with a compatible DIP pin-out. After placing all the components together, the final product is shown in Figure 6-13 (a) and (b). 


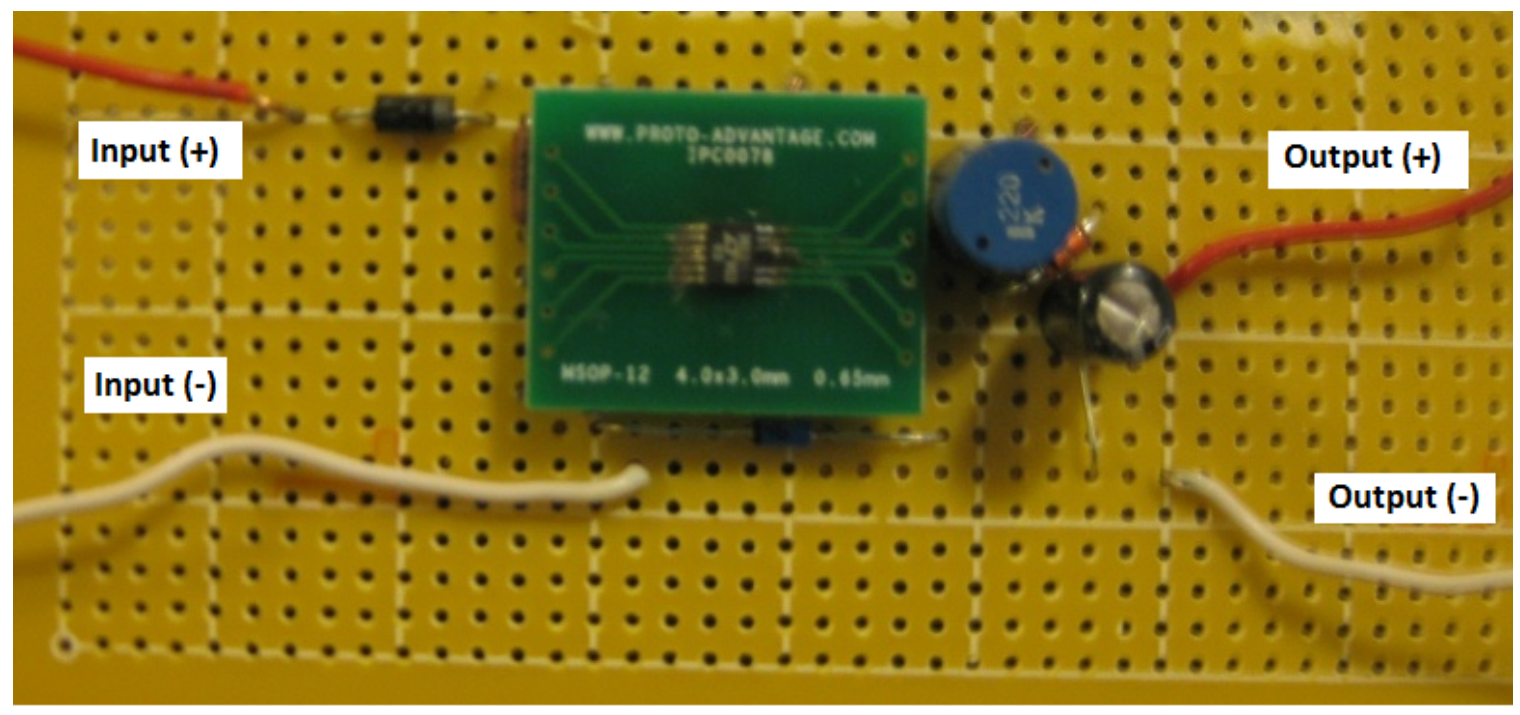

(a) Top-view of charge controller

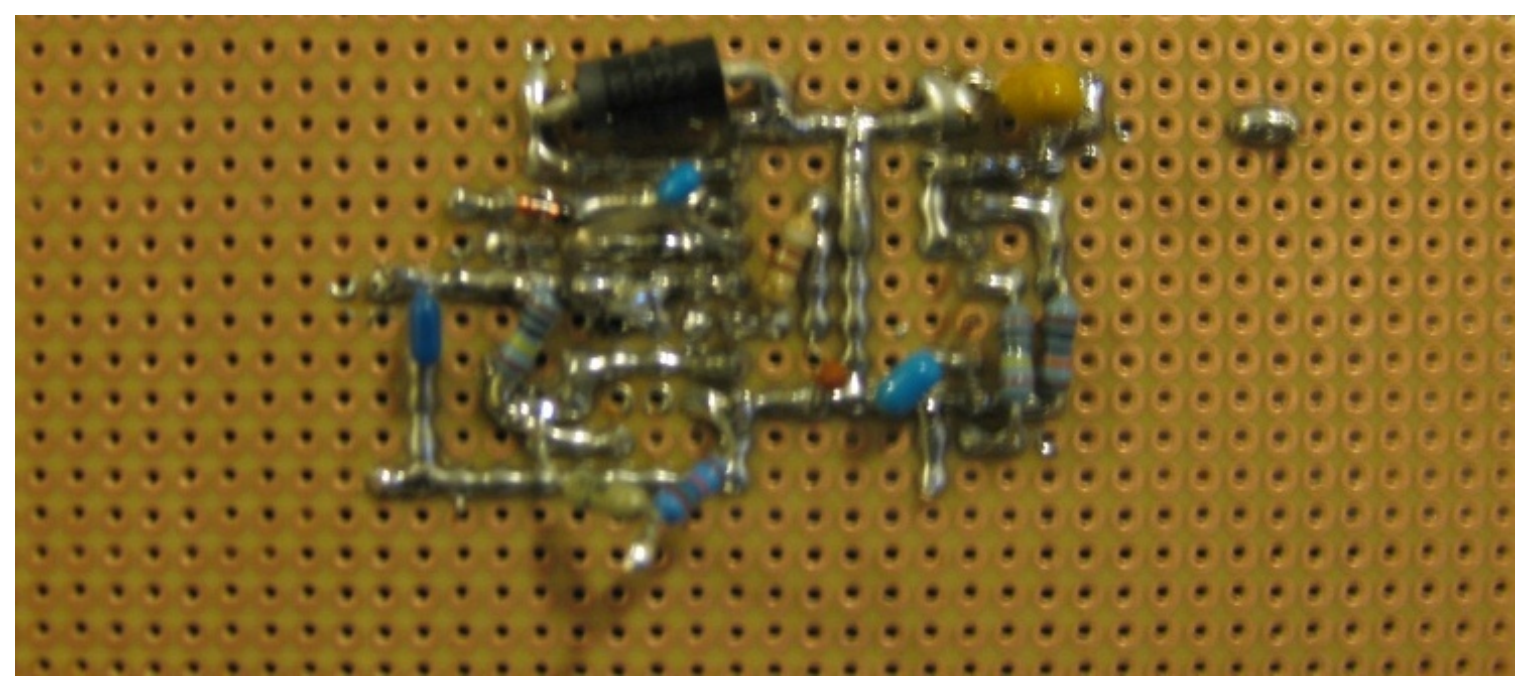

(b) Bottom-view of charge controller

Figure 6-13: Constructed through-hole LT3652 solar battery charger 


\subsection{1-Testing Different Modes of Operation for the Charge Controller}

Similar to how the simulation was operated, discrete voltage levels will be used in order to determine the threshold voltages for the different modes of operation of the charge controller. In addition, without using a solar panel as an input to the charge controller, a voltage source will be tied directly to the input pin of the IC to replicate the theoretical peak-power voltage for a $40 \mathrm{~W}$ solar panel.

\subsection{2-Problems Encountered with Charge Controller}

When connected to a $12 \mathrm{~V}$ lead-acid battery, the charge controller did not operate as expected. The reasons for the differences could be caused by the switching fluctuations seen by the sensing resistor. Through implementation, the sensing resistor was connected as closely as possible to the sense pin. The switching noise, as measured by the oscilloscope, showed that the voltage across the sensing pin never reached the expected value of $100 \mathrm{mV}$ (representing a maximum 1.0 A charge current). Using an available 75 amp-hour $12 \mathrm{~V}$ lead-acid battery at approximately $80 \%$ charge, the charger is expected to provide a 1.0 A charge current and trickle charge at approximately $13.0 \mathrm{~V}$.

During testing, the initial voltage from the battery terminal was measured as $12.45 \mathrm{~V}$. At this voltage, the charger should immediately sense that the battery must be quickly charged in order to reach its full capacity as seen through the simulations. However, this result was not observed. Instead, the battery began to trickle charge at approximate $0.15 \mathrm{~A}$ without any variations in charge current for an hour of charge. The results of the battery charging are shown in Figure 6-14 and 6-15. 


\section{Demonstration of Battery Charging Over Time}

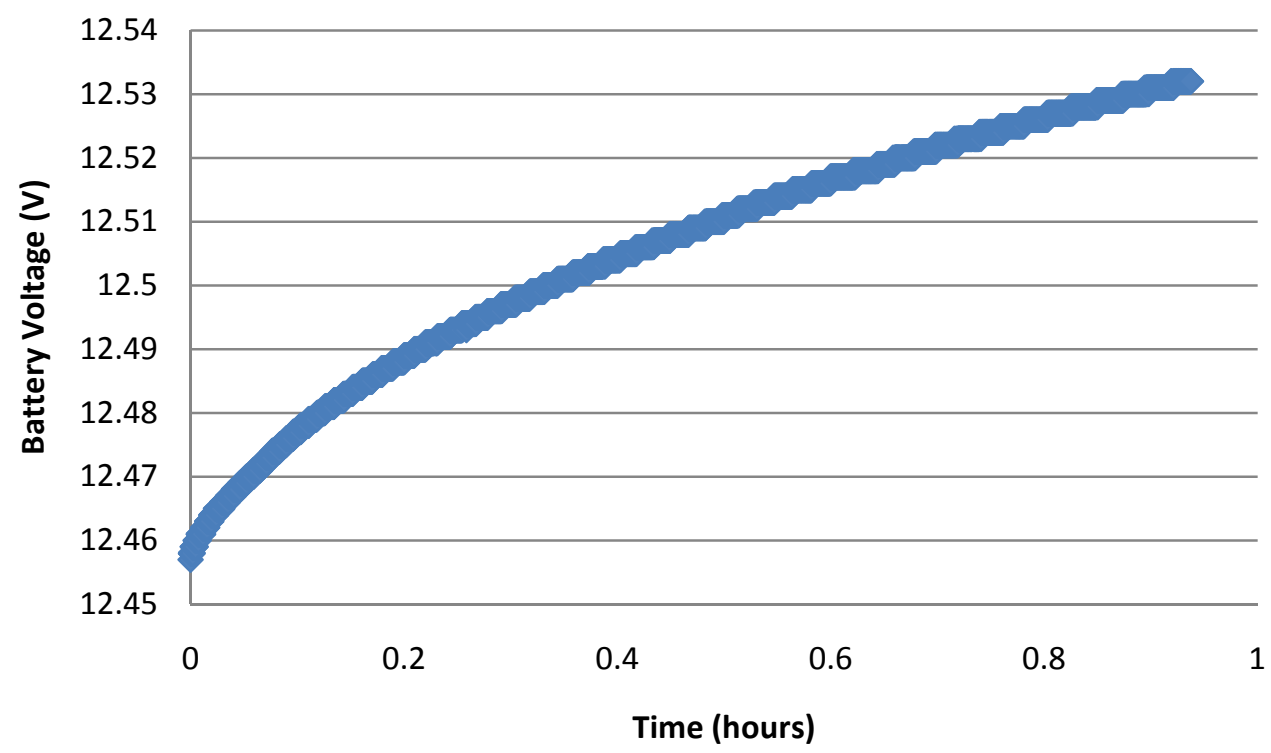

Figure 6-14: Battery voltage variation of time using designed charger

\section{Solar Battery Charger Charging Current Over Time}

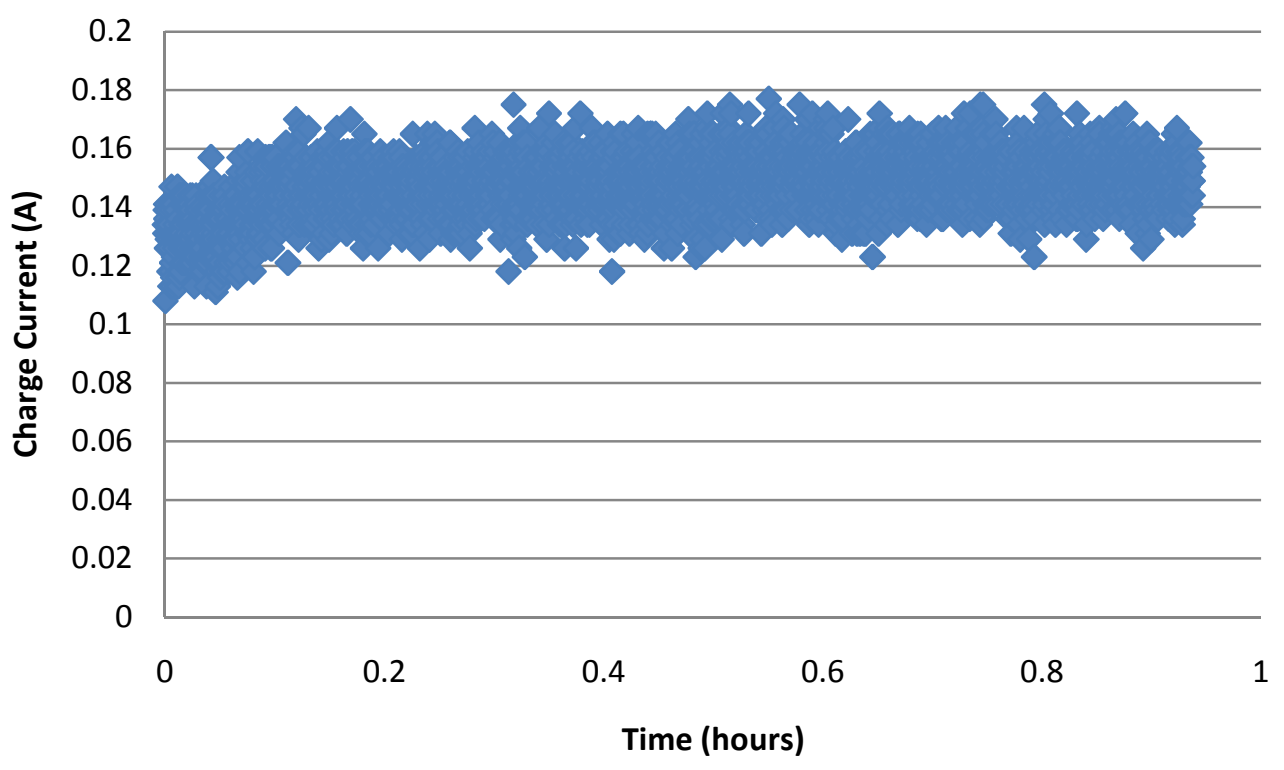

Figure 6-15: Battery charge current over time using designed charger 
As seen over the extended period of time, the charge current does not increase to the $1.0 \mathrm{~A}$ simulated value. Thus, the controller went through some trouble-shooting to determine the source of the problem; however, before any conclusions could be developed, the charge controller adapter and integrated circuit were damaged beyond repair. Due to the shipping time associated when ordering parts, the charge controller could not be obtained in time for completion. Therefore, testing on the charger has momentarily stopped and will be included as a future work project as described in Chapter 8.

\section{7-DC-DC Converter for 20 V Output}

As determined in Chapter 4, the optimal voltage to achieve $96 \%$ power efficiency was found to be $20 \mathrm{~V}$. After determining how the battery will be charged, the next sequence of events is to determine how the voltage from the battery can be increased from its nominal $12 \mathrm{~V}$ to $20 \mathrm{~V}$. From power electronics, the basic circuit used to step the voltage to a higher value is called a boost converter. Categorized as a special form of a DC/DC converter, the boost circuitry as shown in Figure 6-16 uses an inductor, MOSFET, and a diode to produce a set output voltage based on the switching rate (also referred to as the time-on or duty cycle) of the MOSFET. 

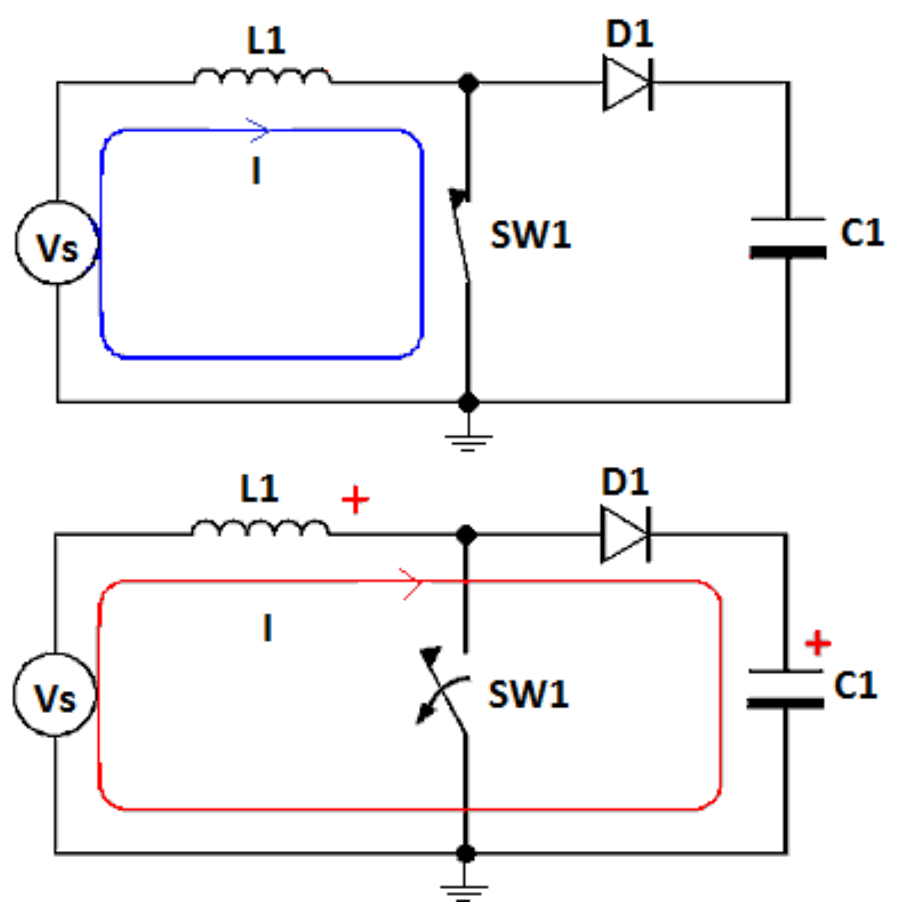

Figure 6-16: Basic boost converter circuit layout and general operation

A brief introduction for a basic boost converter will establish the background before selecting an IC that will be used to step-up the battery's voltage to a regulated $20 \mathrm{~V}$ for the luminaire. Without going into the specifics for the boost converter, the general derivation for the output voltage comes from the duration of time that the switch is closed as shown in the top image of Figure 6-16. In this position the source is connected only through the inductor and as a storage component, the inductor becomes energized for a certain amount of time- denoted by the duty cycle of the converter. When the switch opens as shown in the bottom image of Figure 6-16, the energy stored within the inductor charges the capacitor by passing through the diode. Thus the energy initially stored by the inductor when the switch was in the "ON" position is now stored in the capacitor, which also represents the output of the converter. 
Analyzing and equating the current and voltage representations for the capacitor and inductor during the "ON" and "OFF" stages of the switch, equation (6.12) generalizes the step-up effect of the boost converter during continuous conduction mode (CCM):

$$
\frac{V_{\text {out }}}{V_{S}}=\frac{1}{1-D}
$$

In order to achieve the necessary regulated $20 \mathrm{~V}$ output voltage, the LT3757 controller has been selected to perform the necessary step-up operation while providing high power efficiencies. The following sections will thoroughly describe the design, simulation, and testing for the boost converters that will be implemented as an intermittent stage between the battery and luminaire as shown from the flow chart in Figure 6-1.

\section{8_LT3757 Boost Controller Description and General Schematic}

The main concern when choosing a controller is the variability in the input voltages. Since a boost converter will be used for the system integration, the controller must be able to accept the voltage variations from the lead-acid battery caused by the different levels of battery stage of charge. Linear Technology's LT3757 is suitable for numerous applications that require a boost, flyback, SEPIC, or inverting DC/DC converter with either positive or negative output voltages. In addition, the LT3757 controller has a wide input range that spans from $2.9 \mathrm{~V}$ to $40 \mathrm{~V}$, which easily fulfills the voltage variability from the battery. 
With the detailed understanding of each pin's purpose, the LT3757 datasheet also contains a schematic for one of the typical application for using the IC. Figure 6-17 shows the modified boost converter that accepts input voltages ranging from $11 \mathrm{~V}$ to $14 \mathrm{~V}$ and outputs a regulated $20 \mathrm{~V}$ at a rated $2 \mathrm{~A}$.

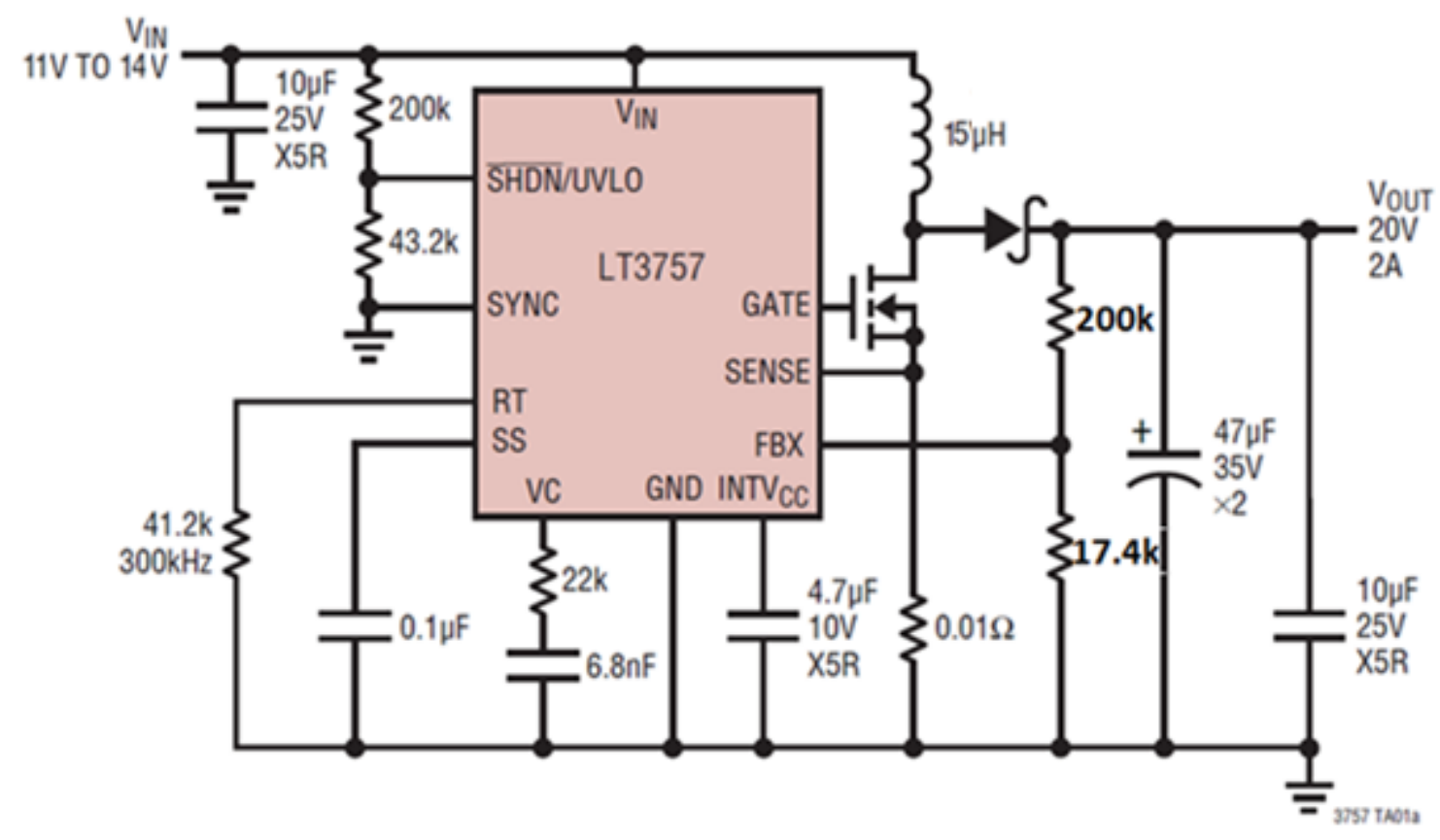

Figure 6-17: LT3757 boost converter application with $24 \mathrm{~V}$ output at rated 2 A [26]

With the basic idea of the circuit schematic for the boost converter in Figure $6-17$, the feedback loop can be modified in order to scale the output voltage to $20 \mathrm{~V}$. Additionally, when parts are used for the actual design, the luminaire will require a larger output current; thus, the components such as the diode and inductor should be selected based on their tolerance for higher currents. 


\section{9-LT3757 Converter Design and Simulation Results}

The boost converter for the luminaire application does not require a great deal of modifications from the schematic in Figure 6-17. As determined in Chapter 4 , the desired output voltage for powering the luminaire is $20 \mathrm{~V}$. Thus, in order to obtain a regulated $20 \mathrm{~V}$ output, the feedback resistances must be modified based on the feedback pin's positive output mode of operation. Briefly mentioned in the feedback pin description, the pin voltage is referenced from a voltage value of $1.6 \mathrm{~V}$. Thus, using a voltage divider at the feedback pin for a $20 \mathrm{~V}$ output voltage and an arbitrary resistance value for R1 (resistor connected to output voltage) of $200 \mathrm{k} \Omega$ for simplicity, equation (6.13) shows the general sizing formula for selected resistor values [30].

$$
V_{\text {OUT }}=1.6 V *\left(1+\frac{R 2}{R 1}\right)
$$

Based on the equation above, with a selected resistance value of $200 \mathrm{k} \Omega$ for $\mathrm{R} 1, \mathrm{R} 2$ is determined as $17.391 \mathrm{k} \Omega$. Thus, the two resistor values for $\mathrm{R} 1$ and $\mathrm{R} 2$ in the feedback loop design are selected as $17.4 \mathrm{k} \Omega$ and $200 \mathrm{k} \Omega$, respectively. 
In addition, the inductor size must be selected to avoid having the converter operate in discontinuous conduction mode (DCM). When the converter operates in DCM, the inductor.is used inefficiently and requires higher power components to ensure the larger peak inductor currents will not damage output components. Thus, to determine the minimum inductance required for the converter, an initial calculation for the maximum duty cycle (denotes when the converter has the minimum input voltage) is shown in equation (6.14).

$$
D_{\text {max }}=\frac{V_{\text {out }}-V_{\text {in }}(\min )}{V_{\text {out }}}=\frac{20-11}{20}=0.45
$$

From the determined maximum duty cycle, the ripple current can be calculated by equation (6.15), where $x$ denotes the percentage of peak-to-peak ripple current from the inductor with respect to the maximum output current. $\mathrm{X}$ is recommended to fall within the range of 0.2 to 0.6 ; however, larger $\Delta \mathrm{IL}$ result in fast transient responses and allows the use of lower inductances, but results in higher input current ripple and greater core loss. For the design, $a x$ of 0.4 has been selected.

$$
\Delta I_{L}=\chi * I_{o(\max )} * \frac{1}{1-D_{\max }}=0.4(2)\left(\frac{1}{0.55}\right)=1.4545
$$

From the ripple current and minimum input voltage, the minimum inductor size $\left(\mathrm{L}_{\text {crit }}\right)$ can be calculated based on the minimum peak current through the inductor as shown in equation (6.16).

$$
L_{\text {crit }}=\frac{V_{I N(\min )}}{\Delta I_{L^{* f}}} * D_{\text {max }}=\frac{11}{1.4545 * 300,000} * 0.45=11.3438 \mu \mathrm{H}
$$


Thus, from the critical inductance determined from equation (6.16), the inductance value selected as $15 \mu \mathrm{H}$ to ensure that the boost converter will operate in $\mathrm{CCM}$ at minimum load ( $0.35 \mathrm{~A}$ for one section of the luminaire).

After establishing the component changes for the schematic of Figure 617, LTSpice will again be used to simulate the circuit with the modifications. The layout and results are shown and described in the following subsections.

\subsection{1-Boost Converter LTSpice Schematic}

The implementation of the LT3757 on LTSpice is relatively straightforward. As calculated previously, the feedback resistance values have been modified and two Schottky diodes will be used in place of the single Schottky (Figure 6-17) to relieve the current strain on the diodes. In addition, since LTSpice is only used as a simulation tool to demonstrate the proof of concept for the boost converter, the parts associated with the output must be able to withstand the current stresses depending on the amount of current required by the luminaire. For this reason, an attached load on the output of the converter will represent the luminaire drawing $4 \mathrm{~A}$ (3.6 A was rounded up for device protection) when all sections of the luminaire are operating. Figure 6-18 shows the screen-capture of the schematic implemented on LTSpice. 


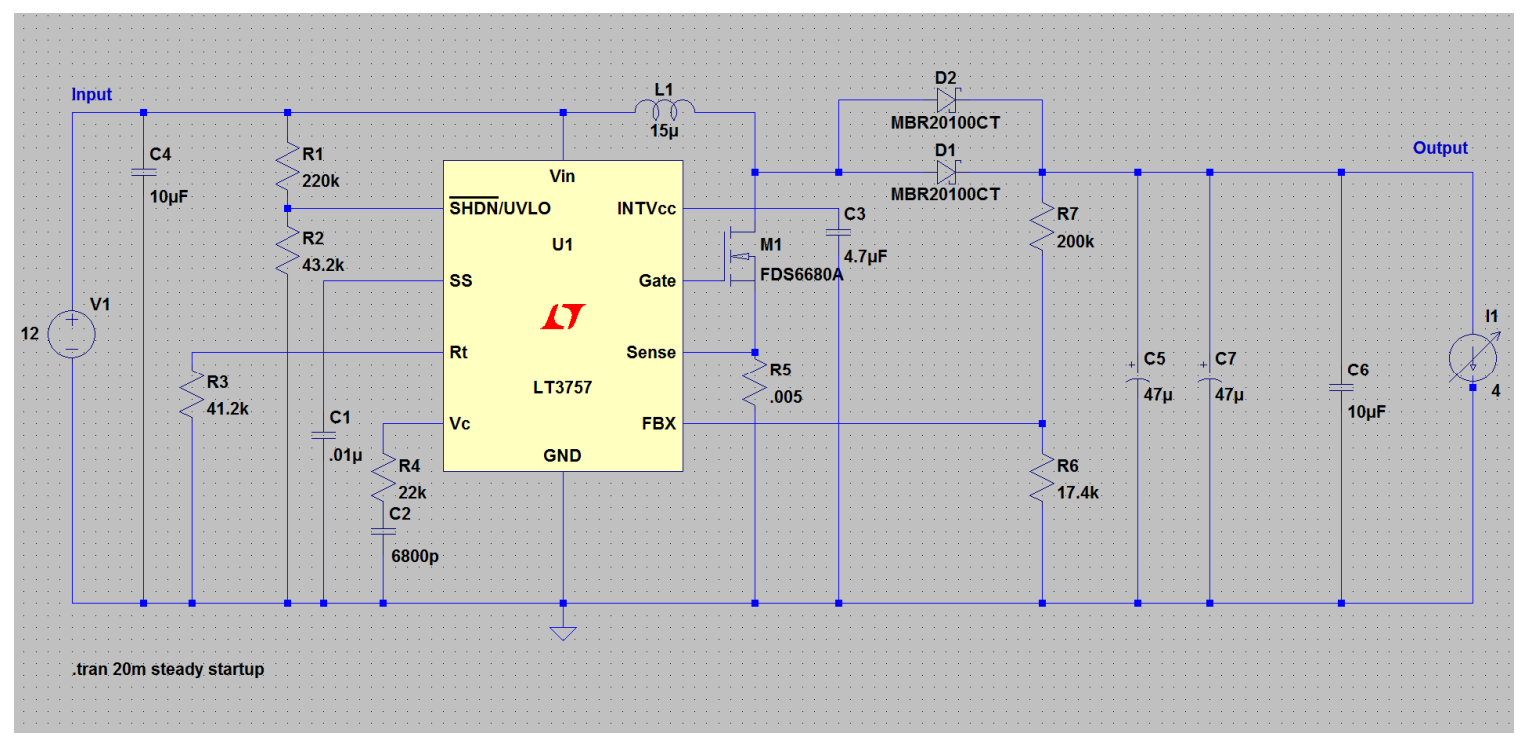

Figure 6-18: LTSpice circuit schematic for simulating the LT3757 controller

\subsection{2-Boost Converter LTSpice Simulation Results}

After confirming that no errors are present in the boost converter schematic, the circuit was simulated for until steady state has been reached. Figure 6-19 depicts the initialization of the controller before steady state has been reached.

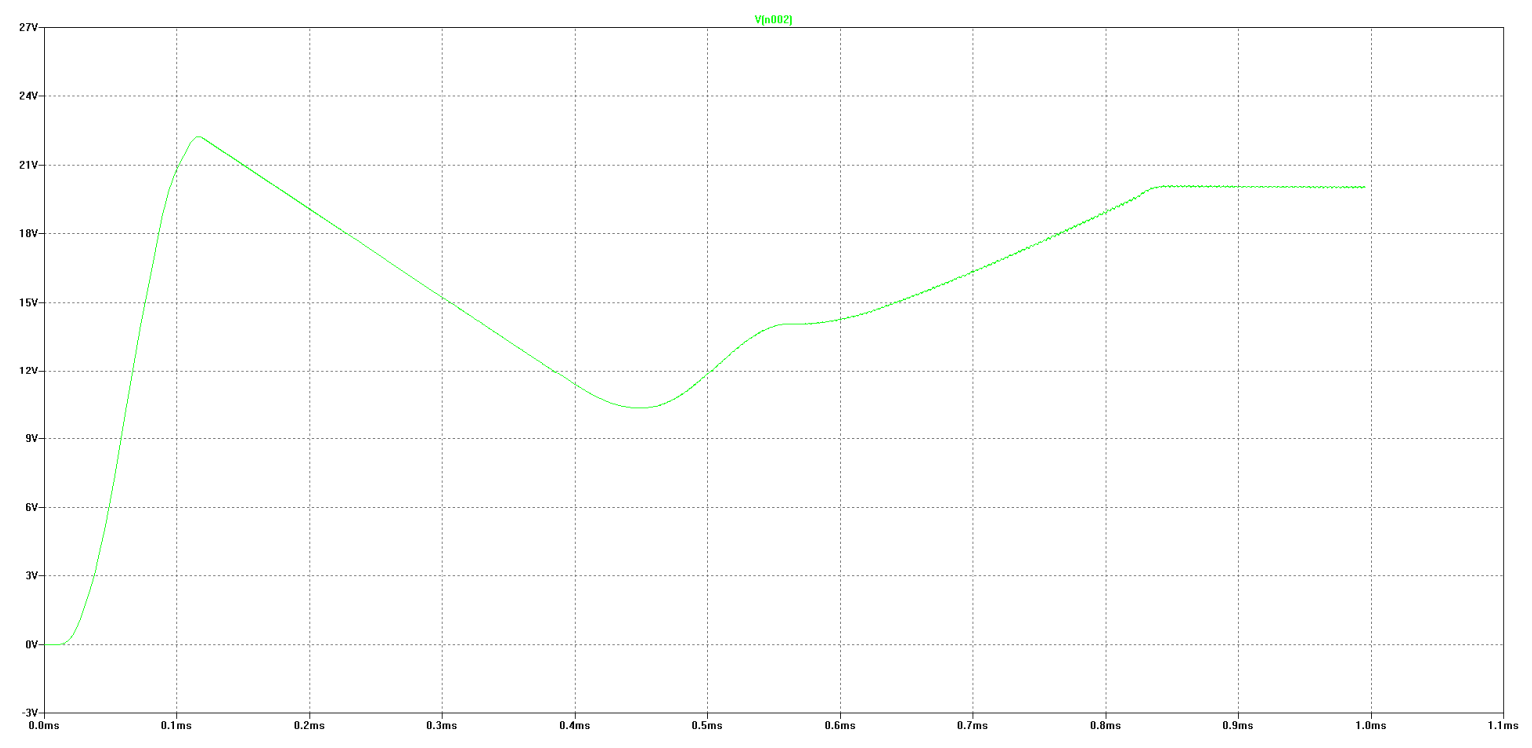

Figure 6-19: Initialization of LT3757 boost converter modeled by LTSpice 
From the initial startup of the controller, the converter starts to achieve steady state after approximately $1.1 \mathrm{~ms}$ as illustrated by the green line. Shortly after $1.1 \mathrm{~ms}$, a slight output voltage ripple can be seen as the controller begins to oscillate and stabilize around $20 \mathrm{~V}$ as shown in Figure 6-20.

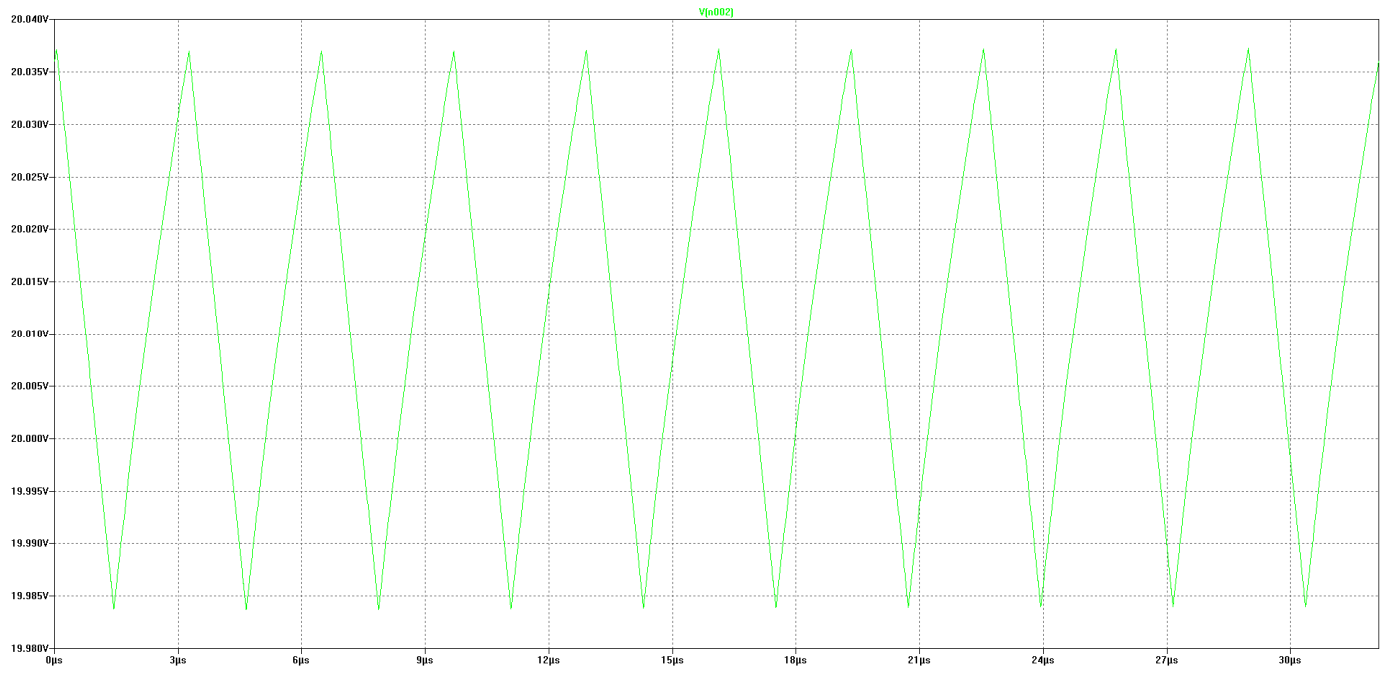

Figure 6-20: Steady state voltage of LT3757 boost converter modeled through LTSpice Within power electronics, voltage rippling effects can ultimately damage systems if their magnitudes are large enough. As seen from the voltage waveform in Figure 6-20, the output voltage waveform demonstrates only slight voltage ripples around the desired $20 \mathrm{~V}$ output voltage. This slight voltage ripple is reassuring from a design point-of-view since the slight fluctuation will not drastically provide a large overvoltage that could damage the luminaire. For comparison with the determined experimental output ripple, the simulated output ripple is calculated through equation (6.17) as follows [26]:

$$
\begin{aligned}
\% V_{\text {OUT RIPPLE }} & =\frac{V_{\text {OUT-MAX }}-V_{\text {OUT-MIN }}}{V_{\text {OUT }- \text { NOMINAL }}} * 100 \% \\
& =\frac{20.037-19.9839}{20} * 100 \% \\
& =0.2655 \%
\end{aligned}
$$


The amount of variability in the simulated output voltage was determined to be $0.2655 \%$; this value elaborates on the fact that the boost converter regulates the $20 \mathrm{~V}$ output voltage effectively and additional output capacitors for smoothing effects will not be necessary.

The next simulation test will verify that the converter operates in CCM even at minimum loads. During the previous simulations, the converter was tested at full-load (4 $\mathrm{A}$ or the equivalent of all sections of the luminaire turning on), which guarantees the inductor current will not fall below $0 \mathrm{~A}$ due to the high output current. However, when one section of the luminaire turns on (minimum load), the inductor current must not fall below $0 \mathrm{~A}$ in order to maintain CCM. To demonstrate that the converter is still operating in CCM, the output load is set to draw $0.35 \mathrm{~A}$ and the output waveform is shown in Figure 6-21.

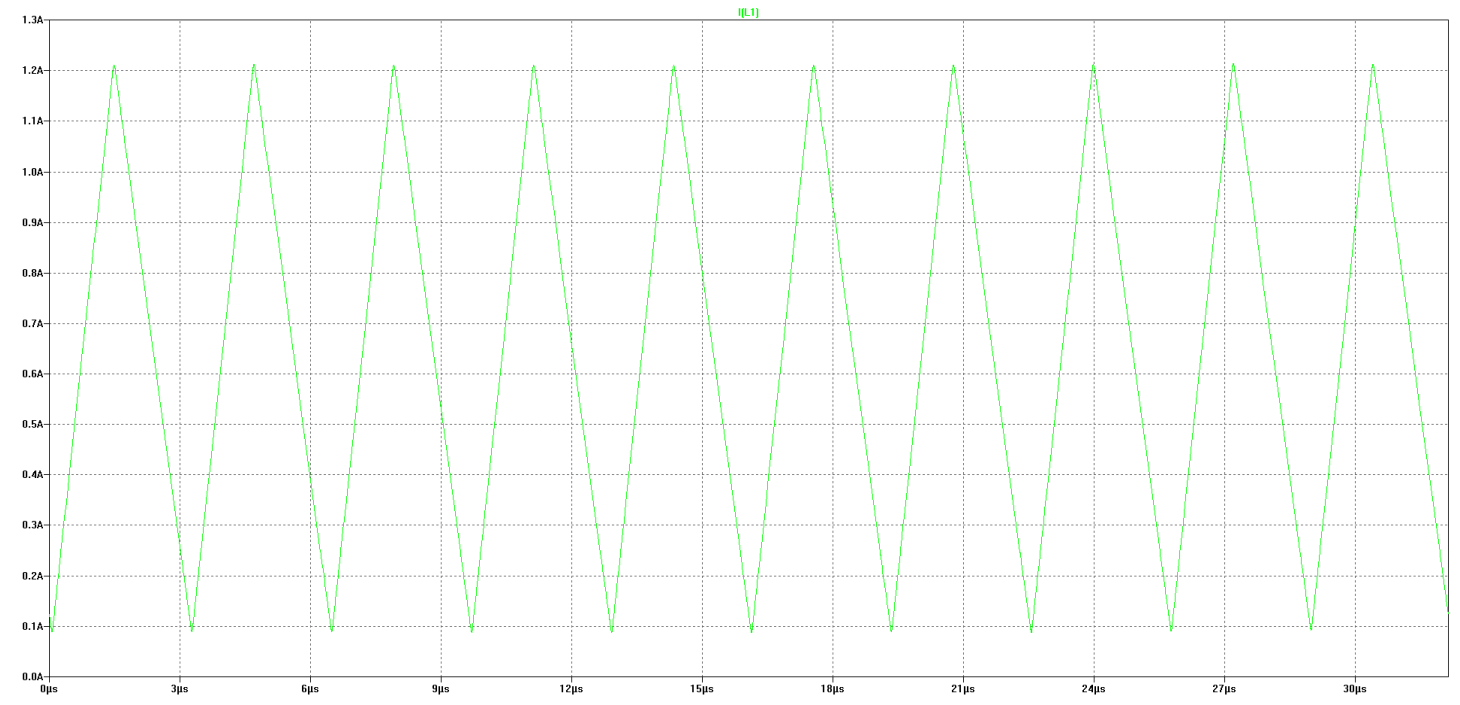

Figure 6-21: Inductor current for boost converter at minimum load (0.35 A)

As seen in Figure 6-21, the minimum output current from the inductor is greater than $0 \mathrm{~A}$, which denotes $\mathrm{CCM}$ operation at even minimal load. 


\subsection{0-Experimental Testing of LT3757}

After verifying the operation of the LT3757, parts were ordered for the converter and constructed based on the drawn LTSpice schematic shown in Figure 6-16. Similarly to the charge controller, all parts were ordered as throughhole and will be mounted onto a protoboard to minimize costs. Also, since a through-hole technique will be used for construction of the boost converter, a separate adapter must be included in order to match the LT3757 IC package selection with a compatible DIP pin-out. After purchasing the components, the circuit was constructed as shown in Figure 6-21.

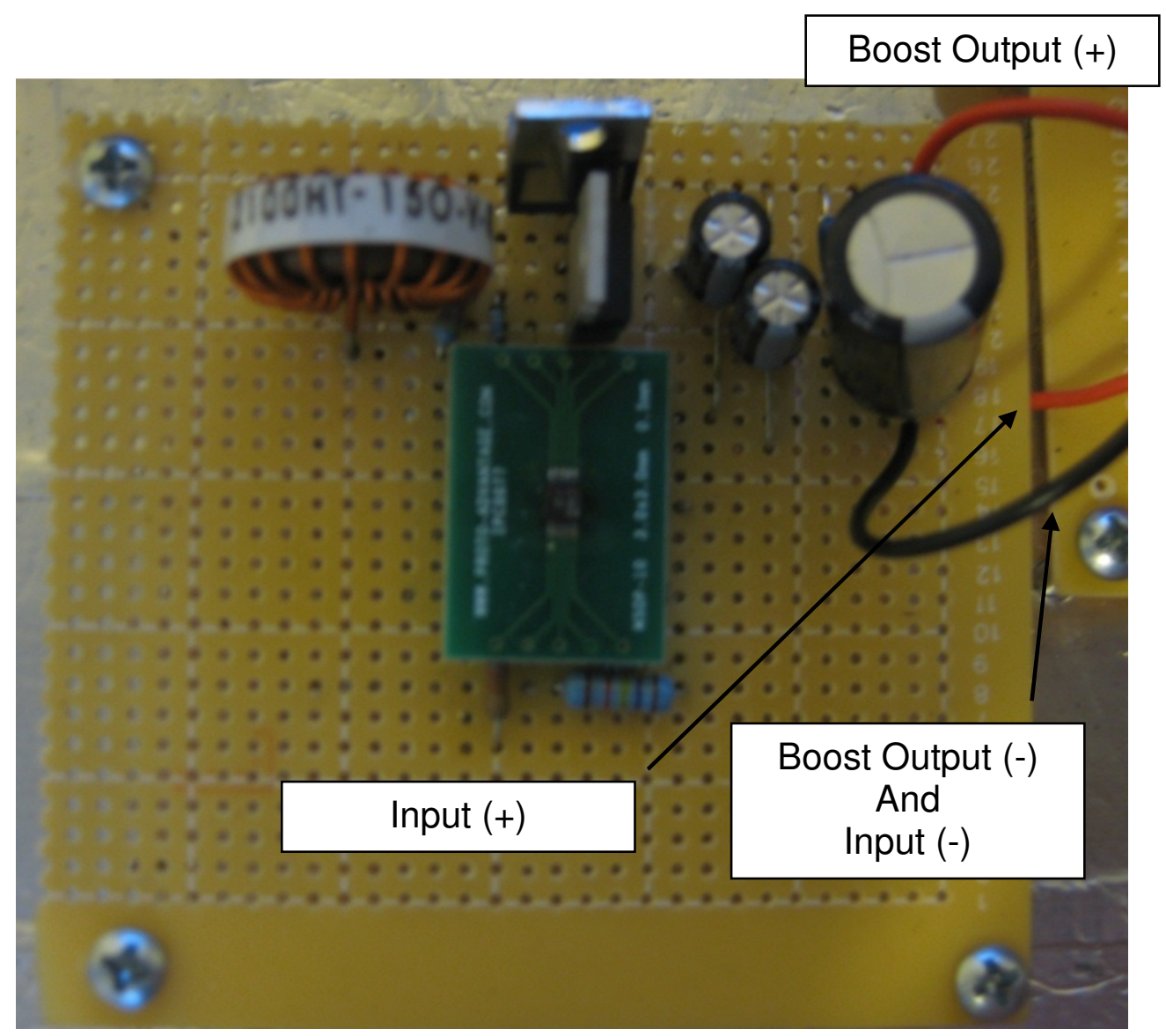

Figure 6-22: Constructed through-hole LT3757 boost converter 2 


\subsection{1-Problems Encountered with Boost Converter Design}

During the implementation of the boost converter, several problems were encountered that required additional modifications to achieve more desirable results. These problems were unavoidable due to the nature of the circuit layout. Since a protoboard was used to construct the circuit, solder leads and the unavailability of a ground plane introduced additional resistance and switching noise that inadvertently affects the MOSFET, which consequently affects the voltage sensing pin.

The first necessary alteration was to modify how the voltage was being sensed at the SENSE pin. According to the LT3757 datasheet, the pin has a maximum voltage tolerance of $120 \mathrm{mV}$; thus if the experimental value were to exceed this value, the controller would no longer be regulating at the proper $20 \mathrm{~V}$ output. To limit the voltage sensed at this pin, the sensing resistor was reduced to half of its design value (from $0.01 \Omega$ to $0.005 \Omega$ ). In addition, since the controller is operating at $300 \mathrm{kHz}$, the rate at which the MOSFET turns on and off is subject to voltage fluctuations from the controller. Therefore a low-pass filter was added in conjunction with the current sensing resistor and source of the MOSFET to limit the amount of noise present in the system.

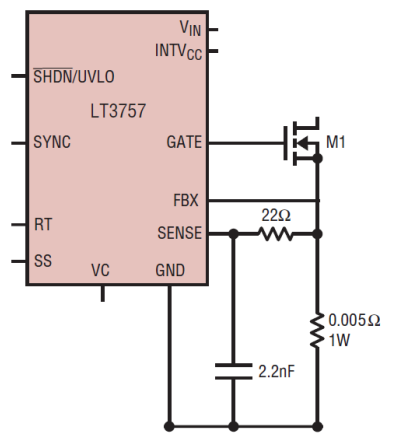

Figure 6-23: Low-pass filter for boost converter to reduce high frequency noise [26] 
The low-pass filter was implemented with a resistor and capacitor combination as shown in Figure 6-22. As seen by the filter, the input voltage is essentially the node connecting the drain of the MOSFET, $22 \Omega$ resistor, and current sensing resistor; and the output is the node connecting to the SENSE pin. The two passive components were chosen based on a frequency that is at least twice the frequency of the controller $(300 \mathrm{kHz})$; the selected values are based off filter design values for other applications that use the LT3757. Thus, the calculation for the cutoff frequency of the low-pass filter can be shown in equation (6.18).

$$
f_{c}=\frac{1}{2 \pi R C}=\frac{1}{2 \pi(22)\left(2.2 * 10^{-9}\right)}=3.2883 \mathrm{MHz}
$$

The cutoff frequency designed is $3.2883 \mathrm{MHz}$; therefore, any frequency beyond this value will be filtered out-eliminating high switching noises that could affect the SENSE pin voltage.

Prior to implementing the low-pass filter, the maximum load that the system could handle - without dramatic variation on the output voltage-was approximately 1.0 A; however, after implementing the low-pass filter, the maximum load that the controller can tolerate increased to roughly $2.5 \mathrm{~A}$. Although this value is less than the desired output load of $3.6 \mathrm{~A}$ at $20 \mathrm{~V}$ (equating to $72 \mathrm{~W}$ to power the luminaire), the voltage modification stage of the system design can be altered to include two boost converters, each of which will control half the luminaire and provide a theoretical $1.8 \mathrm{~A}$ at $20 \mathrm{~V}$. 
The use of two boost converters instead of one has its own advantages and disadvantages. One advantage is that if one converter were to malfunction, only one side of the luminaire will be affected; thus, this creates a partially isolated system. Also in terms of power efficiencies, when operating at larger loads, the boost converter's efficiency decreases due to the additional power dissipated as heat through the switching components. On the other hand, the disadvantages associated with having two boost converters are the voltage variations between converters and the cost of implementing the second converter. However, properly implementing the boost converters will only cause slight voltage variations when measured. Furthermore, these voltage differences would cause an unsubstantial current difference that one would not be able to see through the LEDs with a naked eye. The configuration of the boost converters in conjunction with selected sections will be discussed in the last chapter as a precedent for future work.

Within the following subsection a few tests will be conducted to quantify the quality of the boost converter and experimentally shows how insignificant the disparities are between both boost converters. These tests will include load regulation, line regulation, output voltage ripple, and power efficiency. 


\subsection{2-Line Regulation}

The first experimental test conducted deals with the line regulation of the boost converter. Line regulation refers to the ability of the converter to maintain the designed output voltage at full-load even when the input voltage fluctuates. By calculating line regulation, approximations can be made to see how much change is expected when the input of the system is unknown.

The starting point for this experimental test deals with the expected fluctuations in input voltages. As mentioned before, the input to the boost convert is supplied by a $12 \mathrm{~V}$ lead-acid battery, whose voltage can range anywhere from approximately $11 \mathrm{~V}$ to $13.5 \mathrm{~V}$. Thus, the boost converter should be able to at least manage input voltage fluctuations within the various levels of battery capacity. As a safety factor, line regulation was measured from $11 \mathrm{~V}$ to 14.5 $\mathrm{V}$ to include the entirety of the possible battery voltages. The measured input and output parameters for the boost as well as the calculated power and efficiencies for varying input voltages at full-load (2 A) are shown in Table 6-2. 
Table 6-2: Measured line regulation data for boost converters

\begin{tabular}{|c|c|c|c|c|c|c|c|c|}
\hline $\begin{array}{c}\text { Boost } \\
\text { Converter }\end{array}$ & $\begin{array}{c}\text { Input } \\
\text { Voltage } \\
\text { (V) }\end{array}$ & $\begin{array}{l}\text { Input } \\
\text { Current } \\
\text { (A) }\end{array}$ & $\begin{array}{l}\text { Output } \\
\text { Voltage } \\
\text { (V) }\end{array}$ & $\begin{array}{l}\text { Output } \\
\text { Current } \\
\text { (A) }\end{array}$ & $\begin{array}{c}\text { Input Power } \\
\text { (W) }\end{array}$ & $\begin{array}{l}\text { Output Power } \\
\text { (W) }\end{array}$ & Efficiency & $\begin{array}{c}\text { Line } \\
\text { Regulaton }\end{array}$ \\
\hline \multirow{8}{*}{1} & 11 & 3.995 & 19.67 & 1.98 & 43.945 & 38.947 & $88.63 \%$ & \multirow{8}{*}{$0.20 \%$} \\
\hline & 11.5 & 3.79 & 19.68 & 1.98 & 43.585 & 38.966 & $89.40 \%$ & \\
\hline & 12 & 3.626 & 19.68 & 1.98 & 43.512 & 38.966 & $89.55 \%$ & \\
\hline & 12.5 & 3.47 & 19.69 & 1.98 & 43.375 & 38.986 & $89.88 \%$ & \\
\hline & 13 & 3.316 & 19.7 & 1.98 & 43.108 & 39.006 & $90.48 \%$ & \\
\hline & 13.5 & 3.177 & 19.7 & 1.98 & 42.890 & 39.006 & $90.95 \%$ & \\
\hline & 14 & 3.054 & 19.7 & 1.98 & 42.756 & 39.006 & $91.23 \%$ & \\
\hline & 14.5 & 2.933 & 19.71 & 1.98 & 42.529 & 39.026 & $91.76 \%$ & \\
\hline \multirow{8}{*}{2} & 11 & 4.017 & 19.61 & 1.98 & 44.187 & 38.828 & $87.87 \%$ & \multirow{8}{*}{$0.40 \%$} \\
\hline & 11.5 & 3.838 & 19.67 & 1.98 & 44.137 & 38.947 & $88.24 \%$ & \\
\hline & 12 & 3.656 & 19.67 & 1.98 & 43.872 & 38.947 & $88.77 \%$ & \\
\hline & 12.5 & 3.498 & 19.67 & 1.98 & 43.725 & 38.947 & $89.07 \%$ & \\
\hline & 13 & 3.318 & 19.68 & 1.98 & 43.134 & 38.966 & $90.34 \%$ & \\
\hline & 13.5 & 3.177 & 19.69 & 1.98 & 42.890 & 38.986 & $90.90 \%$ & \\
\hline & 14 & 3.064 & 19.69 & 1.98 & 42.896 & 38.986 & $90.89 \%$ & \\
\hline & 14.5 & 2.937 & 19.69 & 1.98 & 42.587 & 38.986 & $91.55 \%$ & \\
\hline
\end{tabular}

From the measured values shown in Table 6-2, the percentage of line regulation for each boost converter is calculated as shown in equation (6.19) [25]:

$$
\% \text { Line Regulation }=\frac{V_{\text {out (highest input })}-V_{\text {out }(\text { lowest input })}}{V_{\text {out }}(\text { nominal })} * 100 \%
$$

Summarized by the right-most column in Table 6-2, the line regulation is determined as $0.20 \%$ and $0.40 \%$ for boost converters 1 and 2 , respectively. Placing these values into perspective, over the wide range of input voltages that the $12 \mathrm{~V}$ battery could vary, the output voltage will only fluctuate at a maximum of $0.40 \%$ when sourcing $2 \mathrm{~A}$ to the load. 


\subsection{3-Load Regulation}

Similarly to line regulation, load regulation follows the same premise for how the percentage is determined. Load regulation refers to the converter's ability to maintain the output voltage even when the output power fluctuates due to the load being drawn. By determining the load regulation for the converter, approximations for how the converter will operate at different loads can be determined to maximize how much load should be drawn by the converter.

As a basis for the calculating load regulation, two assumptions are made - the nominal voltage for a battery (typically at full capacity) is $13 \mathrm{~V}$ and full-load is represented by an output current of $2 \mathrm{~A}$. From these assumptions, the measured values for determining load regulation are shown in Tables 6-3 and $6-4$.

Table 6-3: Measured load regulation parameters for boost converter 1

\begin{tabular}{|c|c|c|c|c|c|c|c|c|}
\hline Load & $\begin{array}{c}\text { Input } \\
\text { Voltage (V) }\end{array}$ & $\begin{array}{l}\text { Input } \\
\text { Current } \\
\text { (A) }\end{array}$ & $\begin{array}{l}\text { Output } \\
\text { Voltage } \\
\text { (V) }\end{array}$ & $\begin{array}{c}\text { Output } \\
\text { Current } \\
\text { (A) }\end{array}$ & $\begin{array}{c}\text { Input Power } \\
\text { (W) }\end{array}$ & $\begin{array}{c}\text { Output } \\
\text { Power (W) }\end{array}$ & Efficiency & $\begin{array}{c}\text { Load } \\
\text { Regulation }\end{array}$ \\
\hline $0.00 \%$ & 13 & 0 & 19.96 & 0 & 0 & 0 & -- & \multirow{21}{*}{$1.35 \%$} \\
\hline $5.00 \%$ & 13 & 0.177 & 19.94 & 0.1 & 2.301 & 1.994 & $86.66 \%$ & \\
\hline $10.00 \%$ & 13 & 0.339 & 19.93 & 0.2 & 4.407 & 3.986 & $90.45 \%$ & \\
\hline $15.00 \%$ & 13 & 0.501 & 19.91 & 0.3 & 6.513 & 5.973 & $91.71 \%$ & \\
\hline $20.00 \%$ & 13 & 0.658 & 19.9 & 0.4 & 8.554 & 7.96 & $93.06 \%$ & \\
\hline $25.00 \%$ & 13 & 0.818 & 19.89 & 0.5 & 10.634 & 9.945 & $93.52 \%$ & \\
\hline $30.00 \%$ & 13 & 0.975 & 19.87 & 0.6 & 12.675 & 11.922 & $94.06 \%$ & \\
\hline $35.00 \%$ & 13 & 1.137 & 19.86 & 0.7 & 14.781 & 13.902 & $94.05 \%$ & \\
\hline $40.00 \%$ & 13 & 1.301 & 19.85 & 0.8 & 16.913 & 15.88 & $93.89 \%$ & \\
\hline $45.00 \%$ & 13 & 1.459 & 19.84 & 0.9 & 18.967 & 17.856 & $94.14 \%$ & \\
\hline $50.00 \%$ & 13 & 1.625 & 19.82 & 1 & 21.125 & 19.82 & $93.82 \%$ & \\
\hline $55.00 \%$ & 13 & 1.791 & 19.81 & 1.1 & 23.283 & 21.791 & $93.59 \%$ & \\
\hline $60.00 \%$ & 13 & 1.95 & 19.8 & 1.2 & 25.35 & 23.76 & $93.73 \%$ & \\
\hline $65.00 \%$ & 13 & 2.118 & 19.79 & 1.3 & 27.534 & 25.727 & $93.44 \%$ & \\
\hline $70.00 \%$ & 13 & 2.281 & 19.77 & 1.4 & 29.653 & 27.678 & $93.34 \%$ & \\
\hline $75.00 \%$ & 13 & 2.453 & 19.76 & 1.5 & 31.889 & 29.64 & $92.95 \%$ & \\
\hline $80.00 \%$ & 13 & 2.618 & 19.74 & 1.6 & 34.034 & 31.584 & $92.80 \%$ & \\
\hline $85.00 \%$ & 13 & 2.795 & 19.73 & 1.7 & 36.335 & 33.541 & $92.31 \%$ & \\
\hline $90.00 \%$ & 13 & 2.973 & 19.72 & 1.8 & 38.649 & 35.496 & $91.84 \%$ & \\
\hline $95.00 \%$ & 13 & 3.14 & 19.71 & 1.9 & 40.82 & 37.449 & $91.74 \%$ & \\
\hline $100.00 \%$ & 13 & 3.3316 & 19.69 & 2 & 43.3108 & 39.38 & $90.92 \%$ & \\
\hline
\end{tabular}


Table 6-4: Measured load regulation parameters for boost converter 2

\begin{tabular}{|c|c|c|c|c|c|c|c|c|}
\hline Load & $\begin{array}{c}\text { Input } \\
\text { Voltage (V) }\end{array}$ & $\begin{array}{c}\text { Input } \\
\text { Current } \\
\text { (A) }\end{array}$ & $\begin{array}{c}\text { Output } \\
\text { Voltage } \\
\text { (V) }\end{array}$ & $\begin{array}{c}\text { Output } \\
\text { Current } \\
\text { (A) }\end{array}$ & $\begin{array}{l}\text { Input Power } \\
\text { (W) }\end{array}$ & $\begin{array}{c}\text { Output } \\
\text { Power (W) }\end{array}$ & Efficiency & $\begin{array}{c}\text { Load } \\
\text { Regulation }\end{array}$ \\
\hline $0.00 \%$ & 13 & 0 & 19.96 & 0 & 0 & 0 & -- & \multirow{21}{*}{$1.40 \%$} \\
\hline $5.00 \%$ & 13 & 0.174 & 19.94 & 0.1 & 2.262 & 1.994 & $88.15 \%$ & \\
\hline $10.00 \%$ & 13 & 0.339 & 19.92 & 0.2 & 4.407 & 3.984 & $90.40 \%$ & \\
\hline $15.00 \%$ & 13 & 0.502 & 19.91 & 0.3 & 6.526 & 5.973 & $91.53 \%$ & \\
\hline $20.00 \%$ & 13 & 0.666 & 19.89 & 0.4 & 8.658 & 7.956 & $91.89 \%$ & \\
\hline $25.00 \%$ & 13 & 0.827 & 19.88 & 0.5 & 10.751 & 9.94 & $92.46 \%$ & \\
\hline $30.00 \%$ & 13 & 0.987 & 19.87 & 0.6 & 12.831 & 11.922 & $92.92 \%$ & \\
\hline $35.00 \%$ & 13 & 1.158 & 19.86 & 0.7 & 15.054 & 13.902 & $92.35 \%$ & \\
\hline $40.00 \%$ & 13 & 1.319 & 19.84 & 0.8 & 17.147 & 15.872 & $92.56 \%$ & \\
\hline $45.00 \%$ & 13 & 1.49 & 19.83 & 0.9 & 19.37 & 17.847 & $92.14 \%$ & \\
\hline $50.00 \%$ & 13 & 1.625 & 19.82 & 1 & 21.125 & 19.82 & $93.82 \%$ & \\
\hline $55.00 \%$ & 13 & 1.79 & 19.8 & 1.1 & 23.27 & 21.78 & $93.60 \%$ & \\
\hline $60.00 \%$ & 13 & 1.952 & 19.79 & 1.2 & 25.376 & 23.748 & $93.58 \%$ & \\
\hline $65.00 \%$ & 13 & 2.12 & 19.78 & 1.3 & 27.56 & 25.714 & $93.30 \%$ & \\
\hline $70.00 \%$ & 13 & 2.288 & 19.76 & 1.4 & 29.744 & 27.664 & $93.01 \%$ & \\
\hline $75.00 \%$ & 13 & 2.454 & 19.75 & 1.5 & 31.902 & 29.625 & $92.86 \%$ & \\
\hline $80.00 \%$ & 13 & 2.622 & 19.73 & 1.6 & 34.086 & 31.568 & $92.61 \%$ & \\
\hline $85.00 \%$ & 13 & 2.793 & 19.72 & 1.7 & 36.309 & 33.524 & $92.33 \%$ & \\
\hline $90.00 \%$ & 13 & 2.966 & 19.71 & 1.8 & 38.558 & 35.478 & $92.01 \%$ & \\
\hline $95.00 \%$ & 13 & 3.143 & 19.69 & 1.9 & 40.859 & 37.411 & $91.56 \%$ & \\
\hline $100.00 \%$ & 13 & 3.31 & 19.68 & 2 & 43.03 & 39.36 & $91.47 \%$ & \\
\hline
\end{tabular}

From the measured parameters in Tables 6-3 and 6-4, the load regulation is determined using equation (6.20) as follows [25]:

$$
\% \text { Load Regulation }=\frac{V_{\text {out }(\text { low load })-V_{\text {out }}(\text { full load })}}{V_{\text {out }}(\text { nominal })} * 100 \%
$$

The right-most columns in Tables 6-3 and 6-4 display the load regulation as a percentage for each boost converter-1.35\% (boost converter 1 ) and $1.40 \%$ (boost converter 2). These load regulation values construe that in the worst case scenario between both converters, the output voltage will only vary on average $1.40 \%$ for loads ranging from 0 to $2 \mathrm{~A}$. This value also provides some jurisdiction for determining the input and output requirements for varying loads. 


\subsection{4-Output Voltage Ripple}

Output voltage ripple is a measure of repetitive or steady state deviation in the output voltage. Voltage ripple is typically given as a percentage of the average output voltage. For the two boost converters, an additional $570 \mu \mathrm{F}$ capacitance was added across the output pin to reduce the peak-to-peak current-typically the higher the load, the larger the ripple due to leakage current in the capacitors. Equation (6.21) shows the equation for determining output ripple.

$$
\text { Output Voltage Ripple }=\frac{V_{p p-\text { ripple }}}{V_{\text {output }}}
$$

With the output sourcing $2 \mathrm{~A}$ (full-load), the output voltage ripple was measured for both boost converters using a scope probe. The oscilloscope captures for boost converter 1 and 2 are shown in Figures 6-23 and 6-24, respectably.

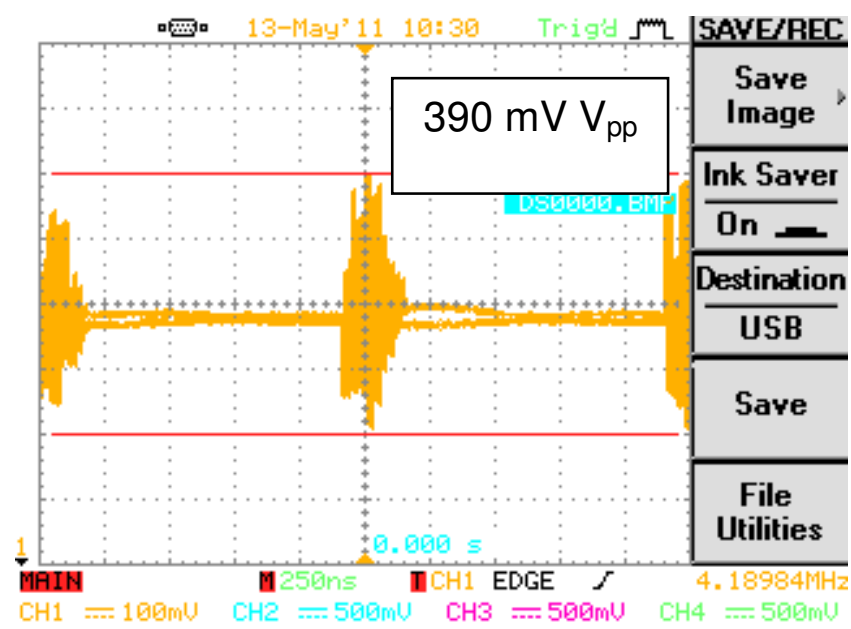

Figure 6-24: Output voltage ripple for boost converter 1 


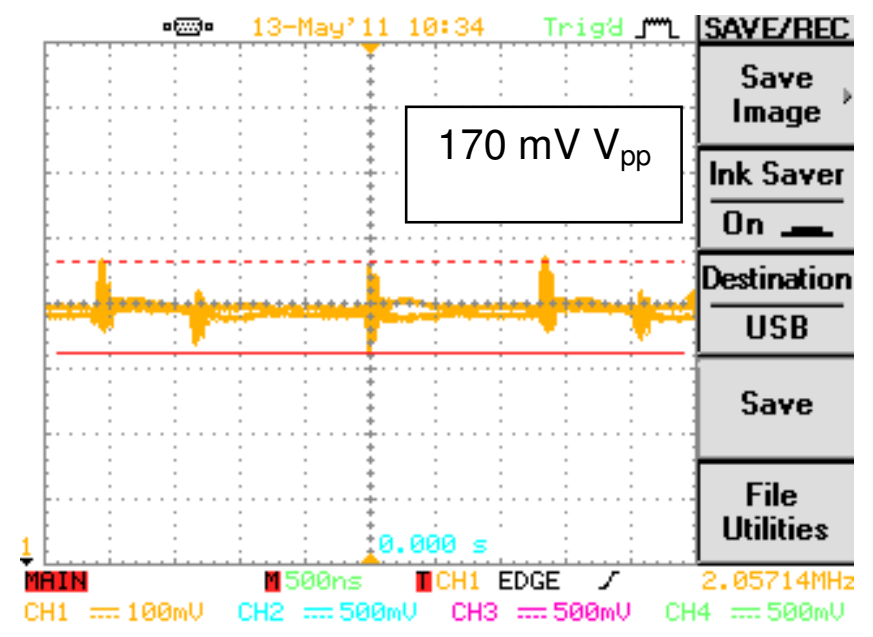

Figure 6-25: Output voltage ripple for boost converter 2

Based on the measured peak-to-peak output voltages in Figures 6-23 and 6-24, the percent output ripple for each boost converter is calculated using equation (6.18). The summary of the percent output ripple is shown in Table 6-5.

Table 6-5: Summary of boost converter percent output ripple

\begin{tabular}{|c|c|}
\hline Boost converter & Percent Output Voltage Ripple \\
\hline 1 & $1.97 \%$ \\
2 & $0.86 \%$ \\
\hline
\end{tabular}

\subsection{5-Power Efficiency}

The power efficiency for each boost converter can be read from either of the line regulation or load regulation tables from the previous sections. For each boost converter, the expected load is $1.8 \mathrm{~A}$ ( $80 \%$ load). Based on this load, the power efficiencies for each converter are summarized in Table 6-6.

Table 6-6: Summary of boost converter power efficiencies

\begin{tabular}{|c|c|}
\hline Boost Converter & $\begin{array}{c}\text { Power Efficiency at } \\
\text { Nominal Operation (1.8 }\end{array}$ \\
\hline $\mathbf{1}$ & $91.84 \%$ \\
\hline $\mathbf{2}$ & $92.01 \%$ \\
\hline
\end{tabular}




\section{CHAPTER 7-CHARACTERIZING AND TESTING LUMINAIRE}

\section{1-Testing Techniques for Characterizing Luminaire}

Since LEDs are a relatively new technology used for outdoor lighting, the lighting system must be tested to see how well the device will correlate with other designed luminaires. For this purpose, the IESNA has devised two lighting measurement procedures for LED lighting —-the LM-79 (Approved Method: Electrical and Photometric Measurements of Solid-State Lighting Products) and LM-80 (Approved Method: Measuring Lumen Maintenance of LED Light Sources). The overall testing results will attempt to follow LM-79 regulations established by the IESNA; however due to some of the more complex tests that require specialized equipment, several experimental analyses will be omitted. In addition, since the LM-80 pertains to the testing the lumen depreciation of the luminaire, this study will also be excluded since proper apparatuses and testing environments are not readily available.

\section{2-Light Measurements (LM-79) Specifications for Luminaire Design}

The LM-79 is a developed testing standard for new LED light fixtures to conform with. The testing and measurement procedures allow the user to evaluate the suitability of a solid-state lighting system for its use in a particular application or to compare other lighting systems against the one designed. The information provided in the study includes classification of the total luminous flux, electrical power, efficacy, and chromaticity of the luminaire [27].

Unlike traditional methods which are based off the use of relative photometry with test lamps and ballasts, LED fixtures are tested using absolute 
photometry with production LEDs and fixtures in the orientation in which it will be installed. Instead of using the normalized test data, absolute testing measures the actual light distribution and intensity produced by the luminaire.

LM-79 testing is usually performed using a goniophotometer. A goniophotometer measures the spatial distribution of a radiation source and displays the photometric properties of light visible to the human eye in relation to a defined angular position. The test set-up is normally performed as shown in Figure 7-1.

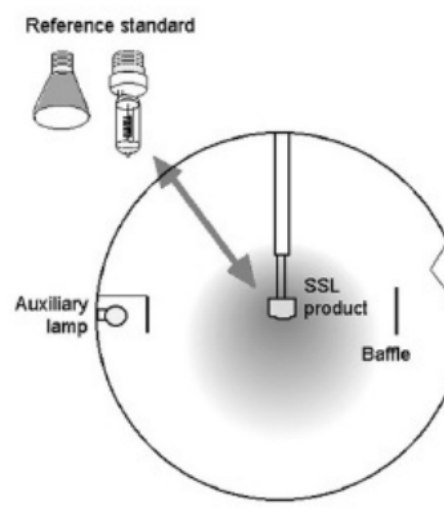

(a) $4 \pi$ geometry

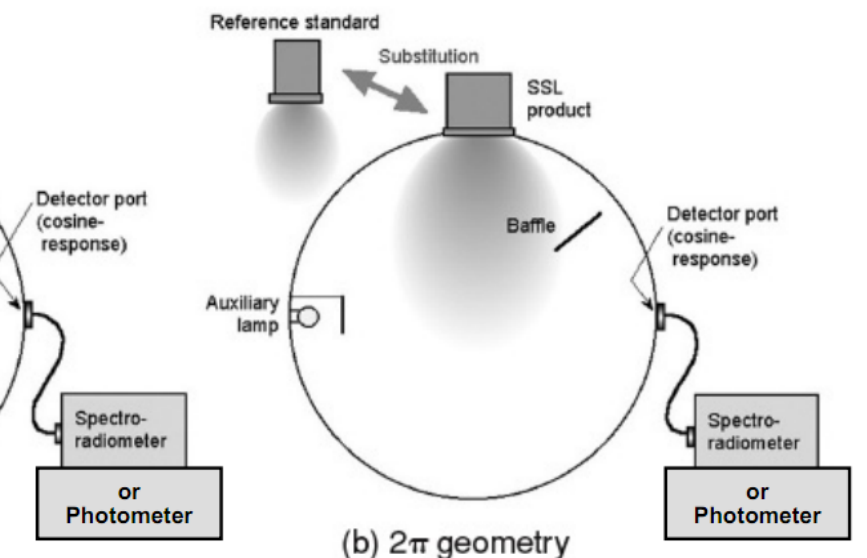

(b) $2 \pi$ geometry

Figure 7-1: Test set-up as per LM-79 testing

Figure 7-1 (a) represents the testing apparatus for all types of solid-state lighting products and Figure 7-1 (b) shows the setup for testing products that only emit light in a forward direction.

Since the following apparatus is not available to use, alternative tests involving a Lux/Candela meter and methods will be conducted in the following sections to demonstrate the overall quality of the design. These tests will allow comparison between the roadway lighting requirements as described in Chapter 4. 


\section{3-Luminous Efficacy}

Secondly when dealing with the voltage and current consumed by each section and the overall fixture as a whole, the power consumption plays an important role in determining the system efficiency-otherwise referred to as luminaire efficacy. Luminaire efficacy is one of the most commonly referred-to parameters when dealing with any sort of luminaire. As defined, a luminaire includes all parts of the system that are required to turn the device on-including, but not limited to, the necessary controls, power supplies, and other electronics [28].

Lighting energy efficiency is described in terms of lamp ratings and fixture efficiency. The lamp rating indicates how much light (in lumens) the lamp will produce when operating at standard room temperatures of $25^{\circ} \mathrm{C}$. The luminous efficacy of a light source is typically measured based on the rated lamp lumens divided by the nominal wattage of the lamp—equating to units of lumens per watt [28]

The City of Los Angeles specifies a minimum luminaire efficacy desired of 50 lumens per watt. This design achieves the luminaire efficacy of $53.9862 \mathrm{Im} / \mathrm{W}$ as shown by the calculation based on equation (7.1):

$$
\begin{aligned}
\text { Luminaire Efficacy } & =\frac{\text { Luminaire Light Output }}{\text { Ballast and Driver Input Power }} \\
& =\frac{3700 \mathrm{~lm}}{(10 \text { sections })\left(0.5272 \frac{A}{\text { section }} * 13 \mathrm{~V}\right)} \\
& =53.9862 \frac{\mathrm{lm}}{\mathrm{W}}
\end{aligned}
$$


The calculated input power was determined using the total power required to turn one section of the luminaire on. This calculation was done by attaching a power supply with a $13 \mathrm{~V}$ input to the boost converter and then determining the current outputted by the power supply as illustrated in Figure 7-2. The voltage and current displayed on the power supply denote the input power used by the luminaire section.

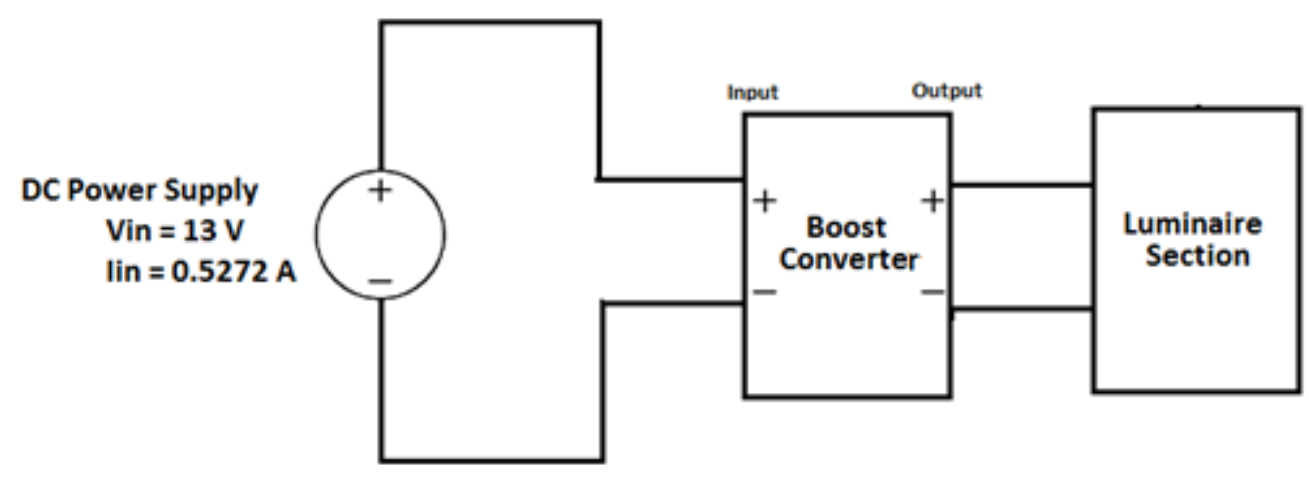

Figure 7-2: Measuring input power with consideration of boost converter efficiency losses

From this calculation, the determined luminaire efficacy is found adequate in meeting the specifications set by the City of Los Angeles. However, since the system is designed to work without connection to the grid, the effective power consumption, which is the driving factor of the calculated luminaire efficacy, is not as important as the quality of light and its relative distribution on a horizontal plane. For this reason, the following sections will introduce various methods of measuring the illumination distribution of the luminaire. These measurements will allow comparisons to be made between IESNA roadway light practices. 


\section{5-Isolux diagram}

One method used to characterize the luminaire is to model the incident light distribution based on varying levels of illumination. Isolux diagrams display contours of equal illuminance produced by a luminaire mounted at a given height; this information gives a general idea how the light will be dispersed. Also, isolux diagrams, when superimposed correctly with the layout of an area, can show how the light will be received within specific positions in the room [29].

For this test, a mounting height of three meters was used to show the illumination distribution as illustrated in Figure 7-2. The origin (denoted by the intersection of 0 meter, 0 meter) describes the center of the luminaire, from three meters away, relative to the grid. As shown in the figure, eight different contours show the luminaire's illumination distribution spread out in relation to the distance from the center of the luminaire.

The two highest measured contours are denoted by the smallest eclipses (labeled as 800 and 900 lux). From the isolux diagram, the contours show that the two areas that contain the maximum illumination lie between the superimposed distributions caused by all ten sections of the luminaire. 


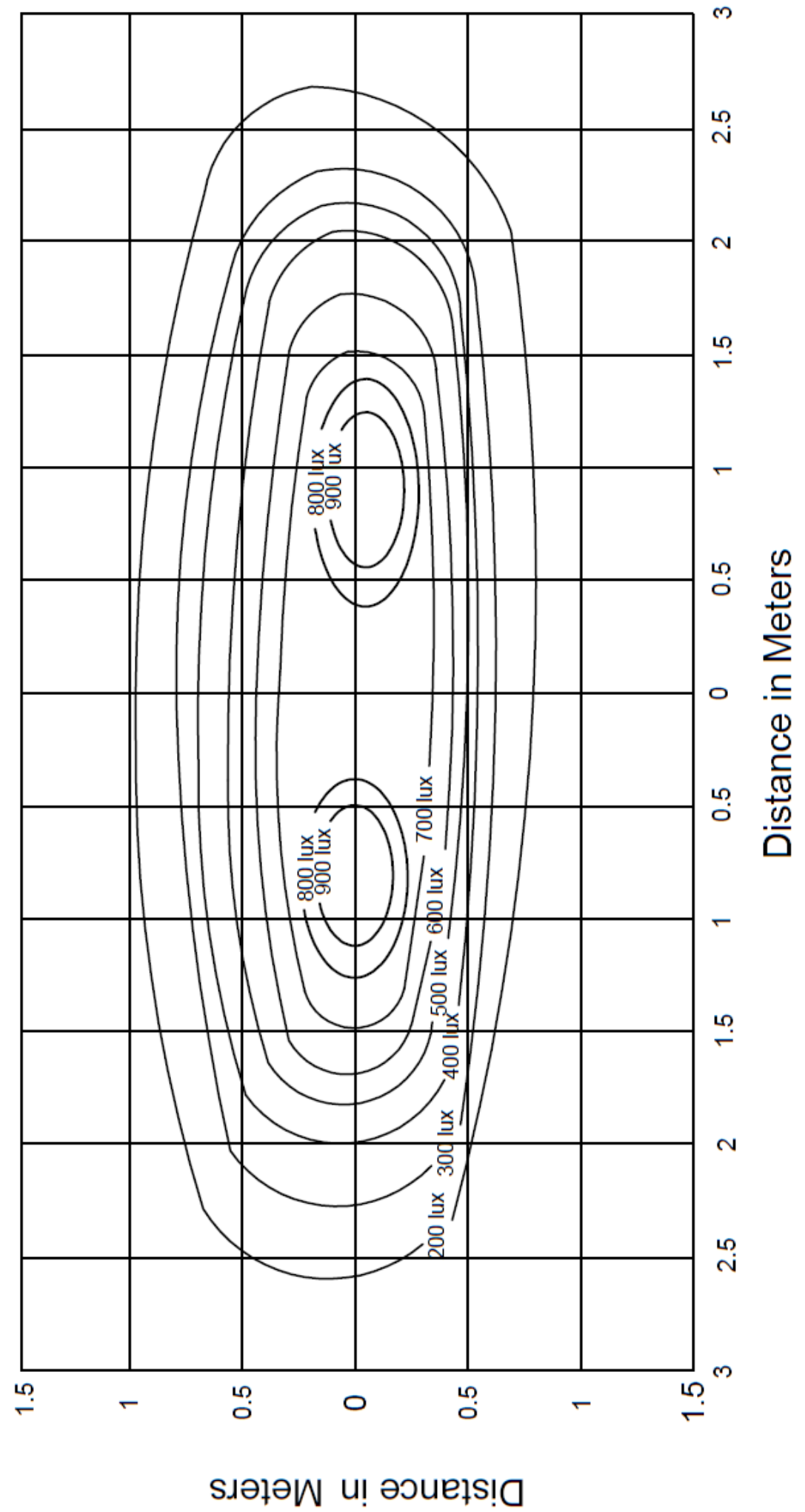

Figure 7-3: Isolux diagram for developed LED luminaire at a mounting distance of 3 meters 
As demonstrated in the ellipse-shaped contours in Figure 7-2, the luminaire exerts a more outward dispersion of light as desired in the roadway ( $\mathrm{x}$ axis) direction. The difference in lighting widths (roadway compared to sidewalk) further justifies the intended design of a type II luminaire in which the outward span ranges between 1.0 to 1.75 times the mounting height. The next section will compare how the illuminance and luminance compare with desired roadway lighting quantities specified by the IESNA.

\section{6-Illuminance Cone Diagram}

Another photometric test used to demonstrate illuminance capability of the luminaire is the illuminance cone diagram. The cone diagram portrays the fixture's ability to provide directive lighting by showing the maximum illuminance for the luminaire from varying mounting heights. Figure 7-4 shows the illuminance cone diagram for the designed luminaire from one meter up to seven meters away; the seven meters representing the approximate mounting height of the luminaire. 


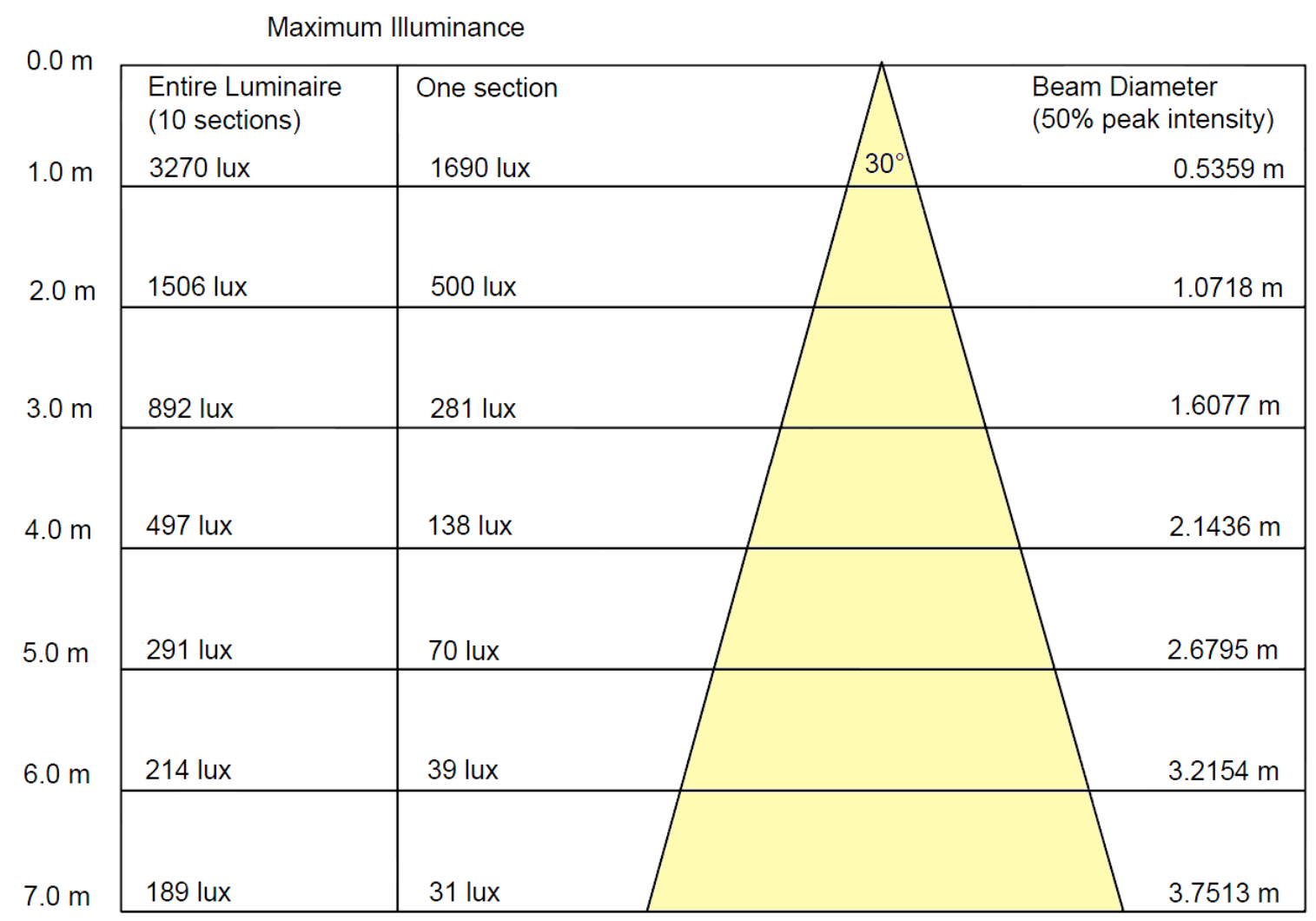

Figure 7-4: Illuminance cone diagram for entire luminaire

To demonstrate the differences between the illuminance cone diagrams provided by the whole luminaire and by one section of the luminaire, Figure 7-4 includes two columns showing the maximum illuminance for ten sections versus one section of the fixture.

Comparing the maximum illumination provided from one section versus all sections at a seven meter mounting height differs quite dramatically. When the entire luminaire is on, the maximum illumination is roughly six times larger than that for one section of the luminaire. This difference shows the effectiveness of overlapping sections of the luminaire. 


\section{7-Comparing Lighting Capabilities to Common IESNA Roadway Practices}

The most important aspect of the luminaire is its ability to meet or exceed the common roadway specs described both by the IESNA RP-8 and the City of Los Angeles. The typical characteristic of the $100 \mathrm{~W}$ fixtures in Los Angeles, the roadway and sidewalk widths of the luminaire should receive sufficient lighting over ranges of $30^{\prime}-36^{\prime}$ and $10^{\prime}-12^{\prime}$, respectively. In order to determine the measured light at each of these instances, Figures 7-6 illustrates the distances associated with both the roadway and sidewalk lighting ranges. The intervals of interest are denoted by tick marks; measured values at these instances will be compared with the common roadway illumination practices listed by the IESNA.

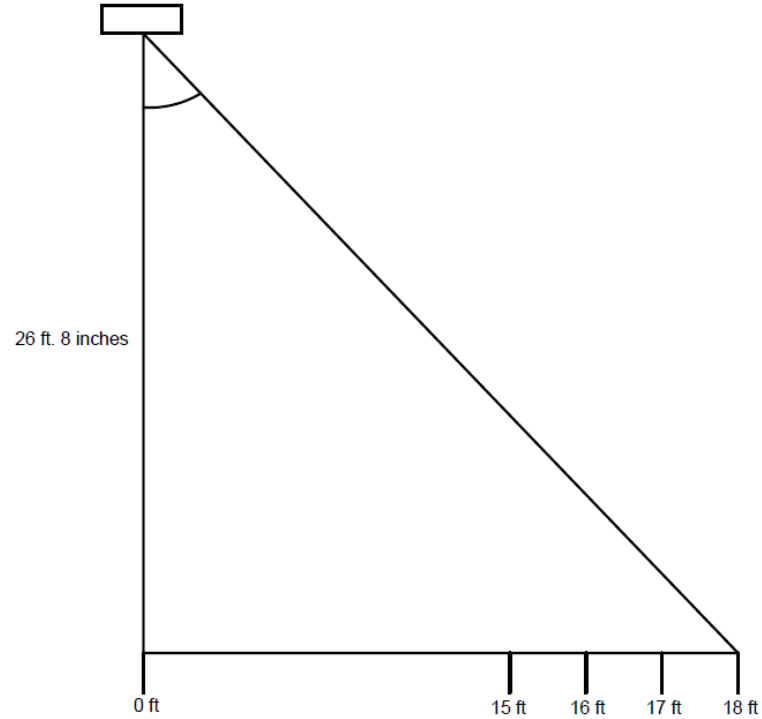

(a)

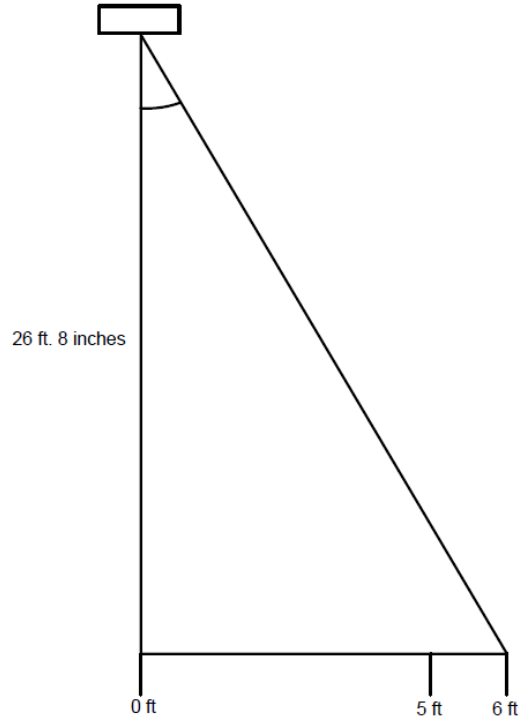

(b)

Figure 7-5: Measurements of interest to be taken for (a) roadway and (b) sidewalk distances 
The distances displayed in Figure 7-5 represent only one-half of the required span supported by the luminaire. To clarify, the typical span for a $100 \mathrm{~W}$ fixture has a roadway range of $30^{\prime}-36^{\prime}$; thus using symmetry, this range can be reduced to just measuring illumination values from 0 ' $-18^{\prime}$. Using this same concept for the required 10' - 12' sidewalk range, measurements will be taken from 0'-6'. Therefore, the area encompassing the surface area of interest can be illustrated by an $18^{\prime} \times 6^{\prime}$ grid. Analyzing a fourth of the entire span suffices for determining whether the extreme ends of the area of illumination provides adequate lighting. The area where a grid will be established and measurements will be taken is depicted in Figure 7-6.

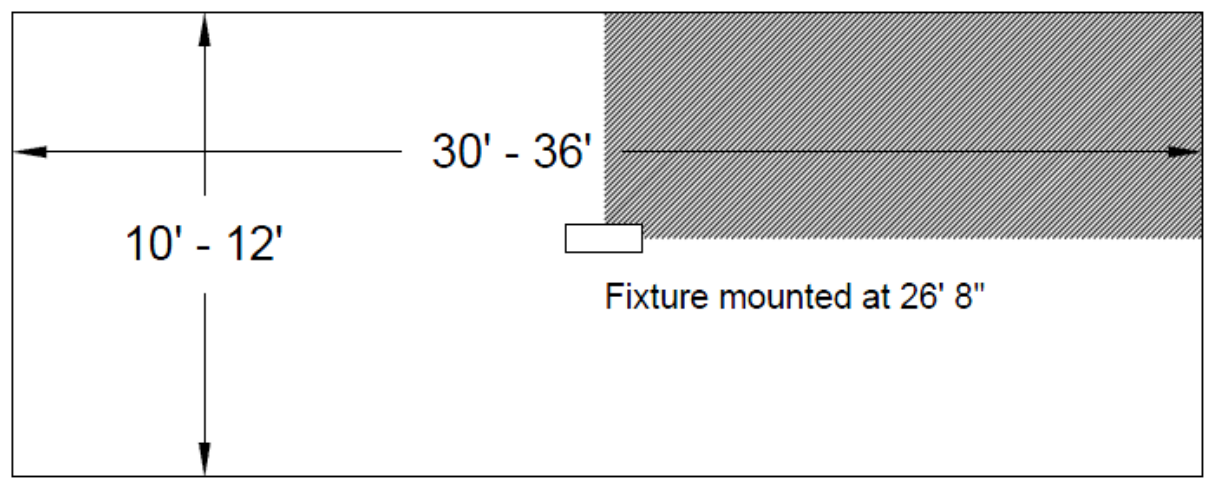

Figure 7-6: Area of illumination constructed based on typical range requirements 


\subsection{1-Lighting Requirements for Roadways Based on IESNA}

Lighting designs have been monitored and documented by numerous sources to ensure that specific areas obtain proper lighting for their intended purposes. Two of the most common standards light analysts use to design luminaires are the regulations established by the IESNA (Illuminating Engineering Society of North America) and the CIE (International Commission on Illumination). The specifications for each standard and their corresponding purpose are summarized in Table 7-1.

Table 7-1: Standards associated with roadway lighting [30]

\begin{tabular}{|l|l|}
\hline \multicolumn{1}{|c|}{ Standards - Year } & \multicolumn{1}{c|}{ Purpose of Standard } \\
\hline ANSI/IESNA RP-8-2000 & Recommended Practice for Roadway Lighting \\
CIE 115 - 1995 & Recommendations for the Lighting of Roads for Motor and Pedestrian Traffic \\
\hline
\end{tabular}

Since the IESNA is more commonly used throughout North America, the ANSI/IESNA RP-8-2000 standard will be followed more closely. The IESNA specific uses three methods for describing lighting of roadways: illuminance, luminance, and small target visibility (STV). The IESNA recommends that the lighting designer satisfy at least one of the methods and attempt to meet the other two requirements as closely as possible. The following tables are an excerpt from the 'Luminance Method' set forth by IESNA. 
Table 7-2: IESNA metrics used to measure light criteria [30]

\begin{tabular}{|c|c|c|c|c|c|}
\hline \multicolumn{2}{|c|}{ Road and Pedestrian Conflict Area } & \multirow{2}{*}{$\begin{array}{c}\text { Average } \\
\text { Luminance } L_{\text {avg }} \\
\left(\mathrm{cd} / \mathrm{m}^{2}\right)\end{array}$} & \multirow{2}{*}{$\begin{array}{c}\text { Uniformity } \\
\text { Ratio } \\
\mathrm{L}_{\text {avg }} / \mathrm{L}_{\min }\end{array}$} & \multirow{2}{*}{$\begin{array}{c}\text { Uniformity } \\
\text { Ratio } \\
L_{\max } / L_{\min }\end{array}$} & \multirow{2}{*}{$\begin{array}{l}\text { Veiling Luminance } \\
\text { Ratio } L_{\text {vmax }} / L_{\text {avg }}\end{array}$} \\
\hline Road & $\begin{array}{c}\text { Pedestrian } \\
\text { Conflict Area }\end{array}$ & & & & \\
\hline Freeway Class A & & 0.6 & 3.5 & 6 & 0.3 \\
\hline Freeway Class B & & 0.4 & 3.5 & 6 & 0.3 \\
\hline \multirow{3}{*}{ Expressway } & High & 1 & 3 & 5 & 0.3 \\
\hline & Medium & 0.8 & 3 & 5 & 0.3 \\
\hline & Low & 0.6 & 3.5 & 6 & 0.3 \\
\hline \multirow{3}{*}{ Major } & High & 1.2 & 3 & 5 & 0.3 \\
\hline & Medium & 0.9 & 3 & 5 & 0.3 \\
\hline & Low & 0.6 & 3.5 & 6 & 0.3 \\
\hline \multirow{3}{*}{ Collector } & High & 0.8 & 3 & 5 & 0.4 \\
\hline & Medium & 0.6 & 3.5 & 6 & 0.4 \\
\hline & Low & 0.4 & 4 & 8 & 0.4 \\
\hline \multirow{3}{*}{ Local } & High & 0.6 & 6 & 10 & 0.4 \\
\hline & Medium & 0.5 & 6 & 10 & 0.4 \\
\hline & Low & 0.3 & 6 & 10 & 0.4 \\
\hline
\end{tabular}

Table 7-3: IESNA metrics for average maintained illumination in pedestrian areas [30]

\begin{tabular}{|l|c|c|c|c|}
\hline \multirow{2}{*}{\begin{tabular}{c}
\multirow{2}{*}{$\begin{array}{c}\text { Functional } \\
\text { Classification }\end{array}$} \\
Major/Major
\end{tabular}} & \multicolumn{2}{|c|}{$\begin{array}{c}\text { Average Maintained Illumination at Pavement } \\
\text { by Pedestrian Area Classification (lux/fc) }\end{array}$} & \multirow{2}{*}{$\mathrm{E}_{\text {avg }} / \mathrm{E}_{\text {min }}$} \\
\cline { 2 - 4 } & High & Medium & Low & \\
\hline Major/Collector & $34.0 / 3.4$ & $26.0 / 2.6$ & $18.0 / 1.8$ & 3 \\
Major/Local & $29.0 / 2.9$ & $22.0 / 2.2$ & $15.0 / 1.5$ & 3 \\
Collector/Collector & $26.0 / 2.6$ & $20.0 / 2.0$ & $13.0 / 1.3$ & 3 \\
Collector/Local & $24.0 / 2.4$ & $18.0 / 1.8$ & $12.0 / 1.2$ & 4 \\
Local/Local & $21.0 / 2.1$ & $16.0 / 1.6$ & $10.0 / 1.0$ & 4 \\
\hline
\end{tabular}

Tables 7-2 and 7-3 serve as an introduction to the numerical values that the designed luminaire will attempt to mimic. The next section will compare the actual results with the desired requirements to see whether these values correlate. 


\subsection{2-IIlumination Comparison for Designed Luminaire}

Following the distances of interests in Figure 7-6, measurements were taken based on the relative roadway (X-coordinate) and sidewalk (Y-coordinate) location on the horizontal plane with respect to the mounted luminaire (0' sidewalk, 0' roadway). The measured illuminance corresponding to the incremental roadway and sidewalk distances away from the mounted luminaire is depicted in Table 7-2 (a).

Next, the measured illumination points are then compared to the average illumination $\mathrm{E}_{\mathrm{avg}}$ to show how well these values compare with the ratios in Table 7-3. To perform this calculation, an average illuminance value was determined using the measured values in Table 7-4 (a); the illuminance average was then determined to be 82.05 lux. Using this value, each entry in Table 7-4 (a) is recalculated to show the ratio of average illuminance $\left(E_{\text {avg }}\right)$ to measured illuminance $\left(E_{\min }\right)$; the results are documented in Table 7-4 (b).

Table 7-4: Measured illuminance and normalized ratios to compare with IESNA roadway practices

(a) Illumination (lux) for varying distances away from mounted fixture

\begin{tabular}{|c|c|c|c|c|c|c|c|c|c|c|c|c|c|c|c|c|c|c|c|c|}
\hline \multirow{2}{*}{\multicolumn{2}{|c|}{ Illuminance (lux) }} & \multicolumn{19}{|c|}{ Roadway Distance from Center (ft.) } \\
\hline & & 0 & 1 & 2 & 3 & 4 & 5 & 6 & 7 & 8 & 9 & 10 & 11 & 12 & 13 & 14 & 15 & 16 & 17 & 18 \\
\hline \multirow{7}{*}{$\begin{array}{c}\text { Sidewalk } \\
\text { Distance } \\
\text { from } \\
\text { Center (ft.) }\end{array}$} & 0 & 148 & 149 & 153 & 158 & 162 & 166 & 166 & 164 & 165 & 167 & 166 & 162 & 150 & 133 & 114 & 93 & 73 & 58 & 42 \\
\hline & 1 & 136 & 140 & 145 & 151 & 156 & 159 & 159 & 160 & 158 & 159 & 157 & 154 & 143 & 131 & 107 & 88 & 70 & 55 & 41 \\
\hline & 2 & 110 & 108 & 123 & 129 & 134 & 138 & 138 & 137 & 142 & 137 & 137 & 136 & 124 & 110 & 96 & 76 & 63 & 49 & 38 \\
\hline & 3 & 87 & 92 & 98 & 100 & 105 & 110 & 110 & 112 & 113 & 113 & 111 & 107 & 100 & 89 & 74 & 62 & 51 & 41 & 31 \\
\hline & 4 & 65 & 69 & 73 & 75 & 78 & 80 & 80 & 84 & 85 & 84 & 84 & 79 & 76 & 69 & 59 & 50 & 41 & 34 & 27 \\
\hline & 5 & 50 & 52 & 54 & 56 & 57 & 58 & 58 & 61 & 61 & 60 & 61 & 58 & 54 & 50 & 44 & 38 & 33 & 28 & 24 \\
\hline & 6 & 40 & 42 & 43 & 44 & 45 & 46 & 36 & 47 & 47 & 47 & 46 & 45 & 42 & 40 & 36 & 32 & 28 & 23 & 20 \\
\hline
\end{tabular}


(b) Ratios for sidewalk illumination to compare with IESNA roadway practices

\begin{tabular}{|c|c|c|c|c|c|c|c|c|c|c|c|c|c|c|c|c|c|c|c|c|}
\hline \multirow{2}{*}{\multicolumn{2}{|c|}{$\begin{array}{c}\text { Average to } \\
\text { Measured } \\
\text { Illuminance Ratios }\end{array}$}} & \multicolumn{19}{|c|}{ Roadway Distance from Center (ft.) } \\
\hline & & 0 & 1 & 2 & 3 & 4 & 5 & 6 & 7 & 8 & 9 & 10 & 11 & 12 & 13 & 14 & 15 & 16 & 17 & 18 \\
\hline \multirow{7}{*}{$\begin{array}{c}\text { Sidewalk } \\
\text { Distance } \\
\text { from } \\
\text { Center (ft.) }\end{array}$} & 0 & 0.55 & 0.55 & 0.54 & 0.52 & 0.51 & 0.49 & 0.49 & 0.5 & 0.5 & 0.49 & 0.49 & 0.51 & 0.55 & 0.62 & 0.72 & 0.88 & 1.12 & 1.41 & 1.95 \\
\hline & 1 & 0.6 & 0.59 & 0.57 & 0.54 & 0.53 & 0.52 & 0.52 & 0.51 & 0.52 & 0.52 & 0.52 & 0.53 & .57 & 0.63 & .77 & 0.93 & 1.17 & 1.49 & 2 \\
\hline & 2 & 0.75 & 0.76 & 0.67 & 0.64 & 0.61 & 0.59 & 0.59 & 0.6 & 0.58 & 6 & 6 & 0 & 66 & .75 & .85 & 1.08 & 1.3 & 1.67 & 2.16 \\
\hline & 3 & 0.94 & 0.89 & 0.84 & 0.82 & 0.78 & 0.75 & 0.75 & 0.73 & 0.73 & 0.73 & 0.74 & 77 & 0.82 & 0.92 & 1.11 & 1.32 & 1.61 & 2 & 2.65 \\
\hline & 4 & 1.26 & 1.19 & 1.12 & 1.09 & 1.05 & 1.03 & 1.03 & 0.98 & 0.97 & 0.98 & 0.98 & 1.04 & 1.08 & 1.19 & 1.39 & 1.64 & 2 & 2.41 & 3.04 \\
\hline & 5 & 1.64 & 1.58 & 1.52 & 1.47 & 1.44 & 1.41 & 1.41 & 1.3 & 1.3 & 1.3 & 1.3 & 1.4 & 1.52 & 1.64 & 1.86 & 2.16 & 2.49 & 2.93 & 3.42 \\
\hline & 6 & 2.05 & 1.95 & 1.91 & 1.86 & 1.82 & 1.78 & 2.28 & 1.75 & 1.75 & 1.75 & 1.78 & 1.82 & 1.95 & 2.05 & 2.28 & 2.56 & 2.93 & 3.57 & 4.1 \\
\hline
\end{tabular}

Referring to Table 7-3, typical roadway practices require a maximum of

18.0 lux and a uniformity ratio of 6 between the average illuminance and the measured illuminance. Table 7-4 (a) and (b) display shaded regions in the corner of each table to represent the area containing the lowest measured illuminance. In comparison with the desired illumination, roadway distances up to $18^{\prime}$ (the equivalent total span of $36^{\prime}$ ) and sidewalk distances up to 6' (equivalent total span of 12') provides sufficient illumination for the 'Local' intersection type. The lowest measured illuminance within the specified area is 20 lux and the corresponding ratio between average and measured illuminance is 4.1. Therefore, based on the measured values, the luminaire adequately meets the minimum illuminance requirement set by the IESNA.

Figure 7-7 summarizes the data from Table 7-4 to create a threedimensional image of the levels of illumination. Based on the measured data, which represents one quadrant of the lit area, symmetry was used to determine the illumination distribution for the entire area shown in Figure 7-6 (total area covers $\left.36^{\prime} \times 12^{\prime}\right)$. The horizontal plane in Figure 7-7 represents the distances away from the mounted luminaire (located at $0 \mathrm{ft}$., $0 \mathrm{ft}$.) and the height denotes the measured illuminance at a specific coordinate. 


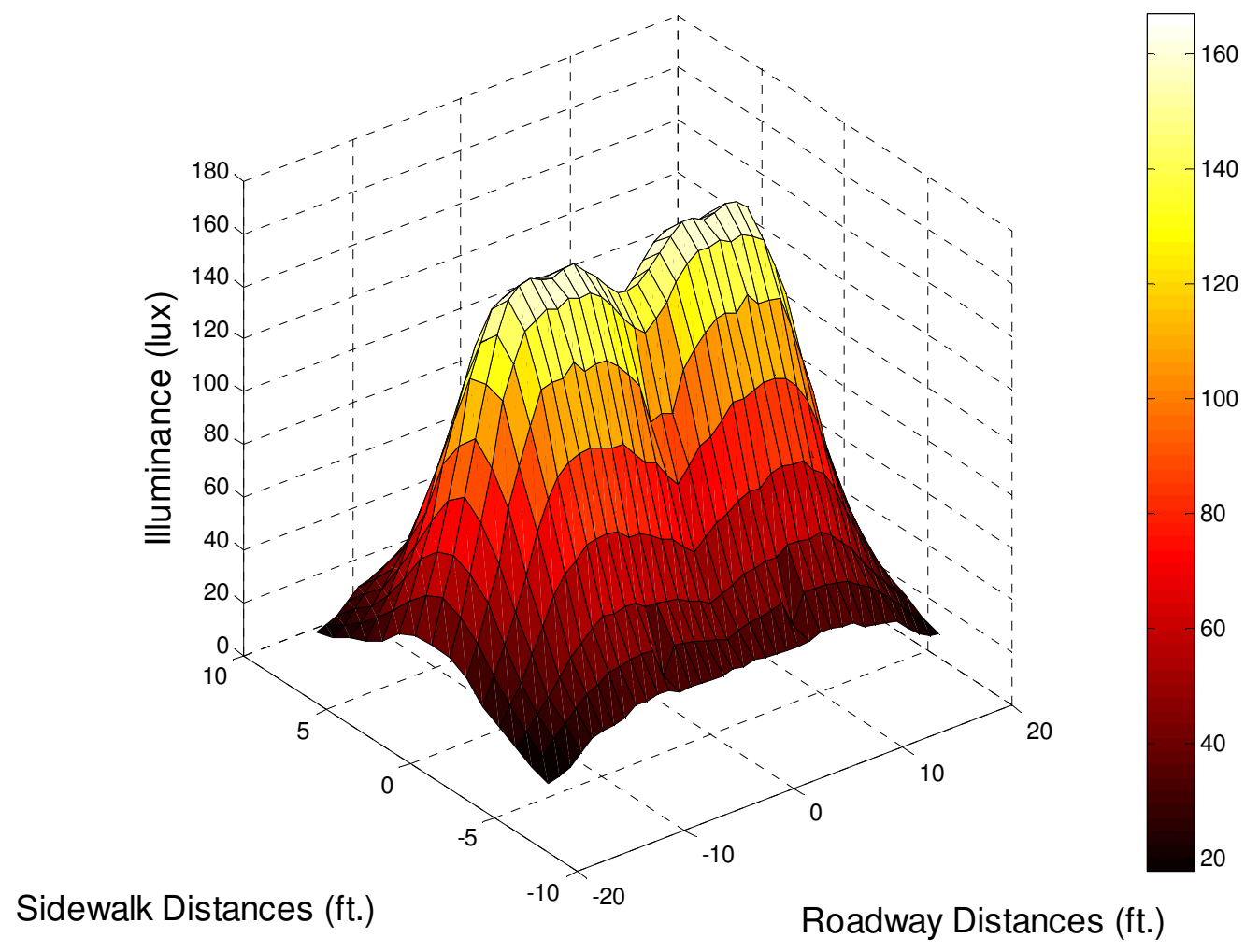

Figure 7-7: 3-D model of illumination pattern for the designed fixture mounted at 26' 8"

\subsection{3-Luminance Comparison for Designed Luminaire}

The last comparative measure deals with the luminance at each distance away from the light fixture. Illuminance as measured using a lux or candela meter describes the amount of light coming from a light fixture that lands on a surface-for this application, the surface of interest is the road pavement. In contrast, luminance pertains to the actual amount of light reflecting off of the surface in a particular direction, and can normally be thought of as the measured brightness of a surface as seen by the eye [31]. 
The brightness or luminance of the surface that the eye sees depends on the reflectance or ratio of reflected light to incident light. Equation 7-2 relates the two lighting quantities together with a reflectance factor as shown [32].

$$
\text { Luminance }=\text { Illuminance } * \text { Reflectance }
$$

The unit for luminance in the above equation is expressed in apostlibs. Since the unit for illuminance (lux) cannot be directly converted into the desired quantity for comparing with the IESNA luminance values measured in $\mathrm{cd} / \mathrm{m}^{2}$, apostlibs must first be converted to the $\mathrm{SI}$ unit $\mathrm{cd} / \mathrm{m}^{2}$ by multiplying the apostlib value by a factor of 0.3183 (reciprocal of $\pi$ ). However, when describing reflectance, the road pavement's shininess and the lightness or degree of grayness (from black to white) must also be taken into account. Due to the complexity and variation in the possibly types of pavements available, Table 7-5 describes three quick estimates to convert the illuminance values to the equivalent luminance values.

Table 7-5: Pavement color and conversion values for luminance and illuminance [33]

\begin{tabular}{|c|c|c|}
\hline Pavement Color & Illuminance (lux) & Luminance $\left(\mathrm{cd} / \mathrm{m}^{2}\right)$ \\
\hline Light & 1 & 0.125 \\
Average & 1 & 0.0714 \\
Dark & 1 & 0.0556 \\
\hline
\end{tabular}

Using the conversion factor in Table 7-5, the luminance values for both the roadway and sidewalk distances are summarized in Table 7-6. 
Table 7-6: Pavement luminance $\left(\mathrm{cd} / \mathrm{m}^{2}\right)$ for varying distances away from mounted fixture

\begin{tabular}{|c|c|c|c|c|c|c|c|c|c|c|c|c|c|c|c|c|c|c|c|c|c|}
\hline & \multirow{2}{*}{\multicolumn{2}{|c|}{$\begin{array}{l}\text { Luminance } \\
(\mathrm{cd} / \mathrm{m} 2)\end{array}$}} & \multicolumn{19}{|c|}{ Roadway Distance from Center (ft.) } \\
\hline & & & 0 & 1 & 2 & 3 & 4 & 5 & 6 & 7 & 8 & 9 & 10 & 11 & 12 & 13 & 14 & 15 & 16 & 17 & 18 \\
\hline \multirow{21}{*}{$\begin{array}{c}\text { Sidewalk } \\
\text { Distance } \\
\text { from } \\
\text { Center } \\
\text { (ft.) }\end{array}$} & \multirow{7}{*}{$\begin{array}{c}\text { Light- } \\
\text { colored } \\
\text { Pavement }\end{array}$} & 0 & 18.5 & 18.6 & 19.1 & 19.8 & 20.3 & 20.8 & 20.8 & 20.5 & 20.6 & 20.9 & 20.8 & 20.3 & 18.8 & 16.6 & 14.3 & 11.6 & 9.1 & 7.3 & 5.3 \\
\hline & & 1 & 17.0 & 17.5 & 18.1 & 18.9 & 19.5 & 19.9 & 19.9 & 20.0 & 19.8 & 19.9 & 19.6 & 19.3 & 17.9 & 16.4 & 13.4 & 11.0 & 8.8 & 6.9 & 5.1 \\
\hline & & 2 & 13.8 & 13.5 & 15.4 & 16.1 & 16.8 & 17.3 & 17.3 & 17.1 & 17.8 & 17.1 & 17.1 & 17.0 & 15.5 & 13.8 & 12.0 & 9.5 & 7.9 & 6.1 & 4.8 \\
\hline & & 3 & 10.9 & 11.5 & 12.3 & 12.5 & 13.1 & 13.8 & 13.8 & 14.0 & 14.1 & 14.1 & 13.9 & 13.4 & 12.5 & 11.1 & 9.3 & 7.8 & 6.4 & 5.1 & 3.9 \\
\hline & & 4 & 8.1 & 8.6 & 9.1 & 9.4 & 9.8 & 10.0 & 10.0 & 10.5 & 10.6 & 10.5 & 10.5 & 9.9 & 9.5 & 8.6 & 7.4 & 6.3 & 5.1 & 4.3 & 3.4 \\
\hline & & 5 & 6.3 & 6.5 & 6.8 & 7.0 & 7.1 & 7.3 & 7.3 & 7.6 & 7.6 & 7.5 & 7.6 & 7.3 & 6.8 & 6.3 & 5.5 & 4.8 & 4.1 & 3.5 & 3.0 \\
\hline & & 6 & 5.0 & 5.3 & 5.4 & 5.5 & 5.6 & 5.8 & 4.5 & 5.9 & 5.9 & 5.9 & 5.8 & 5.6 & 5.3 & 5.0 & 4.5 & 4.0 & 3.5 & 2.9 & 2.5 \\
\hline & \multirow{7}{*}{$\begin{array}{c}\text { Average- } \\
\text { colored } \\
\text { Pavement }\end{array}$} & 0 & 10.6 & 10.6 & 10.9 & 11.3 & 11.6 & 11.9 & 11.9 & 11.7 & 11.8 & 11.9 & 11.9 & 11.6 & 10.7 & 9.5 & 8.1 & 6.6 & 5.2 & 4.1 & 3.0 \\
\hline & & 1 & 9.7 & 10.0 & 10.4 & 10.8 & 11.1 & 11.4 & 11.4 & 11.4 & 11.3 & 11.4 & 11.2 & 11.0 & 10.2 & 9.4 & 7.6 & 6.3 & 5.0 & 3.9 & 2.9 \\
\hline & & 2 & 7.9 & 7.7 & 8.8 & 9.2 & 9.6 & 9.9 & 9.9 & 9.8 & 10.1 & 9.8 & 9.8 & 9.7 & 8.9 & 7.9 & 6.9 & 5.4 & 4.5 & 3.5 & 2.7 \\
\hline & & 3 & 6.2 & 6.6 & 7.0 & 7.1 & 7.5 & 7.9 & 7.9 & 8.0 & 8.1 & 8.1 & 7.9 & 7.6 & 7.1 & 6.4 & 5.3 & 4.4 & 3.6 & 2.9 & 2.2 \\
\hline & & 4 & 4.6 & 4.9 & 5.2 & 5.4 & 5.6 & 5.7 & 5.7 & 6.0 & 6.1 & 6.0 & 6.0 & 5.6 & 5.4 & 4.9 & 4.2 & 3.6 & 2.9 & 2.4 & 1.9 \\
\hline & & 5 & 3.6 & 3.7 & 3.9 & 4.0 & 4.1 & 4.1 & 4.1 & 4.4 & 4.4 & 4.3 & 4.4 & 4.1 & 3.9 & 3.6 & 3.1 & 2.7 & 2.4 & 2.0 & 1.7 \\
\hline & & 6 & 2.9 & 3.0 & 3.1 & 3.1 & 3.2 & 3.3 & 2.6 & 3.4 & 3.4 & 3.4 & 3.3 & 3.2 & 3.0 & 2.9 & 2.6 & 2.3 & 2.0 & 1.6 & 1.4 \\
\hline & \multirow{7}{*}{$\begin{array}{c}\text { Dark- } \\
\text { colored } \\
\text { Pavement }\end{array}$} & 0 & 8.2 & 8.3 & 8.5 & 8.8 & 9.0 & 9.2 & 9.2 & 9.1 & 9.2 & 9.3 & 9.2 & 9.0 & 8.3 & 7.4 & 6.3 & 5.2 & 4.1 & 3.2 & 2.3 \\
\hline & & 1 & 7.6 & 7.8 & 8.1 & 8.4 & 8.7 & 8.8 & 8.8 & 8.9 & 8.8 & 8.8 & 8.7 & 8.6 & 7.9 & 7.3 & 5.9 & 4.9 & 3.9 & 3.1 & 2.3 \\
\hline & & 2 & 6.1 & 6.0 & 6.8 & 7.2 & 7.4 & 7.7 & 7.7 & 7.6 & 7.9 & 7.6 & 7.6 & 7.6 & 6.9 & 6.1 & 5.3 & 4.2 & 3.5 & 2.7 & 2.1 \\
\hline & & 3 & 4.8 & 5.1 & 5.4 & 5.6 & 5.8 & 6.1 & 6.1 & 6.2 & 6.3 & 6.3 & 6.2 & 5.9 & 5.6 & 4.9 & 4.1 & 3.4 & 2.8 & 2.3 & 1.7 \\
\hline & & 4 & 3.6 & 3.8 & 4.1 & 4.2 & 4.3 & 4.4 & 4.4 & 4.7 & 4.7 & 4.7 & 4.7 & 4.4 & 4.2 & 3.8 & 3.3 & 2.8 & 2.3 & 1.9 & 1.5 \\
\hline & & 5 & 2.8 & 2.9 & 3.0 & 3.1 & 3.2 & 3.2 & 3.2 & 3.4 & 3.4 & 3.3 & 3.4 & 3.2 & 3.0 & 2.8 & 2.4 & 2.1 & 1.8 & 1.6 & 1.3 \\
\hline & & 6 & 2.2 & 2.3 & 2.4 & 2.4 & 2.5 & 2.6 & 2.0 & 2.6 & 2.6 & 2.6 & 2.6 & 2.5 & 2.3 & 2.2 & 2.0 & 1.8 & 1.6 & 1.3 & 1.1 \\
\hline
\end{tabular}

For both summaries of the luminance for the measured values, the calculations were made for three types of pavements. As seen from the luminance values, the measurements compare quite favorably with the average luminance values from Table 3-4. To summarize, the estimated values with luminance table, Table 7-7 shows the calculated average luminance and uniformity ratio for each pavement type, which will then be compared with the IESNA values from Table 7-2.

Table 7-7: Summary of average luminance and uniformity ratios for luminaire for $12^{\prime}$ x $36^{\prime}$ area

\begin{tabular}{|c|c|c|c|}
\cline { 2 - 4 } \multicolumn{1}{c|}{} & $\begin{array}{c}\text { Average } \\
\text { Luminance } \\
\left(\mathrm{cd} / \mathrm{m}^{2}\right)\end{array}$ & $\begin{array}{c}\text { Uniformity } \\
\text { Ratio } \\
\left(\mathrm{L}_{\text {avg }} / \mathrm{L}_{\min }\right)\end{array}$ & $\begin{array}{c}\text { Uniformity } \\
\text { Ratio } \\
\left(\mathrm{L}_{\max } / \mathrm{L}_{\min }\right)\end{array}$ \\
\hline $\begin{array}{c}\text { Light-colored } \\
\text { Pavement }\end{array}$ & 11.17 & 4.47 & 8.35 \\
\hline $\begin{array}{c}\text { Average-colored } \\
\text { Pavement }\end{array}$ & 6.38 & 4.47 & 8.35 \\
\hline $\begin{array}{c}\text { Dark-colored } \\
\text { Pavement }\end{array}$ & 4.97 & 4.47 & 8.35 \\
\hline
\end{tabular}


The measurements provide clear evidence that the luminaire is capable of sustaining an average luminance of $0.6 \mathrm{~cd} / \mathrm{m}^{2}$ over the entire lit area-as denoted by the left-most column in Table 7-7. The only difference between the measurements arises from the uniformity ratios. In terms of the desired street light replacement by the City of Los Angeles, the designed luminaire provides a uniformity ratio less the indicated value of 10 for the local roadway type. Since Table 7-7 summarizes the uniformity ratio for the largest range required at a local intersection (12' $\left.x 36^{\prime}\right)$, if the luminance were limited to the minimum area (10' $x$ 30 '), the uniformity ratios are surely to decrease as shown by Table 7-9.

Table 7-8: Summary of average luminance and uniformity ratios for luminaire for 10' x $30^{\prime}$ area

\begin{tabular}{|c|c|c|c|}
\cline { 2 - 4 } \multicolumn{1}{c|}{} & $\begin{array}{c}\text { Average } \\
\text { Luminance } \\
\left(\mathrm{cd} / \mathrm{m}^{2}\right)\end{array}$ & $\begin{array}{c}\text { Uniformity } \\
\text { Ratio } \\
\left(\mathrm{L}_{\text {avg }} / \mathrm{L}_{\min }\right)\end{array}$ & $\begin{array}{c}\text { Uniformity } \\
\text { Ratio } \\
\left(\mathrm{L}_{\max } / \mathrm{L}_{\min }\right)\end{array}$ \\
\hline $\begin{array}{c}\text { Light-colored } \\
\text { Pavement }\end{array}$ & 13.46 & 2.83 & 4.39 \\
\hline $\begin{array}{c}\text { Average-colored } \\
\text { Pavement }\end{array}$ & 7.69 & 2.83 & 4.39 \\
\hline $\begin{array}{c}\text { Dark-colored } \\
\text { Pavement }\end{array}$ & 5.98 & 2.83 & 4.39 \\
\hline
\end{tabular}

Similarly to Figure 7-7, the luminance calculations for the light-colored pavement in Table 7-6 is represented as three-dimensional model in Figure 7-8. The figure uses symmetry to project the luminance on all quadrants to denote the area lit by the designed luminaire. 


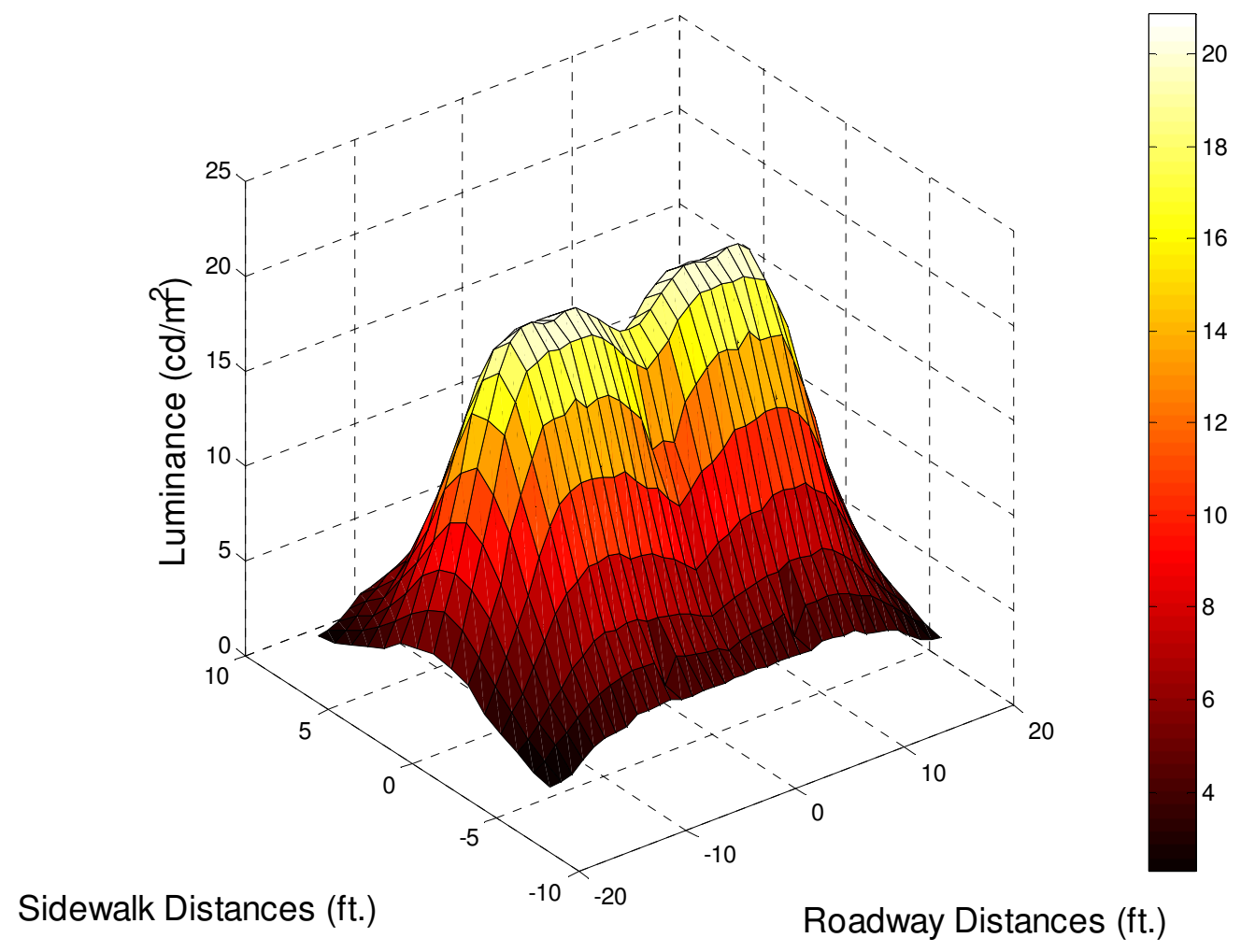

Figure 7-8: 3-D model of luminance pattern for the designed fixture mounted at 26 ' 8 " on a lightcolored pavement

Compared to the isolux diagram shown in Figure 7-3, both the illuminance and luminance diagrams follow the same relative contour levels of lighting. Two central peaks are shown in both Figures 7-7 and 7-8, which again represents the overlapping sections of the designed luminaire. The center of the luminaire (at the origin) still contains a high level of illuminance and perceived brightness on the light-colored pavement as indicated by the white-yellow area.

The measured and estimated values show that the designed luminaire is capable of replacing its counterpart in roadway applications due to the directional LED illumination and the high average luminance maintained over various types of pavement. 


\section{8-Summary of Luminaire Specifications}

This section summarizes the basic specifications in terms of power requirement and lamp features with a side-by-side comparison with desired requirements for LED light fixtures by the Bureau of Street Lighting in Los Angeles. As demonstrated through the earlier sections of this chapter, many of the features of the luminaire are adequately met in accordance with the desired requirements. Table 7-10 summarizes the designed luminaire with the desired specifications.

Table 7-9: Luminaire classification

\begin{tabular}{|c|c|c|}
\hline Power Requirement & $\begin{array}{l}\text { Designed } \\
\text { Luminaire }\end{array}$ & $\begin{array}{c}\text { Desired } \\
\text { Luminaire }\end{array}$ \\
\hline LED Lamp Input Voltage (Typ.) [V] & 13 & -- \\
\hline LED Lamp Input Current (Typ.) [A] & 5.272 & -- \\
\hline LED Lamp Input Power (Typ.) [W] & 68.536 & $\leq 73$ \\
\hline Power consumption (Typ.) [W] & 75.3896 & $\leq 85$ \\
\hline \multicolumn{3}{|l|}{ Lamp Features for Type II Luminare } \\
\hline Equals to or Replaces & \multicolumn{2}{|c|}{100 W HPS } \\
\hline LED Lamp Initial Flux (Typ.) [Im] & 3700 & $\geq 3700$ \\
\hline Color Temperature [K] & Minimum of 4600 & $4300+/-300$ \\
\hline Color Rendering Index (CRI) & 72 & $\geq 65$ \\
\hline Luminaire Efficacy [Im/W] & 53 & $\geq 50$ \\
\hline
\end{tabular}

As seen by the side comparison, many of the lamp features are met. The only difference may arise from the color temperature of the luminaire which sits at the end of the desired spectrum $(4,600 \mathrm{~K})$. Thus for the final product, a shielding material may be used to reduce the color temperature of the perceived light. 


\section{CHAPTER 8-CONCLUSION AND FUTURE WORK}

\section{1-Cost Reduction in Stand-Alone System Implementation}

The total cost of the designed system implementation is derived from the price of components and materials. Within this section a summary of the actual expenses and estimated future purchases will be used to compare with an existing $100 \mathrm{~W}$ street light. The difference in price will justify the costeffectiveness of the overall system.

Based on the Bureau of Street Lighting in Los Angeles, the typical cost for installing a modern lighting system on most residential streets is about $\$ 3,400$. From this value, a $\$ 200$ cost was determined to be derived from just the fixture and bulb (when purchased in large quantities) [34]. The cost of implementing the designed system is summarized in Table 8-1.

Table 8-1: Estimated cost of implementing designed stand-alone street light (excludes pole installation)

\begin{tabular}{|l|r|}
\hline Component & \multicolumn{1}{|c|}{ Cost } \\
\hline DC/DC Converters [approximate] & $\$ 30.00$ \\
LEDs & $\$ 338.44$ \\
12 V Lead-Acid Battery (40 Ah) [approximate] & $\$ 97.19$ \\
Solar Battery Charger [approximate] & $\$ 25.00$ \\
40 W Solar Panel [approximate] & $\$ 109.00$ \\
Enclosure Material [estimated] & $\$ 70.00$ \\
Infrared Camera and Controls [estimated] & $\$ 150.00$ \\
\hline Total Cost & $\$ 819.63$ \\
\hline
\end{tabular}


The cost of $\$ 819.63$ represents the one-time cost of the designed system. From an initial comparison, the designed system is approximately four times the price of the 100 W HPS lighting fixture and filament. The $\$ 200$ cost of the modern system, however, does not include the price for operation.

The main component driving the push for changes in roadway lighting pertains to the cost of electricity. Since the designed system will solely rely on solar-powered source, the associated electrical cost is $\$ 0$. However, in the case of the modern lighting system, the yearly cost of operating the equivalent $100 \mathrm{~W}$ fixture, based on a 15.3 cents/kWhr in California, can be determined based on equation (8.1) as follows [35].

$$
\begin{aligned}
\text { Electricity Cost } \text { modern system } & =\left(P_{\text {system }}\right)(\text { Time On })(\text { Cost of electricty }) \\
& =(100 \mathrm{~W})\left(4382.9065 \frac{\mathrm{hrs}}{\text { year }}\right)\left(\frac{\$ 0.000153}{\mathrm{Whr}}\right) \\
& =\$ 67.058 \text { per year }
\end{aligned}
$$

The calculated electricity cost in equation (8.1) demonstrates the annual cost for operating only one streetlight. If this value was used to model the electrical cost for all streetlights in Los Angeles (approximately 44,000 fixtures), the savings from replacing the modern system with the designed system within this thesis would save over $\$ 2.9$ million a year [36]. 


\section{2-Next Generation of Work}

As described through the introduction of this thesis, the design and implementation of the light system serve as the preliminary stage for the overall goal. The final design shall encompass an infrared detection system, which will be capable of triggering individual sections of the luminaire based on the following criteria: (1) the distance the pedestrian is away from the fixture's span and (2) the number of individuals existing in the vicinity of the luminaire.

This section serves as an introduction to the future work to be done. As described through section 6.10 , the luminaire will be controlled by two separate boost converters-each of which will power half the luminaire. The sections were split based on the positioning of the DC/DC converters within the fixture. Figure 8-1 depicts the allocation of sections to each boost converter from the topview of the luminaire. If one boost converter were to fail during operation, the fixture will still provide directional lighting across the required lit area.

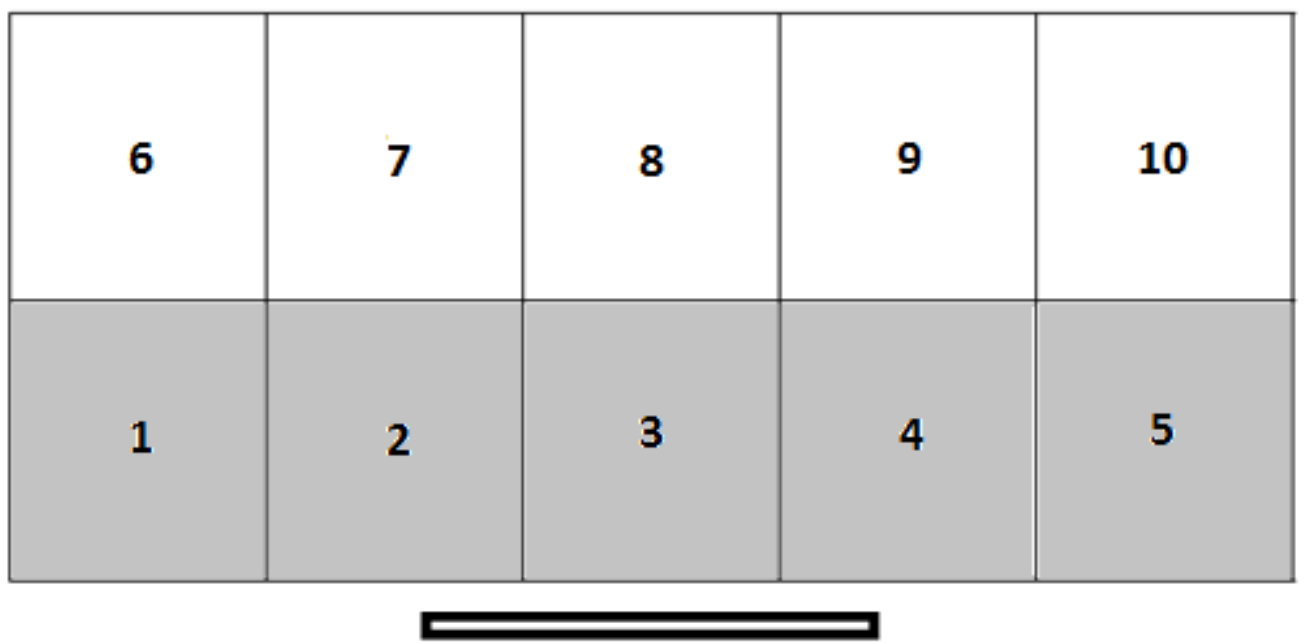

Boost Converters

Figure 8-1: Allocation of sections to corresponding boost converter 
The difference in color between the ten sections of the luminaire in Figure 8-1 describes the two divisions that will be individually controlled by a separate boost converter. Sections $1-5$ will be powered by boost converter 2 and sections $6-10$ will be powered by boost converter 1 . Figure $8-2$ describes the overall layout of the converters and the wiring incorporated within the fixture and Figure 8-3 illustrates the connection scheme from the battery to luminaire.

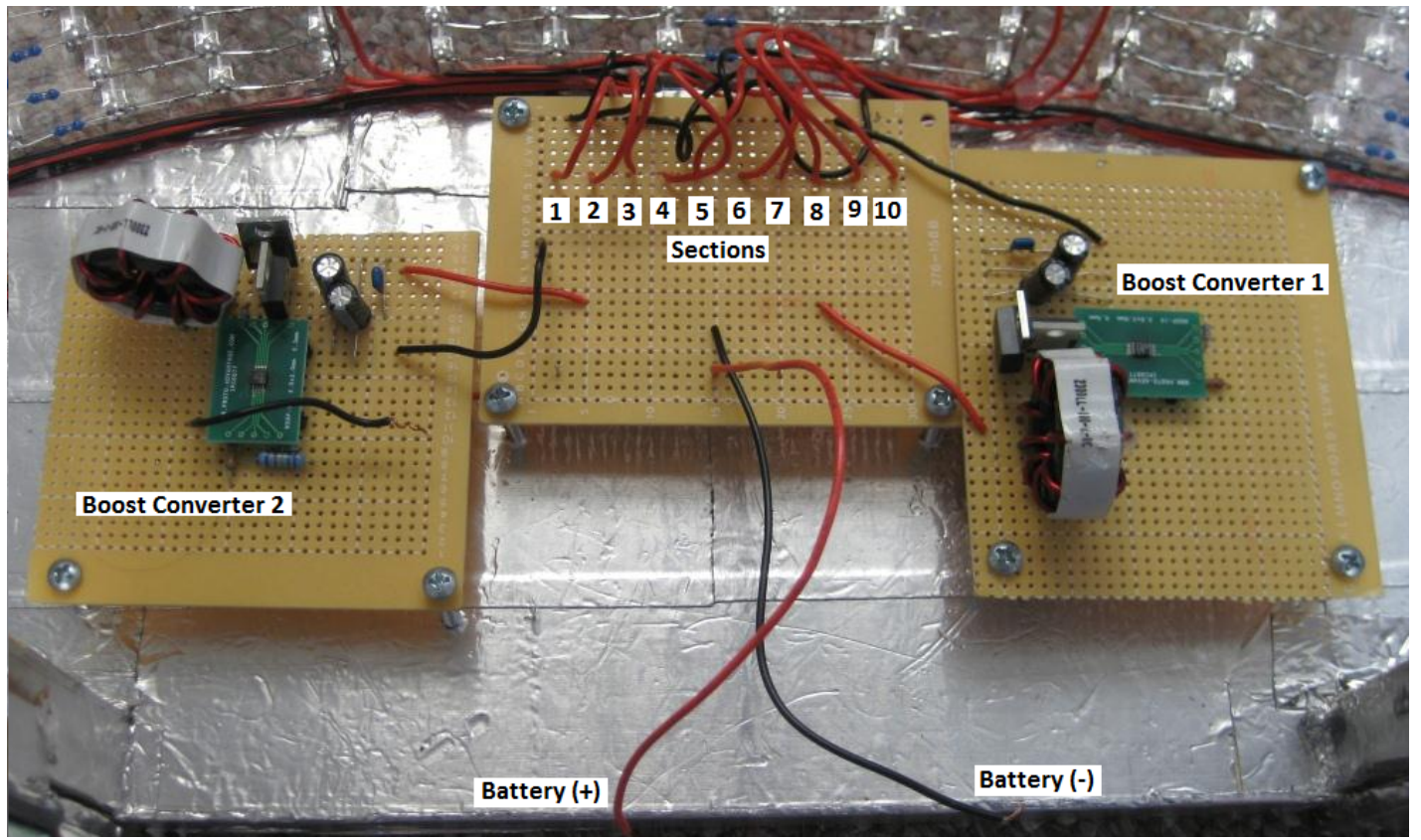

Figure 8-2: Connection configuration for powering the luminaire

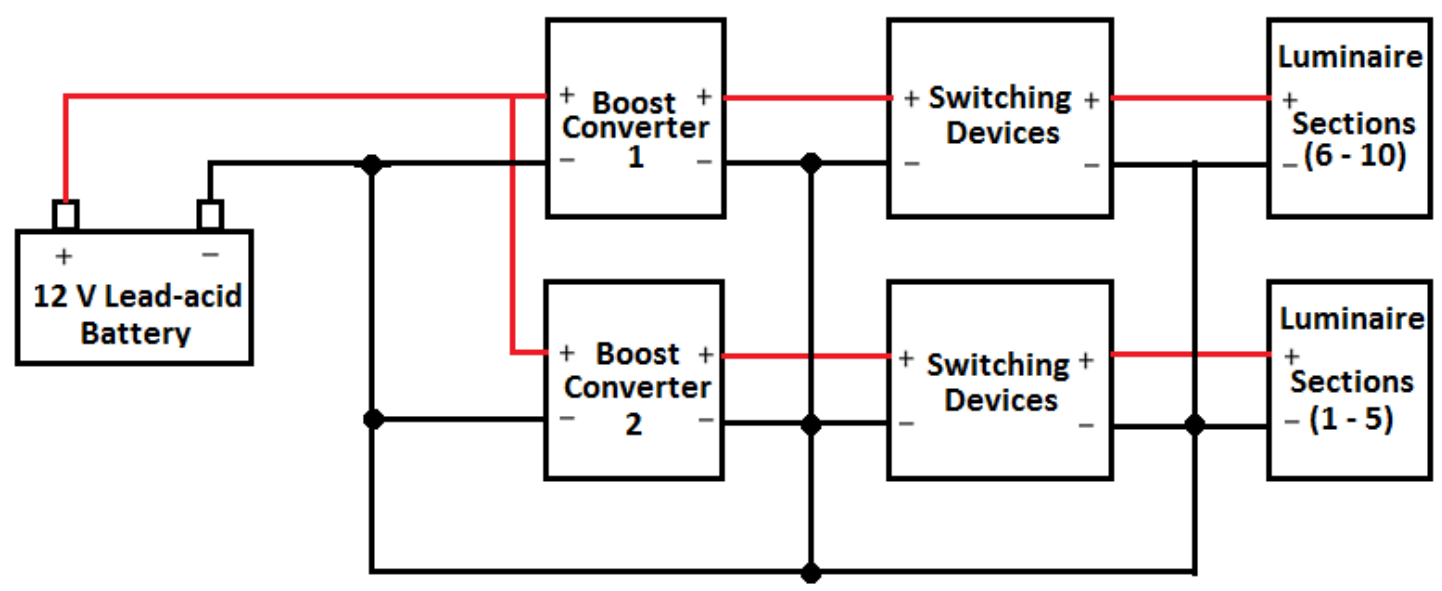

Figure 8-3: Connection block diagram of wiring shown in Figure 8-2 
The battery terminals provide the voltage to be stepped-up through each boost converter. Although not shown in Figure 8-2, the boost converters share a common input and ground with the battery as indicated in Figure 8-3. All the ground rails from each section of the luminaire are connected to one common node, which is also shared by the output ground of the boost converters. The middle protoboard shows the connection of all positive voltage rails for the luminaire and are numbered accordingly based on Figure 8-1.

The final step requires choosing desired switching devices which can turn on selected sections of the luminaire. When the switches are chosen, they will then be implemented onto the middle protoboard in Figure 8-2 and will be coordinated with an infrared feedback device. With the thresholds established for the feedback device, the system will now be capable of triggering different sections of the luminaire based on the person's distance and the amount of pedestrians within the fixed area that the light can provide adequate illumination.

Lastly, the solar battery charger had a few complications that resulted in the undeveloped circuit. The solar charger has been designed with the proper parameters and simulated with desired results as shown by the thorough descriptions in Chapter 6. The next step requires implementing the charger on a PCB board or reattempting on a protoboard. Tests should be performed accordingly to ensure that the battery charger operates as determined in the simulations. 


\section{3-Conclusion of Results}

This thesis presented the first stage in the design and implementation of an LED luminaire system. The resulting product displayed very favorable results in terms of the desired lighting and characteristics desired by the City of Los Angeles and the IESNA. The LED luminaire design provides a more uniform distribution of light and is more cost-effective than its counterpart.

To begin the process in designing the luminaire, Chapter 4 described the confining factors for sizing the system and selection of parts. Analyzing several low-powered LEDs allowed justifications in optimizing the system for power efficiency and cost. The information through a Gaussian approximation method described how using a line-of-sight model and surface tilt angles allowed achievable light spans.

The calculations in Chapter 5 allowed estimations to be made based on the energy requirements by the luminaire and energy production by the photovoltaic module. From the theoretical power consumption calculations for the system, a maximum operational time threshold was established to maintain a high battery state of charge. This information paved way for determining whether a specific battery charger could be used for a chosen solar panel.

With the selection of components to power the luminaire, a solar battery charger and DC/DC converters were designed and implemented in Chapter 6 to integrate the luminaire with the necessary power stage. A thorough description of the design process for the battery charger and DC/DC converters served to respectively address how the battery would be replenish and how the desired 
voltages will be obtained to power the luminaire.

Lastly in Chapter 7, several tests were designed and implemented to demonstrate the effectiveness of the designed luminaire. The results demonstrate the illumination capabilities of the light and the extent of which the brightness of the fixture could be perceived on three types of roadway pavements. The analysis performed on the luminaire allowed a comparison of the fixture with the described requirements and typical roadway lighting luminance.

In summation, this thesis demonstrated the feasibility and proper light distributions of the luminaire through the use of sectionalized lighting. Future work will be able to utilize this portrayed information to demonstrate the light's ability to provide directive lighting based on an individual's movement. 


\section{Bibliography}

[1] Shaheen, S. E., Ginley, D. S., \& Jabbour, G. E. (2005, January). Organic-Based Photovoltaics: Toward Low-Cost Power Generation. Materials Research Soceity, 30, 1019.

[2] Messenger, R. A., \& Ventre, J. (2010). Photovoltaic Systems Engineering (3rd ed.). Boca Raton, Florida, USA: CRC Press.

[3] Scheuermann, K., Boleyn, D., Lilly, P., \& Miller, S. (2001). Measured Performance of California Buydown Program Residential PV Systems. California Energy Commission.

[4] (1990). Retrieved January 15, 2011, from National Renewable Energy Laboratory: http://rredc.nrel.gov/solar/pubs/redbook/PDFs/CA.PDF

[5] Kimber, A., Mitchell, L., Nogradi, S., \& Wenger, H. (2006). The Effect of Soiling on Photolvoltaic Systems Located in Arid Climates. Proceedings of the 4th World Conference on Photovoltaic Energy Conversion. Waikoloa.

[6] Solar Electric Modules. (n.d.). Retrieved July 21, 2010, from Wholesale Solar: http://www.wholesalesolar.com/pdf.folder/Download\%20folder/solar-panels.pdf

[7] Combs, S. (2008). Solar Energy. In The Energy Report 2008 (pp. 137-158). Austin: Texas Comptroller of Public Accounts.

[8] Institute, P. (2006). U.S. Solar Industry Year in Review, 2006. Retrieved February 18, 2011, from http://www.prometheus.org/system/files/Year_in_Solar_2006.pdf

[9] Jones, E. D. (2001). Light Emitting Diodes (LEDs) for General Illumination. Washington DC: Optoelectronics Industry Development Association.

[10] Lighting Design Lab. (2010). Advantages of LED Lighting. Retrieved July 17, 2010, from Lighting Design Lab: http://www.lightingdesignlab.com/articles/LED_fund/led_advant.htm

[11] LC LED Corporation. (2007). The Advantages of LED Lights. Retrieved July 17,2010 , from L. C. LED LightComp LED Corp: http://www.lc-led.com/articles/ledlights.html

[12] Lighting Design Lab. (2010). Disadvantages of LED Lighting. Retrieved July 17, 2010, from Lighting Design Lab:

http://www.lightingdesignlab.com/articles/LED_fund/led_disadvant.htm

[13] Philips Lumileds. (2008, September 17). LEDs: Coming Soon to a Street Light Near You. Retrieved July 16, 2010, from Philips Lumileds: www.philipslumileds.com/uploads/166/WP14-pdf

[14] The IESNA Light Sources Committee. (2005). IESNA Technical Memorandum on Light Emitting diode (LED) Sources and Systems. The Lighting Authority.

[15] City of Los Angeles. (2010, October 20). Bureau of Street Lighting General Specifications for Solid State Lighting LED Roadway Luminaires. Retrieved December 20, 2010, from City of Lost Angeles - Department of Public Works Bureau of Street Lighting: http://bsl.lacity.org/LED_General_Specs_70w_100w_102010.pdf

[16] City of Los Angeles. (2011, January 28). City of Los Angeles LED Pilot Project - Minimum Requirements for Testing and Evaluation of LED Equipment. Retrieved February 16, 2011, from City of Los Angeles Department of Public Works - Bureau of Street Lighting: http://bsl.lacity.org/LED_Pilot_Project_Minimum_Requirements_012811b.pdf

[17] Compu Phase. (2010). Candela, Lumen, Lux: the equations. Retrieved November 13, 2010, from Copu Phase Automatisering: http://www.compuphase.com/electronics/candela_lumen.htm

[18] Yang, H., Bergmans, J. W., Schenk, T. C., Linnartz, J.-P. M., \& Rietman, R. (2008, December 16). An analytical model for the illuminance distribution of a power LED. Optical Society of America, 16(26).

[19] Lighting Research Center. (2004, July). Parking Lot and Area Luminaires. Functional Luminaires using HPS and MH Lamps, 9(1), 48.

[20] ITACA. (2005, January). A Guide to Lead-Acid Battries. Retrieved February 10, 2011, from ITACA: http://itacanet.org/eng/elec/battery/battery.pdf

[21] PowerStream Technologies. (n.d.). Sealed Lead Acid Battery Size Chart. Retrieved January 21, 2011, from PowerStream: http://www.powerstream.com/Size_SLA.htm 
[22] State of Louisiana. (n.d.). Stand Alone PV System Sizing Worksheet (example).

Retrieved March 22, 2011, from Department of Natural Resources:

http://dnr.louisiana.gov/assets/docs/energy/altfuel/PV\%20Sizing\%20Guide\%20w-

blank.pdf

[23] Linear Technology Corporation. (2010). LT3652 - Power Tracking 2A Battery Charger for Solar Power. Retrieved January 17, 2011, from Lineary Technology:

http://cds.linear.com/docs/Datasheet/3652fc.pdf

[24] Drew, J. (2009). Designing a Solar Battery Charger. Linear Technology Magazine, 12-15.

[25] Taufik. (2009). Introduction to Power Electronics. San Luis Obispo.

[26] Linear Technology Corporation. (2008). LT3757 - Boost, Flyback, SEPIC and Inverting Controller. Retrieved January 25, 2011, from Linear Technology:

http://cds.linear.com/docs/Datasheet/3757fb.pdf

[27] B-K Lighting. (2099, November 30). Technical Reports LM-78 and LM-80. Retrieved April 18, 2011, from B-K Lighting: http://www.bklighting.com/cimages/nw-339.pdf

[28] U.S. Department of Energy. (2009, September). Energy Efficiency and Renewable Energy. Retrieved April 20, 2011, from U.S Department of Energy:

http://apps1.eere.energy.gov/buildings/publications/pdfs/ssl/luminaire_efficacy.pdf

[29] Tregenza, P., \& Loe, D. (2009). The Design of Lighting. London: Taylor \& Francis eLibrary.

[30] McLean, D. (2003). New TAC Roadway Lighting Research. Lynden: DMD \& Associates.

[31] Ove Arup \& Partners Consulting Engineers PC. (2006, March 1). Definitions and Background. Retrieved April 2, 2011, from TPub Integrated Publishing:

http://www.tpub.com/content/gsacriteria/gsa_courtroom_lighting/gsa_courtroom_lighting0 012.htm

[32] Cornell University. (n.d.). Ambient Environment: Lighting and Color. Retrieved April 30, 2011, from Cornell University Ergonomics Web:

http://ergo.human.cornell.edu/studentdownloads/DEA3500notes/Lighting/lightingnotes $1 . h$ tml

[33] U.S. Department of Transportation. (2008, March 12). European Road Lighting

Technologies. Retrieved April 25, 2011, from Federal Highway Administration:

http://international.fhwa.dot.gov/euroroadlighting/04.cfm

[34] Los Angeles Bureau of Street Lighting. (2011). Basic Street Lighting Information.

Retrieved May 1, 2011, from City of Los Angeles Bureau of Street Lighting:

http://www.ci.la.ca.us/bsl/slinfo2.htm

[35] U.S. Energy Information Administration. (2011, January). Average Retail Price of Electricity to Ultimate Customers by End-Use Sector, by State. Retrieved May 2, 201, from Independent Statistics \& Analysis:

http://www.eia.doe.gov/cneaf/electricity/epm/table5_6_a.html

[36] City of Los Angeles Bureau of Street Lighting. (2011, May 5). Total Savings by Council District. Retrieved May 10, 2011, from City of Los Angeles Department of Public Works: http://bsl.lacity.org/LED_Energy_Savings_050511.pdf 
Appendix A: Enclosure Dimensions

\section{Side View}

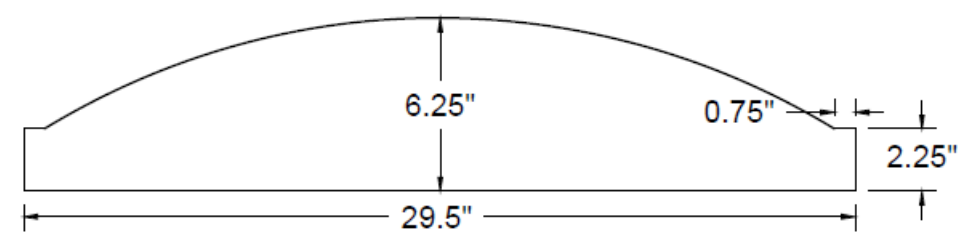

Top View

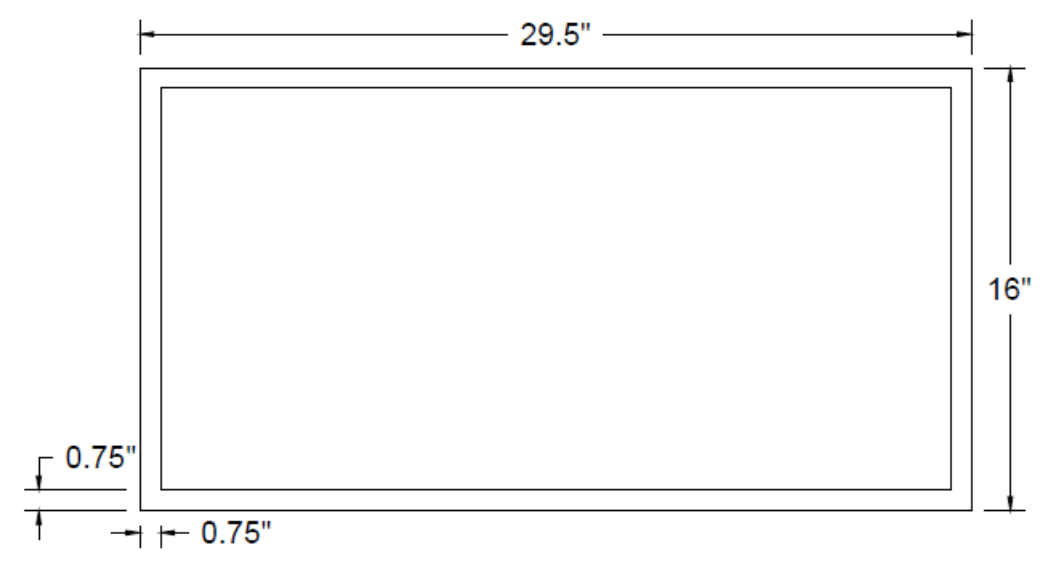

